\title{
Developing obstetric care pathways
}

Citation for published version (APA):

Lemmens, S. M. P. (2021). Developing obstetric care pathways: the birth of consensus. [Doctoral Thesis, Maastricht University]. Ipskamp Printing BV. https://doi.org/10.26481/dis.20210305sl

Document status and date:

Published: 01/01/2021

DOI:

10.26481/dis.20210305sl

Document Version:

Publisher's PDF, also known as Version of record

\section{Please check the document version of this publication:}

- A submitted manuscript is the version of the article upon submission and before peer-review. There can be important differences between the submitted version and the official published version of record.

People interested in the research are advised to contact the author for the final version of the publication, or visit the DOI to the publisher's website.

- The final author version and the galley proof are versions of the publication after peer review.

- The final published version features the final layout of the paper including the volume, issue and page numbers.

Link to publication

\footnotetext{
General rights rights.

- You may freely distribute the URL identifying the publication in the public portal. please follow below link for the End User Agreement:

www.umlib.nl/taverne-license

Take down policy

If you believe that this document breaches copyright please contact us at:

repository@maastrichtuniversity.nl

providing details and we will investigate your claim.
}

Copyright and moral rights for the publications made accessible in the public portal are retained by the authors and/or other copyright owners and it is a condition of accessing publications that users recognise and abide by the legal requirements associated with these

- Users may download and print one copy of any publication from the public portal for the purpose of private study or research.

- You may not further distribute the material or use it for any profit-making activity or commercial gain

If the publication is distributed under the terms of Article $25 \mathrm{fa}$ of the Dutch Copyright Act, indicated by the "Taverne" license above, 


\section{DEVELOPING OBSTETRIC CARE PATHWAYS}

- The birth of consensus - 


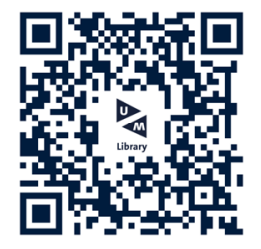

(C) S.M.P. Lemmens, Maastricht 2021.

All rights reserved. No parts of this book may be reproduced or distributed in any form by any means, without prior written permission of the author.

ISBN: 978-94-6421-212-9

Cover design: Evelien Jagtman

Lay-out: Tiny Wouters

Printed by: Ipskamp printing www.proefschriften.net

The research described in this thesis was funded by the Dutch Organization for Health Research and Development, ZonMW, research programme Pregnancy and Childbirth, project number 209010006 and ROS Robuust.

Financial support by the $\mathrm{SBOH}$ for the publication of this thesis is gratefully acknowledged.

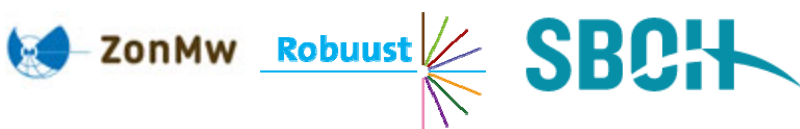




\title{
DEVELOPING OBSTETRIC CARE PATHWAYS
}

\author{
- The birth of consensus -
}

\begin{abstract}
PROEFSCHRIFT
ter verkrijging van de graad van doctor aan de Universiteit Maastricht, op gezag van de Rector Magnificus, Prof. dr. Rianne M. Letschert, volgens het besluit van het College van Decanen, in het openbaar te verdedigen op 5 maart 2021 om 12:00 uur
\end{abstract}

door

Stéphanie Maria Paula Lemmens 


\section{Promotores}

Prof. dr. M.E.A. Spaanderman

Prof. dr. L.J.M. Smits

\section{Copromotor}

Dr. H.C.J. Scheepers

\section{Beoordelingscommissie}

Prof. dr. B.W.W. Kramer (voorzitter)

Prof. dr. W.J.J. Assendelft (Radboud UMC)

Prof. dr. M.J. Nieuwenhuijze (Academie Verloskunde Maastricht)

Prof. dr. J.A.M. Van der Post (Amsterdam UMC)

Prof. dr. L.J.I. Zimmermann (Maastricht UMC) 



\section{TABLE OF CONTENTS}

PART I Developing obstetric care pathways

$\begin{array}{lll}\text { CHAPTER } 1 & \text { General introduction } & 11\end{array}$

CHAPTER 2 Agreement Conform Current Operational Rules and Directives 25 (ACCORD): a novel tool to reach multidisciplinary consensus

CHAPTER $3 \quad$ Do Representatives represent you? 43

CHAPTER $4 \quad$ Perinatal factors related to pregnancy and childbirth 55 satisfaction: a prospective cohort study

CHAPTER 5 The Risk Matrix Approach: a helpful tool weighing 73 probability and impact when deciding on preventive and diagnostic interventions

$\begin{array}{lll}\text { CHAPTER } 6 & \text { General discussion }\end{array}$

$\begin{array}{ll}\text { CHAPTER } 7 & \text { Valorisation } \\ \end{array}$

$\begin{array}{lll}\text { CHAPTER } 8 & \text { Summary } & 123\end{array}$

Samenvatting 130

PART II Obstetric care pathways - Zorgpaden verloskunde

$\begin{array}{ll}\text { Introductie } & 139\end{array}$

$\begin{array}{lll}\text { HOOFDSTUK } 1 \quad \text { Basis prenatale zorg } & 151\end{array}$

$\begin{array}{lll}\text { HOOFDSTUK } 2 & \text { Obesitas } & 159\end{array}$

$\begin{array}{lll}\text { HOOFDSTUK } 3 & \text { Hyperemesis gravidarum } & 161\end{array}$

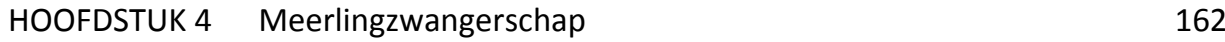

$\begin{array}{lll}\text { HOOFDSTUK } 5 & \text { Foetale groeibeperking } & 164\end{array}$ 
$\begin{array}{lll}\text { HOOFDSTUK } 6 & \text { Foetale macrosomie } & 170\end{array}$

$\begin{array}{lll}\text { HOOFDSTUK } 7 & \text { Diabetes gravidarum } & 174\end{array}$

$\begin{array}{lll}\text { HOOFDSTUK } 8 & \text { Pre-existente diabetes mellitus } & 181\end{array}$

$\begin{array}{lll}\text { HOOFDSTUK } 9 & \text { Hypertensieve aandoeningen } & 183\end{array}$

HOOFDSTUK 10 Verschillende klachten tijdens de zwangerschap 193

$\begin{array}{lll}\text { HOOFDSTUK } 11 \text { Vroeggeboorte } & 197\end{array}$

$\begin{array}{lll}\text { HOOFDSTUK } 12 \text { Serotiniteit } & 204\end{array}$

HOOFDSTUK 13 Normale baring 206

$\begin{array}{lll}\text { HOOFDSTUK } 14 \text { Niet vorderende baring } & 211\end{array}$

$\begin{array}{lll}\text { HOOFDSTUK } 15 \text { Schouderdystocie } & 213\end{array}$

$\begin{array}{lll}\text { HOOFDSTUK } 16 & \text { Fluxus postpartum } & 214\end{array}$

$\begin{array}{lll}\text { HOOFDSTUK } 17 & \text { Kraamzorg } & 223\end{array}$

$\begin{array}{lll}\text { Addendum } & \text { Afkortingen } & 239\end{array}$

Samenstelling werkgroepen $\quad 241$

Geraadpleegde achterban $\quad 245$

$\begin{array}{ll}\text { Publicatielijst } & 249\end{array}$

Curriculum vitae $\quad 251$

Dankwoord 253 



\section{PART I}

Developing obstetric care pathways 


$$
\text { . }
$$




\section{CHAPTER 1}

General introduction 



\section{GENERAL INTRODUCTION}

"Als eene verlossing geheel regelmatig en dus volkomen natuurlijk verloopt, dan heeft de wetgever gemeend, die gerustelijk aan de leiding van eene vroedvrouw te kunnen toevertrouwen. Wij zouden dus daaruit reeds met eenigen grond kunnen besluiten, dat de bijstand, die bij zulk eene verlossing moet verleend worden, zeer eenvoudig is. Ik wil dit dan ook geenszins ontkennen, maar alleen opmerken hoe, niettegenstaande die eenvoudigheid, de verloskundigen en daaronder de coryphaeën in de wetenschap, het nog maar altijd niet eens kunnen worden, welke hulp en nog veel minder, op welke wijze die hulp moet worden verleend."

W.M.H. Sanger, hoogleraar gynaecologie, De onvolkomenheid der verloskundige wetenschap, 1867.

\section{DUTCH OBSTETRIC SYSTEM}

The Dutch obstetric healthcare system is divided in three different echelons, primary, secondary and tertiary care. In primary care, autonomous community midwives provide care for women with presumed low risk pregnancies, checkups are performed at the women's home and/or at the midwifery's own practice. In secondary care, clinical trained midwives, residents and gynecologists provide care for women with established high-risk pregnancies. Tertiary care takes place in centers with a perinatology department combined with a neonatal intensive care unit and an obstetric high-risk department for critically ill pregnant women. In secondary and tertiary care, all checkups are performed in hospital ${ }^{1}$.

In 1865 a new law was introduced in The Netherlands, which divided obstetric responsibilities in pathological labor for doctors and physiological labor for midwives ${ }^{2}$. The citation above is an example of the fact that the collaboration between gynecologists and midwives in The Netherlands has a long history, but also that both professions have a different vision on how to classify and execute obstetric care. To date, midwives and gynecologists both have their own professional organization, the Dutch Society of Obstetrics and Gynecology (NVOG) and the Royal Dutch Association of Midwives (KNOV), as well as monodisciplinary guidelines and protocols.

If women are classified as low-risk throughout pregnancy, they receive midwife-led care until the postpartum period. Transfer of care from midwife to gynecologist, antenatal, intrapartum or postpartum, is a result of having one or more risk factors for pregnancy-related complications, unexpected abnormal findings and/or the 
occurrence of complications during pregnancy or childbirth. The risk assessment of midwives is based on and described in the 'List of Obstetric Indications' (the VIL) ${ }^{3}$. This risk assessment results in a division of women having 'low' or 'high' risk pregnancies, after which their obstetric care is either provided by a midwife (low risk) or a gynecologist (high risk), respectively. A collaboration between both professions resulting in shared responsibilities by both is not facilitated in this fragmented system.

The Dutch rather reactive maternity system came under heavy criticism as a result of the findings in Euro-Peristat, that showed the Netherlands to be amongst the highest rates of perinatal death compared to other European countries ${ }^{4}$. A steering committee established by the Minister of Health Care published two reports in 2009 and $2016^{5,6}$. In these reports, they acknowledged the high perinatal mortality rates and promoted a more proactive approach to care for women during pregnancy and delivery. The recommendations include patient-centered and shared care, combined with shared decision-making as key concepts of the future obstetric care system ${ }^{5,6}$. These reports underscored the need for organizational improvement and emphasized the importance of closer collaboration between independent midwives and gynecologists. Over the last years, changes in the Dutch obstetric system have been noticed, with a movement towards more shared care (Figure 1.1), but the historical development of both professions still influences contemporary practice ${ }^{7,8}$.

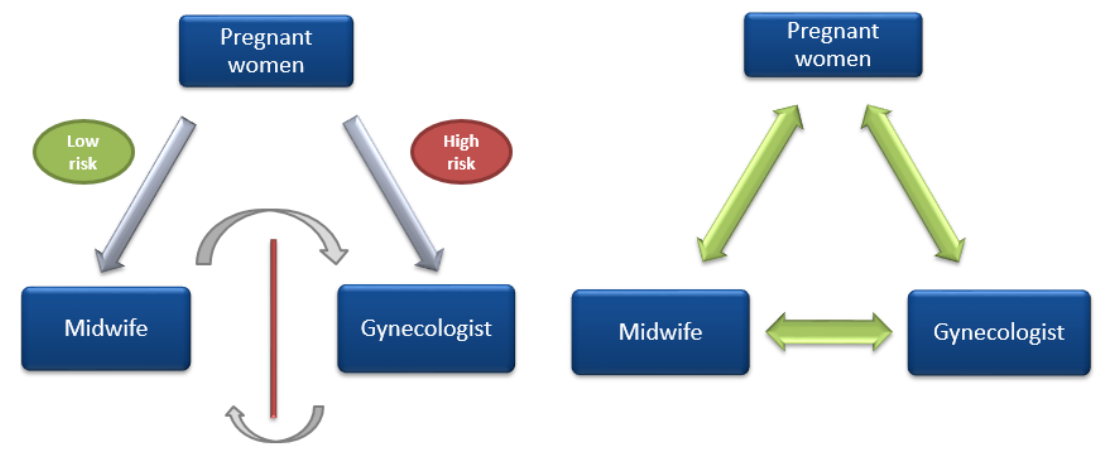

Figure 1.1 Relationship between pregnant women and obstetric professionals old situation (left) and new situation with shared care (right). 


\section{LIMBURG OBSTETRIC QUALITY SYSTEM}

An initiative for closer collaboration was born in Limburg, a province in the southeastern part of The Netherlands, by the founding of the Limburg Obstetric Consortium, a partnership by obstetric healthcare professionals. This consortium started in 2013 with the Limburg Obstetric Quality System (LOQS) project. A committee of five obstetric professionals coordinated this project. Gynaecologists, independent midwives and representatives of maternity care centers, all working in primary, secondary or tertiary obstetric care in Limburg, participated. Even though this was not the first attempt to improve obstetric care in the Netherlands, it was one of the most extensive ones ${ }^{9}$. The main goal of the LOQS project was to develop collaborative shared obstetric care pathways, to come to risk-based personalized and with it preventive care, and to structurally and timely monitor and review outcome in order to continuously improve care and to come to one integral patient record system. Because, in our view, collaboration across disciplines and adequate referral between the various echelons first requires consensus on the content of care and shared protocols for daily practice. This was a challenging task within a team of professionals with different training, guidelines and perspectives on obstetric care, but with the effort of all participants, the project was successful. Together we developed shared protocols for a broad range of obstetric subjects. Care pathways included decisions on a medical level, as well as on an organizational level. While developing these care pathways, extensive discussions had to determine which step had to be taken by which caregiver in any specific situation, including relevant referral procedures and referral indications. Diagnostic thresholds were redefined and the introduction of new interventions was discussed.

\section{GROUP DECISION-MAKING}

There are some requirements to collaborate successfully together with professionals with their own view and perspectives across overlapping disciplines. To cooperate constructively, responsibilities need to be shared and there should be mutual trust, respect and recognition of each other's capacities. Preferably there is an interdependent rather than an autonomous collaboration, and the collaborating process should be a constantly developing, dynamic and interactive process ${ }^{10}$.

To this end, we had to develop a novel strategy to come to balanced group discussions that supported novel guideline development (Agreement Conform 
Current Operational Rules and Directives-tool (ACCORD-tool) $)^{11}$. Within the ACCORDtool all stakeholders have a say and each vote counts equally. Moreover, this bottomup development strategy is thought to result in stronger supported inter-professional directives and richer decisions. By using a bottom-up strategy, the ideas of all participating professionals can be captured in an early stage of the process ${ }^{12,13}$. When people are consulted about their ideas and opinions, they typically feel better about a decision, even when the decision does not correspond with their personal preference $^{13}$.

The newly developed ACCORD-tool consists of a four-step bottom-up approach: first summarize current evidence on a specific topic based on existing guidelines, second translate evidence into statements pivotal for clinical decisions, third send statements in an online survey to all involved professionals to rank statements by level of agreement on a 10-point Likert-scale (1 totally disagree - 10 totally agree), and finally review the results of the survey within a team of mandated representatives to take final decisions. By using the ACCORD strategy, it was possible to discuss a broad range of obstetric topics and reach fast, concrete and acceptable agreement on diagnostic thresholds, referral indications and the steps that need to be taken by professionals in specific obstetric situations.

\section{REPRESENTATION}

For collaborative decision making within a large heterogeneous group of professionals, a strategy using a small group of chosen representatives weighing the balance of disciplines represented in the group is thought to be most efficient ${ }^{13}$. At the beginning of the process, the group has to decide which level of agreement finalizes a decision. Decision-making by consensus aims to reach agreement with resolutions that are satisfactory to all group members and meet all of their concerns. Group decision-making, group-dynamics, and subsequently group satisfaction, are subject to social influence factors. Individuals can adjust their behaviour to the group norm, they can combine their preferences to create a shared decision or merge ideas resulting in group polarization, or they can follow an influential person which can lead to false agreement favouring the dominant viewpoint. These elements can affect the process by which decisions are reached and the decision outcomes themselves. Moreover, this can result in a situation in which the electorate might value taken decisions as not representative in case fundamental issues differ from their opinion. 
Continuous feedback from representatives to their peers of what was decided for what reasons remains therefore of utmost importance.

Within the LOQS-project, peers mandated representatives to take decisions ${ }^{14}$. These representatives were expected to reflect the opinions of their group, rather than voicing their personal preferences. This is important because professionals must be willing to implement new policies in daily practice, even when the ultimate decision does not correspond with their personal preference. Implementation is easier if professionals support the decisions taken by their representatives. A high level of concordance between the representative and his/her peers suggests a high level of agreement, but if statements that are not agreed upon are critically important, the level of satisfaction with the process may be low, in spite of otherwise high levels of agreement. Level of agreement alone may therefore be insufficient to guarantee satisfied participants.

\section{PATIENT SATISFACTION}

As described above, several factors can influence group-processes and the satisfaction level of the participants in a project. When developing care pathways one must consider these influential factors, but the patients' perspective on the healthcare they receive is just as important. Patient satisfaction and birth experience are important factors influencing short- and long-term outcomes of both mother and child $^{15}$. One in six women has a negative recall of their birth experience ${ }^{15,16}$ and the prevalence of posttraumatic stress disorders in women resulting from childbirth is estimated at $2.9 \%{ }^{17}$. The healthcare professional is influential in shaping a woman's birthing experience ${ }^{18}$, and the interaction with the healthcare professional has shown to have a greater influence upon women's perceptions of birth than the physical experience of the birth itself ${ }^{19}$. Good collaboration between different healthcare providers with uniformity in medical decision-making, an adequate risk assessment and transfer of care, is thought to influence the expectations of pregnant women and to have a positive influence on patient satisfaction ${ }^{20}$.

\section{RISK: PROBABILITY AND IMPACT}

To simulate the much-needed shared care between gynaecologists and midwives, processes in Dutch obstetric care needed to be redefined and reorganized. Therefore, the introduction of new interventions, and discussing current diagnostic thresholds 
and definitions was necessary. Deciding upon interventions and diagnostic thresholds and definitions, means in essence deciding upon risks. Risk is generally described as the combination of the associated likelihood of occurrence together with the consequences of an event ${ }^{21,22}$. A new intervention can decrease the probability of an event to occur and/or can have an effect on the consequences, and result in a less catastrophic impact. In any case, an intervention is expected to change the risk. In healthcare, prior to introducing a new intervention, professionals have to consider what risk they believe is acceptable and what effect of the intervention they desire. Despite professionals inform patients about risks and decide on interventions with patients on a daily basis, most of them think in terms of decreasing probability, instead of considering probability and impact together.

Using a risk matrix is a qualitative approach to prioritize risk and start interventions to mitigate the risk ${ }^{21,23}$. A risk matrix consists of numbered rows and columns, indicating categories of probability (likelihood) and impact (consequences) ascending in severity. A risk score can be calculated to compare different risks and add an objective value to the risk, with a higher score indicating a higher risk. A risk matrix can give insight in the actual risk, visualizing what happens when probability or impact of risks changes at individuals or population level, and a risk matrix can be a helpful tool to start a constructive discussion within a decision process ${ }^{23,24}$.

During pregnancy, healthcare professionals continuously assess risks based on their knowledge, experience and existing guidelines. The risk assessment for pregnant women in the current system is dichotomously categorized in low or high risk. To improve risk stratification, the Expect Study I started in conjunction with the LOQS project, and evaluated and validated first trimester obstetric prediction models ${ }^{25-27}$. As a result, risk assessment in the new situation, depends on the use of a prediction model or if not available, on the 'old' obstetric indication list $\left(\mathrm{VIL}^{3}\right)$ or on risk factors adopted from the NICE guidelines ${ }^{28,29}$. A pregnant women will follow a specific care pathway, depending on her risk, which can be individually adjusted.

If risk factors arise for developing pregnancy related complications, the care pathway advises additional measures to monitor this. In the old situation, these women were referred to the gynecologist fur further evaluation and follow-up. In the new situation, a community midwife will see these women primarily as long as her pregnancy is uncomplicated even though she is considered high-risk, with some additional appointments with a gynecologist. At the end of the LOQS project, our 
principles turned into an extensive document containing a framework for shared obstetric care, created together by all obstetric professionals in the province. 


\section{AIM AND OUTLINE OF THIS THESIS}

The main purpose of this thesis is two-fold: in part I, we describe the process of reaching agreement on the content of care to create shared care pathways in obstetrics, we evaluated the effect of decision-making by representatives, factors influencing patient satisfaction and we present a risk-matrix approach that can be used in decision-making. In part II of this thesis, we present the result of our teamwork: 19 shared care pathways for obstetric care (in Dutch).

\section{Part I}

Chapter 2 presents the ACCORD-tool, an approach which can be used in a decisionmaking process to reach consensus within a group of professionals with differences in training, guidelines and perspectives.

Chapter 3 evaluates the effect of either randomly selected or appointed representatives in relation to representatives-peer agreement for the hospital and first-line setting.

Chapter 4 presents factors that are independently associated with pregnancy and childbirth satisfaction of women who recently gave birth.

Chapter 5 describes the effect of interventions and diagnostic thresholds on modelled risk, using a risk matrix approach (RMA), and factors influencing this decision-making process.

Chapter 6 provides a general discussion of the results presented in this thesis, their implications and limitations, and suggestions for further research.

Chapter 7 addresses the relevance and impact of this thesis for society and obstetric healthcare in Limburg, The Netherlands.

Chapter 8 consists of an English and Dutch summary of the results of this thesis. 


\section{Part II}

In this part, the LOQS care pathways are presented. Because these care pathways are implemented in the province of Limburg, these are written in Dutch. Care pathways were developed for the following obstetric topics:

- Antenatal care for uncomplicated pregnancies

O Obesity

- Hyperemesis gravidarum

○ Twin pregnancy

- Fetal growth restriction

- Fetal macrosomia

- Gestational diabetes

- Diabetes mellitus in pregnancy

- Hypertensive disorders in pregnancy

- Vaginal bleeding in pregnancy

O Fever in pregnancy

- Rupture of membranes

- Preterm labor

- Post term care

- Normal labor

- Prolonged labor

- Shoulder dystocia

- Hemorrhage postpartum

- Maternity care 


\section{REFERENCES}

1. Zondag L CF, De Geus M. Midwifery in the Netherlands. Royal Dutch association of Midwives (KNOV). 2017.

2. van der Lee N, Driessen EW, Houwaart ES, Caccia NC, Scheele F. An examination of the historical context of interprofessional collaboration in Dutch obstetrical care. J Interprof Care. 2014;28(2): 123-7.

3. Vademecum. O. Verloskundig Vademecum 2003. Eindrapport van de Commissie Verloskunde van het College voor zorgverzekeringen. Diemen. 2003.

4. EURO-PERISTAT Project WS, EUROCAT \& EURONEOSTAT. European Perinatal Health Report. 2008.

5. geboorte Sze. Een goed begin, veilige zorg rond zwangerschap en geboorte. 2009.

6. geboortezorg' EZI. Zorgstandaard Integrale Geboortezorg. https://www.kennisnetgeboortezorg.nl/kennisbank/algemeen/documenten/8291-zorgstandaard-integralegeboortezorg; 2016.

7. Boesveld IC, Valentijn PP, Hitzert M, Hermus MAA, Franx A, de Vries RG, et al. An Approach to measuring Integrated Care within a Maternity Care System: Experiences from the Maternity Care Network Study and the Dutch Birth Centre Study. Int J Integr Care. 2017;17(2):6.

8. Visser GHA. Obstetric Care in the Netherlands: Relic or Example? Journal of Obstetrics and Gynaecology Canada. 2012;34(10):971-5.

9. Consortium N. Obstetric Consortium Studies [Available from: http://www.studiesobsgyn.nl/home/ page.asp?page_id=354.

10. Bressen T. Consensus decision-making: what, why, how. ABA Books2012.

11. SMP Lemmens HS, VA Lopes van Balen, YCM Roselaers, RG De Vries, MEA Spaanderman. Agreement Conform Current Operational Rules and Directives (ACCORD): A Novel Tool to Reach Multidisciplinary Consensus. Journal of Women's Health and Gynecology. 2019; 6(5):1-11.

12. Vaucher C, Bovet $E$, Bengough $T$, Pidoux V, Grossen $M$, Panese $F$, et al. Meeting physicians' needs: a bottom-up approach for improving the implementation of medical knowledge into practice. Health research policy and systems. 2016;14(1):49.

13. Pagliari C. The potential influence of small group processes on guideline development. Journal of evaluation in clinical practice. 2000;7(2):165-73.

14. Lemmens SMP LVBV, De Vries RG, Scheepers HCJ and Spaanderman MEA. Do representatives represent you? Integrative Journal of Nursing and Health. 2019;2(1):90-4.

15. Goodman P MM, Tavakoli AS. . Factors related to childbirth satisfaction. Journal of advanced nursing. Journal of advanced nursing. 2004;46(2):212-9.

16. Rijnders $M B H$, Schönbeck $Y$. Perinatal factors related to negative or positive recall of birth experience in women 3 years postpartum in the Netherlands. . Birth. 2008;35(2):107-16.

17. Grekin R, O'Hara MW. Prevalence and risk factors of postpartum posttraumatic stress disorder: a meta-analysis. Clin Psychol Rev. 2014;34(5):389-401.

18. Larkin P, Begley CM, Devane D. Women's experiences of labour and birth: an evolutionary concept analysis. Midwifery. 2009;25(2):e49-59.

19. Hollander MH, van Hastenberg E, van Dillen J, van Pampus MG, de Miranda E, Stramrood CAl. Preventing traumatic childbirth experiences: 2192 women's perceptions and views. Arch Womens Ment Health. 2017;20(4):515-23. 
20. Lemmens SMP, van Montfort P, Meertens LJE, Spaanderman MEA, Smits LJM, de Vries $R G$, et al. Perinatal factors related to pregnancy and childbirth satisfaction: a prospective cohort study. J Psychosom Obstet Gynaecol. 2020:1-9.

21. Duijm NJ. Recommendations on the use and design of risk matrices. Safety Science. 2015;76:21-31.

22. Wall KD. The trouble with risk matrices. 2011 [Available from: https://pdfs. semanticscholar.org/ f2be/55d4454451788fca458da018ac9b4b7953f8.pdf.

23. Talbot J. What's right with risk matrices?: An great tool for risk managers. Internet. Version 1. 31000 risk2011 [Available from: https://31000risk.wordpress.com/ article/what-s-right-with-risk-matrices-3dksezemjiq54-4/.

24. Nicolai Bodemer WG. Risk perception. The sage handbook of risk communication. 2015.

25. Linda J.E. Meertens HCJS, Sander M.J. van Kuijk, Robert Aardenburg, Ivo M.A. van Dooren, Josje Langenveld, Annemieke M. van Wijck, Iris Zwaan, Marc E.A. Spaanderman, Luc J.M. Smits. External Validation and Clinical Usefulness of First Trimester Prediction Models for the Risk of Preeclampsia: A Prospective Cohort Study. Fetal Diagn Ther. 2019;45(6): 381-93.

26. Meertens LJE SL, van Kuijk SMJ, Aardenburg R, van Dooren IMA, Langenveld J, Zwaan IM, Spaanderman MEA,, HCJ. S. External validation and clinical usefulness of first-trimester prediction models for small- and large-for-gestational-age infants: a prospective cohort study. BJOG. 2019;126(4):472-84.

27. Meertens LJE, van Montfort $P$, Scheepers HCJ, van Kuijk SMJ, Aardenburg R, Langenveld J, et al. Prediction models for the risk of spontaneous preterm birth based on maternal characteristics: a systematic review and independent external validation. Acta Obstet Gynecol Scand. 2018.

28. Excellence NIfHaC. NICE Clinical guideline Antenatal care. RCOG Press at the Royal College of Obstetricians and Gynaecologists; 2008.

29. NICE Clinical Guideline Hypertension in Pregnancy. 2011. 



\section{CHAPTER 2}

\section{Agreement Conform Current Operational Rules and Directives (ACCORD): a novel tool to reach}

multidisciplinary consensus

S.M.P. Lemmens, H.C.J. Scheepers, V.A. Lopes van Balen, Y.C.M. Röselaers, R.G. De Vries, M.E.A. Spaanderman Journal of Womens Health and Gynecology 2019,5:1-11 


\section{ABSTRACT}

Objective

Collaboration between health care professionals with overlapping expertise but fundamental different views and perspectives requires consensus on best care practices. The aim of the current study is to evaluate a novel model to reach fast, concrete and acceptable agreement.

\section{Study design}

The Agreement Conform Current Operational Rules and Directives-tool (ACCORD) is developed to promote collaboration between independent midwives $(M)$ in primary care, and gynecologists-obstetricians (G) working in secondary and tertiary care. The ACCORD-tool consists of a four-step, bottom-up approach: first summarize the current evidence, second translate the evidence into statements, third send online surveys to all caregivers $(n=137)$ in the work field to rank these statements by their level of agreement, and finally review the statements with a team of representatives $(n=23)$ to reach consensus. Statements are directly accepted or rejected when agreement is high (exceeding 8 ) or low (below 3 ) on a scale 1-10. Statements are discussed when scores are neutral (between 3 and 8 ), or have a broad range in opinion (SD >2). Outcome measures are the completion of a consensus document within the chosen time frame and the level of acceptance by the participants of both the consensus document and the ACCORD-tool and its influencing factors.

\section{Results}

After discussion of $75 \%$ of statements, the consensus rate was $92 \%$. A document with recommendations for the entire field ofobstetric care was finished within the chosen period of two years. Participants' satisfaction expressed in 'recommending the tool' and 'being pleased with the final document' differs between collaborating professions ( $M=5.6 \pm 2.4$ vs. $G=7.9 \pm 1.4, p<0.01$ and $M=6.1 \pm 1.9$ vs. $G=8.3 \pm 0.9, p<0.01$, on a 1-10 scale, respectively). Satisfaction is positively influenced by the information supplied on scope, purpose and method before and during the process and the extent to which everyone's opinion is considered. A feeling of power imbalance and loss of autonomy negatively affects participants' satisfaction.

\section{Conclusion}

The ACCORD-tool is a promising approach for developing collaborative interprofessional schedules with moderate-to-good acceptance by participants, within a limited time frame. 


\section{BACKGROUND}

The contemporary practice of medicine is increasingly relying on multidisciplinary collaboration, characterized by a situation in which different professionals work on the same project but independently, parallel or sequential ${ }^{1}$. Multidisciplinary collaboration is commonly defined by five underlying pillars ${ }^{1,2}$. First, responsibilities need to be shared to cooperate constructively. Second, a partnership needs to occur based on mutual trust and respect, valuing the contributions and perspectives of the other professionals. Third, an equal partnership calls for interdependent rather than an autonomous collaboration. Fourth, individuals participating in a multidisciplinary collaboration need to recognize each other's professional capacities based on their knowledge and experience. Finally, a good collaboration is a constantly developing, dynamic and interactive process ${ }^{1}$. Collaborating across disciplines requires agreement on best care practices within a team consisting of members with different training, guidelines and perspectives. It is thought that a judgement that integrates the expertise of several professionals results in better decisions ${ }^{3,4}$. Participants collaborating in a multidisciplinary team must come to consensus coping with problematic issues as concerns about best practices, autonomy, equal influence, and income.

Group decisions made by consensus aim to result in decisions that are satisfactory to all group members. A process that includes the input of all participants and listens to all of their concerns, generates more agreement with the final decision and greater cooperation in implementation ${ }^{3,5}$. A common known technique to reach consensus in a small group of people is the Delphi method. The Delphi technique uses panel members that are selected experts in the field that have no direct face-to-face contact and remain anonymous to each other ${ }^{4}$. The Delphi method recommends 10-18 experts on a panel and uses the concept of iterative feedback rounds, with the opportunity for panel members to reflect on their previous response ${ }^{4}$. One strength of the Delphi method is its use of expert opinion, but its weakness is that it is a top-down approach. In order to ensure that new protocols will be implemented by a diverse group of professionals, it is necessary to use a bottom-up approach. A bottom-up approach starts with a commitment to meet the needs of professionals who are most affected by the new policy ${ }^{6,7}$. Furthermore, it is important to ensure an equal participation of all professionals involved in the project to prevent imbalances, and a meaningful discussion of content based on current evidence without discussions lead by emotions and personal interests. To this end, we developed a 
new model to reach a concrete and acceptable management agreement within a reasonable period of time. This paper describes the evaluation of this model on both effectiveness defined as the level of consensus on content and a process evaluation defined as satisfaction of the participants and factors influencing this satisfaction. The level of consensus needs to be high in order to have a successful implementation of the decisions made. The evaluation of the process is important to investigate factors influencing participant's satisfaction and to improve the decisionmaking process in the future.

\section{METHODS}

This novel model was named the Agreement Conform Current Operational Rules and Directives-tool (ACCORD). The ACCORD-tool had to meet three important criteria. First, the tool had to be acceptable to those using it. The participating professionals discussed current professional guidelines and protocols, thereby weighing their opinions and concerns, to reach consensus on content of care for clinical practice. Second, the tool had to be concrete, with recommendations based on scientific evidence and decisions that were directly and conclusively applicable in daily practice. In addition, the opinions of participants were weighed and presented objectively (using means and standard deviations, SD), to prevent agreements solely based on emotions, self-interest, and strong but unfounded opinions. Decisions were agreed upon when at least $85 \%$ of the team was in favor. Third, the process had to be fast with consensus on two main topics every three months.

The ACCORD-tool which complies with the above mentioned criteria consists of four steps to reach consensus (Figure 2.1). In a chosen period of 2 years, acceptable and practical professional choices and actions were assessed, discussed and determined according to these four steps. The first step involves a summary of existing evidence for each subject selected, performed by the researcher of the project group. This overview of the current knowledge and guidelines is send to the participants of the team before the team meeting. The second step includes the creation of a flowchart, based on data extracted from literature, specifying the options on which a decision should be taken. In the third step these decision points are translated into statements and all participants are invited to rank each statement in an online survey by level of agreement on a 1 (totally disagree) to 10 (totally agree) Likert-scale (Survey Monkey, Palo, Alto, CA, USA). By using a ranking scale we are able to assess the opinions of participants in a more or less objective manner, using means and SDs. The survey gives 
participants the opportunity to express any concerns regarding a topic in text boxes added to each statement. In the fourth step survey results are presented and discussed by a team of professionals representing their peers in an effort to reach consensus. Statements with a mean between 3 and 8 , or a SD>2 must be discussed, a mean below 3 or above 8 and a SD<2 leads to immediate rejection or acceptance respectively. The final document, containing all agreements, is intended to serve as a guiding document to support professionals in their daily practice. It is not meant to substitute for clinical judgement. In the example, suspected fetal growth restriction is further elaborated, but steps one to four were applied on all subjects. We evaluated the tool by assessment of the level of consensus and the satisfaction of the participants, measured with an online survey (see results - process evaluation).

\section{STEP 1 Summary of the literature based on (inter)national guidelines and protocols}

STEP 2 Flowchart defining decision points and guiding questions

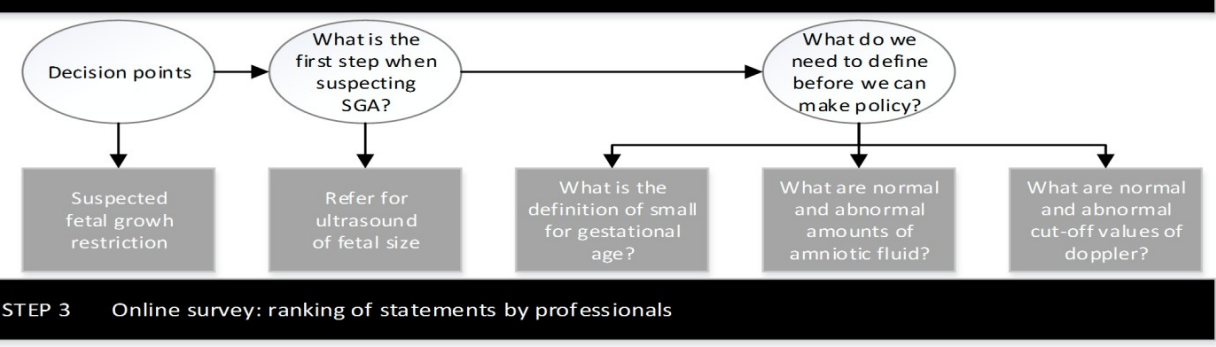

The cut-off value for defining a fetus small-for-gestational-age (SGA) is the $10^{\text {th }}$ percentile.

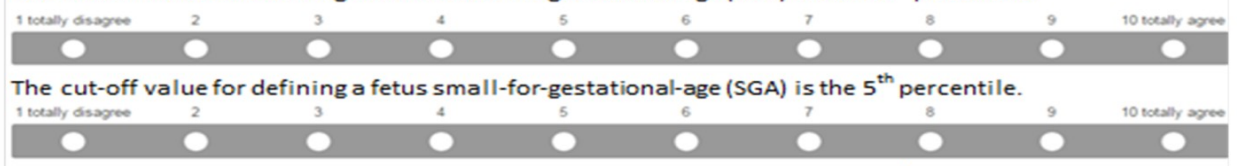

The cut-off value for defining a fetus small-for-gestational-age (SGA) is the $2.3^{\text {th }}$ percentile.

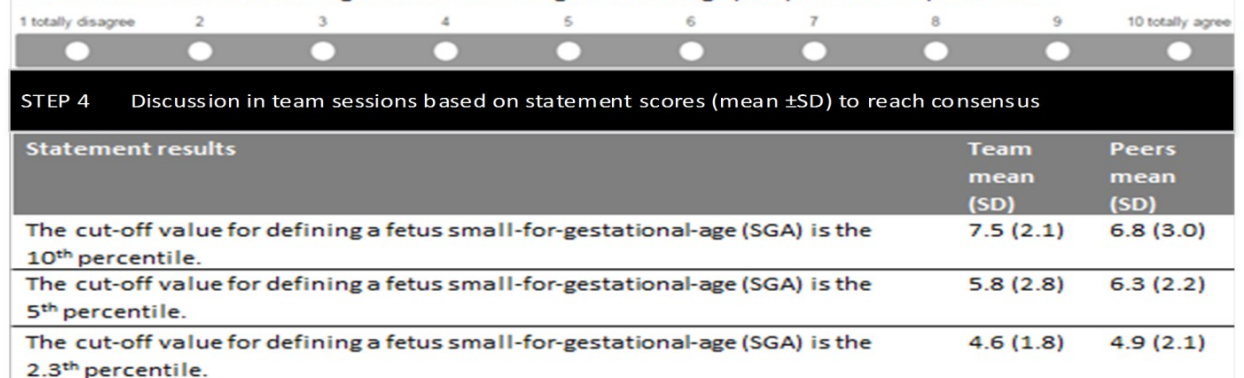

Figure 2.1. Four step ACCORD method, * SGA: small for gestational age, as to illustrate. 


\section{Participants}

The organizational structure of the ACCORD-tool consists of three groups: 1) a project group, consisting of a gynecologist, an independent midwife, a researcher who worked as a resident in gynecology and a former clinical working midwife. Together they were responsible for the organizational process, preparation of the meetings (summarize literature, send the survey etcetera.), structuring the meetings and documentation of the decisions made, 2) one or more team(s) with representatives chosen and mandated by their peers to take final decisions during team meetings and 3) a group of peers, all professionals in the field which were invited to give their opinion on obstetric topics in the surveys (Figure 2.2). Professionals of different disciplines or echelons within disciplines should be invited to participate. All participants' email addresses were obtained and a declaration of collaboration was signed in which the participants agreed to comply with the rules, including principles for teamwork, mutual respect and communication.

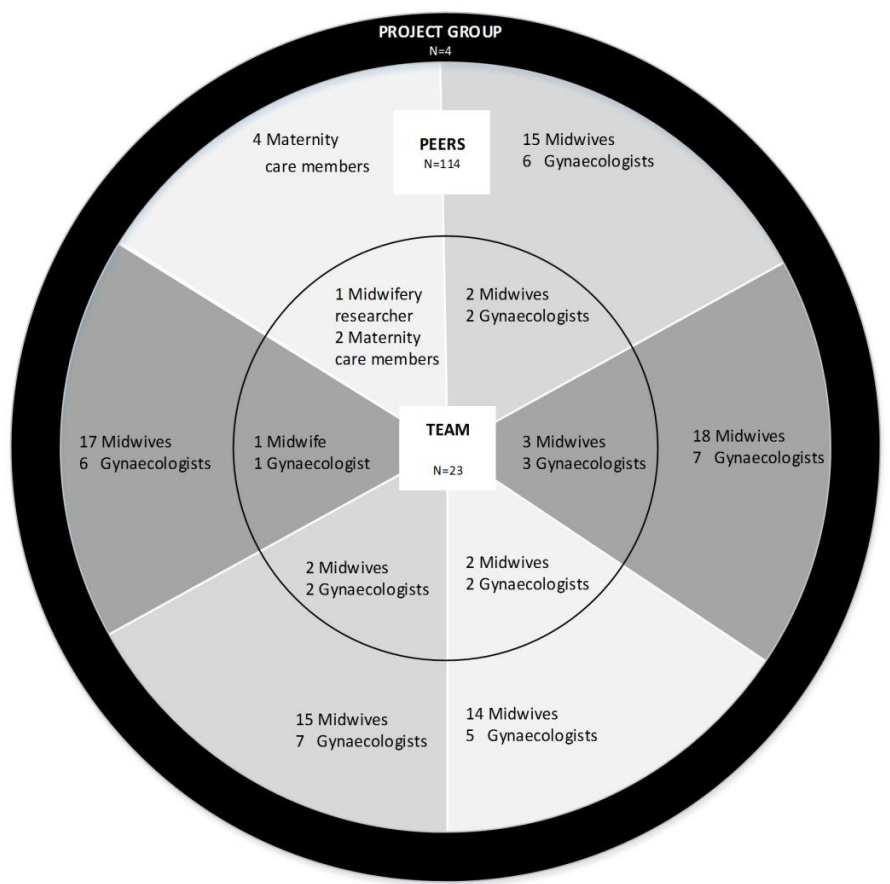

Figure 2.2. Participants are divided in a group of peers and a team of representatives. 


\section{Statistics}

Data are expressed as mean with standard deviation and analysed parametrically. Logistic regression was used to calculate odds ratios to analyse associations with satisfaction with the tool. Multivariate analysis within the domains of audited associates (representation, participation, tool and profession) was used to determine the key components of these associates. Spearman's correlation was used to analyse the relation between audited associates and satisfaction (recommendation of the tool and pleased with the final document, yes $=$ score $>6$ on 1-10 Likert scale). A two sided p-value $<0.05$ was considered statistically significant. Statistical analysis was performed using IBM SPSS Statistics 21.

\section{RESULTS}

We included all 141 professional participants that worked in primary, secondary or tertiary obstetric care between 2013 and 2016 within the catchment area of interest. The coordinating project group $(n=4)$ consisted of obstetric professionals, each with their own expertise. Two teams of representatives $(n=23)$ and a group of peers $(n=114)$ consisted of gynecologists, independent midwives and maternity care members. In total 14 surveys were sent with 507 guiding questions answered by ranking 681 statements and covering 19 main subjects (Figure 2.3). The overall response rate was $85 \%$ for the team and $37 \%$ for their peers. Based on the mean and SD, $15 \%$ of all statements were directly accepted, $2 \%$ were rejected and the teams decided $8 \%$ to be inconclusive due to indistinct formulation. The vast majority of statements (75\%) had to be discussed which resulted in acceptance (29\%), acceptance in a modified form (19\%) in response to new information emerged during the discussion, and rejection (27\%) of statements. Consensus was reached on $92 \%$ of statements $(15 \%+29 \%+19 \%=63 \%$ accepted, $2 \%+27 \%=29 \%$ rejected $)$ and $98 \%$ of all guiding questions were answered. For 3 out of 19 subjects, new statements were formulated and two instead of one team meeting were needed to take final decisions. 


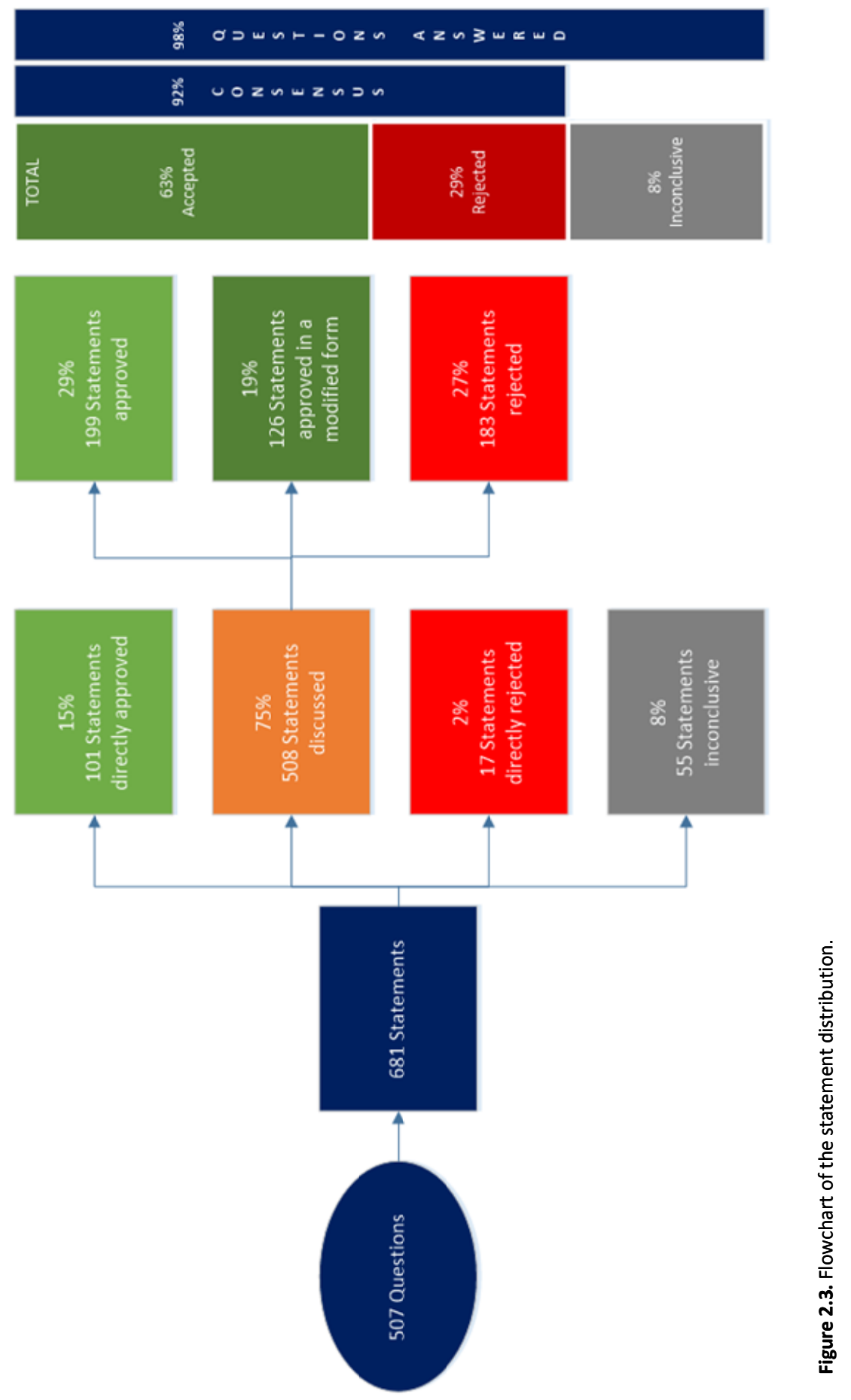




\section{Process evaluation}

For gynecologists and midwives, the mean and SD for each statement are shown in Table 2.1. For the two main questions, regarding recommending the ACCORD-tool (M $5.6 \pm 2.4$ vs. $G 7.9 \pm 1.4, p<0.01)$ and the satisfaction with the final document $(M 6.1 \pm 1.9$ vs. $G \quad 8.3 \pm 0.9, p<0.01$ ), significant differences are seen with higher mean scores for gynecologists.

Table 2.1. Statement means and SD for midwives and gynecologists.

\begin{tabular}{|c|c|c|c|c|c|}
\hline \multirow[t]{2}{*}{ Question } & \multicolumn{2}{|c|}{$\begin{array}{l}\text { Midwives } \\
\text { Total } n=43\end{array}$} & \multicolumn{2}{|c|}{$\begin{array}{c}\text { Gynaecologists } \\
\text { Total } n=10\end{array}$} & \multirow[b]{2}{*}{$p$-value } \\
\hline & Mean & SD & Mean & SD & \\
\hline \multicolumn{6}{|l|}{ Representation } \\
\hline $\begin{array}{l}\text { I trusted my representative totally in decision } \\
\text { making. }\end{array}$ & 8.3 & 1.4 & 10.0 & 0.0 & $<0.01$ \\
\hline $\begin{array}{l}\text { The representative in my region has informed me } \\
\text { sufficiently during the process on the progress of the } \\
\text { developed care pathways. }\end{array}$ & 7.2 & 2.1 & 9.7 & 0.6 & 0.05 \\
\hline $\begin{array}{l}\text { The representative in my region has informed me } \\
\text { sufficiently during the process on the decisions } \\
\text { made. }\end{array}$ & 7.2 & 2.3 & 9.7 & 0.6 & 0.07 \\
\hline \multicolumn{6}{|l|}{ Participation } \\
\hline $\begin{array}{l}\text { My opinion is sufficiently taken into account during } \\
\text { the process. }\end{array}$ & 5.9 & 2.2 & 8.7 & 0.9 & $<0.01$ \\
\hline $\begin{array}{l}\text { The view of my region was respected during the team } \\
\text { meetings. }\end{array}$ & 5.9 & 2.3 & 8.1 & 1.9 & $<0.05$ \\
\hline I was not taken seriously. & 5.0 & 2.7 & 2.6 & 2.1 & $<0.05$ \\
\hline I experienced a power imbalance. & 6.3 & 2.2 & 4.2 & 3.1 & 0.07 \\
\hline \multicolumn{6}{|l|}{ Tool } \\
\hline $\begin{array}{l}\text { I received sufficient information before the start of } \\
\text { the project to know what was going to happen }\end{array}$ & 5.4 & 2.2 & 8.0 & 1.6 & $<0.01$ \\
\hline The opinion of all participants was asked. & 6.8 & 2.5 & 8.6 & 0.8 & $<0.01$ \\
\hline The results were presented objectively. & 6.6 & 2.5 & 8.6 & 1.0 & $<0.01$ \\
\hline $\begin{array}{l}\text { The opinion of all participants was weighted in the } \\
\text { process }\end{array}$ & 6.1 & 2.7 & 8.4 & 1.4 & $<0.01$ \\
\hline \multicolumn{6}{|l|}{ Profession } \\
\hline I experienced financial consequences. & 5.6 & 2.8 & 5.5 & 2.5 & 0.91 \\
\hline I experienced a difference in view & 7.9 & 1.6 & 8.3 & 1.1 & 0.42 \\
\hline I experienced a difference in expertise. & 6.7 & 1.7 & 7.6 & 1.6 & 0.13 \\
\hline I experienced loss of autonomy & 6.8 & 2.3 & 4.6 & 2.5 & 0.01 \\
\hline \multicolumn{6}{|l|}{ Other } \\
\hline I would recommend the used tool to others. & 5.6 & 2.4 & 7.9 & 1.4 & $<0.01$ \\
\hline I am pleased with the final document. & 6.1 & 1.9 & 8.3 & 0.9 & $<0.01$ \\
\hline
\end{tabular}

Representation - Both professions trusted their representatives (M $8.3 \pm 1.4$ vs. G $10.0 \pm 0.0, p<0.01)$, and were satisfied with the way the representatives informed them about the progress ( $M 7.2 \pm 2.1$ vs. $G 9.7 \pm 0.6, p=0.05$ ) and the decisions made by the team ( $M 7.2 \pm 2.3$ vs. $G 9.7 \pm 0.6, p=0.07$ ). 
Participation - Gynecologists had significantly higher mean scores, for questions regarding the weighing of their opinion during the process (M 5.9 \pm 2.2 vs. G $8.7 \pm 0.9$, $p<0.01$ ) and respecting the opinion of the region during the team meetings ( $\mathrm{M} 5.9 \pm 2.3$ vs. $\mathrm{G} 8.1 \pm 1.9, \mathrm{p}<0.01$ ). Midwives may have felt a certain degree of a power imbalance ( $\mathrm{M} 6.3 \pm 2.2$ vs. $\mathrm{G} 4.2 \pm 3.1, \mathrm{p}=0.07$ ), although not significantly different compared to gynecologists. The factor 'not taken seriously' (M 5.0 \pm 2.7 vs. $G 2.6 \pm 2.1, p<0.05$ ) had a low mean score for both professions, but, compared to gynecologists midwives felt they were taken less seriously.

Tool - Midwives judged the amount of information they received prior to the project to be less sufficient (M 5.4 \pm 2.2 vs. $G 8.0 \pm 1.6, p<0.01$ ) as compared to gynecologists. Midwives were also more likely to be unaware of the impact the project would have on their daily practice. Both professions reported three factors of positive influence, although in each case scores were lower for midwives: 1) all participants were asked to give their opinions ( $M 6.8 \pm 2.5$ vs. $G 8.6 \pm 0.8, p<0.01$ ), 2 ) the results were presented objectively ( $\mathrm{M} 6.6 \pm 2.5$ vs. $\mathrm{G} 8.6 \pm 1.0, \mathrm{p}<0.01$ ) and 3 ) the opinions of all participants were weighed in the process ( $M 6.1 \pm 2.7$ vs. $G 8.4 \pm 1.4, p<0.01$ ).

Profession - Financial consequences (M 5.6 \pm 2.8 vs. G 5.5 $\pm 2.5, p=0.91$ ) coming from the chosen decisions were scored neutral. Both professions reported difference in views ( $M 7.9 \pm 1.6$ vs. $G 8.3 \pm 1.1, p=0.42$ ) and expertise ( $M$ 6.7 \pm 1.7 vs. $G 7.6 \pm 1.6$, $p=0.13)$. Considering other influencing factors, midwives scored higher on loss of autonomy compared to gynecologists ( $M 6.8 \pm 2.3$ vs. $G 4.6 \pm 2.5, p<0.05$ ). The black boxes in Figure 2.4 show factors that have a significant effect on recommending the used ACCORD-tool to others and the opinion on the final document. In appendix II all significant correlations are shown. Essential for recommending the tool is the information supply during the process by the representative on the progress of the decisions (OR $1.7(95 \%-\mathrm{Cl} 1.1-2.7)$ ), team meetings in which the view of different regions is respected (OR $2.2(95 \%-\mathrm{Cl} 1.2-4.2))$ and the information supplied prior to the project (OR $2.7(95 \%-\mathrm{Cl} 1.1-6.3))$. If participants reported a power imbalance (OR 0.5 (95\%-Cl $0.2-0.8)$ ) or loss of autonomy (OR 0.7 (95\%-Cl $0.5-0.9)$ ), they were less likely to recommend the tool. Being pleased with the final document is dependent on the way the opinion of the participants was taken into account during the process (OR $1.8(95 \%-\mathrm{Cl} 1.0-3.1)$ ) and if the results were considered to be presented objectively (OR 1.9 (95\%-Cl 1.2-2.9)). Experiencing a power imbalance (OR $0.3(95 \%-\mathrm{Cl} 0.1-0.7)$ ) or loss of autonomy (OR $0.7(95 \%-\mathrm{Cl} 0.5-1.0)$ ) had a negative influence on the opinion of the final product. 


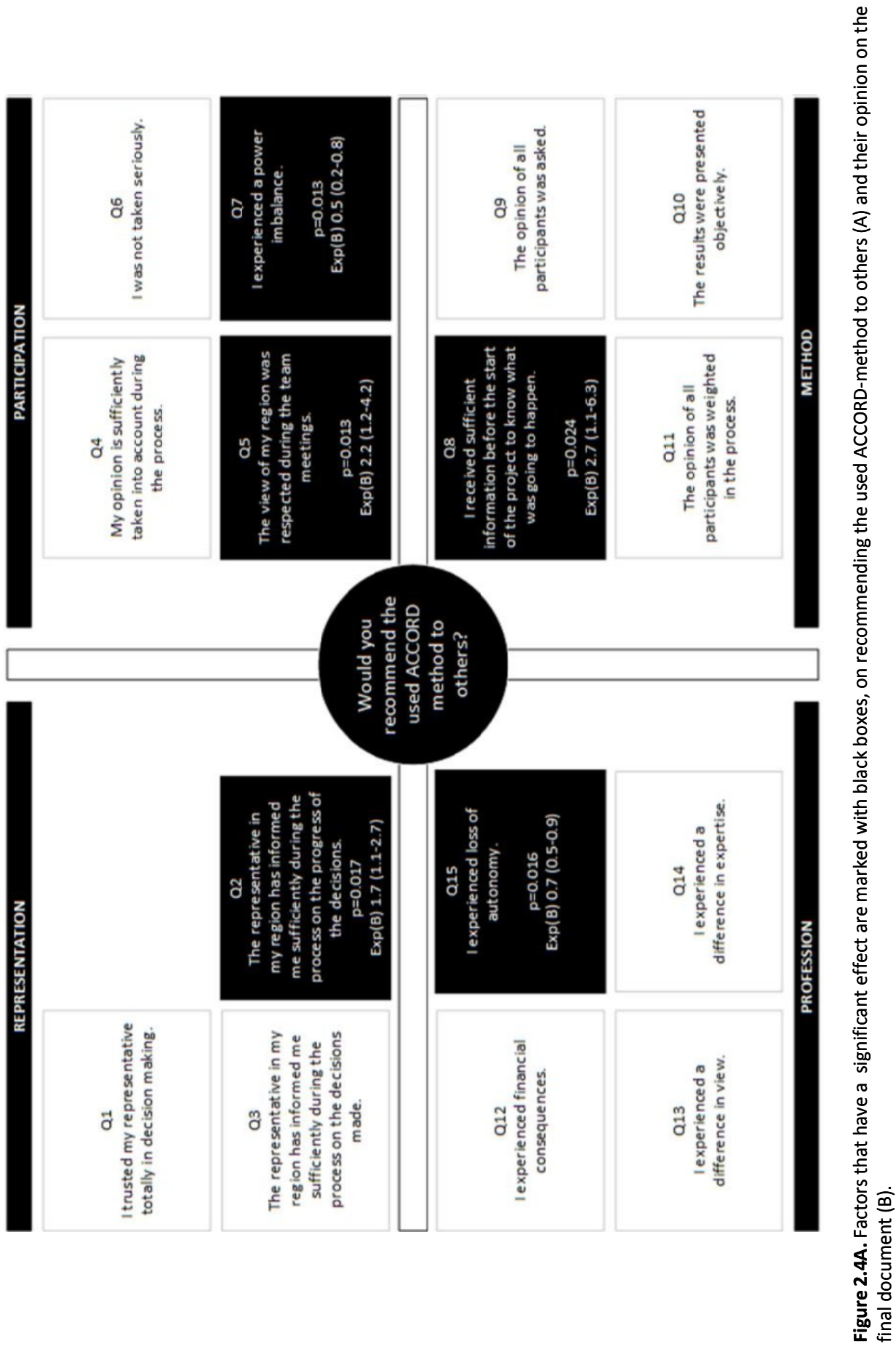




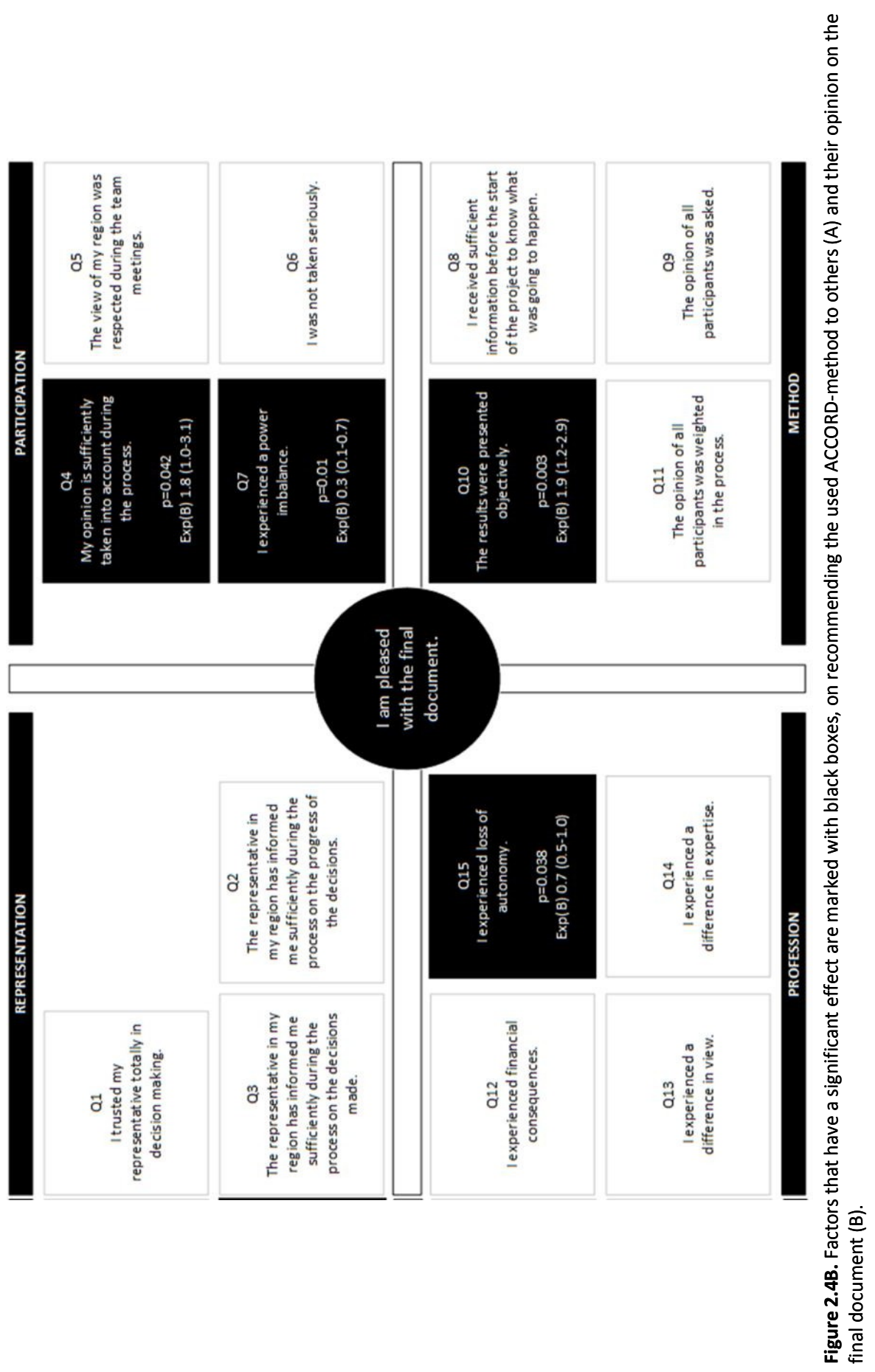




\section{DISCUSSION}

By using the ACCORD-tool consensus was reached on $92 \%$ of all statements that were rated. Despite being based on current scientific evidence, three-quarters of all statements were debated before consensus was reached. Our process analysis showed that gynecologists were more satisfied with the process than midwives.

\section{Barriers for collaboration in obstetrics}

During our decision-making process, we faced some challenges we had to overcome. It is known that the Dutch obstetric care system has several substantial barriers to collaboration $^{8}$. Midwives care for healthy pregnant and childbearing women, while gynecologists/obstetricians attend women with complications in pregnancy and childbirth, resulting in fundamentally different perspectives and different views on the course of pregnancy and delivery ${ }^{9}$. Midwives view pregnancy and delivery as healthy, physiological events whereas gynecologists are more prone to be concerned about adverse events. Consequently, gynecologists conduct more checks on the condition of the pregnant women and intervene more frequently than midwives ${ }^{10}$. These different views became evident during our team meetings, where the professionals discussed for instance the amount of check-ups during pregnancy, the need and value of medical interventions, the introduction of new interventions and diagnostic thresholds. Starting point for these discussions were the survey results. The mean and SD for each statement and for each profession (gynecologists and midwives) were presented), but also concerns expressed in the survey comments. Besides a different view between gynecologists and midwives, hierarchical structures influenced our decision-making process. In general, healthcare environments are characterized by hierarchical structures, with the specialist on top of the hierarchy. ${ }^{11}$ Professionals at the lower end of the hierarchy, tend to be uncomfortable to raise their concerns or bring up the problems their facing ${ }^{11}$. When hierarchical differences come into play, different perceptions on collaboration and communication can diminish collaborative interactions necessary to provide the best care. Research of Van der Lee already showed that although obstetricians express a willingness to cooperate with them, midwives experience a power imbalance in their relationships with their specialist colleagues ${ }^{8}$. Midwives feel that obstetricians see themselves as having a superior role and believe that this perceived power imbalance may arise partially from a different level (university versus vocational) and length of education ${ }^{12}$. 
Midwives felt they were not taken seriously or trusted, reporting that when they referred a pregnant woman to the hospital, gynecologists would often repeat the evaluation of the woman ${ }^{8}$. From a historical perspective, this feeling of power imbalance can be explained as a result of the hierarchical structure. Midwives started as autonomous professionals, responsible for all pregnant women, only consulting another caregiver if the child had died during delivery ${ }^{12}$. However, already in the nineteenth century a new law was introduced in The Netherlands, which divided obstetric responsibilities in pathological labor for doctors and physiological labor for midwives, thereby restricting the autonomy of midwives ${ }^{12}$. Evaluating our process, midwives also reported they felt a certain degree of power imbalance between them and gynecologists, despite the fact that every professional had the opportunity to give their opinion and each opinion counted equally. Probably this is due to the aforementioned historical context. By developing shared protocols using the ACCORD-tool and increasing the collaboration between both professions, we expect that this feeling of power inequality will decrease in future decision-making processes.

In addition, separation of the financial structures of both occupational groups could lead to competing financial interests that may put pressure on given care ${ }^{9,13}$. Midwives are independent entrepreneurs and changes in obstetric care management, can result in loss of income. In our decision-making process, the survey contained statements regarding financial consequences to give professionals the opportunity to express any concerns. These concerns were taken into account and discussed during the team meetings.

Given the five pillars of successful collaboration, almost all supportive elements were incomplete or absent in our project. Even though these secondary conditions for collaboration were not met, the ACCORD-tool allowed midwives and gynecologists to achieve moderate to good results in reaching consensus. We therefore regard the four steps of the ACCORD-tool as a promising approach for reaching consensus in situations where collaboration between stakeholders is mandatory but difficult.

Instead of designing a novel strategy we could have used the top-down Delphimethod $^{14,15}$. The Delphi technique uses panel members that are selected experts in the field that have no direct face-to-face contact. Two strengths of this technique, because each individual panel member can write his comments, recommendations and solutions to the problem independently and anonymously, unaffected by peer pressure, status or dominant viewpoints of other participants ${ }^{4,15-17}$. The Delphi 
method uses the concept of iterative feedback rounds, in which participants are able to revise their opinion after they received feedback, until after some rounds the opinions of the participants stabilize $e^{4,16,18}$. The use of experts and anonymity is at the same time one of the weaknesses of the Delphi technique, as this is a top-down approach in which the opinion of the people working in the field which are most affected by the decisions, is not investigated. This could be a challenge for implementation when the expert opinion does not correspond to the opinion of the professionals in the field. Anonymity may lead to a lack of accountability ${ }^{17}$.

In our situation however, the ACCORD-tool offered certain advantages. Most important, ACCORD allowed face-to-face contact between at least a subgroup of the participants during the team meetings. This face-to-face contact gave the project group the opportunity to clarify uncertainties, discuss the survey results, and give direct feedback to each other. Second, in contrast to the Delphi-method, where only the opinion of the expert panel is weighted, the ACCORD-tool considers the opinion of all participants to be equally important. This bottom-up approach helps to create shared responsibility via an enriched and constructive conversation. If the opinions of the professionals involved are ignored, there is a real risk of a lack of support for decisions made and, as a consequence, a lower likelihood of implementation of the new agreements ${ }^{19}$. This ACCORD-tool is useful in every situation where group decisions have to be reached affecting working-protocols that have to be followed thereafter. This can be multidisciplinary healthcare teams with specialists, general practitioners and other first line professionals, but also in business organizations for example. Just as many other tools applied in the use of reaching consensus, the ACCORD-tool aims to facilitate collaboration within different professionals groups. Our experience with the ACCORD-tool was that it was able to reach a high degree of consensus within different groups that lacked the ability to cooperate effectively.

\section{Limitations}

A potential limitation of the ACCORD-tool is the labour-intensive character of writing the summary of the guideline based evidence, preparing the surveys and team sessions by a medically trained researcher. The up side of these labour intensive preparations, however, is that the time investment for participants was limited and team sessions were highly efficient. Our starting point to summarize evidence was extracting information from existing national and international guidelines and local 
protocols. No systematic search in medical databases was performed, as guidelines and protocols represent topics on which professionals, top-down, have already agreed upon. Due to the fact that guidelines are usually revised every five years, it is possible that we missed evidence based on recent articles.

\section{Future perspectives}

Important for other professionals who will use the ACCORD-tool, is to pay close attention to the way participants receive information at the beginning of the project, and to be aware of possible influencing factors, both positive and negative. The final product is more likely to be appreciated and the tool is more likely to be recommended to others when the views of all participants are respected and negative influencing factors are limited. Moreover, the representatives should be encouraged to act as ambassadors, providing objective information about the deliberations to their peers, especially in cases where decisions were difficult to reach.

\section{CONCLUSION}

The ACCORD-tool proved to be an efficient approach for collaboratively reaching agreements on the content of care with a moderate-to-good acceptance by participants in a group of professionals with different views and perspectives. 


\section{REFERENCES}

1. D'Amour D, Ferrada-Videla M, San Martin Rodriguez L, Beaulieu MD. The conceptual basis for interprofessional collaboration: core concepts and theoretical frameworks. J Interprof Care. 2005;19 Suppl 1:116-31.

2. Xyrichis A, Lowton K. What fosters or prevents interprofessional teamworking in primary and community care? A literature review. International journal of nursing studies. 2008;45(1):140-53.

3. Bressen T. Consensus decision-making: what, why, how. ABA Books 2012.

4. Crisp J, Pelletier D, Duffield C, Adams A, Nagy S. The Delphi method? Nursing research. 1997;46(2): 116-8.

5. Hartnett T. Consensus oriented decision making: New Society Publishers; 2011.

6. Meslin EM. The value of using top-down and bottom-up approaches for building trust and transparency in biobanking. Public Health Genomics. 2010;13(4):207-14.

7. Sabatier PA. Top-Down and Bottom-Up Approaches to Implementation Research: a Critical Analysis and Suggested Synthesis. Journal of Public Policy. 2008;6(1):21-48.

8. van der Lee N, Driessen EW, Scheele F. How the past influences interprofessional collaboration between obstetricians and midwives in the Netherlands: Findings from a secondary analysis. Journal of Interprofessional Care. 2016;30(1):71-6.

9. Perdok H, Jans S, Verhoeven C, van Dillen J, Batenburg R, Mol BW, et al. Opinions of professionals about integrating midwife- and obstetrician-led care in The Netherlands. Midwifery. 2016;37:9-18.

10. Birthplace in England Collaborative G, Brocklehurst P, Hardy P, Hollowell J, Linsell L, Macfarlane $A$, et al. Perinatal and maternal outcomes by planned place of birth for healthy women with low risk pregnancies: the Birthplace in England national prospective cohort study. Bmj. 2011;343:d7400.

11. Rosenste MODAH. Professional Communication and Team Collaboration. Patient Safety and Quality: An Evidence-Based Handbook for Nurses Agency for Healthcare Research and Quality (US); 2008.

12. van der Lee N, Driessen EW, Houwaart ES, Caccia NC, Scheele F. An examination of the historical context of interprofessional collaboration in Dutch obstetrical care. J Interprof Care. 2014;28(2): 123-7.

13. VLN Schölmerich AP, H Ghorashi, AJM Waelput, P Groenewegen, S Denktas. Improving interprofessional coordination in Dutch midwifery and obstetrics: a qualitative study. BMC pregnancy and childbirth. 2014.

14. Jones J. Consensus methods for medical and health services research. Bmj. 1995;311:5.

15. Lunenburg FC. Decision Making in Organizations International Journal of Management, Business, and Administration. 2011;15 (1).

16. Dodge B, Clark, R. . Research on the Delphi Technique. Educational Technology. 1977;17(4):3.

17. C. G. The Delphi technique: a critique. Journal of Advanced Nursing. 1987;12:6.

18. Okoli C, Pawlowski SD. The Delphi method as a research tool: an example, design considerations and applications. Information \& Management. 2004;42(1):15-29.

19. Cabana MD. Why don't physicians follow clinical practice guidelines. JAMA.282(15):8. 



\section{CHAPTER 3}

\section{Do Representatives represent you?}

S.M.P. Lemmens, V.A. Lopes van Balen, H.C.J. Scheepers, R.G. De Vries, M.E.A. Spaanderman

Integrative Journal of Nursing and Health 2019;2(1):90-94 


\section{ABSTRACT}

\section{Introduction}

Representation by a small group of chosen representatives is a common used strategy for decision making within a large heterogeneous group of people. In hospital and first-line setting, we measured the level of representatives-peers agreement for representatives that were selectively chosen by peers and those that were randomly selected.

\section{Method}

Professionals working in hospital-obstetric and first-line midwifery domains, 23 representatives and 114 represented peers, gave their opinion on obstetric topics by ranking 681 statements on a 10-point Likert-scale. Correlations between representatives and peers scores were assessed with Bland-Altman difference plots. Level of agreement was evaluated by area under the curve (AUC) of the difference in statement score.

\section{Results}

Statement scores of chosen representatives correlated well with their peers $(r=0.91)$. Fifty percent of representatives and peers scores differed less than 1.9 point. The average representative-peers agreement was $77 \%$. Selectively chosen gynecologists and midwives showed comparable levels of agreement (gyn AUC 0.77 vs. mid AUC $0.75, p=0.105)$, whereas randomly selected professionals tend to differ in professional view (gyn AUC 0.80 vs. mid AUC 0.74, p=0.052). The selection method led to no differences within the group of gynecologists (chosen AUC 0.77 vs. random AUC 0.80, $p=0.220$ ) and midwives (chosen AUC 0.75 vs. random AUC 0.74, $p=0.859$ ).

\section{Conclusion}

Decision making by representatives within a diverse group of professionals, largely reflects the opinion of their peers. The selection method of representatives and the professionals' working environment do not statistically affect the level of representative-peers agreement. 


\section{INTRODUCTION}

Collaboration of professionals across overlapping disciplines, each with their own view and perspectives, requires shared and supported guidelines regarding medical decision making. To come to shared guidelines, a bottom-up development strategy is thought to result in stronger supported inter-professional directives. Especially by allowing the ideas of a diverse group of professionals across disciplines to be captured in an early stage of the development process ${ }^{1,2}$. When people are consulted about their ideas and opinions, they typically feel better about a decision, even when the decision does not correspond with their preference ${ }^{2}$. Furthermore, to reach an agreement it is important to have a setting where participants are aware of each other's opinion and arguments and can respond to them. Participants in multidiscipline decision-making must first agree on the level of agreement needed to move forward: unanimous consent, near unanimity, a super or simple majority, an executive committee, or the vote of a committee made up of representatives from each group ${ }^{3}$.

When a large heterogeneous group has to make decisions, a strategy using a small group of chosen representatives weighing the balance of disciplines represented in the group is thought to be most efficient ${ }^{2}$. These representatives are expected to reflect the opinions of their group, rather than insisting on their personal preferences. However, data regarding this presumption are lacking. To this end, we evaluated the degree to which decisions made by selectively chosen representatives reflected the opinion of the group they are supposed to be representing. We also evaluated if the decisions of randomly selected representatives reflected the views of their peers and if the professionals working environment affects the representation of their peers, comparing gynecologists working in a moderate-to-large-team hospital setting with midwives working in small-to-single private practices.

\section{METHODS}

\section{Participants}

Between 2013 and 2016 a total of 137 professionals participated in our interprofessional guideline development project, in the catchment area of the tertiary Maastricht University Medical Centre, the Netherlands. The participants included gynaecologists working in moderate-to-large-team hospital teams, midwives working 
in small-to-single first line practices and professionals working in maternity care. They were either assigned to the group of chosen representatives $(n=23)$ or to the group of peers $(n=114)$. The group of representatives included 10 gynecologists, 11 midwives and 2 maternity care board members. The group of peers included 31 gynecologists, 79 midwives and 4 peers working in maternity care, a distribution that accurately reflects the distribution in the field. Because status, expertise and working experience in years differed between representatives, an equal number of midwives and gynecologists in the representation group were selected to ensure an equal distribution from the same layer of the status hierarchy. We excluded the in total six professionals working in maternity care, because this group was too small to compare statement scores between representatives and peers. Representatives were selectively chosen by their peers in different ways: anonymous voting, public voting or because they stepped forward to take the responsibility of representing their peers. The randomly selected representatives were selected by using an online random number generator.

\section{Design}

A four-step bottom-up approach was used to decide upon a wide range of obstetric topics that lead to uniform work-agreements. In the first step, current guidelines were summarized, inconsistencies were highlighted and pivotal questions formulated. Secondly, on essential topics a flowchart was created which showed different options on which a decision should be taken. Thirdly, after translation of these decision points into statements the participants ranked these statements $(n=681)$ by their level of agreement on a 1 (disagree) to 10 (agree) Likert-scale in an online survey (Survey Monkey, Palo, Alto, CA, USA). Representatives ranked the statements based on their own professional opinion. Each participant's vote counted equally. Finally, representatives formulated decisions and recommendations for daily practice after discussion of statements based on the mean and standard deviation (SD). Statement scores between 3 and 8 or a SD $>2$ were discussed. Statements with a mean below 3 or above 8 and a SD<2 were immediately rejected or accepted, respectively. Decisions were agreed upon when at least $85 \%$ of the representatives were in favour. No veto rights were allowed. After each meeting the representatives were responsible for reporting the final recommendations to their peers. We used the ranking score of each statement in the comparisons, correlations and level of agreement scores of representatives and peers. All agreements, scores and 
arguments used and weighted to come to certain decisions in case of discussion, were systematically documented and added to the final guideline to inform peers regarding the decision process.

\section{Statistical analysis}

Correlations between the scores of the representative and his/her peers were assessed. We compared the statement scores of specifically chosen with randomly selected representatives (gynecologists and midwives). The differences in scores were plotted against the average of the difference in a Bland-Altman plot ${ }^{4}$. Differences in opinion are illustrated by displaying the average cumulative percentage ( $y$-axis) of differences in statement scores ( $x$-axis). The average level of agreement was presented by the area under the curve (AUC) of the difference in statement score and cumulative prevalence. The level of agreement was considered poor (AUC<50\%), moderate (AUS 50-69\%), good (AUC 70-90\%) or excellent (AUC>90\%). Analyses were performed using SPSS version 21.0, property of IBM. Graphs were created using SPSS and Microsoft ${ }^{\circledR}$ Excel (2010) both supplied by Maastricht University.

\section{RESULTS}

Statement means of chosen representatives, both gynecologists and midwives, and their peers correlated well ( $r=0.91$ ) (Figure 3.1). Differences in opinion are illustrated by displaying the average cumulative percentage ( $y$-axis) of differences in statement scores (x-axis). In Figure 3.2, the average differences in statement scores between the selected representatives and their peers are depicted for both gynecologists and midwives.

By view, the best representation is achieved by randomly selected gynecologists, with less than 1.3 point difference compared to their peers in $50 \%$ of the scores. For the other groups the percentage difference in statement scores is slightly higher; 1.5 point for selectively chosen gynecologic representatives, 1.7 point for randomly selected midwifery representatives and 1.9 point for selectively chosen midwifery representatives compared to their peers. Statistically, comparing the AUC used as a measure for agreement, no significant differences are seen between the four groups. Both, the selection method and the professional group did not statistically affect the level of agreement. The selectively chosen professionals (gyn AUC 0.77 vs. mid 
AUC 0.75, p=0.105) showed the same levels of agreement, but randomly selected professionals (gyn AUC 0.80 vs. mid AUC 0.74, $p=0.052$ ) tend to differ in professionals view and opinion. No significant differences were seen comparing both professional groups: gynecologists (selectively AUC 0.77 vs. random AUC 0.80, p=0.220) and midwives (selectively AUC 0.75 vs. random AUC 0.74, $p=0.859$ ).

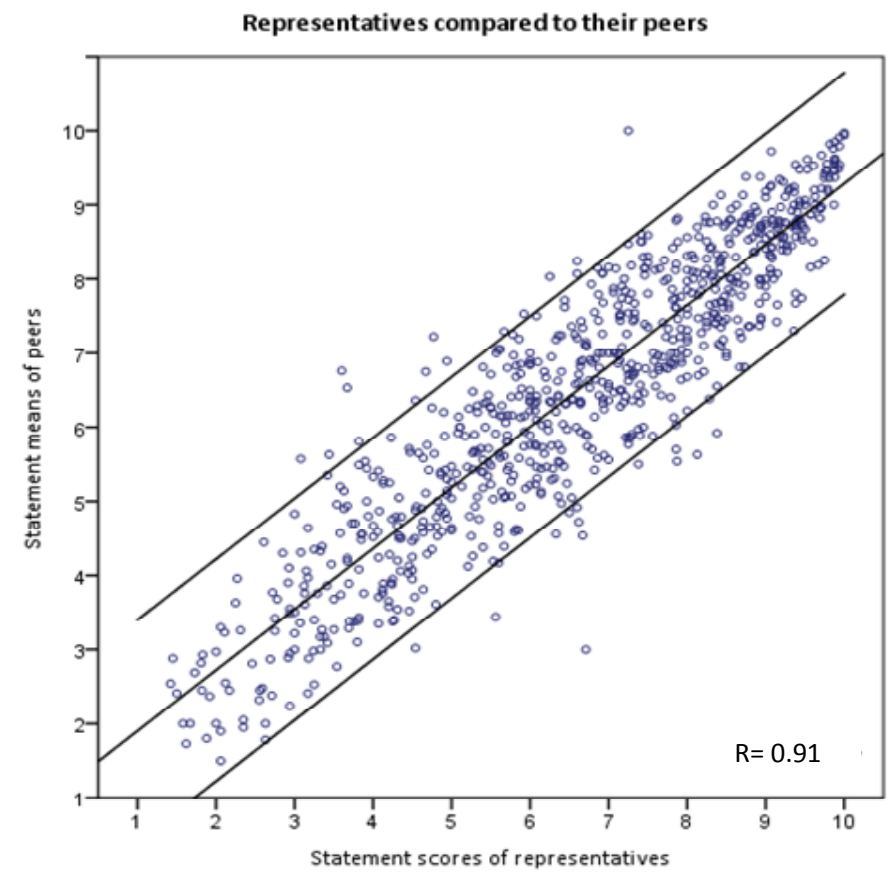

Figure 3.1. Scatterplot of statement means of the representatives ( $x$-axis) versus their peers ( $y$-axis) and a $95 \%$ confidence interval.

The Bland-Altman plot (Figure 3.3) shows the agreement between the selectively chosen representatives and their peers on specific topics. The mean difference across all valued statements is 0.195 (upper limit 1.973, -1.583 lower limit), indicating that most opinions are scored within $a+/-18 \%$ radius of each other. 


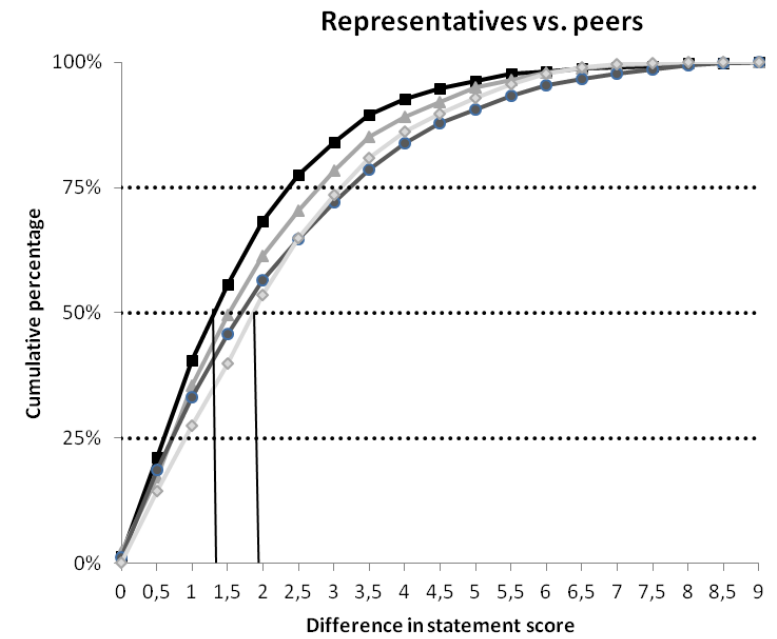

$\begin{array}{llll}\longrightarrow \text { Randomly selected gynecologists } & \text { AUC } 0,80 & - \text { Selectively chosen gynecologists AUC } 0,77 \\ \longrightarrow \text { Randomly selected midwives } & \text { AUC } 0,74 & \text { Selectively chosen midwives AUC } 0,75\end{array}$

Figure 3.2. Cumulative percentage of differences in statement means between representatives and their peers. Four groups are visualized: randomly chosen gynaecologists, randomly chosen midwives, specifically selected gynaecologists and specifically selected midwives. The vertical lines show that in $50 \%$ of all scores the difference in mean score between the representatives and their peers is less than 1.9 point.

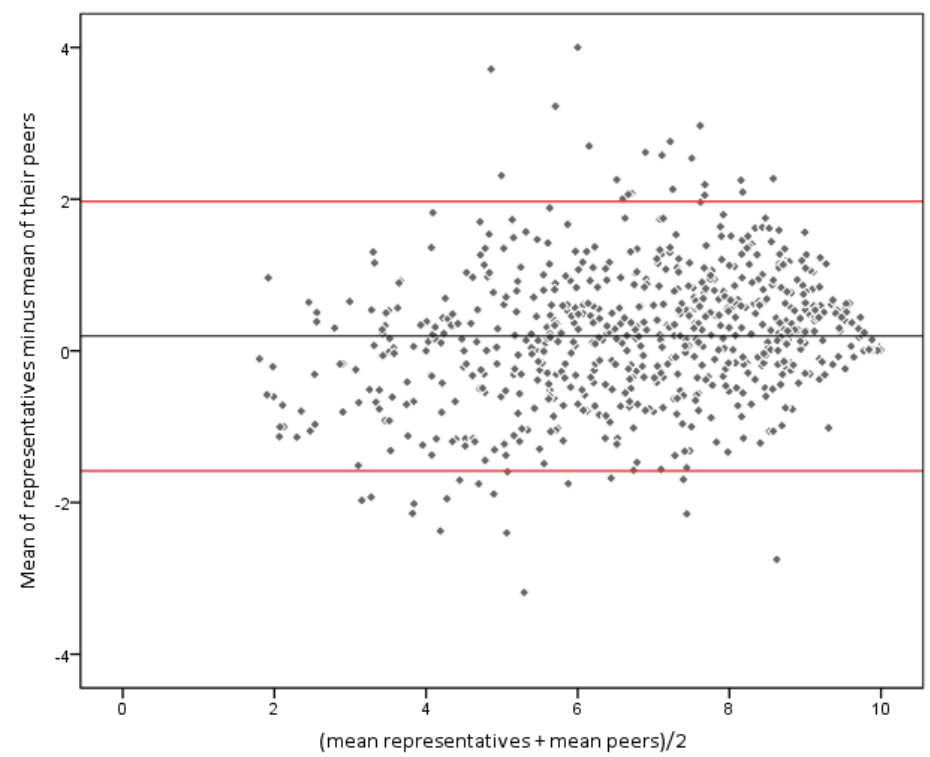

Figure 3.3. Bland-Altman plot showing the agreement between representatives and their peers. The mean of the difference is 0.195 (upper limit $1.973,-1.583$ lower limit). 


\section{DISCUSSION}

To come to inter-professional guidelines, usually a small group of representatives develops these directives. We evaluated if decisions made by chosen or randomly selected representatives working in different professional settings reflect the opinion of their constituency. We observed comparable levels of representative-peer agreement (AUC $0.74-0.80,74-80 \%$ ) in selected and randomly chosen representatives irrespective of their professional setting. This can be looked at in at least two ways: on the one hand, $74 \%-80 \%$ concordance suggests a high level of agreement, but on the other hand representatives and peers disagreed on $20-26 \%$ of statements, a not insignificant number, especially when fundamental issues are at stake. If the statements that are not agreed upon are critically important, the level of satisfaction with the process may be low, in spite of otherwise high levels of agreement. Level of agreement alone is therefore insufficient to guarantee satisfied participants. Participants must also agree that they will support the decisions made by this process and they must be willing to implement new policies in daily practice, even when the ultimate decision does not correspond with their personal preference.

Reaching unanimous agreement in group decisions is rarely possible, particularly when the topic to be decided upon is multifaceted and when the decision affects participants' daily practice. Several social factors influence group decision-making and group- interaction. Individuals adjust their behavior to what they perceive is the group norm ${ }^{2}$. This phenomenon helps to explain the differences between the results of the surveys, filled in individually, and the final decisions after group discussion. Positively, in mutual respectful collaboration, individuals usually combine their preferences to create a shared decision, also known as social decision schemes ${ }^{2}$. Negatively, expressing views and perspectives in a multidisciplinary group may also lead to group polarization. This can result in merging of ideas which favor the dominant viewpoint ${ }^{5}$. Individuals can be docile and inclined to follow a dominantly held view, especially if this originates from an influential person. This can lead to false agreement. These dominant views can stem from individuals with a certain status and/or expertise. Difference in status between individuals in the group is an important factor that contributes to conformity but also to compliance. One's status can have an effect on the consideration of evidence but also on the time spent discussing a certain topic within a group ${ }^{2}$. Besides status, expertise on a specific topic can influence the group decision ${ }^{5}$. If a group member with a recognized expertise expresses an opinion, this can persuade group members to follow and share this 
opinion. Recognizing that status, expertise and years of work experience differed between representatives, wanting to reduce social influence pressure, we chose to have an equal number of representatives from midwives and gynecologists, creating an equal distribution from the same layer of the status hierarchy. We also had an independent meeting chair tasked with monitoring all representatives opinions, especially those not given in the discussion process ${ }^{2}$.

Deciding who acts as a representative can be a challenge. As our results show, the differences in level of agreement are negligible between selectively chosen or randomly selected representatives. The selectively chosen professionals showed the same levels of agreement with their electorate. In our study, each region chose their representatives differently. Some were put forward by their peers to represent them, whereas others were anonymously chosen by voting or offered themselves to represent their peers. As a result, the representatives may have totally different characters that may vary from active participation only when specifically asked to do so, to continuous active participation and persuasive presence. As social decision schemes may lead to conformity and with it more extreme choices made, the representatives' personality could affect an ultimate outcome and decisions made that may not reflect the mainstream opinion. Continuous feedback to the peers of what was decided for what reasons remains therefore of utmost importance.

\section{Limitations}

A potential limitation of this study is the fact that participants ranked statements differently. Even though statements were to be ranked on a gradient, some participants ranked the statements dichotomously (10 or 1). This likely resulted in larger differences between representatives and peers and as a consequence in a decreased representativeness. Despite these differences in ranking, the representatives reached a strong level of agreement.

Secondly, in our analysis, we did not weigh fundamental versus non-fundamental issues. Despite the good level of agreement of the chosen approach to come to agreement, the electorate might value taken decisions as not-representative to their opinion in case fundamental issues differ about $20 \%$ from their opinion. 


\section{CONCLUSION}

Within a diverse group of professionals across disciplines, decision making by representatives largely reflects the opinion of the group they represent. The selection method of the representatives does not statistically affect the level of agreement between representatives and the group represented, although selectively chosen representatives may be most reflective to the group they stand for. 


\section{REFERENCES}

1. Vaucher C, Bovet E, Bengough T, Pidoux V, Grossen M, Panese F, et al. Meeting physicians' needs: a bottom-up approach for improving the implementation of medical knowledge into practice. Health research policy and systems. 2016;14(1):49.

2. Pagliari C. The potential influence of small group processes on guideline development. Journal of evaluation in clinical practice. 2000;7(2):165-73.

3. Hartnett T. Consensus oriented decision making: New Society Publishers; 2011.

4. Bland J.M. ADG. Statistical methods for assessing agreement between two methods of clinical measurement. Lancet. 1986:307-10.

5. Coulter I. Impact of varying panel membership on ratings of appropriateness in consensus panels, a comparison of a multi- and single disciplinary panel. Health Services Research. 1995;30(4). 



\section{CHAPTER 4}

\section{Perinatal factors related to pregnancy and childbirth satisfaction: a prospective cohort study}

S.M.P. Lemmens*, P. van Montfort*, L.J.E. Meertens, M.E.A. Spaanderman, L.J.M. Smits, R. de Vries, H.C.J. Scheepers

* Contributed equally Journal of Psychosomatic Obstetrics and Gynaecology 2020;1-9 


\section{ABSTRACT}

\section{Background}

Satisfaction of pregnancy and childbirth is an important quality measure of maternity care. Satisfaction questionnaires generally result in high scores. However, it has been argued that dissatisfaction relies on a different construct. In response to a worldwide call for obstetric care that is more woman-centered, we identified and described the contributors to suboptimal satisfaction with pregnancy and childbirth.

\section{Methods}

A prospective subcohort of 739 women from a larger cohort (Expect Study I, $n=$ 2614) received a pregnancy and childbirth satisfaction questionnaire. Scores were transformed to a binary outcome whereby a score $<100$ points corresponded with less satisfied women. We performed a multiple logistic regression analysis to define independent perinatal factors related to suboptimal satisfaction.

\section{Results}

Decreased perceived personal well-being, antenatal anxiety, and obstetrician-led care during labor were all independently associated with suboptimal pregnancy and childbirth satisfaction. No difference in satisfaction was found between antenatal care led by a midwife or an obstetrician, but midwife-led antenatal care reduced the odds of suboptimal satisfaction compared to women who were transferred to an obstetrician in the antenatal period. Antenatal anxiety was experienced by $25 \%$ of all women and is associated with decreased satisfaction scores.

\section{Discussion}

Screening and treatment of women suffering from anxiety might improve pregnancy and childbirth satisfaction, but further research is necessary. Women's birthing experience may improve by reducing unnecessary secondary obstetric care. 


\section{INTRODUCTION}

Satisfaction with care delivered during pregnancy and birth is a topic of increasing interest and is an essential component of quality of obstetric care ${ }^{1}$. In the Netherlands, one in six women has a negative recall of their birth experience ${ }^{2}$. The prevalence of post-traumatic stress disorders resulting from childbirth is estimated at $2.9 \%^{3}$. Patient satisfaction and birth experience are important factors influencing short- and long-term outcomes of both mother and child (e.g. postpartum depression, the ability to breast-feed, and child abuse) ${ }^{1}$.

Studies of satisfaction with childbirth care are beset by several problems. The role of the healthcare professional is an influential factor shaping a woman's birthing experience ${ }^{4}$. Findings regarding the contribution of several other factors to satisfaction with obstetric care, such as age and pain, are inconsistent ${ }^{1,5}$. Satisfaction questionnaires administered shortly after birth generally result in high satisfaction scores. It has been argued that women may be unable to assess the perceived maternity care properly because they are unaware of other options ${ }^{6}$. Additionally, satisfaction and dissatisfaction are considered to be different constructs rather than a continuum of each other ${ }^{7}$. It may be better to focus on determinants associated with women who are not perfectly satisfied with the obstetric care services received during pregnancy and birth $^{8}$. Focusing on the less satisfied women may result into renewed insights that could improve obstetric care. At present, few studies have focused on determinants of suboptimal care as perceived as such by pregnant women ${ }^{5}$.

Antenatal anxiety is related to several adverse pregnancy outcomes (e.g. spontaneous preterm birth, low birth weight ${ }^{9}$ and is associated with a negative subsequent birthing experience ${ }^{10}$. The negative influence of maternal anxiety upon satisfaction levels with received obstetric care services has been reported as well, but mostly for specific subgroups (i.e. women with fear of birth) ${ }^{11,12}$.

Women's satisfaction regarding pregnancy and labor is also associated with parity. In general, multiparous women report higher levels of satisfaction as compared to nulliparous women ${ }^{13,14}$. Furthermore, it is likely that multiparous women's expectations concerning their current pregnancy is influenced by their previous experiences with pregnancy, giving birth, and the obstetric care system ${ }^{11}$. These expectations are likely to be more realistic than those of nulliparous women (e.g. prior birth mode is an important prognostic factor for the subsequent mode of birth $^{15,16}$ ) which expectedly contributes to better satisfaction levels ${ }^{13}$. 
In this study, we examined the Pregnancy and Childbirth Satisfaction (PCS) of women who recently gave birth in a prospective multicenter cohort. Our objective was to identify factors independently associated with suboptimal PCS and to evaluate the association of maternal anxiety with subsequent PCS in a general population.

\section{METHODS}

We conducted a cross-sectional analysis among a subgroup of a prospective multicenter cohort study, the Expect Study I. The recruitment of this cohort has been described in detail elsewhere ${ }^{17}$. Briefly, women aged 18 years or older were recruited at their first prenatal visit ( $<16$ weeks of pregnancy), in the south region of the Netherlands between 2013 and 2015. Pregnancies ending in a miscarriage ( $<16$ weeks of gestation) or termination before 24 weeks of gestation and women lost-to-followup were excluded from the main cohort. Additionally, for this study, we excluded twin pregnancies.

Women were approached for participation in a sub cohort of the Expect Study I after completion of the first survey (Figure 4.1). Participants in this subcohort received additional surveys at 24 and 32 weeks of gestation. Moreover, the postpartum survey of the Expect Study, sent 6 weeks after the due date, was extended. The additional questions these women received addressed topics of patient satisfaction, anxiety state, and obstetric care services used. Women who reported preterm birth during the surveys at 24 or 32 weeks were automatically redirected to the postpartum survey.

The medical ethics committee of Maastricht University Medical Center (MUMC+) evaluated the study protocol and declared that no ethical approval was necessary for this study under Dutch law (METC-17-4-057). All participants gave informed consent. Pregnancy and childbirth satisfaction was measured using the pregnancy and childbirth questionnaire (PCQ). The PCQ is a validated questionnaire measuring perceived quality of care among postpartum women ${ }^{18}$. With 25 questions using a five-point Likert scale, it addresses topics specifically related to pregnancy and giving birth. Because the PCQ contains questions addressing childbirth, the PCQ was incorporated in the postpartum questionnaire. PCQ-scores were converted so that higher scores correlate with higher levels of satisfaction. Total scores can range from 25 to 125 points (Cronbach's alpha 0.92). We classified women with a total PCQ score of less than 100 points, mean score <4 out of 5, less satisfied regarding their childbirth experience. In this study, we classified these women as "dissatisfied". 
Therefore, we will refer to this group from now on as Pregnancy and Childbirth Dissatisfaction (PCD) instead of PCS.

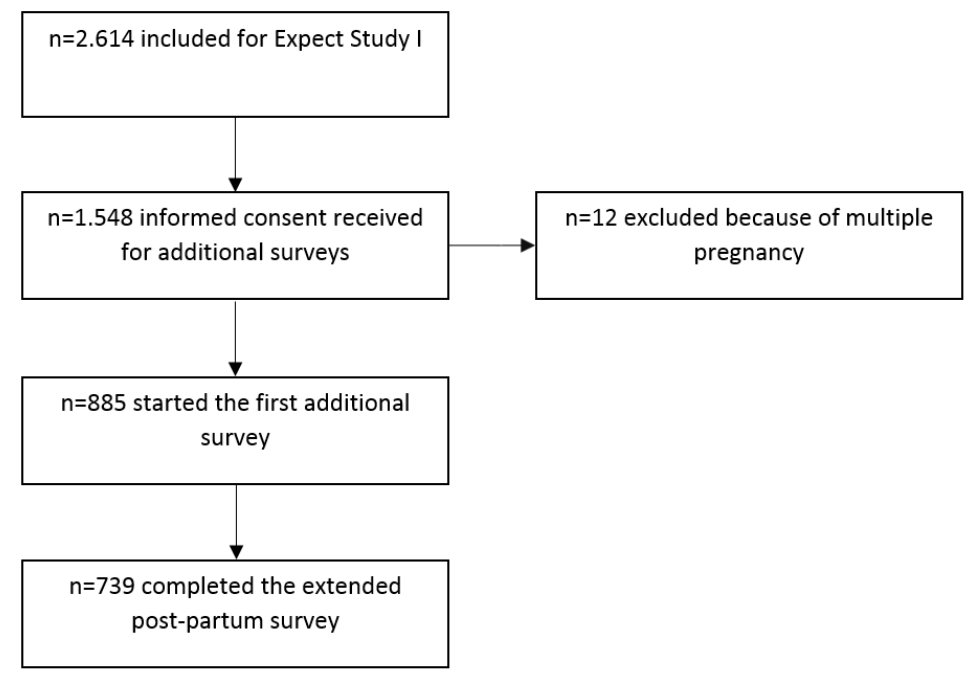

Figure 4.1. Flowchart sub cohort Expect Study I.

To estimate the strength of the association of independent variables with PCD, we used multiple logistic regression analysis. The independent variables of interest were selected from the literature and consist of maternal factors, neonatal health outcomes, and factors related to the obstetric care received. Additionally, we performed sub-analyses for nulliparous and multiparous women.

Maternal factors included demographic variables such as age, educational degree, and socio-economic status. Other factors were; antenatal anxiety, parity (nulliparous or multiparous), decrease in perceived personal wellbeing, a neonatal health composite outcome, and a maternal health composite outcome.

Antenatal anxiety levels were measured using the state anxiety items of the StateTrait Anxiety Inventory (STAI), completed at 24 weeks of gestation. The STAI is a validated and commonly used inventory for the measurement of the general anxiety state. Consisting of 20 items using a four-point Likert scale, STAl scores can range from 20-80. Higher STAI scores represent a higher state of anxiety ${ }^{19}$. We used a threshold of 39 points to identify antenatal anxiety as this cutoff has been suggested to detect clinical significant anxiety symptoms ${ }^{20}$. 
Socio-economic status was estimated using postal codes and corresponding socioeconomic status scores provided by the Dutch government ${ }^{21}$.

A decrease in perceived personal well-being was defined as a postpartum self-report score (scale 0-100) that was at least 10 points lower than the health status reported at enrollment ( $<16$ weeks of gestation). Personal wellbeing was measured with the Euroqol Visual Analog Scale $e^{22}$.

We defined the maternal health composite outcome, a binary outcome, as an occurrence of either pre-eclampsia, gestational diabetes, postpartum hemorrhage (reported blood loss $>1000 \mathrm{ml}$ ), or admission to an intensive or high care unit.

The neonatal composite outcome, a binary outcome defined in Expect Study $\mathrm{I}^{17}$, was defined as an occurrence of one of the following situations; perinatal death within seven days after birth, asphyxia (Apgar score $<7$ after $5 \mathrm{~min}$ ), admission to a neonatal intensive care unit (NICU) within 28 days after birth, birthweight $<2.3$ weight percentile, birth before 32 completed weeks of pregnancy. The birthweight percentile was assessed using Dutch customized birth weight curves which correct for gestational age, ethnicity, gender and parity ${ }^{23}$.

Parity and all items of both the neonatal and maternal composite health outcomes, were retrieved from discharge letters, medical records, and the questionnaires. In case of discrepancies, we contacted the corresponding healthcare professional for the final decision.

Independent variables related to the obstetric care services received were: healthcare professional in lead during antenatal care until at least 34 weeks of gestation (categorical variable: autonomous midwife in a primary care setting, obstetrician in a secondary care setting, or both as a result of transfer of care); healthcare professional during labor (categorical variable: midwife, obstetrician, or both as a result of transfer during labor), birth mode (categorical variable: spontaneous vaginal birth, instrumental vaginal birth, or cesarean section), and usage of analgesics (epidural analgesia, intravenous remifentanil) during labor (yes/no). The variable "transfer of care" refers to transfer in only one direction, namely from midwife (primary care) to obstetrician (secondary care). In case of antenatal or intrapartum transfer of care after 34 weeks of gestation, we considered the healthcare professional who was in lead until 34 weeks of gestation to be the one in lead during antenatal care.

Missing data for explanatory variables were imputed using stochastic regression imputation with predictive mean matching as the imputation model ${ }^{24}$. Characteristics 
of the observed cohort were described as mean \pm standard deviation (SD) for continuous variables. Categorical variables were expressed as an absolute value with a percentage. We compared the distribution of characteristics in order to evaluate the relatedness of the imputed cohort and the observed cohort.

In the Dutch obstetric system, obstetric care is divided in primary, secondary and tertiary care. Autonomous midwives provide care for low-risk pregnant women in primary care independently. Women with high-risk pregnancies receive care by obstetricians in a secondary care (hospital) setting. If women remain low-risk throughout pregnancy, they remain under the supervision of their midwife, including the postpartum period. These women have the option of giving birth at home or in a birthing center supervised by their midwife, or in a hospital supervised by an obstetrician. Women with a high-risk pregnancy are always supervised by an obstetrician and thus give birth in a hospital. Antenatal, intrapartum or postpartum transfer of care, from midwife to obstetrician, is a result of either an unexpected finding or a complication during pregnancy or labor.

\section{RESULTS}

In total 2614 women were included in the Expect cohort of whom 1548 (59\%) gave informed consent for receiving the additional questionnaires. Twelve participants were excluded because of multiple gestation, which complicates the interpretation of the neonatal composite outcome. After providing informed consent, 885 women eventually participated in the sub cohort by completing the first additional survey. The PCQ was completed by the majority of these women $(n=739,84 \%)$, implying a loss to follow-up of $16 \%$.

Table 4.1 displays the characteristics of participants, illustrating the differences between participants lost to follow-up and those who completed the postpartum survey. The differences between these groups were minimal. Women lost to followup had a slightly lower socio-economic status, they tended to have a lower level of education and were more likely to receive analgesics during labor. The postpartum questionnaire is the only instrument with questions regarding a decreased perceived personal well-being and admission to a high care or intensive care unit. As a result, differences with respect to these variables between completers and women lost to follow-up cannot be measured. 
Table 4.1. Characteristics of the non-responders, the observed cohort, imputed cohort, and women lost to follow-up. Data expressed as mean (standard deviation), or $\mathrm{n}(\%)$.

\begin{tabular}{|c|c|c|c|c|c|}
\hline Characteristics & $\begin{array}{c}\text { Non- } \\
\text { response } \\
(n=651)\end{array}$ & $\begin{array}{c}\text { Observed } \\
\text { cohort complete } \\
\text { cases }(n=702)\end{array}$ & $\begin{array}{c}\text { Missing } \\
\text { values, } \\
\text { n (\%) }\end{array}$ & $\begin{array}{c}\text { Imputed } \\
\text { cohort } \\
(n=739)\end{array}$ & $\begin{array}{l}\text { Lost to } \\
\text { follow-up } \\
(n=146)\end{array}$ \\
\hline \multicolumn{6}{|l|}{ Maternal characteristics } \\
\hline Age, years & $30.3(3.9)$ & $30.7(3.7)$ & $0(0.0)$ & $30.7(3.6)$ & 29.9 (3.9) \\
\hline Tertiary level of education, $\mathrm{n}(\%)$ & $355(54.5)$ & $454(64.7)$ & $0(0.0)$ & $478(64.7)$ & $68(46.6)$ \\
\hline Socio-economic status score & $-0.64(1.2)^{*}$ & $-0.5(1.1)$ & $12(1.6)$ & $-0.5(1.1)$ & $-0.8(1.1)$ \\
\hline Body mass index, $\mathrm{kg} / \mathrm{m}^{2}$ & $24.2(4.1)$ & $24.0(4.2)$ & $0(0.0)$ & $24.0(4.2)$ & $24.7(4.3)$ \\
\hline Nulliparous, n (\%) & $295(45.3)$ & $360(51.4)$ & $0(0.0)$ & $383(51.8)$ & $65(44.5)$ \\
\hline State anxiety score & - & $33.4(8.7)$ & $2(0.3)$ & $33.4(8.7)$ & $34.1(7.6)$ \\
\hline Antepartum anxiety, n (\%) & - & $173(24.7)$ & $2(0.3)$ & $184(24.9)$ & $32(21.9)$ \\
\hline \multicolumn{6}{|l|}{ Neonatal outcomes } \\
\hline Neonatal composite outcome, n (\%) & $28(4.3)$ & $31(4.4)$ & $0(0.0)$ & $33(4.5)$ & $9(6.2)$ \\
\hline Birthweight $<2.3$ percentile & $7(1.1)$ & $8(1.1)$ & $0(0.0)$ & $8(1.1)$ & $1(0.7)$ \\
\hline $\begin{array}{l}\text { Preterm birth }<32 \text { weeks of gestation, } \\
\mathrm{n}(\%)\end{array}$ & $13(2.0)$ & $4(0.6)$ & $0(0.0)$ & $5(0.7)$ & $2(1.4)$ \\
\hline APGAR score $<7, \mathrm{n}(\%)$ & $10(1.5)^{*}$ & $10(1.4)$ & $0(0.0)$ & $11(1.5)$ & $4(2.7)$ \\
\hline $\begin{array}{l}\text { NICU admission within } 28 \text { days of birth, } \\
n(\%)\end{array}$ & $16(2.5)$ & $15(2.1)$ & $0(0.0)$ & $16(2.2)$ & $5(3.4)$ \\
\hline Perinatal death, $\mathrm{n}(\%)$ & $7(1.1)$ & $2(0.3)$ & $0(0.0)$ & $2(0.3)$ & $1(0.7)$ \\
\hline \multicolumn{6}{|l|}{ Maternal outcomes } \\
\hline $\begin{array}{l}\text { Decrease in perceived personal } \\
\text { wellbeing, } n(\%)\end{array}$ & - & $182(26.0)$ & $13(1.78)$ & $186(26.0)$ & - \\
\hline Maternal composite outcome, n (\%) & - & 83 (11.9) & $10(1.4)$ & $89(12)$ & - \\
\hline Pre-eclampsia, n (\%) & $12(1.8)$ & $19(2.7)$ & $0(0.0)$ & $21(2.8)$ & $4(2.7)$ \\
\hline Gestational diabetes, n (\%) & $10(1.5)$ & $20(2.9)$ & $0(0.0)$ & $22(3)$ & $8(5.5)$ \\
\hline Postpartum haemorrhage, $\mathrm{n}(\%)$ & $27(4.1)^{*}$ & $46(6.6)$ & $0(0.0)$ & $49(6.6)$ & $6(4.1)$ \\
\hline Intensive or High Care admission, n (\%) & - & $6(0.9)$ & $13(1.8)$ & $7(0.9)$ & $0(0.0)$ \\
\hline Healthcare services & & & & & - \\
\hline Antepartum care led by midwife, $n(\%)$ & - & $451(64.2)$ & $0(0.0)$ & $476(64.4)$ & $91(62.3)$ \\
\hline $\begin{array}{l}\text { Antepartum care led by obstetrician, } \\
\mathrm{n}(\%)\end{array}$ & - & $137(19.5)$ & $0(0.0)$ & $145(19.6)$ & $35(24.0)$ \\
\hline Transfer during antepartum care, $\mathrm{n}(\%)$ & - & $114(16.2)$ & $0(0.0)$ & $118(16.0)$ & $20(13.7)$ \\
\hline Labour led by midwife, $\mathrm{n}(\%)$ & $189(29.0)$ & $233(33.2)$ & $0(0.0)$ & $239(32.3)$ & $38(26.0)$ \\
\hline Labour led by obstetrician, $\mathrm{n}(\%)$ & $335(51.5)$ & $369(52.6)$ & $0(0.0)$ & $394(53.3)$ & $81(55.5)$ \\
\hline Transfer during labour, n (\%) & $127(19.5)$ & $100(14.2)$ & $0(0.0)$ & $106(14.3)$ & $27(18.5)$ \\
\hline Spontaneous vaginal delivery, $\mathrm{n}(\%)$ & $480(73.7)^{*}$ & $525(75.0)$ & $0(0.0)$ & $555(75.1)$ & 99 (67.8) \\
\hline Instrumental vaginal delivery, n (\%) & $63(9.7)^{*}$ & $58(16.7)$ & $0(0.0)$ & $63(8.5)$ & $18(12.3)$ \\
\hline Cesarean section, $\mathrm{n}(\%)$ & $104(16.0)^{*}$ & $117(14.3)$ & $0(0.0)$ & $121(16.4)$ & 29 (19.9) \\
\hline Analgesics during labour, $\mathrm{n}(\%)$ & $303(46.5)^{*}$ & $304(43.3)$ & $4(0.5)$ & $326(44.1)$ & $88(60.3)$ \\
\hline
\end{tabular}

Variables with a minus (-) sign could not be retrieved without the additional surveys. *These variables had missing data among women who did not complete any of the additional surveys; socio-economic state score $(n=13)$; APGAR score $(n=6)$; postpartum haemorrhage $(n=3)$; mode of delivery $(n=4)$; analgesics during labour $(n=21)$.

Overall, total PCQ-scores were high with a mean score of 109.7 out of 125 points for all respondents (SD 12.5). One quarter of all respondents $(n=176)$ had PCD, with a 
mean PCQ score of 92.6 points (SD 6.8). As shown in Table 4.2, these women scored lower on all subscales.

Table 4.2. Pregnancy and Childbirth Questionnaire scores.

\begin{tabular}{lccc}
\hline Scale & $\begin{array}{c}\text { All } \\
\text { respondents } \\
(\mathbf{n = 7 3 9 )}\end{array}$ & $\begin{array}{c}\text { Satisfied } \\
\text { respondents } \\
(\mathbf{n = 5 6 3 )}\end{array}$ & $\begin{array}{c}\text { Dissatisfied } \\
\text { respondents } \\
(\mathbf{n}=\mathbf{1 7 6})\end{array}$ \\
\hline Total score (25 items) & $109.7(12.5)$ & $115(8.3)$ & $92.6(6.8)$ \\
Personal treatment during pregnancy (11 items) & $49.1(5.8)$ & $51(3.9)$ & $41.7(4.1)$ \\
Education information (7 items) & $30.3(4.2)$ & $32(3.2)$ & $25.3(3.1)$ \\
Personal treatment during delivery (7 items) & $30.3(4.5)$ & $32(3.6)$ & $25.6(3.9)$ \\
\hline
\end{tabular}

In the multivariable logistic regression, several factors were significantly associated with PCD. Results were adjusted for all other factors, as shown in Table 4.3. Statistically significant maternal factors associated with PCD were decreased perceived personal wellbeing (odds ratio: $1.62 ; 95 \% \mathrm{Cl}: 1.09-2.40$ ), and antenatal anxiety (odds ratio: $2.23 ; 95 \% \mathrm{Cl}: 1.50-3.30)$. Age was borderline significant with younger women tending to be more likely to experience PCD (odds ratio: 0.95 ; $95 \%$ $\mathrm{Cl}$ : 0.90-1.00).

Regarding factors related to obstetric care services, there was a statistically significant association between PCD and the healthcare professional in charge of antenatal care and during labor. Transfer from primary to secondary care during the antenatal period was associated with increased PCD. Antenatal transfer of care before 34 weeks of gestation, was significantly associated with PCD when compared to uninterrupted midwife led care (odds ratio: $1.82 ; 95 \% \mathrm{Cl}: 1.10-3.00$ ). Antenatal transfer also increased the odds of PCD (albeit not significantly) when compared to uninterrupted obstetrician led care (odds ratio: 1.62; 95\% Cl: 0.93-2.83).

If all labor stages were led by an obstetrician ( $n=368)$, the odds ratio for experiencing PCD was 2.33 (95\% Cl: 1.34-4.08), compared to all labor stages led by a midwife $(n=232)$. For women who were referred by their midwife to an obstetrician during labor $(n=100)$, the odds ratio of PCD was 0.80 (95\% Cl: $0.37-1.65)$ compared to those who were assisted by their midwife from onset of labor.

We performed sub-analyses for nulliparous and multiparous women. This did not result in material differences except for cesarean section. A cesarean section was significantly correlated with PCD in nulliparous women (odds ratio $2.68 ; 95 \% \mathrm{Cl}$ : 1.30-5.57), but not in multiparous women (odds ratio $0.61 ; 95 \% \mathrm{Cl}: 0.25-1.47$ ). 
Table 4.3 Multiple logistic regression of maternal and healthcare factors related to pregnancy and childbirth discontent.

\begin{tabular}{|c|c|c|c|c|}
\hline Determinants & $\begin{array}{c}\text { Satisfied } \\
(n=563) \\
\text { Mean (SD) } \\
\text { or } n(\%)\end{array}$ & $\begin{array}{c}\text { Dissatisfied } \\
(n=176) \\
\text { Mean (SD) } \\
\text { or } n(\%) \\
\end{array}$ & $\begin{array}{l}\text { Unadjusted odds } \\
\text { ratio }(95 \% \mathrm{Cl})\end{array}$ & $\begin{array}{l}\text { Adjusted odds } \\
\text { ratio }(95 \% \mathrm{Cl})\end{array}$ \\
\hline \multicolumn{5}{|l|}{ Patient related factors } \\
\hline Age (continuous) & $30.8(3.7)$ & $30.4(3.7)$ & $0.97(0.93-1.02)$ & $0.95(0.90-1.00)$ \\
\hline Socio-economic status (continuous) & $-0.5(1.1)$ & $-0.5(1.0)$ & $1.02(0.87-1.19)$ & $1.08(0.91-1.29)$ \\
\hline $\begin{array}{l}\text { Primary or secondary level of } \\
\text { education }\end{array}$ & $197(35.0)$ & $64(36.4)$ & 1 [Reference] & 1 [Reference] \\
\hline Tertiary level of education & $366(65.0)$ & $112(63.6)$ & $0.94(0.66-1.34)$ & $1.05(0.71-1.55)$ \\
\hline Multiparous & $271(48.1)$ & $85(48.3)$ & 1 [Reference] & 1 [Reference] \\
\hline Nulliparous & 292 (51.9) & $91(51.7)$ & $0.99(0.71-1.40)$ & $0.98(0.65-1.48)$ \\
\hline No neonatal composite outcome & $537(95.4)$ & $112(63.6)$ & 1 [Reference] & 1 [Reference] \\
\hline Neonatal composite outcome & $26(4.6)$ & $7(4.0)$ & $0.86(0.34-1.90)$ & $0.58(0.22-1.36)$ \\
\hline No maternal composite outcome & 557 (98.9) & $152(86.4)$ & 1 [Reference] & 1 [Reference] \\
\hline Maternal composite outcome & $6(1.07)$ & $24(13.6)$ & $1.21(0.72-1.97)$ & $0.98(0.56-1.67)$ \\
\hline $\begin{array}{l}\text { No decreased perceived personal } \\
\text { wellbeing }\end{array}$ & $435(77.3)$ & $118(67.0)$ & 1 [Reference] & 1 [Reference] \\
\hline $\begin{array}{l}\text { Decreased perceived personal } \\
\text { wellbeing }\end{array}$ & $128(22.7)$ & $58(33.0)$ & $1.70(1.17-2.45)^{*}$ & $1.62(1.09-2.40)^{*}$ \\
\hline No antenatal anxiety & 444 (78.9) & $139(79.0)$ & 1 [Reference] & 1 [Reference] \\
\hline Antenatal anxiety & $119(21.0)$ & $37(21.0)$ & $2.18(1.51-3.15)^{*}$ & $2.23(1.50-3.30)^{*}$ \\
\hline \multicolumn{5}{|l|}{ Healthcare related factors } \\
\hline \multicolumn{5}{|c|}{ Healthcare professional care during antenatal care } \\
\hline Antenatal care led by midwife & $387(68.7)$ & $89(50.6)$ & 1 [Reference] & 1 [Reference] \\
\hline Antenatal care led by obstetrician & $103(18.3)$ & $42(23.9)$ & $1.77(1.15-2.71)$ & $1.12(0.67-1.85)$ \\
\hline Transfer during antenatal care & $73(13.0)$ & $45(25.6)$ & $2.68(1.73-4.14)^{*}$ & $1.82(1.10-3.00)^{*}$ \\
\hline \multicolumn{5}{|l|}{ Healthcare professional during labour } \\
\hline Labour led by midwife & 202 (35.9) & $37(21.0)$ & 1 [Reference] & 1 [Reference] \\
\hline Labour led by obstetrician & $269(47.8)$ & $125(71.0)$ & $2.54(1.70-3.86)^{*}$ & $2.33(1.34-4.08)^{*}$ \\
\hline Transfer during labour & $92(16.3)$ & $14(8.0)$ & $0.83(0.42-1.58)$ & $0.80(0.37-1.65)$ \\
\hline No analgesics used during labour & 324 (57.5) & $89(50.6)$ & 1 [Reference] & 1 [Reference] \\
\hline Analgesics used during labour & $239(42.5)$ & $87(49.4)$ & $1.33(0.94-1.86)$ & $0.71(0.43-1.16)$ \\
\hline \multicolumn{5}{|l|}{ Mode of delivery } \\
\hline Spontaneous vaginal delivery & $436(77.4)$ & $119(67.6)$ & 1 [Reference] & 1 [Reference] \\
\hline Instrumental vaginal delivery & $47(8.3)$ & $16(9.1)$ & $1.25(0.66-2.23)$ & $1.19(0.60-2.30)$ \\
\hline Cesarean section & $80(14.2)$ & $41(23.3)$ & $1.88(1.22-2.87)^{*}$ & $1.53(0.88-2.63)$ \\
\hline
\end{tabular}

\section{DISCUSSION}

In general, women were highly satisfied with the obstetric care received during their pregnancy and childbirth period. Women who experienced PCD scored lower on all subscales, indicating that PCD cannot be attributed to one of the PCQ subscales. Factors statistically significantly and independently related with PCD were antenatal anxiety, decreased perceived personal wellbeing, and labor led by an obstetrician. Antenatal transfer of care significantly increased the odds upon PCD compared to 
antenatal care led by a midwife and tends to increase the odds upon PCD compared to antenatal care led by an obstetrician.

The main strengths of our study are the multicenter prospective cohort design, the large sample size, and the completeness of data. Using a multicenter prospective design improves the probability of collecting a representative sample. Furthermore, it enables optimal measurement of outcomes by minimizing recall bias and recording of all independent variables before completion of the PCQ. Additionally, the PCQ, used to assess satisfaction, has been validated among Dutch women and takes the unique features of the Dutch obstetric care system into account ${ }^{18,25}$.

A limitation of this study is that our sub cohort may suffer from some selection bias due to non-response rates, particularly since participants were included from a larger cohort $^{26}$. However, differences between the sub cohort and main cohort were minimal. Moreover, the differences between women who agreed to receive additional surveys but never responded them and those who did were minimal as well, as shown in Table 4.1. For women who started with the first additional survey eventually only $16 \%$ did not complete the postpartum questionnaire. For women who did complete the postpartum questionnaire, we had $98 \%$ completeness of data. By imputing independent variables containing missing data, we limited the possibility of biased results and a loss of statistical precision ${ }^{27}$.

To obtain sufficient numbers of women with PCD in our analysis, we focused on women who experienced less than perfect obstetric care, using a total PCQ score of less than 100 points as a cutoff. Our study does not have qualitative data regarding the level of satisfaction or dissatisfaction related to the obstetric care services. However, the amount of studies using the PCQ questionnaire is limited and none of these use dissatisfaction as outcome ${ }^{18,25}$.

In line with previous reports, our results indicate that most postpartum women are highly satisfied with obstetric care ${ }^{6,25,28-30}$. We found no association between PCD and maternal demographic factors including, socio-economic status, educational level, and parity. These results correspond with the findings by previous reports ${ }^{14}$. We found a borderline association between PCD and maternal age, whereby younger women tend to be more likely to experience PCD. Results of previous studies are inconsistent regarding the influence of maternal age. Some studies report younger women tend to reflect on their childbirth experience more negatively, whereas a recent study, focusing on discontent as well, does not report any effect of age ${ }^{5,30,31}$. Additionally, since age is a nonmodifiable factor, its relevance in the reduction of PCD 
is limited; still it could serve as a risk indicator increasing awareness among healthcare professionals.

Interestingly, the neonatal and maternal composite outcomes, measures of the occurrence of complications, were not correlated with PCD, but there was a significant association between decreased perceived personal wellbeing and PCD. This suggests that it is not the presence or absence of complications, but rather perceived wellbeing that affects the experience of pregnancy and birth care. It has been reported that the interaction between a woman and her healthcare professional has a greater influence upon women's perceptions of birth than the physical experience of the birth itself ${ }^{32}$.

Our analysis discovered antenatal anxiety is highly correlated to PCD. Nearly a quarter of the women met the criteria of clinically relevant anxiety. Taken together, this makes antenatal anxiety an important factor of interest in order to reduce the number of women who experience PCD.

Referral during antenatal care, which results in transfer from primary care to secondary care, was associated with increased odds of PCD. Although several studies discuss the effects of transfer during labor, studies reporting antenatal transfer are limited. This could be due to the unique Dutch setting, which divides obstetric care between primary and secondary care. Women generally go to a midwife for their first antenatal visit, and in case of a healthy woman with an uncomplicated pregnancy, they receive midwife-led care throughout pregnancy, labor and the postpartum period. Due to the nature of this system, transfer of care is a result of either an unexpected finding or a complication during pregnancy or childbirth. This may increase anxiety. In our analysis we adjusted for clinically relevant anxiety, however the increase of anxiety may be more subtle. Another possibility explaining the increased odds of PCD, may be the result of feelings of loss of control ${ }^{2,32}$.

We found no association of PCD with either mode of birth or primary (midwife-led) or secondary (obstetrician-led) antenatal care. However, we did find a correlation between the healthcare professional in charge during labor and PCD. Women assisted by a midwife throughout all stages of labor were significantly less likely to experience PCD when compared to women assisted by an obstetrician. This accords with previous literature showing that women receiving continuity of midwifery care are more likely to be satisfied ${ }^{33}$. In contrast with the findings of previous reports $2,29,32,34$, transfer during labor was not associated with PCD. The odds of PCD did not differ significantly between women who were transferred during labor and 
women who continued to receive midwife-led care (adjusted odds ratio $0.80 ; 95 \% \mathrm{Cl}$ : 0.37-1.65). Furthermore, the odds of PCD was significantly lower for women who were transferred during labor compared to women who received obstetrician-led care during the entire birthing process (adjusted odds ratio $0.34 ; 95 \% \mathrm{Cl}: 0.17-0.66$ ).

Unfortunately, our data do not permit a reliable analysis regarding the reasons for transfer during labor. A woman may be referred for an emergency with varying degrees of urgency (and experienced associated stress) or a woman may be referred as a result of her request of analgesics. In case of a medical emergency, it is reasonable to believe that a woman will feel a loss of control, which has been strongly associated with a traumatic childbirth experience ${ }^{32}$. Because we do not have information on the reasons for transfer of care, we are not able to analyze this with our data, but it is interesting that women who are transferred have lower levels of PCD. This may suggest that, overall, the Dutch system of primary and secondary care works well with respect to women's birthing experience in relation to transfer during labor.

Our sub-analyses in nulliparous and multiparous women did not yield any material differences except for cesarean section and level of antenatal care. These two factors increase the odds of PCD only in nulliparous women. A possible explanation for this discrepancy could be a difference in expectations between nulliparous and multiparous women. Unmet expectations have been linked to influence women's satisfaction with pregnancy and childbirth ${ }^{13}$. A substantial proportion of multiparous women may have received obstetrician-led antenatal care, or a cesarean in any of their previous pregnancies. As a result, their expectations regarding the course of their current pregnancy may have altered.

\section{Implications}

At the moment, the Dutch obstetric system is changing, with a movement toward more integrated care $^{35,36}$. The Ministry of Health published a report promoting patientcentred care combined with integrated care and shared decision making as key concepts of the future obstetric care system ${ }^{37}$. As a result, there is increased interest in the use of individual risk-management systems and decision support aids ${ }^{17,38}$. Depending on how it is organized, integrated care has the potential to increase positive collaboration between midwives in a primary care setting and obstetricians in a secondary care setting. Those who design models of integrated care should take note 
of the positive birthing experiences associated with midwives and find ways to insure that features of midwife-led care are not lost in the transition ${ }^{39,40}$.

Antenatal anxiety was the most important factor related to a negative childbirth experience. It is already known that maternal anxiety is related to adverse outcomes, but this study shows that it is an independent factor for the way women experience their childbirth ${ }^{9}$.

Current guidelines on anxiety in pregnancy are mostly focused on anxiety or mood disorders and the effects of medication ${ }^{41,42}$. However, they offer little help for women or healthcare professionals who are dealing with the less severe cases. Our study found that almost $25 \%$ of women had an anxiety score that was clinically relevant. Postpartum interventions in women with poor mental health have shown to be cost effective ${ }^{43}$. Our work underscores the need for further research on the effects of screening and treatment for anxiety in pregnancy. Similar to somatic diseases like diabetes and hypertension, pregnancy might be a stress test for women's mental health and early identification and treatment is likely to result in an improved birthing experience ${ }^{44,45}$. Decision support aids are reported to reduce anxiety scores and may be effective tools to imply in order to reduce $P C D^{46}$.

\section{CONCLUSIONS}

Decreased perceived personal well-being, increased anxiety, transfer of care antenatal, and obstetrician-led birth were all independently associated with PCD. One in four women experienced general antenatal anxiety. Women's birthing experience may improve by increased awareness regarding women's antenatal anxiety state and reducing the proportion of women unnecessarily receiving obstetric care in a secondary care setting. 


\section{REFERENCES}

1. Goodman P, Mackey MC, Tavakoli AS. Factors related to childbirth satisfaction. J Adv Nurs. 2004;46(2):212-9.

2. Rijnders $M$, Baston $H$, Schönbeck $Y$, et al. Perinatal factors related to negative or positive recall of birth experience in women 3 years postpartum in the Netherlands. Birth. 2008;35(2):107-16.

3. Grekin R, O'Hara MW. Prevalence and risk factors of postpartum posttraumatic stress disorder: a meta-analysis. Clin Psychol Rev. 2014;34(5):389-401.

4. Larkin P, Begley CM, Devane D. Women's experiences of labour and birth: an evolutionary concept analysis. Midwifery. 2009;25(2):e49-e59.

5. Baas $\mathrm{Cl}$, Wiegers TA, de Cock TP, et al. Client-related factors associated with a "less than good" experience of midwifery care during childbirth in the Netherlands. Birth. 2017;44(1):58-67.

6. Teijlingen ER, Hundley V, Rennie AM, et al. Maternity satisfaction studies and their limitations: "What is, must still be best". Birth. 2003;30(2):75-82.

7. Lee AV, Moriarty JP, Borgstrom C, et al. What can we learn from patient dissatisfaction? An analysis of dissatisfying events at an academic medical center. J Hosp Med. 2010;5(9):514-20.

8. Redshaw M. Women as consumers of maternity care: measuring "satisfaction" or "dissatisfaction"? Birth. 2008;35(1):73-6.

9. Grigoriadis $S$, Graves $L$, Peer $M$, et al. Maternal anxiety during pregnancy and the association with adverse perinatal outcomes: systematic review and meta-analysis. J Clin Psychiatry. 2018;79(5): e1-e22.

10. Munstedt K, von Georgi R, Eichel V, et al. Wishes and expectations of pregnant women and their partners concerning delivery. J Perinatal Med. 2000;28(6):482-90.

11. Tschudin S, Alder J, Hendriksen S, et al. Previous birth experience and birth anxiety: predictors of caesarean section on demand? J Psychosom Obstet Gynaecol. 2009;30(3):175-80.

12. Spice K, Jones SL, Hadjistavropoulos HD, et al. Prenatal fear of childbirth and anxiety sensitivity. J Psychosom Obstet Gynaecol. 2009;30(3):168-74.

13. Christiaens W, Bracke P. Assessment of social psychological determinants of satisfaction with childbirth in a cross-national perspective. BMC Pregnancy Childbirth. 2007;7(1):26.

14. Britton JR. The assessment of satisfaction with care in the perinatal period. J Psychosom Obstet Gynaecol. 2012;33(2):37-44.

15. Verhoeven CJ, Nuij C, Janssen-Rolf CR, Schuit E, et al. Predictors for failure of vacuumassisted vaginal delivery: a case-control study. Eur J Obstet Gynecol Reprod Biol. 2016;200:29-34.

16. Schoen C, Navathe R. Failed induction of labor. Semin Perinatol. 2015;39(6):483-7.

17. Meertens LJE, Scheepers HC, De Vries RG, et al. External validation study of first trimester obstetric prediction models (Expect Study I): research protocol and population characteristics. JMIR Res Protoc. 2017;6(10):e203.

18. Truijens SE, Pommer AM, van Runnard Heimel PJ, et al. Development of the Pregnancy and Childbirth Questionnaire (PCQ): evaluating quality of care as perceived by women who recently gave birth. Eur J Obstet Gynecol Reprod Biol. 2014;174:35-40. 
19. Ploeg HM, Defares PB, Spielberger CD. Handleiding bij de Zelf-Beoordelings Vragenlijst ZBV: een nederlandstalige bewerking van de Spielberger State-Trait Anxiety Inventory STAI-DY: Swets \& Zeitlinger [Manual for 'De Zelf-Beoordelings Vragenlijst (ZBV)', a Dutch version of the Spielberger State-Trait Anxiety Inventory STAI-DY: Swets \& Zeitlinger]; 1980.

20. Julian LJ. Measures of anxiety. Arthritis Care Res. 2011;63:S467-72.

21. SCP. SCP Statusscores: Sociaal en Cultureel Planbureau; 2017. [cited 2017 Aug 08]. Available from: http://www.scp.nl/Formulieren/Statusscores_opvragen.

22. EuroQol-Group. EuroQol-a new facility for the measurement of health-related quality of life. Health Policy. 1990;16(3):199-208.

23. Visser GH, Eilers PH, Elferink-Stinkens PM, et al. New Dutch reference curves for birthweight by gestational age. Early Human Develop. 2009;85(12):737-44.

24. Van Buuren S. Flexible imputation of missing data. 2nd. Boca Raton, FL: Chapman \& Hall/CRC; 2018.

25. Truijens SE, Banga FR, Fransen AF, et al. The effect of multiprofessional simulation-based obstetric team training on patient-reported quality of care: a pilot study. Simul Healthc. 2015;10(4):210-6.

26. Berman DM, Tan LL, Cheng TL. Surveys and response rates. Pediatrics Rev. 2015;36(8):364-6.

27. Sterne JAC, White IR, Carlin JB, et al. Multiple imputation for missing data in epidemiological and clinical research: potential and pitfalls. BMJ. 2009;338:b2393.

28. Karlström A, Nystedt A, Hildingsson I. The meaning of a very positive birth experience: focus groups discussions with women. BMC Preg Childbirth. 2015;15(1):251.

29. Hitzert $M$, Hermus MA, Scheerhagen $M$, et al. Experiences of women who planned birth in a birth centre compared to alternative planned places of birth. Results of the Dutch Birth Centre Study. Midwifery. 2016;40:70-8.

30. Jenkinson C, Coulter A, Bruster S, et al. Patients' experiences and satisfaction with health care: results of a questionnaire study of specific aspects of care. QSHC. 2002;11(4):335-9.

31. Borjesson B, Paperin C, Lindell M. Maternal support during the first year of infancy. J Adv Nurs. 2004;45(6):588-94.

32. Hollander $\mathrm{MH}$, van Hastenberg $\mathrm{E}$, van Dillen J, et al. Preventing traumatic childbirth experiences: 2192 women's perceptions and views. Arch Womens Ment Health. 2017;20(4):515-23.

33. Sandall J, Soltani H, Gates S, et al. Midwife-led continuity models versus other models of care for childbearing women. Cochrane Database System Rev. 2015;(9):Cd004667.

34. Geerts CC, van Dillen J, Klomp T, et al. Satisfaction with caregivers during labour among low risk women in the Netherlands: the association with planned place of birth and transfer of care during labour. BMC Preg Childbirth. 2017;17(1):229.

35. Visser G. Obstetric care in the Netherlands: relic or example?. JOGC. 2012;34(10):971-5.

36. Boesveld IC, Valentijn PP, Hitzert M, et al. An approach to measuring integrated care within a maternity care system: experiences from the maternity care network study and the Dutch Birth Centre Study. Int J Integr Care. 2017;17(2):6.

37. Geboortezorg EZI. Zorgstandaard Integrale Geboortezorg. Utrecht: College Perinatale Zorg; 2016.

38. Schoorel EN, Vankan E, Scheepers HC, et al. Involving women in personalised decisionmaking on mode of delivery after caesarean section: the development and pilot testing of a patient decision aid. BJOG: Int J Obstet Gy. 2014;121(2):202-9. 
39. Perdok H, Jans S, Verhoeven $\mathrm{C}$, et al. Opinions of maternity care professionals and other stakeholders about integration of maternity care: a qualitative study in the Netherlands. BMC Preg Childbirth. 2016;16(1):188.

40. Hodnett ED. Continuity of caregivers for care during pregnancy and childbirth. Birth. 2000;27(3): 218.

41. Yonkers KA, Wisner $\mathrm{KL}$, Stewart $\mathrm{DE}$, et al. The management of depression during pregnancy: a report from the American Psychiatric Association and the American College of Obstetricians and Gynecologists. Obstet Gynecol. 2009;114(3):703-13.

42. National Collaborating Centre for Mental Health. National Institute for Health and Clinical Excellence: Guidance. Antenatal and Postnatal Mental Health: Clinical Management and Service Guidance: Updated edition. Leicester (UK): British Psychological Society; 2014.

43. Chojenta C, William J, Martin MA, et al. The impact of a history of poor mental health on health care costs in the perinatal period. Arch Womens Ment Health. 2019;22:467-73.

44. Hermes W, Tamsma JT, Grootendorst DC, et al. Cardiovascular risk estimation in women with a history of hypertensive pregnancy disorders at term: a longitudinal follow-up study. BMC Preg Childbirth. 2013;13(1):126.

45. Kramer CK, Swaminathan B, Hanley AJ, et al. Each degree of glucose intolerance in pregnancy predicts distinct trajectories of beta-cell function, insulin sensitivity, and glycemia in the first 3 years postpartum. Dia Care. 2014;37(12):3262-9.

46. Tucker Edmonds B. Shared decision-making and decision support: their role in obstetrics and Curr Opin Obstet Gynecol. 2014;26(6):523-30. 



\section{CHAPTER 5}

The Risk Matrix Approach: a helpful tool weighing probability and impact when deciding on preventive and diagnostic interventions

S.M.P. Lemmens, V.A. Lopes van Balen, Y.C.M. Röselaers, H.C.J. Scheepers, M.E.A. Spaanderman 


\section{ABSTRACT}

\section{Background}

Clinical guidelines are developed to lower risks, mostly viewed upon as probability. However, in daily practice, risk is perceived as the combination of probability and the impact of desired and adverse events. This combination of probability and impact can be visualized in a risk matrix. We evaluated the effect of interventions and diagnostic thresholds on modeled risk, by using the risk matrix approach (RMA) in a clinical guideline development process, and investigated which additional factors affected choices.

\section{Methods}

To improve care outcomes, we developed new guidelines in which care professionals had to decide upon novel interventions and diagnostic thresholds. A risk matrix showed the probability and impact of an intervention, together with the corresponding risk category. First, professionals' opinion on required performance characteristics on risk were evaluated by a qualitative online survey. Second, qualitative assessment of possible additional factors affecting final decisions that followed from group discussion and guideline development were evaluated.

\section{Results}

Upfront, professionals opinioned that non-invasive interventions should decrease the general population risk, whereas invasive interventions should decrease the risk in high-risk groups. Nonetheless, when making guidelines, interventions were introduced without reaching the predefined threshold of desired risk reduction. Professionals weighed other aspects besides risk reduction, as financial aspects and practical consequences for daily practice in this guideline-making process.

\section{Conclusion}

Professionals are willing to change policies at much lower level of anticipated effectiveness than defined upfront. Although objectively presented data structured group discussions, decisions in guideline development are affected by several other factors than risk reduction alone. 


\section{BACKGROUND}

During clinical guideline development, healthcare professionals discuss risk and usually weigh the probability of an event occurring. However, risk is generally described as the combination of the linked likelihood of occurrence times the impact of a certain event ${ }^{1,2}$. The impact of that event can be either beneficial or detrimental, ranging from minor to major. Therefore, decisions are affected by estimating chances and taking the characteristics of taken chances into account. Nonetheless, risk is an objective existence which can never be eliminated, is abrupt and often harmful with people suffering loss, may be uncertain in whether and when the event will happen, and is constantly developing with science and technology ${ }^{3}$.

In healthcare, prior to introducing a new intervention or diagnostic threshold, professionals and policy makers have to consider what level of risk they accept and what the expected effect of a newly introduced intervention is. Some interventions have a diagnostic character, whereas others have a preventive or therapeutic effect. A newly introduced intervention may decrease the probability of an event to happen and/or can have an effect on its impact. In any case, an intervention is expected to change risk. When deciding upon new interventions or strategies, these novel actions should at least prevent or lower the risk of an adverse event to occur. Nonetheless, given the paradigm, it may be that professionals, policymakers or even patients may decide differently on the same questions raised.

A risk matrix can be helpful and insightful to agree upon new or changed interventions as they present complex risk data in a concise visual and mathematical way. Using a risk matrix is both a qualitative and quantitative approach to prioritize risk and start interventions to mitigate the risk and to facilitate constructive discussions within a decision process ${ }^{1,4}$. The aim of any risk evaluation tool is to ensure that the decision process is transparent, based on best knowledge and reflecting the common understanding of stakeholders ${ }^{1}$. We evaluated the effect of interventions and diagnostic thresholds on risk, using a risk matrix approach (RMA), and factors influencing the decision-making process towards the development of new guidelines and protocols. 


\section{METHODS}

\section{Participants}

A group of obstetric professionals $(n=131)$ participated from 2013-2016 in a guideline development project in the catchment area of the tertiary Maastricht University Medical Center, the Netherlands ${ }^{5}$.

\section{Decision-making process}

To make decisions and reach consensus on (new) interventions and diagnostic thresholds, we used the novel ACCORD-tool; Agreement Conform Current Operational Rules and Directives-tool and the risk matrix approach ${ }^{5}$. The ACCORDtool consists of a four-step bottom-up approach: first summarize current evidence on a specific topic based on existing guidelines, second translate evidence into statements, third send statements in an online survey (Survey Monkey, Palo, Alto, CA, USA) to the professionals to rank statements by level of agreement on a 10-point Likert-scale ( 1 totally disagree - 10 totally agree), and fourth review the survey results within a team of mandated representatives to make decisions on best given care. Survey results were expressed in statement means with standard deviations (SD). In these, statements with mean between 3 and 8 , or SD >2 were discussed, a mean below 3 or above 8 and a SD $<2$ could be immediately rejected or accepted, respectively. Decisions were agreed upon when at least $85 \%$ of the mandated team was in favour.

For specific topics, we used the RMA. The design of a risk matrix is a basic and often used concept to evaluate risks, which was adapted to our situation and interventions ${ }^{1}$. Our risk matrix consists of five rows and columns, which define categories of probability (likelihood) and impact (consequences). The rows of the risk matrix (Figure 5.1), numbered 1 to 5 , represent probability ranging from rare $(<0.1 \%)$ to very likely $(>10 \%)^{4}$. The columns, numbered 1 to 5 , represent impact ranging from minor to catastrophic, resulting in death. We added healthcare related labels to describe impact, but these can be adjusted depending on the profession. Multiplication of the ordinal numbers of the probability and impact category results in a risk score, presented as risk categories with corresponding colors (Figure 5.2). A higher score indicates a higher risk category. We considered risk-score 1-4 a small risk (dark green), risk-score 5-8 a moderate risk (light green), risk-score 9-14 a high risk (yellow), risk-score 15-19 a very high risk (orange) and risk-score 20-25 an extreme 
risk (red). To assess the change in risk of any intervention, the cells within the matrix contain percentages, estimates based on existing data and knowledge, given the reported chance ${ }^{6,7}$. The cumulative percentage of all cells in one row adds up to $100 \%$. For each intervention, the median population risk ( $p 50$ ) and corresponding $\mathrm{p} 5$ and p95 were assessed.

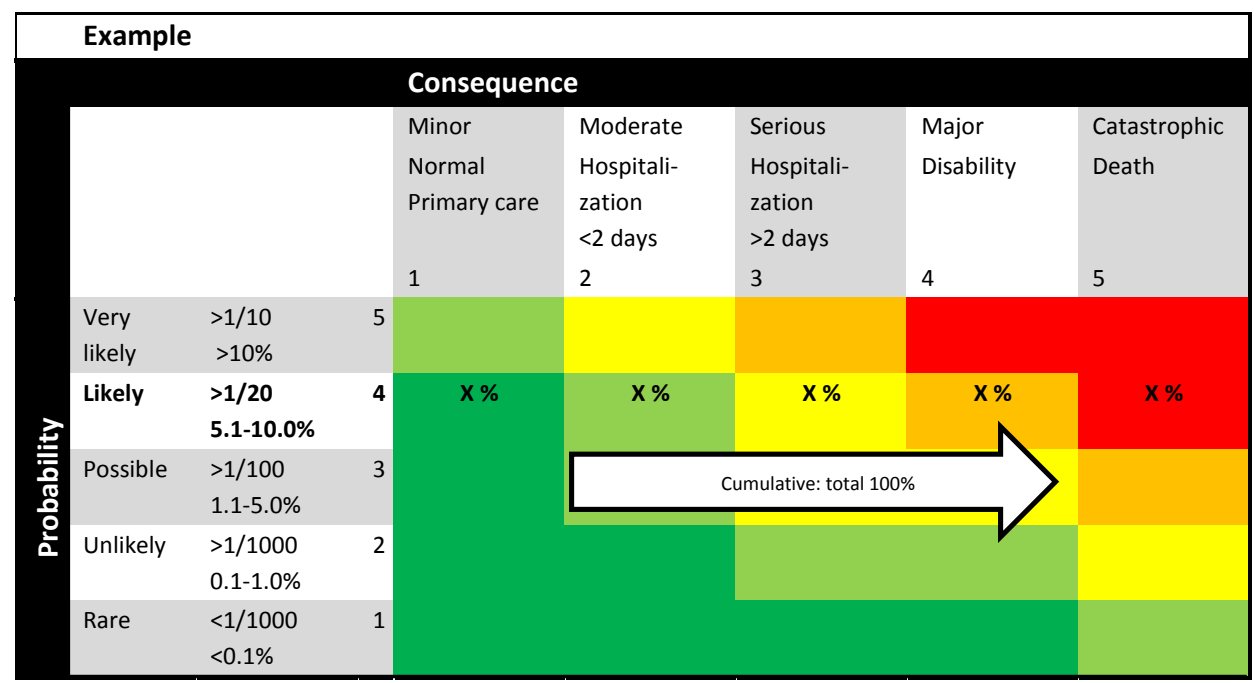

Figure 5.1. Example of a risk matrix.

\begin{tabular}{|c|ccccc|}
\hline Score & $1-4$ & $5-8$ & $9-14$ & $15-19$ & $20-25$ \\
$\begin{array}{c}\text { Risk } \\
\text { category }\end{array}$ & small & moderate & high & very high & extreme \\
\hline
\end{tabular}

Figure 5.2. Risk categories with corresponding scores and colors.

\section{Interventions}

Using the online survey, we first investigated the expectations of professionals on risk reduction regarding non-invasive, moderate-invasive and very-invasive interventions. Second, to explore if the RMA affected the decisions taken in guideline development, we evaluated the effect on risk reduction with a preventive and diagnostic intervention. As a preventive intervention we chose to evaluate the risk of preeclampsia with and without calcium supplementation throughout gestation ${ }^{7,8}$. The World Health Organization and Dutch Health Council recommend pregnant women 
with low calcium intake to take 1 gram calcium supplementation a day ${ }^{9,10}$. Calcium supplementation is not part of standard antenatal care in The Netherlands, despite the fact that calcium is considered a non-invasive intervention reducing the probability of developing preeclampsia significantly ${ }^{7,11}$. A Dutch cohort study shows that approximately one third of pregnant women has a dietary calcium intake below $1 \mathrm{gram} /$ day and, as such, at potential benefit of extra calcium ${ }^{8,12}$.

The clinical effect changing the ultrasonographically determined fetal weight threshold that defines fetuses small for gestational age (SGA) from the 10th to the 5 th growth-chart centile ( $p)$. Changing the threshold was seen a diagnostic intervention. SGA is associated with an increased risk of perinatal morbidity and mortality, especially when not detected prior to delivery ${ }^{6,13}$. The most commonly used definition to describe SGA is an estimated fetal weight or abdominal circumference measured by ultrasound below the $10^{\text {th }}$ centile ${ }^{6,14}$. To detect those at highest risk in order to change the intensity of given care, we redefined and reorganized the diagnostic process and follow-up of SGA fetuses.

For both interventions, professionals had to decide on several questions. First, does the intervention need to decrease the probability of occurrence (chance), or result in a less severe impact (consequence) and/or a decrease in risk category? Second, how much change in chance, consequence or risk category is desired or required to value a new intervention valid? Third, should the new intervention be effective for the whole population or only to individuals at highest risk of adverse outcome? Fourth, are there other factors affecting individual's professional decisions when deciding upon new-to-introduce interventions?

\section{RESULTS}

Upfront, participants opinioned that non-invasive interventions and moderateinvasive interventions should decrease the risk of an event with two risk categories (mean 7.8, SD 1.9 and mean 8.1, SD 1.5), and for very-invasive interventions even three risk categories (mean 8.1, SD 1.9) (Figure 5.3). Non-invasive interventions should decrease the population risk (mean 7.6, SD 1.8), whereas moderate and very invasive interventions should decrease the risk of the highest-risk group (mean 7.6, SD 1.8 and mean 6.8, SD 2.4). Even though these expectations on risk reduction were not met, calcium supplementation and the $10^{\text {th }}$ centile as threshold for diagnosing SGA were still introduced in the new developed guidelines. In this decision-making 


\section{process participants weighed other aspects besides risk reduction, such as financial} aspects, invasiveness of the intervention and consequences for daily practice.

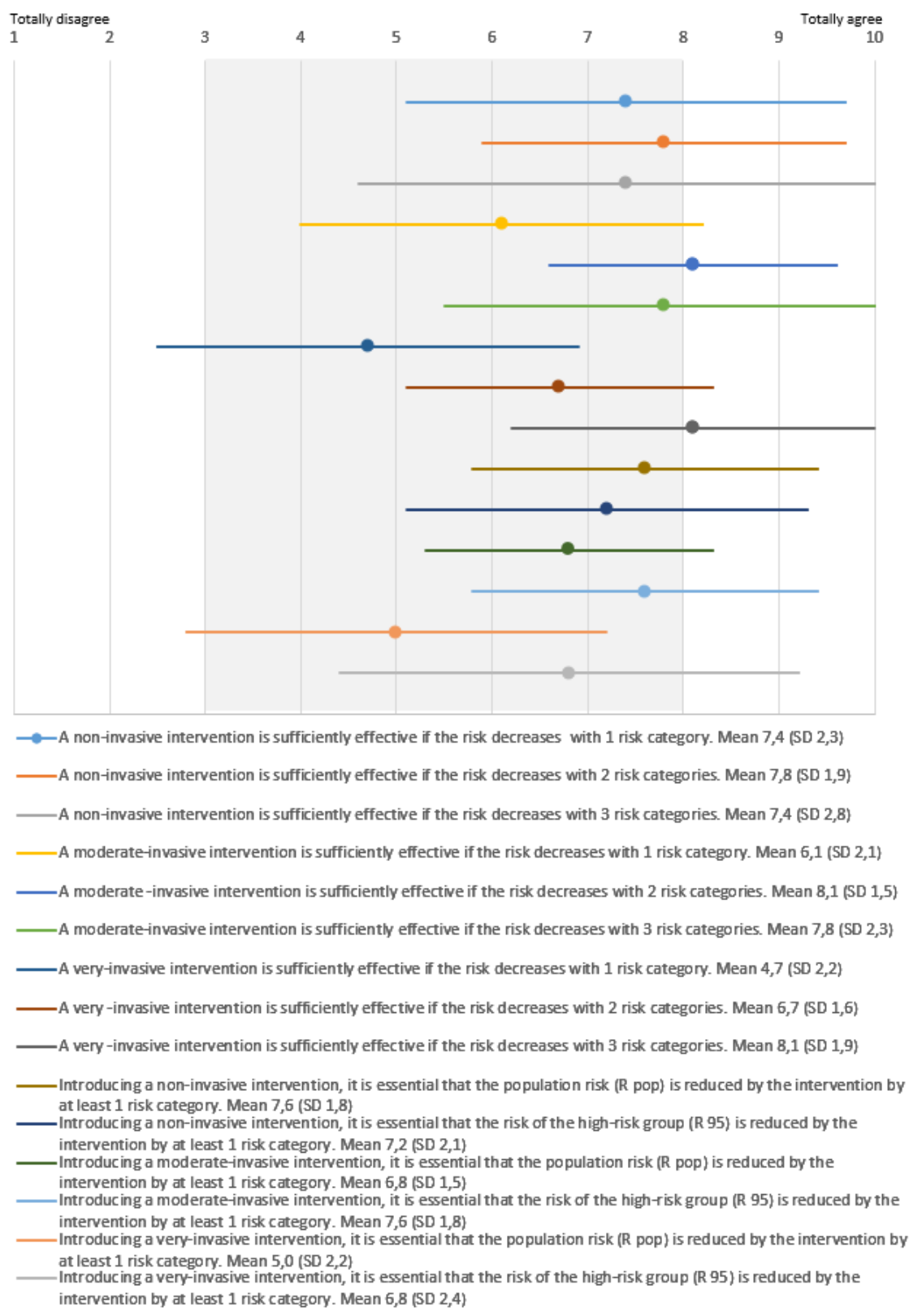

Figure 5.3. Statements with mean and SD for risk reduction. 
Considerations regarding calcium supplementation as preventive intervention for preeclampsia

\section{Survey}

Before discussing the new strategy, only $38 \%$ of the consulted gynecologists and midwives $(n=50)$ responding to the survey, advised extra calcium supplements to their pregnant patients. Of those professionals who advised women to take calcium supplementation, $70 \%$ advised calcium only to women with a high risk of preeclampsia and $30 \%$ only to women with a low dietary calcium intake or in combination with a high risk of preeclampsia. Figure 5.4 presents the statements regarding calcium supplementation with the corresponding mean and SD. The statement regarding calcium supplementation only for pregnant women with a high risk of preeclampsia (mean 8.7, SD 1.6) were most agreed upon. The professionals classified calcium as a non-invasive intervention (mean 8.2, SD 2.1).

\section{Risk matrix}

Figure 5.5 shows probability, impact and associated risk categories for developing preeclampsia in pregnant women without and with calcium supplementation ${ }^{6}$. In women without calcium supplementation the probability of developing preeclampsia is $6.5 \%$, classified as 'likely' (5.1-10\%). The corresponding percentage of maternal death in this group is $0.1 \%$ and $4.3 \%$ suffers from serious maternal morbidity (composite outcome eclampsia, renal failure, HELLP syndrome and admission to intensive care). Weighing the effects of hypertension and preeclampsia, gestational diabetes, instrumental delivery, infection and gestational age at birth and birthweight from our national birth control registry, we estimated that of all women, $28 \%$ would deliver under supervision of their midwife in primary care, the vast majority, 53\%, would be hospitalized for less than 2 days, and $15 \%$ will be hospitalized for more than 2 days. For women who are not taking calcium supplements, the overall median ( $p 50$ ) risk of preeclampsia and corresponding P5-P95 is 8 (4-12). This risk is classified as moderate risk (Figure 5.2) and calculated by multiplying the probability category 4 and the consequence category 2 (Figure 5.5).

If all pregnant women take supplemental calcium, preeclampsia will occur in $4.8 \%$ of women, reducing the probability of preeclampsia from likely to 'possible' (1.1-5\%). Maternal death reduces to $0.02 \%$ and severe maternal morbidity to $3.4 \%$ of cases. Of all women, we estimate that $28 \%$ will deliver under supervision of their midwife in 
primary care, the vast majority of $54 \%$ will be hospitalized for less than 2 days and $15 \%$ will be hospitalized for more than 2 days. Due to the decrease in probability, the risk category changes for 'disability' from very large (orange) to large (yellow) and for 'death' from extreme (red) to very large (orange). For women using calcium supplements, the overall median (p50) risk of preeclampsia and corresponding P5P95 is less than without calcium supplementation but still 6 (3-9), also classified as a moderate risk (Figure 5.2).

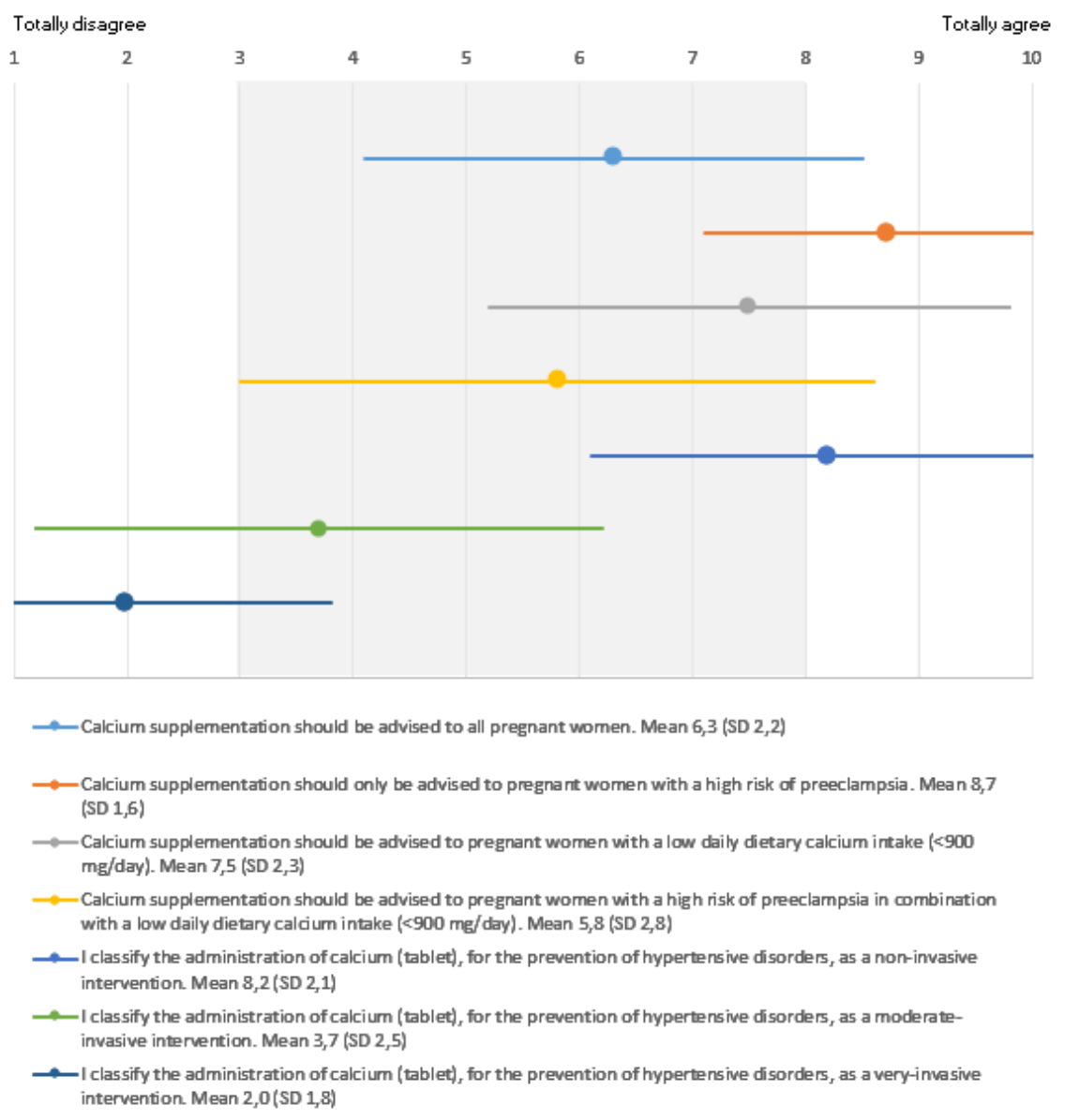

Figure 5.4. Statements with mean and SD for calcium supplementation.

\section{Argumentation}

Although the intervention did change the population's risk as it did not alter risk category, nonetheless, professionals decided to introduce calcium supplementation 
as new intervention to all pregnant women. This decision was made, because calcium supplementation during pregnancy was seen as non-invasive and safe intervention, well tolerated by pregnant women. Moreover, it was argued that it lowered the incidence of preeclampsia especially in women with a low dietary calcium intake (<1000 mg/day), which accounts for approximately $30 \%$ of the Dutch population ${ }^{8}$. Moreover, the absolute chance on the worst outcome, disability or death, became smaller. Besides being beneficial in reducing the incidence of preeclampsia, it also may have a positive effect on related health care costs ${ }^{8}$.

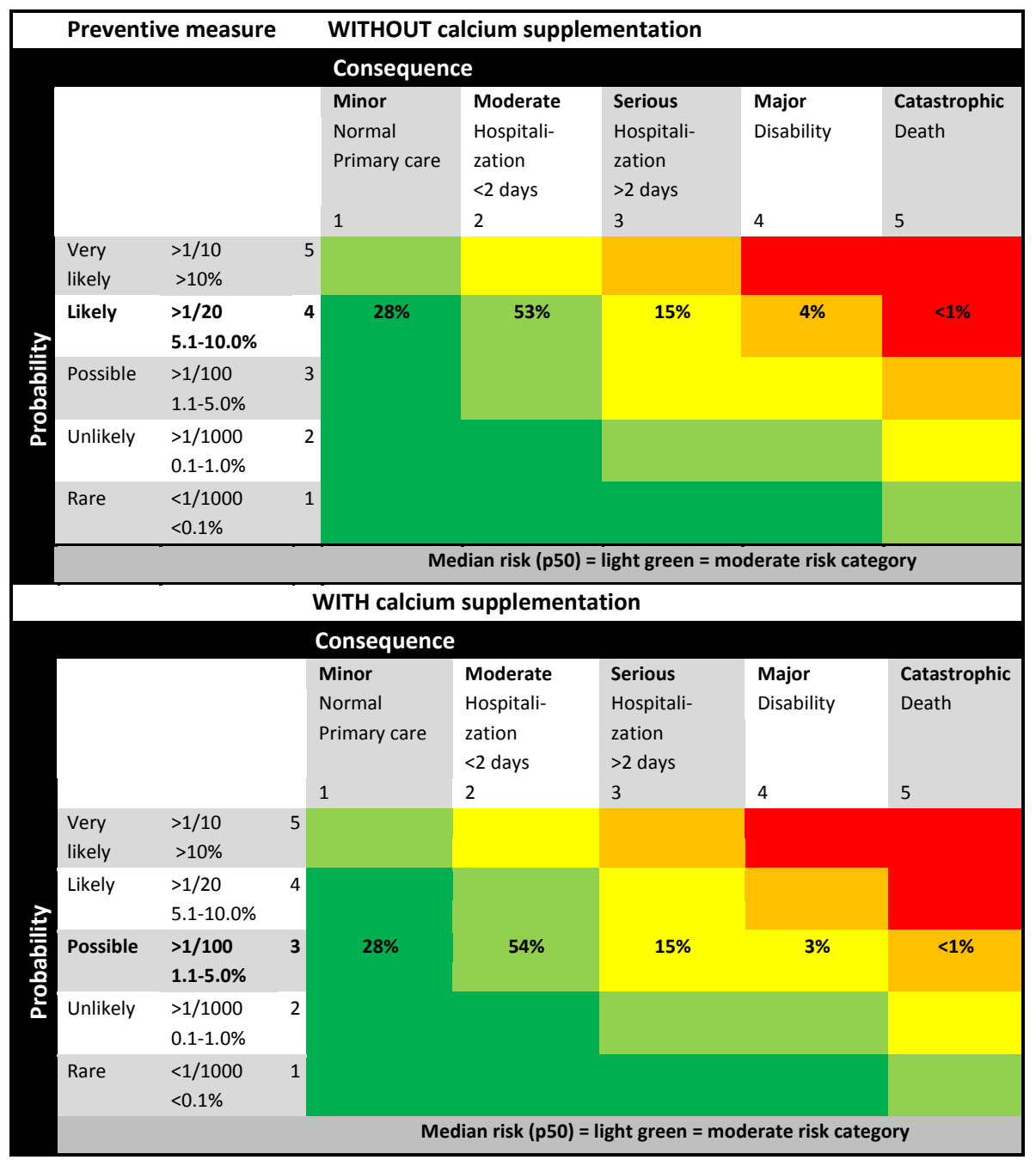

Figure 5.5. Risk matrix approach displaying the risk of preeclampsia and maternal consequences for the situation without and with calcium supplementation. 
Considerations regarding different fetal growth thresholds to diagnose SGA as diagnostic intervention

\section{Survey}

Figure 5.6 presents the statement scores for the $10^{\text {th }}, 5^{\text {th }}$ and $2.3^{\text {th }}$ fetal growth centile, which show a slight preference for the $5^{\text {th }}$ centile as cut-off value (mean 6.5, SD 3.1). Performing an ultrasound to detect an SGA fetus, is classified by professionals as a non-invasive intervention (mean 7.7, SD 2.8). Professionals opinioned that newly introduced non-invasive interventions should decrease the risk of an event with two risk categories (mean 7.8, SD 1.9) and to decrease the population risk with at least one risk category (mean 7.6, SD 1.8).

\section{Risk matrix}

Figure 5.7 presents the probability, impact and associated risk categories for the $10^{\text {th }}$ and $5^{\text {th }}$ centile ${ }^{15}$. After consultation with the professionals, we left the $2.3^{\text {th }}$ centile out of consideration for the risk matrix approach as the $10^{\text {th }}$ and $5^{\text {th }}$ centile were focus of discussion. Of all fetuses, $10 \%$ has an estimated weight by ultrasound below the $10^{\text {th }}$ centile, classified as SGA. After delivery, based on our national birth registry, $23 \%$ of these neonates will be taken care of in primary care, $63 \%$ of these neonates will be admitted to the hospital for less than two days, $13 \%$ for two days or more, $0.3 \%$ will have some degree of disability and the mortality rate is approximately $0.6 \%$. For all fetuses with an estimated growth below the $10^{\text {th }}$ centile, the overall median (p50) risk of complications and corresponding P5-P95 is 8 (4-12), classified as moderate risk with $0.9 \%$ chance on major disability and death (Figure 5.2 \& 5.7). Choosing the $5^{\text {th }}$ centile as cut-off value for fetal growth restriction, the probability decreases from category 'likely' (5.1-10\%) to 'possible' (1.1-5.0\%). Of these neonates $16 \%$ will be taken care of in primary care, $50 \%$ will be hospitalized less than two days, $30 \%$ for two days or more, $1.4 \%$ will have some degree of disability and the mortality rate is around $2.6 \%$ (7). For all fetuses with a growth below the $5^{\text {th }}$ centile, the overall median (p50) risk of complications and corresponding P5-P95 is 6 (3-9), classified as moderate risk (Figure $5.2 \& 5.7$ ), but at the expense of a $4 \%$ risk on major disability and death. Decreasing the cut-off value from the $10^{\text {th }}$ to the $5^{\text {th }}$ centile therefore results in a smaller population risk to be diagnosed SGA but a higher chance on severe consequences. 


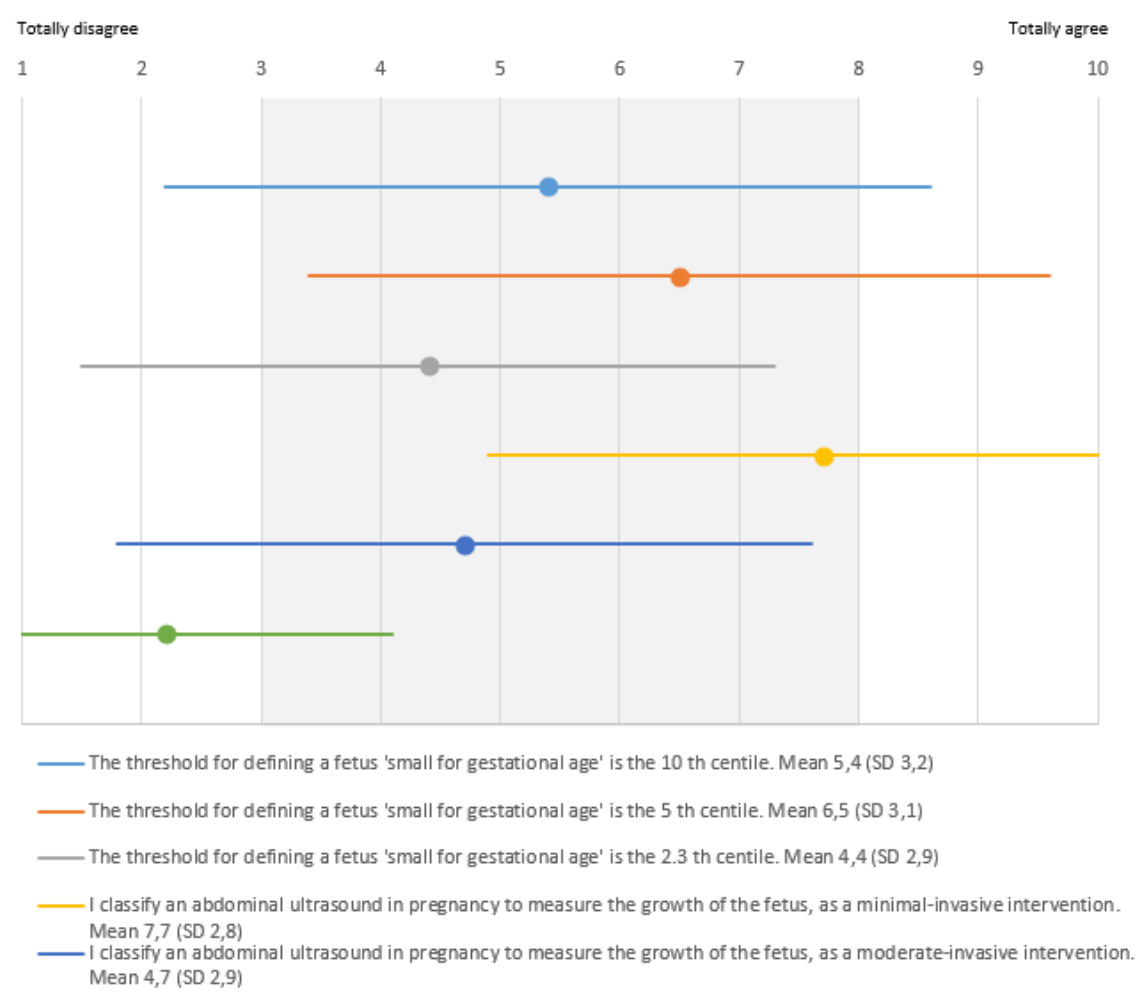

Figure 5.6. Statements with mean and SD for the diagnostic SGA threshold.

\section{Argumentation}

Despite the survey results indicate a preference for the cut-off value for detection of SGA at the fifth centile, the professionals chose the $10^{\text {th }}$ centile after group discussion. They decided in favor of a more sensitive threshold, to detect possible growth restricted fetuses at an early stage in order to prevent severe neonatal consequences. Especially, because of the Dutch situation, in which labor of an undetected SGA fetus without continuously fetal monitoring in a home birthing setting may relate to more offspring morbidity and death ${ }^{13}$. Despite the fact that performing the ultrasound is classified as a non-invasive intervention, the uncertainty for the future parents that comes with the suspicion SGA is seen as an unwanted side effect. Below this centile, healthcare professionals have to take measures for followup (new appointments, repeating ultrasound examination etc.). This implicates intensified surveillance and consequently, for the Dutch situation, shifting care from 
midwife-led to gynecologist-led. This transfer of care from midwife to gynecologist automatically results in financial consequences on population level, but also on an individual professional level.

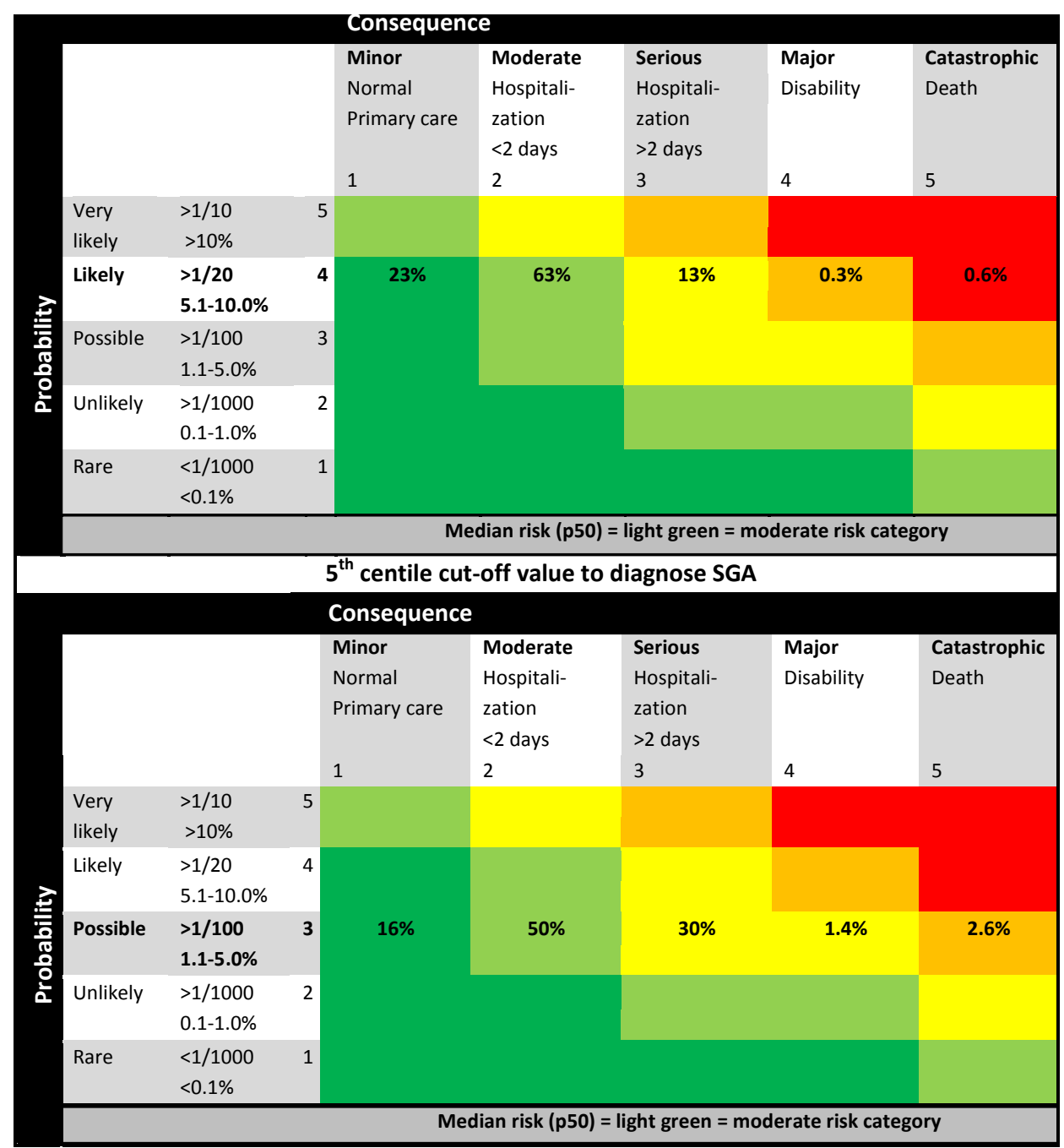

Figure 5.7. Risk matrix approach displaying the differences in neonatal consequences for small for gestational age fetuses, using the 10th and 5th centile as threshold for the fetal abdominal circumference measured by ultrasound ${ }^{15}$. 


\section{DISCUSSION}

Although by most clinicians, risk is viewed upon as chance, in decisional processes, risk describes the combination of probability and impact of an event. In designing and constructing guidelines, risk matrices could be pivotal to present data objectively, to structure group interactions and to come to balanced choices ${ }^{16}$. Before deciding upon new interventions, we first investigated the professional's opinion on risk reduction by newly introduced interventions and thresholds. The participants opinioned that newly introduced interventions and thresholds should decrease the risk of an event with two to three risk categories. Furthermore, non-invasive interventions should reduce risks on population level, not only in the highest risk group. Nonetheless, despite these expectations on risk reduction, calcium supplementation and a higher cut-off value for diagnosing SGA were introduced. This indicates that decisions made to delineate guidelines are affected by changes in multi-dimensional risk, but apparently also depend on several other factors, in which lowering the most extreme unwanted but preventable outcome, financial aspects, practical consequences for daily practice were most dominant.

Besides the actual risk, risk perception also influences decision-making. Risk perception refers to the people's subjective assessment of the probability of a specified type of accident happening and its possible impact ${ }^{17-19}$. The subjective judgement of risk includes personal beliefs, attitudes, experiences and feelings, irrespective of their validity, but also involves people's social and cultural background ${ }^{17,19,20}$. Perception of risk does not discriminate between risk knowledge on the one hand and the value judgement about its acceptability or tolerability on the other hand ${ }^{20}$. People usually underestimate continuous everyday risks as they are less salient compared with dread risks that may be overestimated, even if both cause the same number of fatalities ${ }^{17}$. Several factors can bias risk perception, such as memorability, age, or media coverage of an event ${ }^{17}$. Overall, important in assessing risks is the ease with which people can imagine how risk materializes in daily practice $^{21}$. Experience with specific risks and memories in specific situations contributes to a more realistic risk perception ${ }^{17}$.

We presented both interventions in two separate risk matrices, to show the effect of each intervention to experts that are constructing professional guidelines. The risk matrix without the intervention is seen as reference point. The effect of calcium on the prevention of preeclampsia is less evident than the effect of changing the threshold for SGA. Nevertheless, it took less time for the professionals to decide 
upon calcium supplementation to be implemented into the guidelines, rather than reaching consensus on the threshold for diagnosing SGA. During the decision process, it became clear that for each intervention different aspects were relevant. On the one hand, despite the absent change in population risk category with and without calcium supplementation, extra calcium given to all pregnant women is expected to cause a substantial reduction on population level in the incidence of preeclampsia as well as related health care costs ${ }^{8}$. Moreover, calcium supplementation is viewed upon as relatively inexpensive intervention, side-effects are uncommon and if any usually mild, and the professionals in our project classified calcium as a non-invasive intervention $^{8}$. On the other hand, by changing the threshold for SGA from the $10^{\text {th }}$ to the $5^{\text {th }}$ centile, the population risk lowered, but at the expense of more offspring complications. Despite a lower population risk, the professionals decided to set the threshold for fetal growth restriction at the $10^{\text {th }}$ centile. This indicates that other factors, in addition to the populations risk level, were important in this decisionmaking process. On the one hand, decreasing the diagnostic threshold results in more severe neonatal consequences that could have been prevented. On the other and, setting the threshold at the $10^{\text {th }}$ centile results in intensified surveillance shifting care from midwife-led to gynecologist-led. In deciding what to recommend in the guidelines, numerous factors different from population risk and its extremes were mentioned. First, although an ultrasound was viewed upon as minimal invasive procedure, the risk for parent's uncertainty that comes with the suspicion SGA and the subsequent medicalization was seen as an undesired side effect. Second, as the professionals decided to diagnose SGA definitively after two subsequent ultrasounds that are below the chosen threshold with a two week interval, professionals perceived this period of uncertainty quiet long for the future parents ${ }^{14}$. Third, although not easily mentioned by professionals, in the Dutch reimbursement system, referring more pregnant women from midwife-led to obstetrician-led care would have negative impact on midwifes income and consequently a positive impact on hospitals finances. Weighing the magnitude of the affected population (5\%), its financial consequences and the professionals perceived preventable impact on the worst outcome, professionals decided in favor of a more sensitive diagnostic threshold. Especially given the possible effect of undetected SGA on the chosen level of fetal surveillance during labor in the Dutch home birthing situation was considered a very undesired condition.

The Dutch obstetric system is unique with community midwives providing care for women with low risk pregnancies in primary care and clinical trained midwives, 
residents and gynecologists providing care for women with high-risk pregnancies in secondary and tertiary care ${ }^{22}$. Transfer of care from midwife to gynecologist, is a result of having one or more risk factors for pregnancy-related complications, unexpected abnormal findings and/or the occurrence of complications during pregnancy or childbirth. As a consequence, midwives view pregnancy and delivery as healthy, physiological events whereas gynecologists are more prone to be concerned about adverse events. These different views became evident during our team meetings, when professionals discussed the need and value of medical interventions. For decisions made with help of the risk matrix, at population level, actual risk rather than risk category was directive, and an increase in extreme risk was also considered an important issue to be taken into consideration, especially as a timely instituted intervention is capable in reducing the risk. Besides risk, hierarchical structures influenced our decision-making process. Midwives experience a power imbalance in their relationships with their specialist colleagues, which can be explained from a historical perspective ${ }^{23}$. Midwives started as autonomous professionals, responsible for all pregnant women, only consulting another caregiver if the child had died during delivery. As a consequence, midwives were afraid of losing their autonomy by introducing new interventions and changes in current thresholds. In addition, the felt magnitude of the intervention for the individual pregnant women and their healthcare professional were valued in deciding.

We used the risk matrices in combination with the ACCORD tool, a bottom-up approach for developing collaborative interprofessional protocols. The ACCORD tool shows many similarities with the 'Grading of Recommendations Assessment, Development, and Evaluation' (GRADE) model and the Evidence to Decision Framework (EtDF) which are frequently used when creating a guideline. However, the main goal of the ACCORD tool is to reach consensus on content of care for clinical practice, thereby weighing current professional guidelines and protocols against the opinions and concerns of the participating disciplines ${ }^{5}$. Similar to the GRADE and EtDF, we identified and prioritized topics to be discussed and summarized current evidence on these topics based on existing guidelines. As guidelines represent topics on which professionals, top-down, have already agreed upon, no systematic search in medical databases was performed, as is the case with the GRADE or EtDF ${ }^{24}$.

Obviously, the RMA approach comes with limitations, as the decisions taken are explainable but not always directly logically following the matrix. First, the design of the matrix, the number of rows and columns, and the category scaling and labels are commonly used but arbitrary. Moreover, the percentages filled in the matrix are 
estimates based on existing data, sensitive to changes in time and place. Therefore, there remains a certain level of subjectivity in the presented figures leaving room for individuals interpretation ${ }^{2}$. On the one hand, lack of exactness is unwanted, on the other hand, understanding the different aspects that are weighed during decision making helps to make balanced choices that can be explained to peers and followers. Second, although better than chance alone, a risk matrix still oversimplifies the complexity of risk. Therefore, risk matrices can only be used as a tool to support risk informed decisions, not for making or computing decisions. Assessment of likelihood, consequences and resulting risk scores actually requires subjective interpretation, whereby different users may obtain different ratings of the same quantitative risks ${ }^{4}$. Therefore, we have to accept that subjective decision-making will always be a part of a risk assessment process, independent of the tool used ${ }^{2}$. Third, risk matrices lack any time valuation, whereas the risk of a certain problem to occur in a week might be very different from the risk of the same problem in a year. A risk can be static over time while others can change overnight. For decision-making, time has to be considered as a separate factor additional to the risk matrix. Our time frame is limited to pregnancy. Time is not a concern for our studied interventions, if calcium supplementation is used in an adequate dosage of 1 gram/day from 20 weeks of gestation until the end of pregnancy ${ }^{25}$. The risk of preeclampsia is larger in second and third trimester of pregnancy, but this is the case for every pregnant women, independent of calcium use ${ }^{26}$. The threshold for SGA is not time related. However, gestational age is an important factor, affecting neonatal morbidity and mortality rates, when fetal growth-restriction results in induction of labor ${ }^{27}$. Fourth, because it is a two-dimensional interpretation of risk $I$ it cannot account for interventions that in themselves add a risk.

\section{CONCLUSION}

In guideline development, a risk matrix approach is useful to weigh both probability and impact of an event in a concise way, to detail the effect of a newly introduced intervention on modelled risk, and to stimulate risk informed decisions. Nonetheless, decisions taken not only rely on reducing risk, but also on reducing the most unwanted but hardly prevalent outcome, financial aspects, perceived magnitude of the intervention and practical consequences for daily professional's practice. 


\section{REFERENCES}

1. Duijm NJ. Recommendations on the use and design of risk matrices. Safety Science. 2015;76:21-31.

2. Wall KD. The trouble with risk matrices. 2011 [Available from: https://pdfs.semanticscholar.org/ f2be/55d4454451788fca458da018ac9b4b7953f8.pdf.

3. $\mathrm{Ni} \mathrm{H}$, Chen A, Chen N. Some extensions on risk matrix approach. Safety Science. 2010;48(10): 1269-78.

4. Talbot J. What's right with risk matrices?: An great tool for risk managers. Internet. Version 1. 31000 risk2011 [Available from: https://31000risk.wordpress.com/article/ what-s-right-with-risk-matrices-3dksezemjiq54-4/.

5. SMP Lemmens HS, VA Lopes van Balen, YCM Roselaers, RG De Vries, MEA Spaanderman. Agreement Conform Current Operational Rules and Directives (ACCORD): A Novel Tool to Reach Multidisciplinary Consensus. Journal of Women's Health and Gynecology. 2019;6(5):1-11.

6. Unterscheider J, Daly S, Geary MP, Kennelly MM, McAuliffe FM, O'Donoghue K, et al. Optimizing the definition of intrauterine growth restriction: the multicenter prospective PORTO Study. American journal of obstetrics and gynecology. 2013;208(4):290 e1-6.

7. Hofmeyr J. Calcium supplementation during pregnancy for preventing hypertensive disorders and related problems. Cochrane Library. 2014.

8. Meertens LJE. Should women be advised to use calcium supplements during pregnancy? A decision analysis. Maternal and Child Nutrition. 2017.

9. WHO Guideline Calcium supplementation in pregnant women. 2013.

10. Gezondheidsraad. Advies voedingsnormen calcium, vitamine $d$, thiamine, riboflavine, niacine, pantotheenzuur en biotine. . 2000.

11. L. Smits PvM, L. Meertens, S. Lemmens, J. Willemse, Y. Röselaers, M. Spaanderman, H. Scheepers. De Limburgse aanpak, Populatiebrede preventie van pre-eclampsie. Nederlands Tijdschrift voor Obstetrie \& Gynaecologie. 2019;132(5):130-2.

12. Heppe DH, Medina-Gomez C, Hofman A, Franco OH, Rivadeneira F, Jaddoe VW. Maternal first-trimester diet and childhood bone mass: the Generation R Study. Am J Clin Nutr. 2013;98(1):224-32.

13. Evers AC, Brouwers HA, Hukkelhoven CW, Nikkels PG, Boon J, van Egmond-Linden A, et al. Perinatal mortality and severe morbidity in low and high risk term pregnancies in the Netherlands: prospective cohort study. Bmj. 2010;341:c5639.

14. NVOG richtlijn JATVS, S.A. Scherjon, J. Van Dillen. NVOG richtlijn Foetale Groeirestrictie. 2017.

15. Mlynarczyk M, Chauhan SP, Baydoun HA, Wilkes CM, Earhart KR, Zhao Y, et al. The clinical significance of an estimated fetal weight below the 10th percentile: a comparison of outcomes of $<5$ th vs 5 th-9th percentile. American journal of obstetrics and gynecology. 2017;217(2):198 e1- e11.

16. Lipkus IM. Numeric, verbal, and visual formats of conveying health risks: suggested best practices and future recommendations. Med Decis Making. 2007;27(5):696-713.

17. Nicolai Bodemer WG. Risk perception. The sage handbook of risk communication. 2015.

18. Sjöberg L. Risk perception by the public and by experts: a dilemma in risk management. Research in Human Ecology. 1999;6(2).

19. Kasperson RE. The social amplification of risk: a conceptual framework. RIsk Analysis. $1988 ; 8(2)$. 
20. Aven T, Renn O. On risk defined as an event where the outcome is uncertain. Journal of Risk Research. 2009;12(1):1-11.

21. De Vries NK. Risico's en risicoperceptie. Ned Tijdschr Tanheelkd 2002.

22. Zondag L CF, De Geus M. Midwifery in the Netherlands. Royal Dutch association of Midwives (KNOV). 2017.

23. van der Lee N, Driessen EW, Houwaart ES, Caccia NC, Scheele F. An examination of the historical context of interprofessional collaboration in Dutch obstetrical care. J Interprof Care. 2014;28(2):123-7.

24. Moberg J, Oxman AD, Rosenbaum S, Schunemann HJ, Guyatt G, Flottorp S, et al. The GRADE Evidence to Decision (EtD) framework for health system and public health decisions. Health research policy and systems. 2018;16(1):45.

25. Hofmeyr GJ, Manyame S, Medley N, Williams MJ. Calcium supplementation commencing before or early in pregnancy, for preventing hypertensive disorders of pregnancy. Cochrane Database Syst Rev. 2019;9:CD011192.

26. Dekker G, Sibai B. Primary, secondary, and tertiary prevention of pre-eclampsia. The Lancet. 2001;357(9251):209-15.

27. richtlijn N. Dreigende vroeggeboorte 2012 [Available from: https://richtlijnendatabase.nl/ richtlijn/dreigende_vroeggeboorte/dreigende_vroeggeboorte_-_startpagina.html. 



\section{CHAPTER 6}

General discussion 



\section{GENERAL DISCUSSION}

The Dutch obstetric healthcare system is divided in three different echelons, primary, secondary and tertiary care. This maternity system came under heavy criticism as the Netherlands were to have about the highest rates of perinatal death compared to other European countries. In the following analyzing reports, governmental committees acknowledged the high perinatal mortality rates and promoted a more proactive approach in care for women during pregnancy and delivery. Recommendations included patient-centered and shared care, combined with shared decision-making as key concepts of the future obstetric care system. Reports underscored the need for organizational improvement and emphasized the importance of closer collaboration between independent midwives and gynecologists. Instead of central orchestration, 10 decentral obstetrical regions were initially formed in which professionals could decide themselves how to improve their regions care.

This thesis provides insight in the choices made to come to improved collaboration of obstetric healthcare professionals regarding the development of shared care pathways in the Limburg region. Hereby highlighting different aspects necessary for good collaboration, when stakeholders with different views and perspectives have to reach consensus in a group decision-making process. Furthermore, it highlights aspects relevant to patient satisfaction and describes how to use a model for risk assessment in daily practice.

\section{SHARED CARE PATHWAYS}

The Dutch obstetric system is unique with community midwives providing care for women with presumed low risk pregnancies in primary care and clinical trained midwives, residents and gynecologists providing care for women with high-risk pregnancies in secondary and tertiary care ${ }^{1}$. Midwives and gynaecologists in The Netherlands have their own professional society and their own clinical guidelines on which their practice is based, the Dutch Society of Obstetrics and Gynaecology (NVOG) and the Royal Dutch Association of Midwives (KNOV). These guidelines and local protocols were not aligned with one another on many different levels, resulting in variations in clinical practice across the region. Therefore, the Limburg Obstetric Quality System (LOQS) project was started, an initiative for closer collaboration between healthcare professionals in primary, secondary and tertiary obstetric care. 
The main goal of the LOQS project was to develop collaborative shared obstetric care pathways, to come to risk-based personalized and with it preventive care, and to structurally and timely monitor and review outcome in order to continuously improve care, the latter requiring a transmural patient record system.

Shared obstetric care pathways requires consensus on the content of care and shared protocols for daily practice. As far as we know, we are the first region in The Netherlands in which so many professionals participated in the development of shared obstetric pathways. Care pathways in obstetrics are more and more being implemented $^{2}$. They are presumed to standardize care, support implementation of evidence into practice, create continuity of care, uniformity in decision-making and the patient receiving correct and corresponding information by different healthcare professionals ${ }^{3}$. The LOQS pathways focus on medical management of specific conditions during pregnancy, labour and the postpartum period and differentiate between different levels of risk.

Before the start of the project, risk assessment during pregnancy was was dichotomously categorized in low or high risk and based on the knowledge and experience of the healthcare professionals together with existing guidelines, such as the 'List of Obstetric Indications' (VIL) ${ }^{4}$. To improve this risk stratification, the Expect Study I started concurrently with the LOQS project, and evaluated and validated existing first trimester obstetric prediction models to support risk-based personalized care $^{5-7}$. From these, risk assessment for developing gestational diabetes and/or preeclampsia now depends on the use of an online prediction model. The display of the modelled risk also serves as structure to come to shared decision making. For other potential complications during gestation, such as preterm birth, macrosomia and intra-uterine growth restriction, the VIL and risk factors as described in the NICE guidelines will be leading as current models did not meet the external validation requirements necessary to safely guide care ${ }^{8,9}$. Pregnant women will follow a specific care pathway which can be individually adjusted, depending on their risk. The care pathways facilitate shared care which means that even if a pregnant women has several risk factors, this not automatically means transfer of care from midwife to gynaecologist. In daily practice, a women with some risk factors for developing obstetric complications, will have some necessary appointments, for example ultrasounds, with her gynaecologist and other 'standard' appointments with her community midwife. This facilitates less transfer of care and more shared responsibilities between midwives and gynecologists, and with it, support of 
proactive care. The developed care pathways are implemented in every hospital and almost every midwifery practice in the region. Pathways are available online and will be constantly updated with new evidence.

\section{COLLABORATION}

To understand the process healthcare professionals have to go through developing shared care pathways, it is relevant to understand the basics needed for good collaboration. Adverse events are often traced back to poor collaboration, communication and ineffective teamwork ${ }^{10,11}$. "Collaborative practice is an interprofessional process for communication and decision making that enables the separate and shared knowledge and skills of care providers to synergistically influence the client/patient care provided"12. For a constructive and successful collaboration, several essential elements have to be present ${ }^{3,13,14}$.

First, there should be shared responsibilities and accountability. Which means active participation of the professionals involved in decision-making and accepting shared responsibility for the outcomes of the decision-making process ${ }^{3}$. In the developed care pathways, it is therefore clearly defined who is responsible for what care and at what moment during pregnancy, childbirth and the postpartum period. In this way, the professional that is most appropriates at that moment and for that specific situation, takes care of the patient ${ }^{12}$. Even when a woman has one or more risk factors for developing obstetric complications, a community midwife can provide care in collaboration with a gynaecologist, of course depending on the nature of these risk factors and when caretakers truly share responsibilities and accountability.

Second, a partnership needs to occur based on mutual trust and respect, valuing the contributions and perspectives of all professionals involved ${ }^{13,14}$. Each obstetric professional must be able to trust the integrity of his colleague as the foundation of their professional relationship ${ }^{12}$. In the Dutch obstetric system, midwives and gynaecologists have varying levels of educational and occupational training, resulting in fundamentally different perspectives and different views on the course of pregnancy and delivery ${ }^{15}$. Midwives view pregnancy and delivery as healthy events, whereas gynaecologists anticipate more on possible adverse events. Their common goal is to address the patients' needs and provide good quality obstetrical care. To achieve this goal, an effective cooperation in which both professions acknowledge and respect the other disciplines' perspective and viewpoints is necessary. At the same time, a good collaboration is a constantly developing, dynamic and interactive 
process, which requires professionals to examine and alter their own professional view and perspectives and be willing to change their daily practice, based on new evidence ${ }^{3,14}$. But at any rate, shared care relies on mutual trust and respect.

Third, an equal partnership calls for interdependent rather than autonomous collaboration. Contemporary healthcare is becoming more and more complex, which consequently makes professionals interdependent ${ }^{14}$. In obstetrics, midwives and gynaecologists have to work together as a team with respect to the autonomy of both professions. They both have the authority to make decisions independently and act within their respective scopes of practice. Both professions need to fully understand and support practice autonomy, as well as, shared decision making ${ }^{12}$.

Some initiatives that could contribute to a better collaboration are e.g. frequently scheduled face-to-face meetings with both midwives and secondary caregivers to discuss the care pathway for selected women that would benefit from shared care, simulation-based obstetric team training ${ }^{16,17}$ and resident obstetricians spending time at community midwifery practices. By this way, all professionals will be aware and underscore their interdependent position implicit to our Dutch organisation of obstetric care that comes with equal partnership.

Fourth, participant capacities should be recognized based on their knowledge and experience. A collaborative practice involves good working relationships and a working environment in which the contribution of all participants is fully utilized and respected. Our shared care strategy is a good example of using each other's capacities. Specific interventions, for example ultrasounds in case of foetal growth restriction is suspected, are best performed by a gynaecologist. However, when foetal growth is normal after two ultrasounds, this women can have her other appointments with her own community midwife. Also the more general appointments, for example with more information supplied on breastfeeding, can best be performed by a community midwife, even for women with a higher risk at complications.

Fifth, another, and probably the most essential, component of good collaboration is good communication ${ }^{18}$. In healthcare often critical information must be accurately communicated $^{10}$. Especially in case of consultation or transfer of care from midwife to gynaecologist and vice versa, it is important that both professionals share the same information regarding the patient and issues related decision-making. Patients want to have the feeling that both professionals communicated well with each other and that they receive information that is in line with each other, instead of conflicting 
information ${ }^{18}$. A shared electronic patient information system, used by midwives, gynaecologists, paediatricians, maternity care and preferably other youth health care workers would be a great step in better communication and consequently better communication between healthcare professionals. At the moment the patient records of hospitals and midwifery practices don't have the option to communicate with each other. On the one hand, despite all efforts spent on one integral dossier within our LOQS project, given the hospitals rules and regulations for software, unfortunately, no operational, truly integrated patient record system exists that fits and is affordable for our Dutch obstetric care structure. On the other hand, the LOQS guidelines along with de Expect calculator tremendously impacted the efficiency, uniform transparency and effective communication in the structured weekly transmural joint conference on new pregnant women.

\section{THE BIRTH OF CONSENSUS}

Collaboration across disciplines and adequate referral between various echelons requires first consensus on the content of care, shared protocols for daily practice and joint decisions about the division of tasks. The current Dutch obstetric guidelines do not facilitate shared care. Obstetric caregivers work in fragmented worlds with their own professional society, Dutch Society of Obstetrics and Gynaecology (NVOG) and the Royal Dutch Association of Midwives (KNOV), and are encouraged to identify pregnant women as strictly in one level of care ${ }^{19}$. Within the LOQS-project, we developed care pathways that explicitly facilitate shared obstetric care.

A group of professionals reaching agreement on the content of care requires group decision-making. Advantages of group decision-making compared to decisions made by individuals are the ability of group decision-making to lead to synergy, which refers to Aristotle's famous words that "the whole is more than the sum of its parts", and sharing of information ${ }^{20}$. As each participant contributes new information and expertise, bringing to bear a broader range of perspectives, a group discussion can result in more complete and robust solutions and recommendations ${ }^{21}$. Providing the opportunity for all the involved stakeholders to have a voice in decisions which directly affect their daily practice, can have a positive effect on their motivation to implement decisions, commitment with the decisions and their satisfaction with the process $^{22,23}$.

Besides these advantages of group decision-making, some disadvantages exist. Decisions made by a group are less efficient, because group participation slows down 
the decision-making process ${ }^{23,24}$. Furthermore, groupthink and social pressure towards conformity can prevent effective decision-making ${ }^{21,23,25}$. When groupthink occurs, participants are not able to identify and assess alternative solutions to a problem, as they actively suppress dissenting viewpoints to minimize conflicts ${ }^{21}$. Social decision schemes may lead to conformity and with it extreme choices made, that may not reflect the mainstream opinion. Another disadvantage of group decision-making can be a diffusion of responsibility, because everyone is equal responsible for the decisions made, participants can deny personal responsibility $\left({ }^{23}\right)$. Several methods are developed to improve group decision-making and to reduce the influence of the aforementioned disadvantages of group processes. One of these methods is the known Delphi technique ${ }^{22}$. The Delphi technique uses panel members that are selected experts in the field that have no direct face-to-face contact and remain anonymous to each other ${ }^{22,26}$. The Delphi method recommends 10-18 experts on a panel ${ }^{26}$. Each individual panel member can write their comments, recommendations and solutions to the problem independently and anonymously ${ }^{22}$. The Delphi method uses the concept of iterative feedback rounds, with the opportunity for panel members to reflect on their previous response until consensus or a decision is reached ${ }^{26}$. The strength of the Delphi method is its use of expert opinion, but its weakness is that it is a top-down approach.

To ensure that a diverse group of professionals will implement new protocols, it is necessary to use a bottom-up approach with equal participation and, a meaningful discussion of content focused on clear targets. To this end, we developed a new model to reach a concrete and acceptable management agreements.

This novel model, described in this thesis, is named the Agreement Conform Current Operational Rules and Directives-tool (ACCORD) ${ }^{27}$. We evaluated this tool on effectiveness, defined as the level of consensus on content, and performed a process evaluation thereby evaluating the level of satisfaction of the participants and factors influencing this satisfaction. In our process, the ACCORD-tool offered certain advantages compared to Delphi. Most important, ACCORD allowed face-to-face contact during the team meetings. Due to this face-to-face contact there was an opportunity to clarify uncertainties, discuss the survey results, and give direct feedback to each other. Second, in contrast to the Delphi-method, where only the opinion of the expert panel is weighted, by using the ACCORD-tool the opinion of all participants was considered to be equally important. This bottom-up approach helps to create shared responsibility via an enriched and constructive conversation. A 
process that includes the input of all participants and listens to all of their concerns generates more agreement with the final decision and greater cooperation in implementation $^{25,28-30}$. The described process of decision-making with help of the ACCORD-tool can be extrapolated to other professions, for example, multidisciplinary healthcare teams with specialists, general practitioners and/or other first line professions, but also to non-medical businesses where different professionals have to collaborate.

Before a decision was finalized with the ACCORD-method, participants had to decide on the level of agreement needed to move forward, known as the decision rule ${ }^{31}$. Examples of decision rules are unanimous agreement, near unanimity, a super or simple majority, an executive committee, or the vote of a committee made up of representatives from each group ${ }^{25,29,31}$. Consensus does not require unanimity ${ }^{30}$. Group decisions made by consensus aim to result in decisions that are satisfactory to all group members. When all participants consent to a decision, unanimity is achieved. Participants can give consent to a decision because they choose to cooperate with the direction of the group, even when the decision does not correspond with their personal preference ${ }^{29}$. In the LOQS-project, we used the consensus process to generate as much agreement as possible, but we choose to finalize a decision with a majority rule, at least $85 \%$ (10 out of 12 ) of the team members had to agree with the decision.

\section{REPRESENTATION}

For decision-making by a large heterogeneous group of people, a strategy using a small group of chosen representatives weighing the balance of disciplines represented in the group, is thought to be most efficient ${ }^{25}$. Within the LOQS-project, a small team of representatives consisting of midwives, gynaecologists and delegates of maternity care reached consensus and made decisions for their peers ${ }^{32}$. For an effective implementation, the decisions should have the support of all professionals in the field ${ }^{24}$. This implicates that that decisions made by the team of representatives should reflect the opinion of the group they are supposed to be representing, their peers.

At the start of the LOQS-project, each region chose their representatives differently. Some were put forward by their peers to represent them, whereas others were anonymously chosen by voting or offered themselves to represent their peers. As a result, the representatives had very different characters that varied from active 
participation only when specifically asked to do so, to continuous active participation and persuasive presence. The representatives' personality could have had an effect on the ultimate outcome, which emphasizes the importance of continuous feedback to the peers of what was decided for what reasons.

Evaluating the project, participants reported that they were pleased with the way their representative was chosen ( $M$ mean 8.1, SD 2.0 vs. G mean 9.4, SD 0.9). Both professions trusted their representatives ( $M$ mean 8.3, SD 1.4 vs. G mean 10.0, SD 0.0) and were satisfied with the way their representatives informed them about the progress ( $M$ mean 7.2, SD 2.1 vs. G mean 9.7, SD 0.6) and the decisions made by the team (M mean 7.2, SD 2.3 vs. G mean 9.7, SD 0.6). .

Comparable levels of representative-peer agreement were found for representatives that were specifically selected by their peers compared to randomly chosen representatives, irrespective of their professional setting. Although selectively chosen representatives seemed most reflective to the group they stand for. Maybe this is the case because selectively chosen representatives know from the beginning that they represent their peers, and therefore chose for the mainstream solutions instead of the extremes. Alternatively, it is possible that they are chosen, just because their opinion is mainstream and reflects most of the time the opinion of the group members.

We found a $74 \%-80 \%$ concordance in statement scores between representatives and their peers, which suggests a high level of agreement. However, $74 \%-80 \%$ concordance also means disagreement on $20-26 \%$ of statements, a significant number especially when fundamental issues are at stake. If the statements that are not agreed upon are critically important, the level of satisfaction with the process may be low, despite of otherwise high levels of agreement. Level of agreement alone is therefore insufficient to guarantee satisfied participants. Participants were asked at the beginning of the project, to agree that they will support the decisions made by this process and are willing to implement new policies in daily practice, even when the ultimate decision did not correspond with their personal preference.

\section{RISK ASSESSMENT}

By using the online risk assessment and counselling tool, developed in the Expect study I, and the designed collaborative care pathways, we standardized the firsttrimester risk evaluation and subsequent preventive and guiding measures for all pregnant women in the region. Besides this risk assessment on patient level, we used 
a risk matrix approach (RMA) in our clinical guideline-making process, to discuss and decide on new interventions and diagnostic thresholds. Risk is generally described as the combination of the linked chance of occurrence times the impact of a certain event $^{33,34}$. In a risk matrix this chance and impact of an intervention are presented in a concise visual and mathematical way. The colours in a risk matrix varying from green to red, correlate to a risk score and risk category.

The preventive intervention we deliberated on included calcium supplementation throughout gestation to reduce the risk of preeclampsia ${ }^{8,9}$. As diagnostic intervention, we modelled the clinical effect of a sonographically determined foetal weight threshold on the $10^{\text {th }}$ or $5^{\text {th }}$ growth-chart centile $(p)$ for diagnosing small for gestational age infancy (SGA). Using an online survey, we investigated the performance expectations of professionals on risk reduction regarding non-invasive, moderate-invasive and very-invasive interventions. Upfront, participants desired noninvasive and moderate-invasive interventions to decrease the risk of an event with two risk categories, and very-invasive interventions three risk categories, all of which can be considered very substantial. Non-invasive interventions should decrease the population risk, whereas moderate to very interfering interventions should decrease the risk of the small highest-risk group. Nonetheless, ultimately, interventions were introduced without reaching the predefined threshold of anticipated risk reduction. This indicates that, in the end, professionals weighed other aspects besides risk reduction. Financial aspects played a role, either personal income that is at stake or financial consequences on healthcare populational level. In addition, the felt magnitude of the intervention for the individual pregnant women and their healthcare professional, as well as consequences for daily practice were valued in deciding. Moreover, at population level, actual risk rather than risk category was directive, and an increase in extreme risk was also considered an important issue to be taken into consideration, especially as a timely instituted intervention is capable in reducing the risk, even mild to moderately. The aforementioned factors influencing risk assessment played a role to a greater or lesser extent throughout the LOQSproject and will be described in the next paragraph.

\section{CHALLENGES}

During the project, several challenges had to be overcome. Most healthcare environments are characterized by hierarchical structures, with the specialist on top of the hierarchy ${ }^{10}$. Professionals at the lower end of the hierarchy, tend to be 
uncomfortable to raise their concerns or bring up the problems they're facing ${ }^{10}$. When hierarchical differences come into play, different perceptions on collaboration and communication can exist, which can diminish collaborative interactions necessary to provide the best care.

When evaluating our process, midwives reported they felt a certain degree of power imbalance between them and gynaecologists (M mean 6.3, SD 2.2, G mean 4.2, SD 3.1), despite an equal vote for every professional in the process and with even more midwives than gynaecologists participating. Gynaecologists had significantly higher mean scores, for questions regarding the weighing of their opinion during the process (M mean 5.9, SD 2.2, G mean 8.7, SD 0.9) and respecting the opinion of the region during the team meetings ( $M$ mean 5.9, SD 2.3, G mean 8.1, SD 1.9).

The study of Van der Lee also detail that there is still inequality felt in current practice, especially by midwives. In this study, midwives report to feel that obstetricians see themselves as having a superior role ${ }^{35}$. This perceived power imbalance is hypothesized to arise partially from a different level and length of education (university versus vocational) ${ }^{36}$ but also from a historical perspective. This feeling of power imbalance could be explained because of a hierarchical structure. Midwives started as autonomous professionals, responsible for all pregnant women, only consulting another caregiver if the child had died during delivery ${ }^{36}$. During the eighteenth century, the 'doctor obstetrici' and obstetrical surgeon developed, an expert in obstetrics and the female body and an academically trained surgeon in obstetrics $^{36}$. Since then the responsibilities and activities of midwives became more and more restricted, and doctors and obstetrical surgeons were progressively in the lead $^{36}$.

Another factor that possibly influenced our decision-making process was the financial aspect. Despite questions about possible financial consequences coming from the chosen decisions were scored neutral ( $M$ mean 5.6, SD 2.8, G mean 5.5, SD 2.5), the payment structure remains a sensitive subject. Midwives are independent entrepreneurs and changes in obstetric care management, can result in loss of income. Most midwifery practices have a small team with one to three midwives, whereas clinical working midwives and some gynaecologists are employed by the local hospital. Due to the current financial structure, with incentives that may influence referrals from primary to secondary care and vice versa, some degree of financial competition amongst caregivers within and throughout lines may exists and this reimbursement system does not facilitate good collaboration ${ }^{17,19}$. For the 
pregnant women, home deliveries are the cheapest birthing option in the current system. If women, labelled as having a 'low risk' pregnancy, would like to deliver in hospital, they have to pay extra and if they want to give birth under the supervision of an obstetrician they have to pay most of the costs themselves ${ }^{37}$. Ideas on the funding of integrated obstetric care, are published in 2016 by the Dutch Healthcare authority (Zorgstandaard) ${ }^{38}$. This report advises to establish integrated collaboration first, followed by funding for integrated care. In the ideal situation, care providers are paid based on their actual performance, pregnant women can give birth in a birthing centre under the supervision of their midwife without extra costs and insurance companies have only limited influence on the financial structures.

Besides the financial barrier, professionals, especially midwives, have reflected ongoing tension about being afraid losing their autonomy by following the care pathways, a sentiment not felt by gynaecologists (feeling of loss of autonomy, $M$ mean 6.8, SD 2.3, G mean 4.6, SD 2.4). They felt that the care pathways told them 'what to do', leaving little room for personalized care. Other caregivers saw the care pathways as something positive, as they felt encouraged and more confident in their skills by using care pathways ${ }^{2}$. The developed care pathways have to be seen as a guiding document, to support professionals in their daily practice, not as a substitute for clinical judgement.

At the beginning of the project, all participants signed a statement to agree with the decisions made during the project. This short declaration stated that during the implementation phase, all agreements would be implemented, not only the ones you personally agree with. If guidelines were, for practical reasons or changing clinical insights, hard to be implemented or not valid anymore, than that should be addressed within the whole region and adjusted accordingly. Unfortunately, some participants underestimated the impact the novel guidelines would have on their daily practice. Despite the fact that everyone's opinion was weight equally and that there was an equal balance between midwives and gynaecologists in the team meetings, still a part of the participants felt that the final decisions did not reflect their opinion, despite the considerations that led to decisions were transparently detailed throughout the documents. At any rate, two out of six regions decided at first, at the end of the project, not to implement the shared care agreements in daily practice.

On reflection, expectation management and continuous structured feedback to the peers might have been much more important than foreseen. Midwives judged the 
amount of information they received prior to the project to be less sufficient compared to gynaecologists ( $M$ mean 5.4, SD 2.2, G mean 8.0, SD 1.6). Providing more information at the start of the project and clear and structured communication during the process about the decisions taken and the underlying argumentation, may have reduced some of the later tensions and concerns ones the final care pathways were presented to all participants.

\section{PATIENT SATISFACTION}

One of the goals of developing shared obstetric care pathways is to reach better collaboration between obstetric healthcare professionals, with the intention to result in improved healthcare and satisfied women and partners. To evaluate patient satisfaction, we investigated in our population which determinants were associated with women not being perfectly satisfied with the obstetric care services they received during pregnancy and childbirth. Moreover, patient participation was considered during the decision making process. However, the discussions during the team meetings were on such a professional's medical level that the decision was made not to invite participants at this stage of the guidelines-making process.

In the Netherlands, one in six women has a negative recall of their birth experience ${ }^{39}$. Findings regarding the contribution of several factors related to satisfaction with maternity care are contradictory and not always comparable across studies, suggesting that childbirth satisfaction is a complex phenomenon ${ }^{40}$. Our results show that decreased perceived personal well-being, antenatal anxiety, and obstetrician-led care during labour were all independently associated with suboptimal pregnancy and childbirth satisfaction ${ }^{41}$. No differences were found in satisfaction between antenatal care led by a midwife or an obstetrician, but midwife-led antenatal care reduced the odds of suboptimal satisfaction compared to women who were transferred to an obstetrician in the antenatal period. Due to the nature of the Dutch system, transfer of care is, in the antenatal period, a result of either an unexpected finding or a complication during pregnancy. We hope that by using the designed obstetric care pathways, unnecessary secondary obstetric care can be prevented because of better collaboration and expectation-management and that consequently women's birthing experience may improve. Besides, we observed that one in four women experienced mostly undetected antenatal anxiety which associated with decreased satisfaction scores. Therefore, active screening and appropriate guidance of women suffering from antenatal anxiety, might improve pregnancy and childbirth satisfaction. 


\section{FUTURE PERSPECTIVES}

Ideally, the developed care pathways contribute to a future in which obstetric healthcare professionals collaborate perfectly together, with excellent communication, shared responsibilities, only transfer of care when necessary, and resulting in satisfied women, partners, families and professionals. Working together towards this ideal situation at least requires investments of all professionals. The current agreements have to be updated continuously to make sure the newest evidence is incorporated. Moreover, financial structures should change in the future resulting in less barriers for collaboration and decision-making based on best practise. Preferably, a shared maternity notes system should be accessible to all involved healthcare professionals and pregnant women, to reduce errors in referral situations and inadequate information flows ${ }^{19}$. In the ideal world, more caregivers will be invited to participate in the development of care pathways, e.g. paediatricians, general practitioners, social workers, psychologists, and the follow-up of children continues until they are 18 years old, as only then, we really can reflect on quality of given care. In a shared care approach, caregivers such as general practitioners, social workers and psychologists can help to meet the needs and reduce related risks, when a caregiver identifies complicated non-medical factors, such as financial and psychological issues. However, in future projects pregnant women or women who recently gave birth and their partners should be invited to give their opinion on relevant topics. Listening to these experts will hopefully result in adequate and personalized obstetric care and satisfied patients. 


\section{REFERENCES}

1. Zondag L CF, De Geus M. Midwifery in the Netherlands. Royal Dutch association of Midwives (KNOV). 2017.

2. Bick D.E. R-MJ, Fontenla M. A case study evaluation of implementation of a care pathway to support normal birth in one English birth centre: anticipated benefits and unintended consequences. BMC pregnancy and childbirth. 2009;5(9):47.

3. Bick DE, Rycroft-Malone J, Fontenla M. A case study evaluation of implementation of a care pathway to support normal birth in one English birth centre: anticipated benefits and unintended consequences. BMC pregnancy and childbirth. 2009;9:47.

4. Vademecum. O. Verloskundig Vademecum 2003. Eindrapport van de Commissie Verloskunde van het College voor zorgverzekeringen. Diemen. 2003.

5. Linda J.E. Meertens HCJS, Sander M.J. van Kuijk, Robert Aardenburg, Ivo M.A. van Dooren, Josje Langenveld, Annemieke M. van Wijck, Iris Zwaan, Marc E.A. Spaanderman, Luc J.M. Smits. External Validation and Clinical Usefulness of First Trimester Prediction Models for the Risk of Preeclampsia: A Prospective Cohort Study. Fetal Diagn Ther. 2019;45(6):381-93.

6. Meertens LJE SL, van Kuijk SMJ, Aardenburg R, van Dooren IMA, Langenveld J, Zwaan IM, Spaanderman MEA,, HCJ. S. External validation and clinical usefulness of first-trimester prediction models for small- and large-for-gestational-age infants: a prospective cohort study. BJOG. 2019;126(4):472-84.

7. Meertens LJE, van Montfort P, Scheepers HCJ, van Kuijk SMJ, Aardenburg R, Langenveld J, et al. Prediction models for the risk of spontaneous preterm birth based on maternal characteristics: a systematic review and independent external validation. Acta Obstet Gynecol Scand. 2018.

8. Excellence NIfHaC. NICE Clinical guideline Antenatal care. RCOG Press at the Royal College of Obstetricians and Gynaecologists; 2008.

9. NICE Clinical Guideline Hypertension in Pregnancy. 2011.

10. Rosenste MODAH. Professional Communication and Team Collaboration. . Patient Safety and Quality: An Evidence-Based Handbook for Nurses Agency for Healthcare Research and Quality (US); 2008.

11. Manser T. Teamwork and patient safety in dynamic domains of healthcare: a review of the literature. Acta Anaesthesiol Scand. 2009;53(2):143-51.

12. D Way LJ, N Busing Implementation strategies: collaboration in primary care - family doctors \& nurse practitioners delivering shared care. Discussion Paper Written for The Ontario College of Family Physicians. Toronto: Ontario College of family physicians. 2000.

13. Xyrichis $\mathrm{A}$, Lowton $\mathrm{K}$. What fosters or prevents interprofessional teamworking in primary and community care? A literature review. International journal of nursing studies. 2008;45(1):140-53.

14. D'Amour D, Ferrada-Videla M, San Martin Rodriguez L, Beaulieu MD. The conceptual basis for interprofessional collaboration: core concepts and theoretical frameworks. J Interprof Care. 2005;19 Suppl 1:116-31.

15. Perdok H, Jans S, Verhoeven C, van Dillen J, Batenburg R, Mol BW, et al. Opinions of professionals about integrating midwife- and obstetrician-led care in The Netherlands. Midwifery. 2016;37:9-18.

16. Fransen AF, van de Ven J, Merien AE, de Wit-Zuurendonk LD, Houterman S, Mol BW, et al. Effect of obstetric team training on team performance and medical technical skills: a randomised controlled trial. BJOG. 2012;119(11):1387-93. 
17. Perdok H, Jans S, Verhoeven C, Henneman L, Wiegers T, Mol BW, et al. Opinions of maternity care professionals and other stakeholders about integration of maternity care: a qualitative study in the Netherlands. BMC pregnancy and childbirth. 2016;16(1):188.

18. O'Daniel M RA. Professional Communication and Team Collaboration In: RG H, editor. Patient Safety and Quality: An Evidence-Based Handbook for Nurses. 2. Rockville (MD): Agency for Healthcare Research and Quality (US); 2008 april. p. 271-84.

19. VLN Schölmerich AP, H Ghorashi, AJM Waelput, P Groenewegen, S Denktas. Improving interprofessional coordination in Dutch midwifery and obstetrics: a qualitative study. BMC pregnancy and childbirth. 2014.

20. Schulz-Hardt S, Mojzisch A. How to achieve synergy in group decision making: Lessons to be learned from the hidden profile paradigm. European Review of Social Psychology. 2012;23(1):305-43.

21. Cleary $M$, Lees $D$, Sayers J. Leadership, Thought Diversity, and the Influence of Groupthink. Issues Ment Health Nurs. 2019;40(8):731-3.

22. Lunenburg FC. Decision Making in Organizations International Journal of Management, Business, and Administration. 2011;15 (1).

23. KhasawnehAbu-Shanab. Factors Influencing Group Decision Making Performance in a GSS Enabled Environment. Computer Science and Information Technology 2013;1(2):145-52.

24. Vroom VH. Educating managers for decision making and leadership. Management Decision. 2003;41(10):968-78.

25. Pagliari $C$. The potential influence of small group processes on guideline development. Journal of evaluation in clinical practice. 2000;7(2):165-73.

26. Crisp J, Pelletier D, Duffield C, Adams A, Nagy S. The Delphi method? Nursing research. 1997;46(2):116-8.

27. SMP Lemmens HS, VA Lopes van Balen, YCM Roselaers, RG De Vries, MEA Spaanderman. Agreement Conform Current Operational Rules and Directives (ACCORD): A Novel Tool to Reach Multidisciplinary Consensus. Journal of Women's Health and Gynecology. 2019;6(5):1-11.

28. Bressen T. Consensus decision-making: what, why, how. ABA Books2012.

29. Hartnett T. Consensus oriented decision making: New Society Publishers; 2011.

30. John R. Schermerhorn jr JGH, Richard N. Osborn. Organizational Behavior 7th edition: John Wiley \& Sons; 2002.

31. Sam Kaner LL, Catherine Toldi, Sarah Fisk, Duane Berger. Facilitators Guide to Participation2007.

32. Lemmens SMP LVBV, De Vries RG, Scheepers HCJ and Spaanderman MEA. Do representatives represent you? Integrative Journal of Nursing and Health. 2019;2(1):90-4.

33. Duijm NJ. Recommendations on the use and design of risk matrices. Safety Science. 2015;76:21-31.

34. Wall KD. The trouble with risk matrices. 2011 [Available from: https://pdfs.semanticscholar.org/ f2be/55d4454451788fca458da018ac9b4b7953f8.pdf.

35. van der Lee N, Driessen EW, Scheele F. How the past influences interprofessional collaboration between obstetricians and midwives in the Netherlands: Findings from a secondary analysis. Journal of Interprofessional Care. 2016;30(1):71-6.

36. van der Lee N, Driessen EW, Houwaart ES, Caccia NC, Scheele F. An examination of the historical context of interprofessional collaboration in Dutch obstetrical care. J Interprof Care. 2014;28(2):123-7.

37. Visser GHA. Obstetric Care in the Netherlands: Relic or Example? Journal of Obstetrics and Gynaecology Canada. 2012;34(10):971-5. 
38. geboortezorg' EZI. Zorgstandaard Integrale Geboortezorg. https://www.kennisnetgeboortezorg.nl/ kennisbank/algemeen/documenten/8291-zorgstandaard-integralegeboortezorg; 2016.

39. Rijnders $M$, Baston $H$, Schönbeck $Y$, Van Der Pal K, Prins M, Green J, et al. Perinatal factors related to negative or positive recall of birth experience in women 3 years postpartum in the Netherlands. Birth. 2008;35(2):107-16.

40. Goodman P MM, Tavakoli AS. . Factors related to childbirth satisfaction. Journal of advanced nursing. Journal of advanced nursing. 2004;46(2):212-9.

41. Lemmens SMP, van Montfort $P$, Meertens LJE, Spaanderman MEA, Smits LJM, de Vries $R G$, et al. Perinatal factors related to pregnancy and childbirth satisfaction: a prospective cohort study. J Psychosom Obstet Gynaecol. 2020:1-9. 



\section{CHAPTER 7}

Valorisation 



\section{VALORISATION}

This chapter addresses the relevance and the potential societal impact of this thesis. Collaboration between gynecologists and midwives in the Netherlands has a long history. We have a unique obstetric healthcare system which is divided in three different echelons, primary, secondary and tertiary care. In this system, autonomous community midwives provide care for women with presumed low risk pregnancies in primary care. In secondary care, clinical trained midwives, residents and gynecologists provide care for women with high-risk pregnancies and tertiary care takes place in centers with a perinatology department combined with a neonatal intensive care unit and an obstetric high-risk department for critically ill pregnant women ${ }^{1}$.

Midwives and gynecologists have a different vision on how to execute obstetric care and have their own professional organization, as well as monodisciplinary guidelines and protocols. These differences between both professions come with challenges and barriers to overcome when a close collaboration, with continuity of care and accurate communication, is inevitable and of utmost importance.

If women remain uncomplicated throughout pregnancy, they receive midwife-led care until the postpartum period. Transfer of care from midwife to gynecologist, antenatal, intrapartum or postpartum, is a result of having one or more risk factors for pregnancy related complications, an unexpected finding and/or the occurrence of a complication during pregnancy or childbirth. The risk assessment of midwives is based on and described in the 'List of Obstetric Indications' (the VIL) ${ }^{2}$. This risk assessment results in a division of women having 'low' or 'high' risk pregnancies, after which their obstetric care is either provided by a midwife (low risk) or a gynecologist (high risk), respectively. A collaboration between both professions resulting in shared responsibilities by both is not facilitated in this fragmented system.

The Dutch maternity system came under heavy criticism as a result of the findings in the Euro-Peristat, that showed the Netherlands to have among the highest rate of perinatal death compared to other European countries ${ }^{3}$. A steering committee established by the Minister of Health Care published two reports in 2009 and $2016^{4,5}$. In these reports, they acknowledged the high perinatal mortality rates and promoted a more proactive approach to care for women during pregnancy and delivery. The recommendations include patient-centered and shared care, combined with shared decision-making as key concepts of the future obstetric care system ${ }^{4,5}$. These reports 
underscored the need for organizational improvement and emphasized the importance of closer collaboration between independent midwives and gynecologists and the need for a more structured and integrated approach to obstetric care in the Netherlands. Changes in the Dutch obstetric system have been noticed over the last years, but the historical development of both professions still influences contemporary practice ${ }^{6,7}$.

\section{CONSENSUS ON OBSTETRIC CARE}

An initiative for closer collaboration was born by the founding of the Limburg Obstetric Consortium, a partnership by obstetric healthcare professionals, which initiated the Limburg Obstetric Quality System (LOQS) project. The main goal of the LOQS project was to develop collaborative shared obstetric care pathways, to come to risk-based personalized and with it preventive care, and to structurally and timely monitor and review outcomes in order to continuously improve care and to come to one integral patient record system.

To realize these goals, midwives and gynecologists, healthcare professionals with overlapping expertise but fundamental different views and perspectives on obstetric care, needed to collaborate. This first required consensus on best care practices. To this end, we designed a novel model named the Agreement Conform Current Operational Rules and Directives-tool (ACCORD). The ACCORD-tool is based on a fourstep bottom-up approach with equal participation of all involved professionals in the field. A bottom-up development strategy is thought to result in stronger supported inter-professional directives and richer decisions, because the ideas of all participating professionals can be captured in an early stage of the process ${ }^{8,9}$. The four steps consists of summarizing current evidence, translating evidence, based on already approved and existing guidelines, into statements pivotal for clinical decisions, send online surveys to professionals to rank these statements by their level of agreement, and finally review the survey results within a small group of representatives, chosen by their peers, to reach consensus. The consensus rate was high (92\%) and the selected representatives reflected the opinion of the group they were representing in $77 \%$ of all statements.

It was the first time in our region that midwives and gynecologists worked together on this scale to improve obstetric care. Due to face-to-face meetings with representatives of midwives, gynecologists and maternity care members, we were able to discuss the content of care, but more important we could explain our 
differences in view. By listening to each other, and hearing each other's concerns, we had the opportunity to take all these aspects into account, before a final decision was made regarding obstetric interventions and policy. These meetings created mutual respect, but it also became evident that both professions had to be willing to change their daily practice. The developed care pathways consist of basic care pathways for low risk women and additional recommendations for women identified with an increased risk for pregnancy related complications. The care pathways are implemented in every hospital and almost every midwifery practice in the region, they are available online and will be constantly updated with new evidence.

The described process of decision-making with help of the ACCORD-tool can be extrapolated to other regions, but also to other professions, for example multidisciplinary healthcare teams with specialists, general practitioners and/or other first line professions, but also to non-medical businesses where different professionals have to collaborate. However, every group should go through the development process themselves, since professionals must be involved from the start of the decision-making process in order to create broad support for the decisions made. In addition, statements can only be made by experts able to value what variables are cardinal in making proper decisions. Although the method requires more thoughtful effort upfront, given the large amount of generally approved and used regional guidelines in a very short time period, the gained yield afterward is tremendous as compared to more traditional guideline development strategies.

But even more importantly, clinical outcome has improved substantially, an effect not only translational to one aspect of the whole project, and therefore the resultant of all changes made within our mission.

\section{PATIENT SATISFACTION}

In this thesis we also investigated which determinants were associated with patient satisfaction. We focused on women not being perfectly satisfied with the obstetric care services they received during pregnancy and childbirth. Our results show that decreased perceived personal well-being, antenatal anxiety, and obstetrician-led care during labor were all independently associated with suboptimal pregnancy and childbirth satisfaction ${ }^{10}$. We hope that by using the designed obstetric care pathways, unnecessary secondary obstetric care can be prevented because of better collaboration and expectation-management and that consequently women's birthing experience may improve. Besides, we observed that one in four women experienced 
mostly undetected antenatal anxiety which associated with decreased satisfaction scores. Therefore, active screening and appropriate guidance of women suffering from antenatal anxiety, might improve pregnancy and childbirth satisfaction.

\section{RISK ASSESSMENT}

In daily practice, healthcare professionals continuously assess risks. Midwives and gynecologists monitor whether there are predefined risk factors present or if complications arise during pregnancy, childbirth or the postpartum period that warrant referral from primary to secondary/tertiary care. To improve risk stratification during pregnancy, the Expect Study I started concurrently with the LOQS project, and evaluated and validated first trimester obstetric prediction models ${ }^{11-13}$. In the Expect Study II, the prediction models were implemented in daily practice and risk based care based on prediction models was compared with care as usual ${ }^{14,15}$. As a result, risk assessment in our region depends on the use of an online prediction model or if not available, on the obstetric indication list $\left(\mathrm{VIL}^{2}\right)$ or risk factors adopted from the NICE guidelines ${ }^{16,17}$. Risk based care results in a significant reduction of adverse perinatal outcomes in nulliparous women. Besides improved perinatal outcomes, risk based care resulted in a considerable cost reduction without a negative impact on maternal health outcomes ${ }^{15}$. In the current setting, a pregnant women will follow a specific care pathway, depending on her calculated risk, which can be individually adjusted.

Besides the introduction of these first-trimester prediction models, we investigated professionals' opinion on the desired risk reduction of obstetric interventions by using the risk matrix approach (RMA). Risk is mostly viewed upon as probability, but risk is actually the combination of probability and impact of desired and adverse events. By using the RMA, we provided insight in the actual risk of an event, facilitating a constructive discussion with the professionals, before final decisions on new interventions and diagnostic thresholds were made. In our guideline development process, professionals introduced interventions and were willing to change policies, without reaching their predefined threshold of desired risk reduction. This indicates that decisions in guideline development are affected by several other factors than risk reduction alone, such as financial aspects and practical consequences for daily practice. Professionals should be aware of these influencing factors, when they start initiatives for future guideline development. 


\section{TARGET GROUPS}

The results presented in this thesis, the bottom-up ACCORD method to develop guidelines, representative-peer agreement, factors influencing patient satisfaction and a new approach to risk assessment, could contribute to further improvement of guideline development and interprofessional collaboration. As consensus decisionmaking, representation and risk assessment are of interest in a lot of sectors in society, the results described in this thesis are interesting for a much larger audience than healthcare professionals alone. To spread the findings to the international research community, all studies described in this dissertation have been published or are submitted to scientific journals.

Given the tremendous pace at which we were able to improve our collaborative care, we recommend this detailed ACCORD strategy to be a consolidated part of every obstetric collaboration in the Netherlands. Moreover, as the method also regulates multidisciplinary discussion and common participation, implementation is facilitated afterwards. Active and continuous feedback towards all participants may increase the involvement and with it, realization to non-stop improvement in quality of care. 


\section{REFERENCES}

1. Zondag L CF, De Geus M. Midwifery in the Netherlands. Royal Dutch association of Midwives (KNOV). 2017.

2. Vademecum. O. Verloskundig Vademecum 2003. Eindrapport van de Commissie Verloskunde van het College voor zorgverzekeringen. Diemen. 2003.

3. EURO-PERISTAT Project WS, EUROCAT \& EURONEOSTAT. European Perinatal Health Report. 2008.

4. geboorte Sze. Een goed begin, veilige zorg rond zwangerschap en geboorte. 2009.

5. geboortezorg' EZI. Zorgstandaard Integrale Geboortezorg. https://www.kennisnetgeboortezorg.nl/kennisbank/algemeen/documenten/8291-zorgstandaard-integralegeboortezorg; 2016.

6. Boesveld IC, Valentijn PP, Hitzert M, Hermus MAA, Franx A, de Vries RG, et al. An Approach to measuring Integrated Care within a Maternity Care System: Experiences from the Maternity Care Network Study and the Dutch Birth Centre Study. Int J Integr Care. 2017;17(2):6.

7. Visser GHA. Obstetric Care in the Netherlands: Relic or Example? Journal of Obstetrics and Gynaecology Canada. 2012;34(10):971-5.

8. Vaucher C, Bovet E, Bengough T, Pidoux V, Grossen M, Panese F, et al. Meeting physicians' needs: a bottom-up approach for improving the implementation of medical knowledge into practice. Health research policy and systems. 2016;14(1):49.

9. Pagliari $C$. The potential influence of small group processes on guideline development. Journal of evaluation in clinical practice. 2000;7(2):165-73.

10. Lemmens SMP, van Montfort P, Meertens LJE, Spaanderman MEA, Smits LJM, de Vries RG, et al. Perinatal factors related to pregnancy and childbirth satisfaction: a prospective cohort study. J Psychosom Obstet Gynaecol. 2020:1-9.

11. Linda J.E. Meertens HCJS, Sander M.J. van Kuijk, Robert Aardenburg, Ivo M.A. van Dooren, Josje Langenveld, Annemieke M. van Wijck, Iris Zwaan, Marc E.A. Spaanderman, Luc J.M. Smits. External Validation and Clinical Usefulness of First Trimester Prediction Models for the Risk of Preeclampsia: A Prospective Cohort Study. Fetal Diagn Ther. 2019;45(6):38193.

12. Meertens LJE SL, van Kuijk SMJ, Aardenburg R, van Dooren IMA, Langenveld J, Zwaan IM, Spaanderman MEA, HCJ. S. External validation and clinical usefulness of first-trimester prediction models for small- and large-for-gestational-age infants: a prospective cohort study. BJOG. 2019;126(4):472-84.

13. Meertens LJE, van Montfort $P$, Scheepers HCJ, van Kuijk SMJ, Aardenburg R, Langenveld J, et al. Prediction models for the risk of spontaneous preterm birth based on maternal characteristics: a systematic review and independent external validation. Acta Obstet Gynecol Scand. 2018.

14. van Montfort $P$, Willemse JP, Dirksen CD, van Dooren IM, Meertens $L J$, Spaanderman ME, et al. Implementation and Effects of Risk-Dependent Obstetric Care in the Netherlands (Expect Study II): Protocol for an Impact Study. JMIR Res Protoc. 2018;7(5):e10066.

15. van Montfort P, Scheepers HCJ, Dirksen CD, van Dooren IMA, van Kuijk SMJ, Meertens LJE, et al. Impact on perinatal health and cost-effectiveness of risk-based care in obstetrics: a before-after study. American journal of obstetrics and gynecology. 2020.

16. Excellence NIfHaC. NICE Clinical guideline Antenatal care. RCOG Press at the Royal College of Obstetricians and Gynaecologists; 2008.

17. NICE Clinical Guideline Hypertension in Pregnancy. 2011. 



\section{CHAPTER 8}

Summary

Samenvatting 



\section{SUMMARY}

\section{PART I}

\section{CHAPTER 1 Introduction}

The Dutch obstetric healthcare system is unique worldwide, with community midwives providing care for women with presumed low risk pregnancies in primary care and clinical trained midwives, residents and gynecologists providing care for women with established high-risk pregnancies in secondary and tertiary care.

This maternity system came under heavy criticism as the Netherlands were to have about the highest rates of perinatal death compared to other European countries. Governmental committees promoted a more proactive approach in care for women during pregnancy and delivery and recommended patient-centered and shared care, combined with shared decision-making as key concepts of the future obstetric care system. Reports underscored the need for organizational improvement and a closer collaboration between independent midwives and gynecologists.

To reach a closer collaboration between healthcare professionals in primary, secondary and tertiary obstetric care, the Limburg Obstetric Consortium, a partnership by obstetric healthcare professionals, started the Limburg Obstetric Quality System (LOQS) project. The main goal of the LOQS project was to develop collaborative shared obstetric care pathways to come to risk-based personalized and preventive care. Because midwives and gynaecologists both have their own professional organization, as well as monodisciplinary guidelines and protocols, many variations in clinical practice exist. Shared obstetric care pathways are presumed to standardize care, support collaboration and implementation of evidence into practice, create continuity of care, uniformity in decision-making and the patient receiving correct and corresponding information by different healthcare professionals. The LOQS pathways focus on medical management of specific conditions during pregnancy, childbirth and the postpartum period and differentiate between different levels of risk (part II of this thesis).

\section{CHAPTER 2 ACCORD-tool}

Collaboration between midwives and gynaecologists was essential to develop shared care pathways in obstetrics. These healthcare professionals have overlapping 
expertise but fundamental different views and perspectives on obstetric care. To come to shared guidelines, consensus on best care practices was required. To this end we developed the Agreement Conform Current Operational Rules and Directivestool (ACCORD), which consists of a four-step, bottom-up approach to reach consensus. A bottom-up approach with equal participation and discussion of content focused on clear targets is necessary to ensure that new protocols will be implemented by a diverse group of professionals. The four steps consist of summarizing current evidence, translating evidence into statements essential for clinical decisions, send online surveys to professionals to rank these statements by their level of agreement, and finally review the survey results within a small group of representatives. We reached a high consensus rate of $92 \%$ and the result is an extensive document with recommendations for the entire field of obstetric care. The participant's satisfaction with the project was positively influenced by the information supplied on scope, purpose and method before and during the process and the extent to which everyone's opinion was considered. A feeling of power imbalance and loss of autonomy negatively affected professional participants' satisfaction.

\section{CHAPTER 3 Representation}

Representation by a small group of chosen representatives is a commonly used strategy for decision making within a large heterogeneous group of people. These representatives are expected to reflect the opinion of their group, rather than insisting on to their personal preferences. In hospital and first-line setting, we measured the level of representatives-peers agreement for representatives that were selectively chosen by peers and those that were randomly selected. Statement scores of chosen representatives correlated well with their peers $(r=0.91)$ and the average representative-peers agreement was $77 \%$. Selectively chosen gynecologists and midwives showed comparable levels of agreement, whereas randomly selected professionals tend to differ in professional view. This indicates that the selection method of representatives and the professionals' working environment do not statistically affect the level of representative-peers agreement. 


\section{CHAPTER 4 Pregnancy and childbirth discontent}

Satisfaction of pregnancy and childbirth is an important quality measure of maternity care. In response to a worldwide call for obstetric care that is more woman-centered, we identified and described the contributors to suboptimal satisfaction with pregnancy and childbirth. Decreased perceived personal well-being, antenatal transfer of care, antenatal anxiety, and obstetrician-led care during labor were all independently associated with suboptimal pregnancy and childbirth satisfaction. Therefore, active screening and appropriate guidance of women suffering from antenatal anxiety might improve pregnancy and childbirth satisfaction and a women's birthing experience may improve by reducing unnecessary secondary obstetric care.

\section{CHAPTER 5 Risk-matrix approach}

In this chapter we highlights a new perspective on risk assessment during pregnancy and childbirth. In daily practice, healthcare professionals continuously assess risks. Risk is mostly viewed upon as probability, but risk is actually the combination of probability and impact of desired and adverse events. Using a risk matrix is both a qualitative and quantitative approach to prioritize risk and start interventions to mitigate the risk and to facilitate constructive discussions within a decision process. In our guideline development process, professionals opinioned that non-invasive interventions should decrease the general population risk, whereas invasive interventions should decrease the risk of the small highest-risk group. Nonetheless, interventions were introduced and professionals were willing to change policies, without reaching the predefined threshold of anticipated risk reduction. Although objectively presented data structured group discussions, decisions in guideline development are affected by several other factors than risk reduction alone, such as financial aspects, the felt magnitude of the intervention for the individual pregnant woman and their healthcare professional, as well as consequences for daily practice.

\section{CHAPTER 6 General discussion}

This chapter provides a general discussion of the results presented in this thesis together with their implications and limitations. To stimulate collaboration between obstetric healthcare professionals shared care pathways were developed. Various efforts have been made to create a final product with shared care pathways, supported by all involved participants. By using the ACCORD strategy, a bottom-up 
approach, everyone's opinion was weighted equally during the process, due to faceto-face meetings differences in view and concerns could be taken into account, and considerations that led to decisions were transparently communicated. This approach resulted in a high consensus rate on the content of care and our results show a high level of representative-peer agreement, implicating that decisions made by the team of representatives should reflect the opinion of their peers. Despite all these efforts, some participants had underestimated the impact the novel guidelines would have on their daily practice and felt that the final decisions did not reflect their opinion. Evaluating the decision-making process, midwives reported a feeling of power imbalance during the process, financial aspects possibly played a role in decisionmaking and some professionals were afraid losing autonomy by following the designed care pathways. These factors have to be taken into account in future decision-making processes. Expectation management and continuous structured feedback to the peers might have been much more important than foreseen.

Several factors contribute to perceived satisfaction with maternity care. In general, women were highly satisfied with the maternity care they received. However, a decreased perceived personal well-being, antenatal anxiety, antenatal transfer of care, and obstetrician-led care during labour were all independently associated with suboptimal pregnancy and childbirth satisfaction scores. Therefore, women's birthing experience may improve by increased awareness regarding women's antenatal anxiety state and reducing the proportion of women unnecessarily receiving obstetric care in a secondary care setting.

A risk matrix approach was used in our clinical guideline-making process and performance expectations of professionals on risk reduction of different interventions were investigated. However, interventions were introduced without reaching the predefined threshold of anticipated risk reduction. Financial aspects, the felt magnitude of the intervention for the individual pregnant women and their healthcare professional, as well as consequences for daily practice seemed important in deciding.

\section{CHAPTER 7 Valorisation}

The gained knowledge on the bottom-up ACCORD method to develop guidelines, representative-peer agreement, factors influencing patient satisfaction and a new approach to risk assessment, could contribute to further improvement of guideline development and interprofessional collaboration. As consensus decision-making, 
representation and risk assessment are of interest in a lot of sectors in society besides healthcare. Given the tremendous pace at which we were able to improve our collaborative care, we recommend the described ACCORD strategy to be a consolidated part of every obstetric collaboration in the Netherlands. Clinical outcome has improved substantially, an effect not only translational to one aspect of the whole project, but the resultant of all changes made within our mission.

\section{PART ॥}

At the end of the LOQS project, our principles turned into an extensive document containing a framework for shared obstetric care, created together by all obstetric professionals in the province. The developed care pathways consist of basic care pathways for low risk women and additional recommendations for women identified with an increased risk for pregnancy related complications. The care pathways are implemented in every hospital and almost every midwifery practice in the region, are available online and are planned to be constantly updated with new evidence and additional guidelines on novel topics not previously addressed.

Shared care pathways were developed for the following obstetric topics (in Dutch):

- Antenatal care for uncomplicated pregnancies

O Obesity

- Hyperemesis gravidarum

- Twin pregnancy

- Fetal growth restriction

- Fetal macrosomia

- Gestational diabetes

- Diabetes mellitus in pregnancy

- Hypertensive disorders in pregnancy

- Vaginal bleeding in pregnancy

o Fever in pregnancy

- Rupture of membranes

- Preterm labor

- Post term care

- Normal labor

- Prolonged labor

- Shoulder dystocia

- Hemorrhage postpartum

- Maternity care 


\section{SAMENVATTING}

\section{DEEL I}

\section{HOOFDSTUK 1 Introductie}

De organisatie van de Nederlandse geboortezorg is wereldwijd uniek, met eerstelijns verloskundigen die zorg verlenen aan vrouwen met een verondersteld laag risico zwangerschappen en klinisch verloskundigen, arts-assistenten en gynaecologen die zorg verlenen aan vrouwen met vastgesteld hoog risico zwangerschappen in de tweede- en derde lijn.

De geboortezorg kwam zwaar onder druk te staan, omdat Nederland bij de landen hoorde met het hoogste percentage perinatale sterfte in vergelijking met andere Europese landen. De overheid stimuleerde een meer proactieve benadering van de zorg tijdens zwangerschap en bevalling en adviseerde patiëntgerichte en gedeelde zorg, gecombineerd met gedeelde besluitvorming als sleutelconcepten van het toekomstige verloskundige zorgsysteem. Diverse rapporten onderstreepten de noodzaak tot organisatorische veranderingen en een nauwere samenwerking tussen verloskundigen en gynaecologen.

Om een betere samenwerking tussen zorgprofessionals in de eerste, tweede en derde lijn te bewerkstelligen, is het Verloskundig Consortium Limburg, een samenwerking tussen verschillende verloskundige zorgverleners, het Limburg Obstetric Quality System (LOQS)-project gestart. Het hoofddoel van het LOQSproject was het ontwikkelen van gezamenlijke, verloskundige zorgpaden om op die manier gepersonaliseerde en preventieve zorg te kunnen verlenen, afgestemd op het individuele risico. Doordat verloskundigen en gynaecologen beiden hun eigen beroepsvereniging hebben, evenals monodisciplinaire richtlijnen en protocollen, bestaat er veel variatie in de dagelijkse praktijk. Multidisciplinaire zorgpaden worden verondersteld de zorg te standaardiseren, samenwerking en implementatie van nieuwe inzichten in de dagelijkse praktijk te ondersteunen, zorgcontinuïteit en uniformiteit in de besluitvorming te creëren en ervoor te zorgen dat de patiënt dezelfde informatie krijgt van verschillende zorgprofessionals. De LOQS-zorgpaden beschrijven zorg tijdens de zwangerschap, bevalling en het kraambed en bestaan uit laag en hoog risico paden (deel II van dit proefschrift). 


\section{HOOFDSTUK 2 ACCORD-methode}

Een goede samenwerking tussen verloskundigen en gynaecologen is essentieel voor de ontwikkeling van gedeelde zorgpaden. Ondanks het feit dat verloskundigen en gynaecologen expert zijn binnen hetzelfde vakgebied, zijn hun opvattingen en visie met betrekking tot de verloskundige zorg fundamenteel verschillend. Echter, om tot gedeelde richtlijnen te komen, dienen zij eerst consensus te bereiken over de inhoud van deze zorg. Hiertoe hebben we de Agreement Conform Current Operational Rules and Directives (ACCORD)-methode ontwikkeld. Deze methode bestaat uit vier stappen om consensus te bereiken volgens een bottom-up benadering. Een bottomup benadering, met gelijke inbreng van alle professionals en een doelgerichte bespreking van de inhoud, is nodig om ervoor te zorgen dat nieuwe protocollen worden geïmplementeerd door een diverse groep professionals. De vier stappen van de ACCORD-methode bestaan uit het samenvatten van bestaand bewijs (uit bestaande richtlijnen), het vertalen van bewijs in stellingen essentieel voor klinische beslissingen, het verzenden van online enquêtes naar professionals om deze stellingen te beoordelen, en ten slotte de onderzoeksresultaten te bediscussiëren met een kleine groep gemandateerde vertegenwoordigers om tot consensus te komen. We behaalden een hoog consensuspercentage van $92 \%$ en het resultaat van deze inspanningen is een uitgebreid document met aanbevelingen voor de verloskundige zorg. De tevredenheid van de deelnemers over het project werd positief beïnvloed door de verstrekte informatie over de omvang, het doel en de gebruikte methode voor en tijdens het proces en de mate waarin ieders mening werd meegewogen. Een ervaren gevoel van onevenwichtigheid in macht en verlies van autonomie door een klein deel van de deelnemers, heeft de kijk op het project negatief beïnvloed.

\section{HOOFDSTUK 3 Representatie}

Besluitvorming door een kleine groep gekozen vertegenwoordigers, die een grote heterogene groep mensen vertegenwoordigd, is een veelgebruikte strategie binnen besluitvormingsprocessen. Van deze vertegenwoordigers wordt verwacht dat ze de mening van hun achterban weerspiegelen, in plaats van vast te houden aan hun persoonlijke voorkeuren. In dit proefschrift hebben we gekeken naar de mate waarin de beoordeling van stellingen door gemandateerde vertegenwoordigers overeenkwam met de achterban die zij vertegenwoordigden. We hebben zowel 
gekeken naar vertegenwoordigers die geselecteerd waren door hun achterban, als ook naar willekeurig gekozen vertegenwoordigers. De scores van de specifiek geselecteerde vertegenwoordigers correleerden goed met hun achterban $(r=0,91)$ en de gemiddelde overeenkomst tussen vertegenwoordigers en hun achterban was $77 \%$. Specifiek geselecteerde gynaecologen en verloskundigen lieten vergelijkbare niveaus van overeenstemming zien met hun achterban. Willekeurig gekozen professionals neigden meer te verschillen van mening met hun achterban. De selectiemethode van de vertegenwoordigers (specifiek gekozen of willekeurig) en of ze in de eerste- of tweede lijn werkten bleek de mate van overeenkomst tussen de vertegenwoordigers en hun achterban niet statistisch te beïnvloeden.

\section{HOOFDSTUK 4 Patiënt tevredenheid}

Tevredenheid over zwangerschap en bevalling is een belangrijke kwaliteitsindicator binnen de zorg. Als reactie op een wereldwijde oproep om verloskundige zorg aan te bieden die meer aansluit bij de behoeften van de zwangere, identificeerden en beschreven we factoren die lijken bij te dragen aan de tevredenheid van vrouwen over hun zwangerschap en bevalling. Factoren die geassocieerd worden met een verminderde tevredenheid over zwangerschap en bevalling zijn: vrouwen die minder persoonlijk welzijn ervaren, antenatale overdracht van zorg, antenatale angst en een bevalling volledig begeleid door een gynaecoloog. Screening en begeleiding van vrouwen die antenatale angst ervaren en het verminderen van onnodige tweedelijns zorg, zouden zodoende de patiënt tevredenheid kunnen verbeteren.

\section{HOOFDSTUK 5 Risico-matrix}

In dit hoofdstuk belichten we een nieuwe kijk op risicobeoordeling tijdens de zwangerschap en bevalling. In de dagelijkse praktijk beoordelen zorgverleners continu risico's. Een risico wordt meestal gezien als de kans op het optreden van een bepaalde gebeurtenis. Hoewel bij het inschatten van een risico zowel de kans op een gebeurtenis, als ook de impact van deze gebeurtenis wordt meegewogen. Het gebruik van een risicomatrix is zowel een kwalitatieve als kwantitatieve benadering om risico's te prioriteren, interventies te starten om het risico te beperken en om constructieve discussies binnen een besluitvormingsproces te vergemakkelijken. In ons richtlijnontwikkelingsproces waren professionals van mening dat niet-invasieve interventies het risico van de algemene bevolking zouden moeten verminderen en 
invasieve interventies vooral het risico in de hoog risico groepen. Desalniettemin werden interventies ingevoerd en waren professionals bereid om hun beleid te veranderen, zonder dat deze vooraf bepaalde risicoverlaging was bereikt. Hieruit blijkt dat beslissingen binnen richtlijnontwikkeling beïnvloedt worden door andere factoren dan risicoverlaging alleen, zoals financiële aspecten, gevoelde grootte van de interventie voor zowel de zwangere als haar zorgverlener en praktische consequenties voor de dagelijkse praktijk.

\section{HOOFDSTUK $6 \quad$ Algemene discussie}

Dit hoofdstuk bestaat uit een algemene bespreking van de resultaten die in dit proefschrift worden gepresenteerd, met hun bijbehorende implicaties en beperkingen. Om de samenwerking tussen verloskundige zorgprofessionals te stimuleren, zijn gedeelde zorgpaden ontwikkeld. Vele inspanningen zijn geleverd om een eindproduct, bestaande uit gedeelde zorgpaden te creëren, dat ondersteund zou worden door alle betrokken deelnemers. Er is gebruik gemaakt van de ACCORDstrategie, een bottom-up benadering, waarbij ieders mening tijdens het proces evenredig werd meegewogen. Eventuele verschillen in visie en bestaande zorgen konden worden besproken tijdens de team bijeenkomsten en alle overwegingen die tot uiteindelijke besluiten leidden, werden transparant naar de achterban gecommuniceerd. Deze aanpak resulteerde in een hoog consensuspercentage wat betreft de inhoud van de zorg. Daarnaast laten onze resultaten een hoge mate van overeenstemming zien tussen de gemandateerde vertegenwoordigers en hun achterban, wat impliceert dat beslissingen genomen door het team van vertegenwoordigers de mening van hun collega's zou moeten weerspiegelen. Ondanks al deze inspanningen hebben sommige deelnemers de impact van de nieuwe richtlijnen op hun dagelijkse praktijk onderschat en zij vonden dat de uiteindelijke besluiten niet hun mening weerspiegelden. Bij het evalueren van het besluitvormingsproces rapporteerden vooral verloskundigen dat zij een gevoel van onevenwichtigheid tijdens het proces hebben ervaren. Daarnaast speelden financiële aspecten mogelijk een rol bij de besluitvorming en waren sommige professionals bang om hun autonomie te verliezen door de zorgpaden te volgen. Met deze factoren moet bij toekomstige besluitvormingsprocessen rekening worden gehouden. Verwachtingsmanagement en continue gestructureerde feedback aan de achterban zijn wellicht veel belangrijker dan voorzien. 
Verschillende factoren dragen bij aan de tevredenheid over de verloskundige zorg. Over het algemeen waren vrouwen zeer tevreden over de verloskundige zorg die zij kregen. Het ervaren van een verminderd persoonlijk welzijn, antenatale angst, antenatale overdracht van zorg en een bevalling volledig begeleid door een gynaecoloog waren echter allemaal onafhankelijk geassocieerd met suboptimale scores voor zwangerschap en bevalling. Een groter bewustzijn van eventueel aanwezige antenatale angst en het verminderen van het aantal vrouwen dat onnodig verloskundige zorg ontvangt in de tweede lijn, zou om die reden de ervaring van vrouwen omtrent hun bevalling kunnen verbeteren.

In ons proces van klinische richtlijn ontwikkeling werd gebruik gemaakt van een risicomatrix en werd onderzocht wat professionals verwachtten van verschillende interventies ten aanzien van risicoverlaging. Er werden echter interventies geïntroduceerd zonder dat de vooraf gedefinieerde risicoverlaging was bereikt. Financiële aspecten, de gevoelde omvang van de interventie voor de individuele zwangere vrouwen en hun zorgverlener, evenals gevolgen voor de dagelijkse praktijk leken belangrijk bij de besluitvorming.

\section{HOOFDSTUK $7 \quad$ Valorisatie}

De opgedane kennis wat betreft de bottom-up ACCORD-methode voor het ontwikkelen van richtlijnen, de mate van overeenkomst tussen de mening van vertegenwoordigers en hun achterban, factoren die patiënttevredenheid beïnvloeden en een nieuwe benadering van risicobeoordeling, zouden kunnen bijdragen aan verdere verbetering van richtlijnontwikkeling en interprofessionele samenwerking. Besluitvorming door middel van consensus, representatie en het beoordelen van risico's zijn van belang in veel sectoren van de samenleving naast de gezondheidszorg. Gezien het enorme tempo waarin we onze gezamenlijke zorg hebben kunnen verbeteren, raden we de beschreven ACCORD-methode aan als vast onderdeel van elke verloskundige samenwerking in Nederland. De klinische uitkomst is aanzienlijk verbeterd, niet door één aspect van het project, maar het resultaat van alle veranderingen binnen ons project. 


\section{DEEL II}

Aan het einde van het LOQS-project zijn onze principes uitgegroeid tot een uitgebreid document met een raamwerk voor gedeelde verloskundige zorg, dat door alle verloskundigen in de provincie samen is gemaakt. De ontwikkelde zorgpaden bestaan uit basispaden voor vrouwen met een laag risico en aanvullende aanbevelingen voor vrouwen met een verhoogd risico op zwangerschap gerelateerde complicaties. De zorgpaden zijn geïmplementeerd in elk ziekenhuis en bijna elke verloskundigenpraktijk in de regio, ze zijn online beschikbaar en zullen voortdurend worden bijgewerkt met nieuw bewijsmateriaal en aanvullende richtlijnen over nieuwe onderwerpen die nog niet eerder zijn behandeld.

Voor de volgende verloskundige onderwerpen zijn gedeelde zorgpaden ontwikkeld:

- Basis prenatale zorg

O Obesitas

- Hyperemesis gravidarum

- Meerlingzwangerschap

○ Foetale groeibeperking

- Foetale macrosomie

- Diabetes gravidarum

- Pre-existente diabetes mellitus tijdens de zwangerschap

○ Hypertensieve aandoeningen tijdens de zwangerschap

○ Vaginaal bloedverlies tijdens de zwangerschap

○ Koorts tijdens de zwangerschap

- Gebroken vliezen

- Vroeggeboorte

○ Serotiniteit

o Normale baring

- Niet vorderende baring

- Schouderdystocie

- Fluxus postpartum

○ Kraamzorg 



\section{OBSTETRIC CARE PATHWAYS}

\section{ZORGPADEN VERLOSKUNDE}

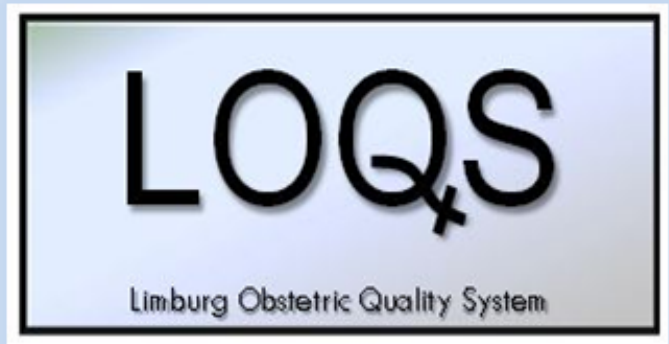





\section{INTRODUCTIE}

Dit hoofdstuk bevat informatie over de aanleiding, visie en het doel van het LOQS project. Daarnaast wordt ingegaan op de gehanteerde methodiek voor de ontwikkeling van de zorgpaden, die heeft geleid tot de totstandkoming van de literatuurdocumenten, besluitenlijsten en het aanbevelingsdocument zorgpaden. Tevens worden de juridische aspecten van de gemaakte afspraken toegelicht.

\section{AANLEIDING EN DOEL}

Het 'Stuurgroep rapport Zwangerschap en Geboorte' ${ }^{1}$ uit 2009, is aanleiding geweest om vanuit het Verloskundig Consortium Limburg multidisciplinaire zorgpaden te ontwikkelen. De missie van het consortium is om, door middel van deze zorgpaden, de verloskundige zorg in Limburg te innoveren, te verbeteren en te uniformeren, en op die manier betere samenwerking tussen zorgverleners en een daling van de perinatale mortaliteit en morbiditeit tot stand te brengen ${ }^{2}$.

\section{METHODIEK}

De zorgpaden zijn mede ontwikkeld door twee werkgroepen, te weten de werkgroep 'Zwangerschap' en de werkgroep 'Baring en kraambed'. Deze werkgroepen komen elke drie maanden gedurende een dag bij elkaar. De werkgroepen zijn samengesteld uit verloskundigen, gynaecologen, medewerkers van de kraamzorgorganisaties en de Academie Verloskunde Maastricht. De werkgroep leden hebben het mandaat van hun kring, maatschap of organisatie en vertegenwoordigen derhalve hun achterban ${ }^{3,4}$. Tevens zijn kinderartsen en anesthesiologen betrokken bij de besluiten die raakvlak hebben met hun vakgebied. Een vermelding als werkgroep lid betekent niet per definitie dat deze persoon alle afspraken in het aanbevelingsdocument zorgpaden inhoudelijk op elk detail onderschrijft.

Bij de ontwikkeling van een zorgpad werd gestart met het bestuderen van de bestaande nationale en internationale richtlijnen (o.a. KNOV, NVOG, ACOG, RCOG, $\mathrm{NICE})^{5}$, gerelateerde artikelen en lokale protocollen. Deze literatuur is per zorgpad samengevat in een literatuurdocument. Er is géén systematische search uitgevoerd in pubmed en/of embase. Na het bestuderen van de literatuur is een stroomdiagram gemaakt, waarin alle beslismomenten/kruispunten zijn vastgelegd. Deze kruispunten zijn omgezet in stellingen (Figuur 1), die vervolgens via een online vragenlijst (Survey 
Monkey) naar alle deelnemers van het consortium ( \pm 135 personen) zijn verzonden. Alle stellingen met een gemiddelde score tussen de 3 en 8 en/of met een standaarddeviatie (SD) >2 zijn tijdens de werkgroep bijeenkomsten besproken (Figuur 2). Deze discussie heeft geresulteerd in definitieve besluiten die zijn weergegeven in het aanbevelingendocument zorgpaden. De zorgpaden zijn als zodanig een multidisciplinaire gewogen vertaling van bestaande richtlijnen en protocollen naar praktische werkafspraken. De zorgpaden vervangen geen richtlijn of protocol.

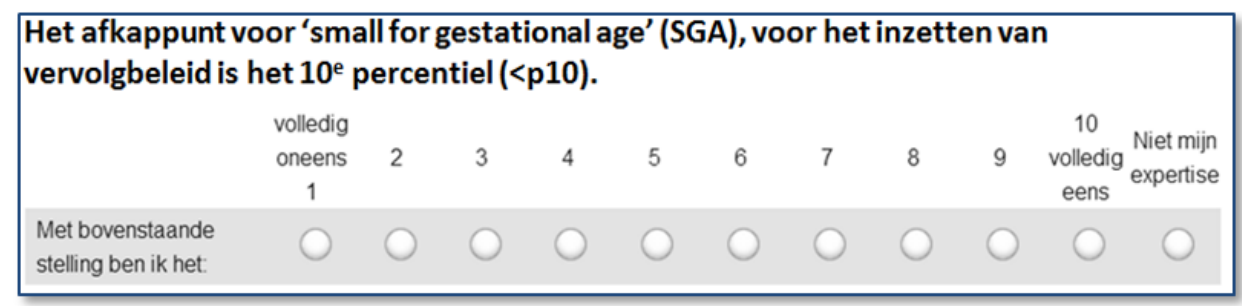

Figuur 1 Voorbeeld stelling zoals gepresenteerd via SurveyMonkey.

\begin{tabular}{|l|l|l|}
\hline Stelling & $\begin{array}{l}\text { Werkgroep } \\
\text { mean (SD) }\end{array}$ & $\begin{array}{l}\text { Achterban } \\
\text { mean (SD) }\end{array}$ \\
\hline $\begin{array}{l}\text { Het afkappunt voor 'small for gestational age' (SGA), } \\
\text { voor het inzetten van vervolgbeleid is het 10 } \\
\text { percentiel (<p10). }\end{array}$ & $7.5(2.1)$ & $6.8(3.0)$ \\
\hline
\end{tabular}

Figuur 2 Voorbeeld (fictief) resultaat stelling, zoals gepresenteerd tijdens een werkgroep bijeenkomst.

\section{KADERS VOOR OVERLEG}

Bij aanvang van de werkgroep bijeenkomsten zijn afspraken gemaakt omtrent de onderlinge omgang tijdens deze bijeenkomsten.

- De grondhouding in de werkgroepen is eerlijkheid en transparantie. Beroepsbelangen en financiële aspecten van de bedrijfsvoering horen hierbij. Indien een besluit om zorg technische redenen op enige manier een negatieve financiële consequentie zou kunnen hebben op de bedrijfsvoering, dient de betreffende zorgverlener dit kenbaar te maken. 
- De grondhouding naar elkaar toe is basale hoffelijkheid en inlevingsvermogen, waarbij je laat zien dat je haar/zijn kant ziet. Daarbij is het belangrijk elkaars belangen mee te nemen in de algemene zienswijze en de daaropvolgende besluitvorming.

- Met elkaar een veilige omgeving creëren waar in openheid gediscussieerd kan worden, met het vertrouwen dat de interne discussies niet verder gecommuniceerd worden.

- Een pragmatische aanpak: als goed onbereikbaar is, is beter beter. Als bewijs ontbreekt, wordt uitgegaan van 'best practice' op basis van de huidige stand van de wetenschap.

\section{EINDPRODUCTEN}

De eindproducten bestaan uit de literatuurdocumenten, besluitenlijsten en het aanbevelingsdocument zorgpaden.

\subsection{Literatuurdocumenten}

De literatuurdocumenten bestaan uit achtergrondinformatie uit de richtlijnen per onderwerp, de risicomatrix indien van toepassing, stellingen uit de vragenlijsten met de bijbehorende overwegingen van de werkgroep en de definitieve besluiten.

\subsection{Besluitenlijsten}

In de besluitenlijsten staan alle originele stellingen zoals deze aan alle consortiumleden zijn voorgelegd via Survey Monkey, de scores per stelling en de uiteindelijke besluiten.

\subsection{Aanbevelingsdocument zorgpaden}

Het aanbevelingendocument zorgpaden begint met een tijdlijn met daaraan gekoppeld alle gemaakte afspraken. Daarna worden per onderwerp de aanbevelingen weergegeven, zoals deze na discussie in de werkgroepen tot stand zijn gekomen. Aan het eind van enkele hoofdstukken is een samenvatting weergegeven. Overal in het aanbevelingendocument waar gynaecoloog geschreven staat, kan tevens gelezen worden dienstdoende arts-assistent en/of klinisch verloskundige onder verantwoordelijkheid van de gynaecoloog. 


\section{JURIDISCHE BETEKENIS}

Het aanbevelingsdocument zorgpaden bevat geen wettelijke voorschriften en is géén richtlijn, noch een protocol, maar bevat aanbevelingen. De aanbevelingen komen voort uit de definitieve besluiten, zoals deze genomen zijn tijdens de werkgroep bijeenkomsten en zijn zoveel mogelijk gebaseerd op bewijs. Indien geen bewijs voorhanden was, werd de aanbeveling op basis van consensus en ervaring van de betrokken zorgverleners gebaseerd, waarbij de mening van de achterban sterk werd meegewogen.

Zorgverleners kunnen (en moeten soms) beargumenteerd afwijken van deze aanbevelingen. Uiteraard dient dit te gebeuren in overleg met de patiënt. In de zorgpaden wordt uitgegaan van een ongecompliceerde eenlingzwangerschap, tenzij anders omschreven.

\section{TOESTEMMING ZWANGERE}

Onderstaande afspraken zijn volgens bovenstaande methodiek opgesteld en gelden voor elk zorgpad zoals beschreven in het aanbevelingendocument.

- Indien een zwangere niet akkoord is met het voorgestelde beleid, dienen alternatieve beleidsmogelijkheden en hun voor- en nadelen besproken en gedocumenteerd te worden.

(gemiddelde (SD): werkgroep 9.1 (1.0), achterban 9.0 (1.4))

- Indien een zwangere niet akkoord is met het voorgestelde beleid, dienen eventuele voor- en nadelen voor moeder en kind, ten gevolge van het niet uitvoeren of instellen van het (alternatieve) beleid, besproken en gedocumenteerd te worden.

(gemiddelde (SD): werkgroep 9.0 (1.1), achterban $9.2(1.3)$ )

- De zorgverlener dient bij een alternatief beleid, indien een zwangere niet akkoord is met het initieel voorgestelde beleid, zijn goedkeuring voor dit alternatieve beleid te documenteren.

(gemiddelde (SD): werkgroep 9.1 (1.1), achterban 8.8 (1.6))

- ledere wijziging, actie of interventie wordt voor het instellen met de zwangere (en haar partner) overlegd, gedocumenteerd en pas na akkoord uitgevoerd. (gemiddelde (SD): werkgroep 7.8 (2.7), achterban $8.2(2.1)$ )

- Indien een zwangere niet akkoord is met het voorgestelde (alternatieve) beleid, of de hulpverlener de wensen van de zwangere als te risicovol inschat, dient de 
hulpverlener overleg met een andere hulpverlener aan te bieden aan de zwangere en dit schriftelijk vast te leggen.

(gemiddelde (SD): werkgroep 8.0 (2.3), achterban 8.2 (1.9))

\section{HERZIENING}

De zorgpaden zijn met zorg samengesteld aan de hand van de recentste richtlijnen, protocollen en wetenschappelijk bewijs na weging van de mening van het gehele professionele veld en bediscussiëring van de uitkomsten door gemandateerde vertegenwoordigers. Om de zorgpaden te blijven ontwikkelen en onderhouden is structurele financiering nodig. Binnen het LOQS project ontbreekt, op dit moment, de mogelijkheid voor deze financiële ondersteuning om ontwikkeling en onderhoud te realiseren.

\section{REFERENTIES}

1. Advies Stuurgroep Zwangerschap en Geboorte, Een goed begin, december 2009.

2. Visiedocument Verloskundig Consortium Limburg, Verloskundige zorg in het Limburg Obstetric Quality System (LOQS), 01-02-2012.

3. Mandaatverklaring Verloskundig Consortium Limburg.

4. Samenstelling werkgroepen, zie addendum.

5. Koninklijke Nederlandse Organisatie van Verloskundigen, Nederlandse Vereniging voor Obstetrie en Gynaecologie, American College of Obstetricians and Gynecologists, Royal College of Obstetricians and Gynaecologists, National Institute for Health and Care Excellence. 


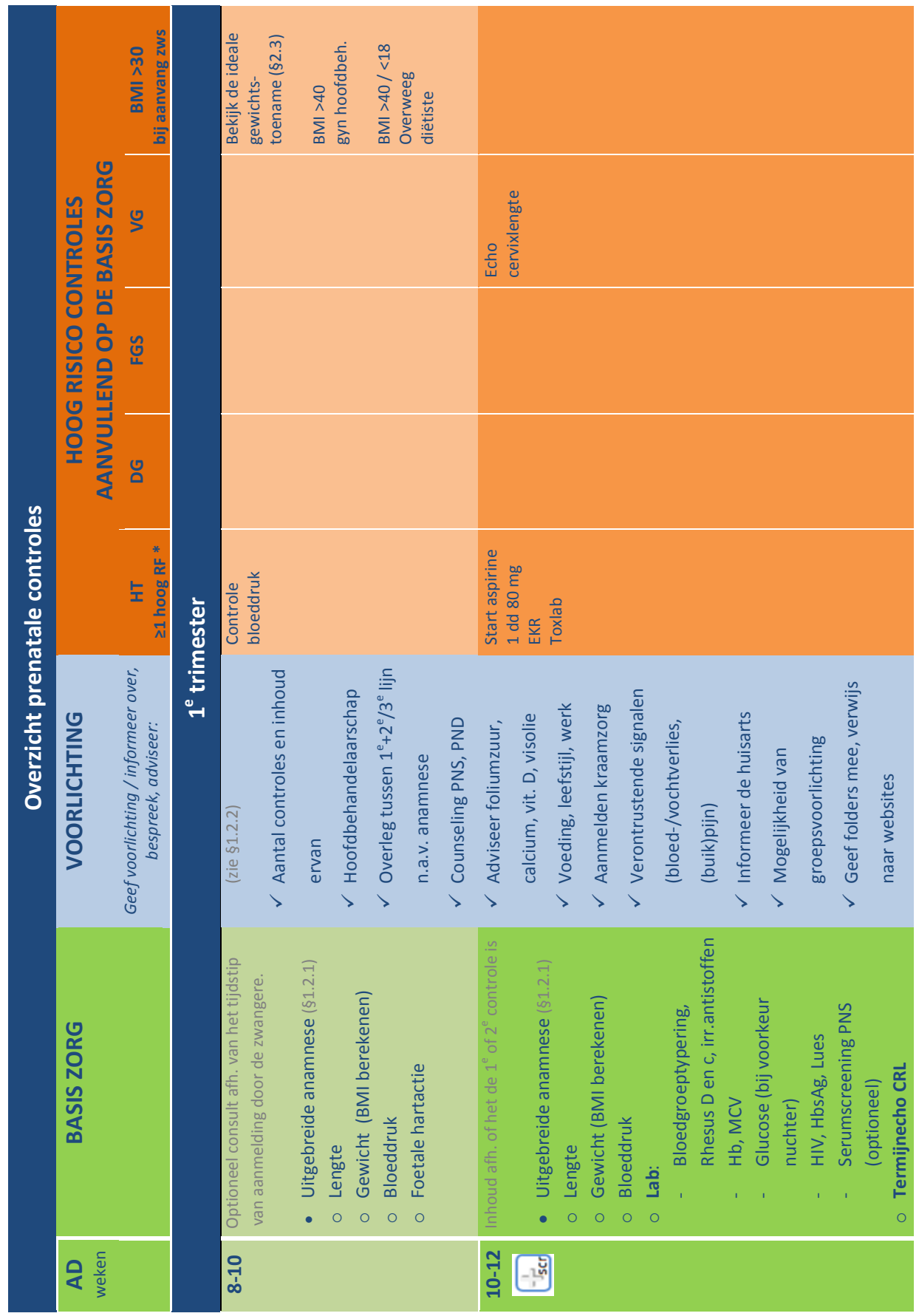




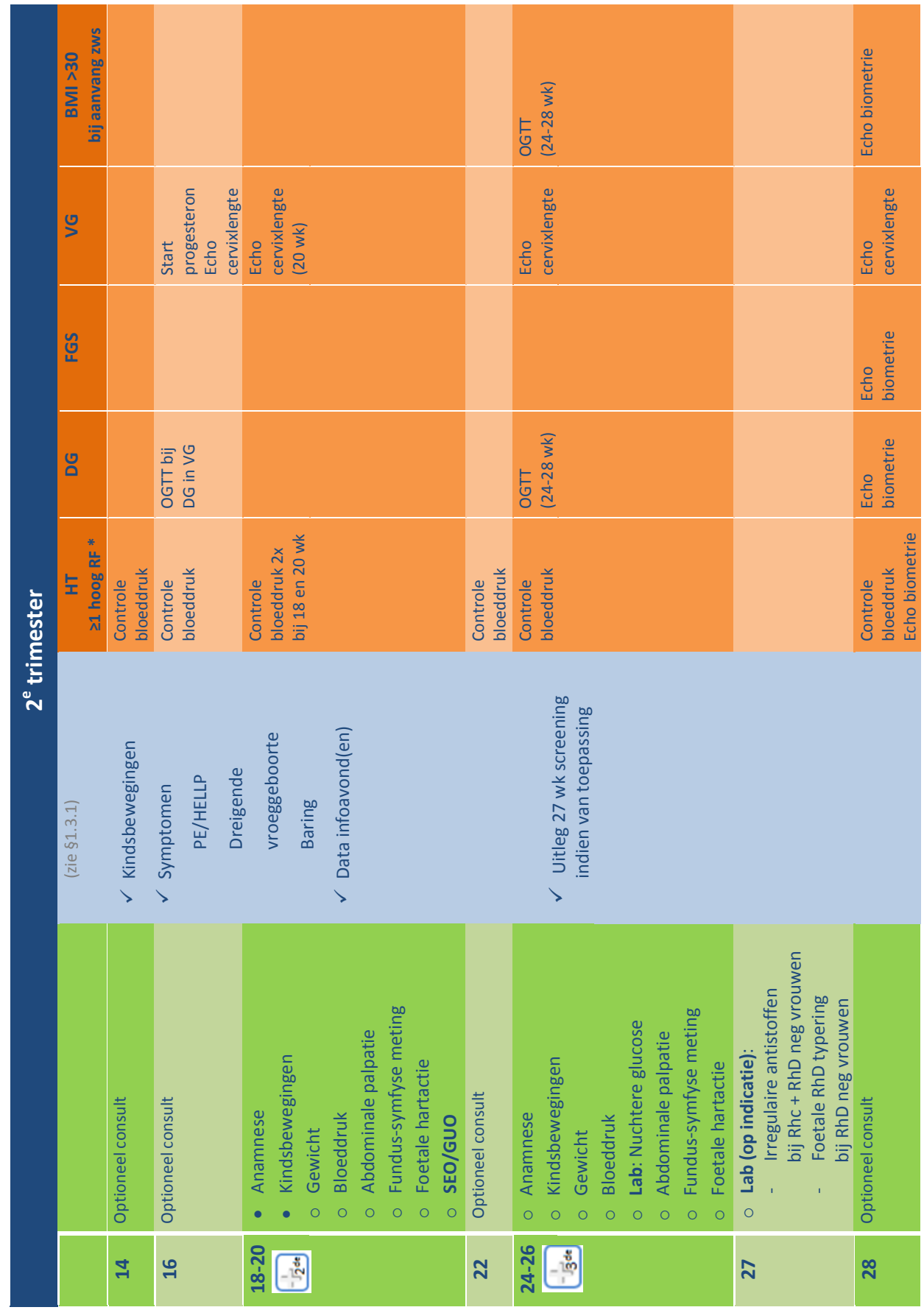




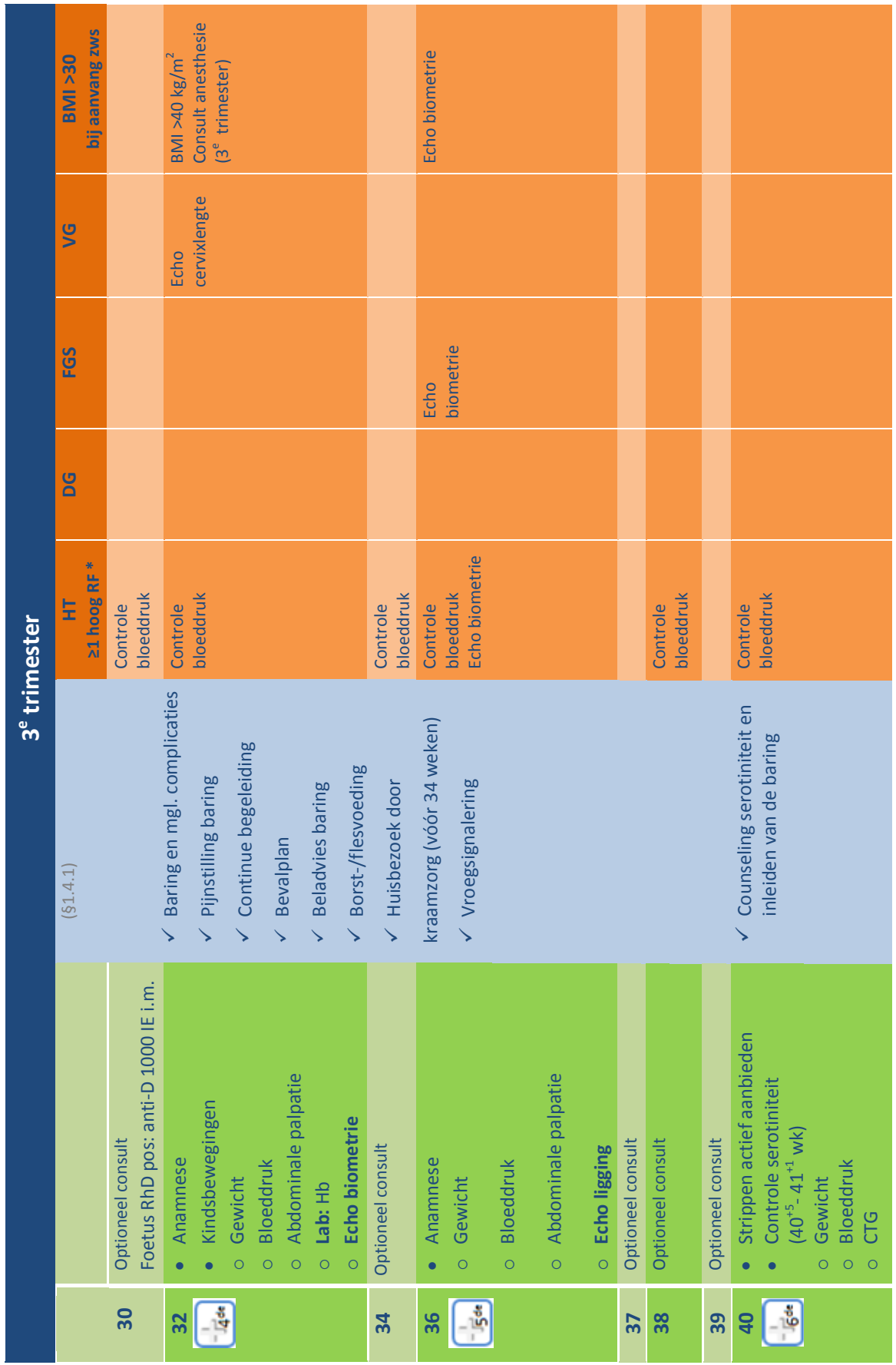




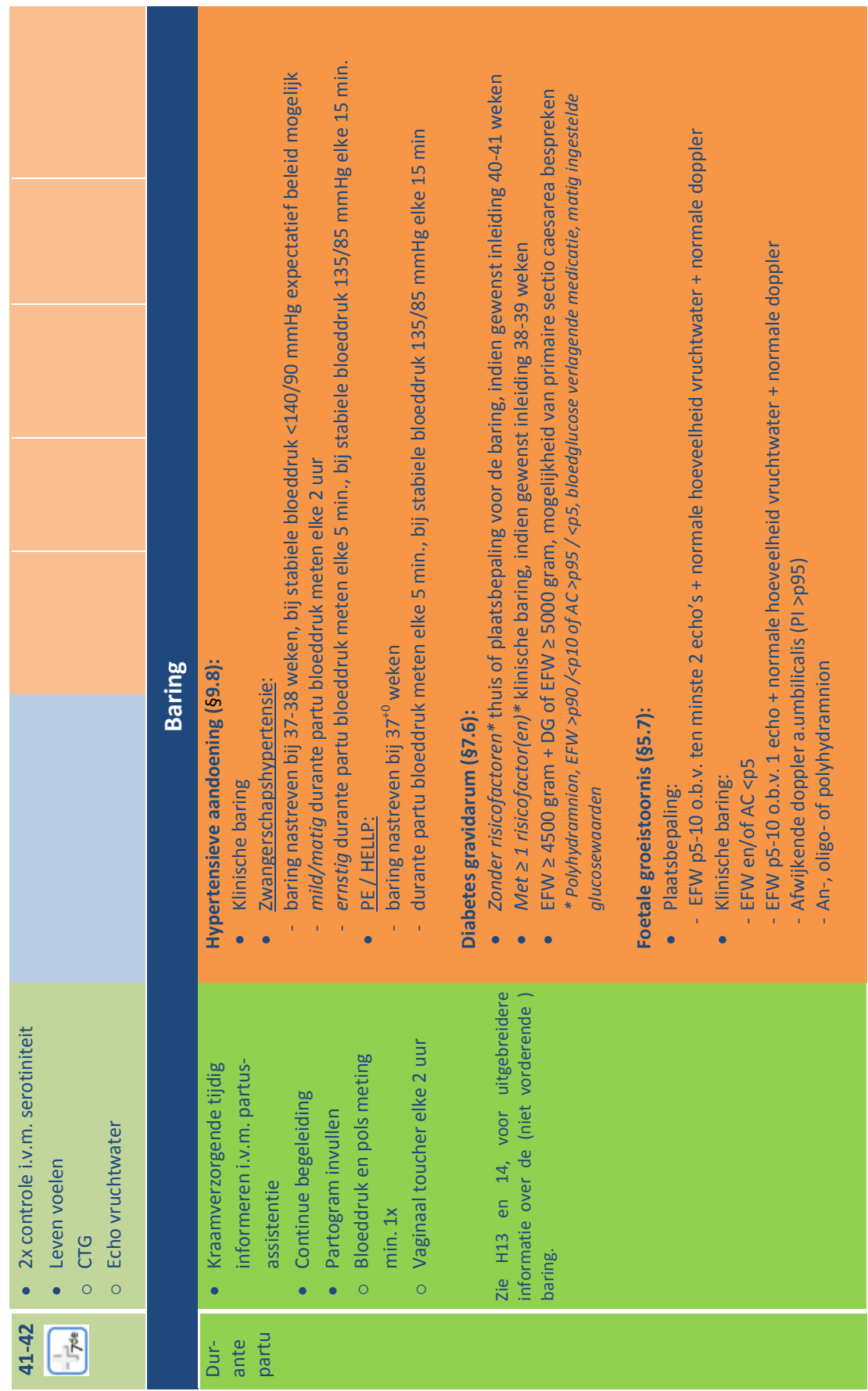




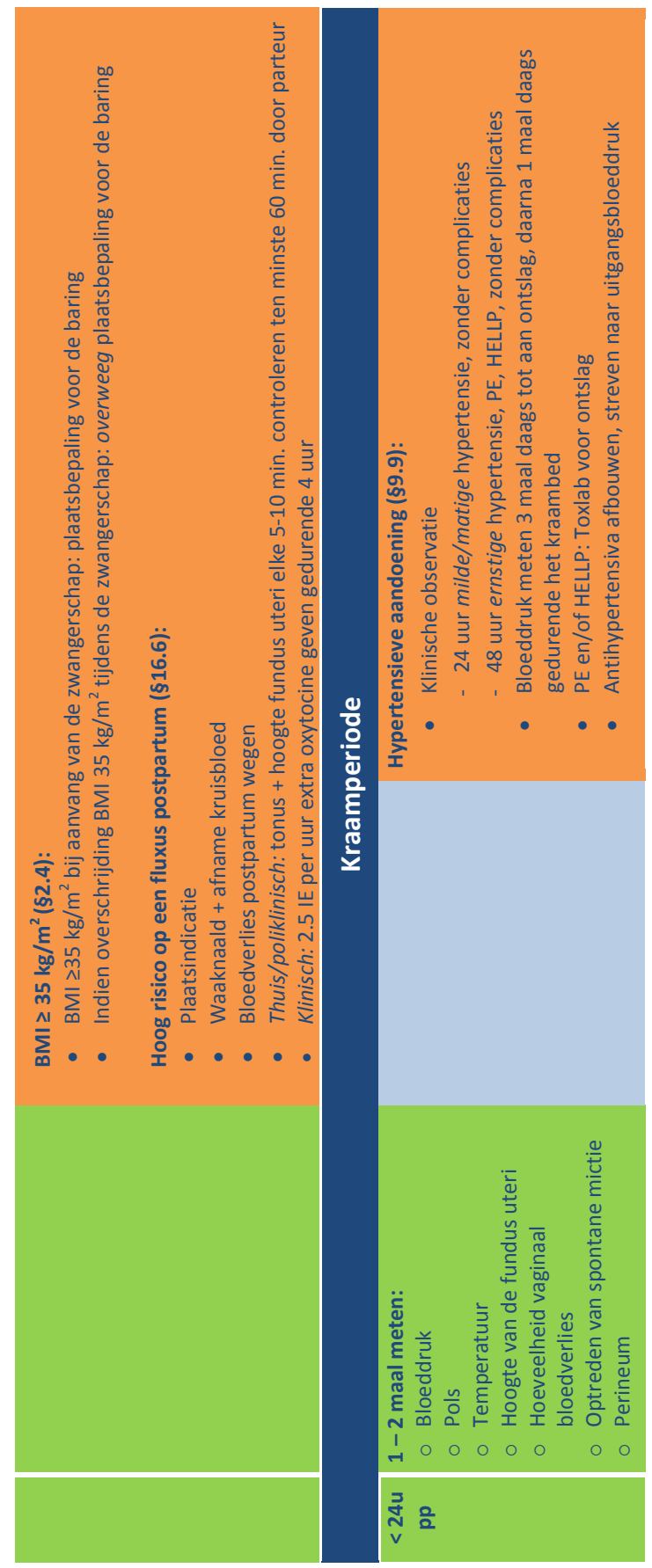



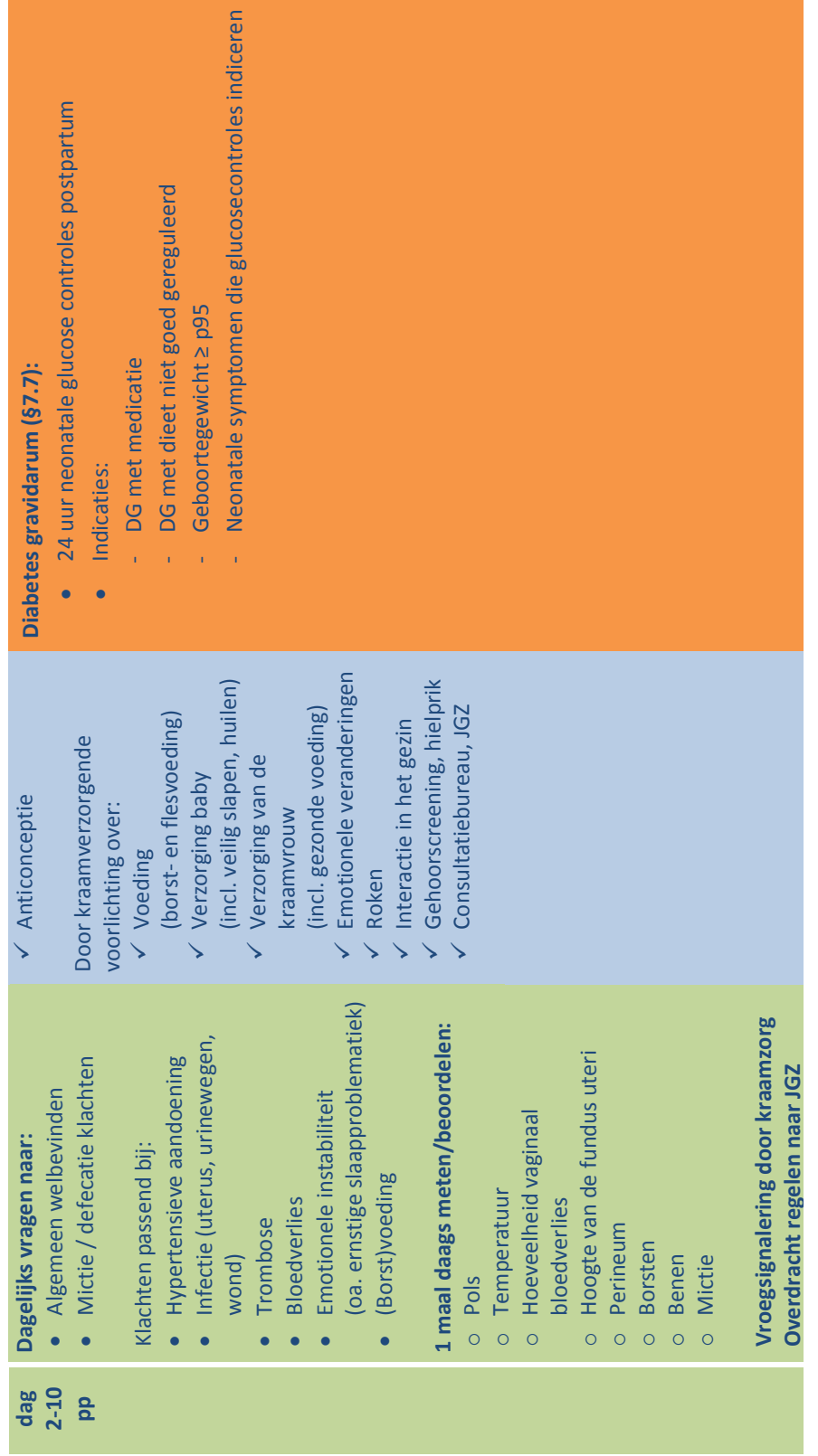


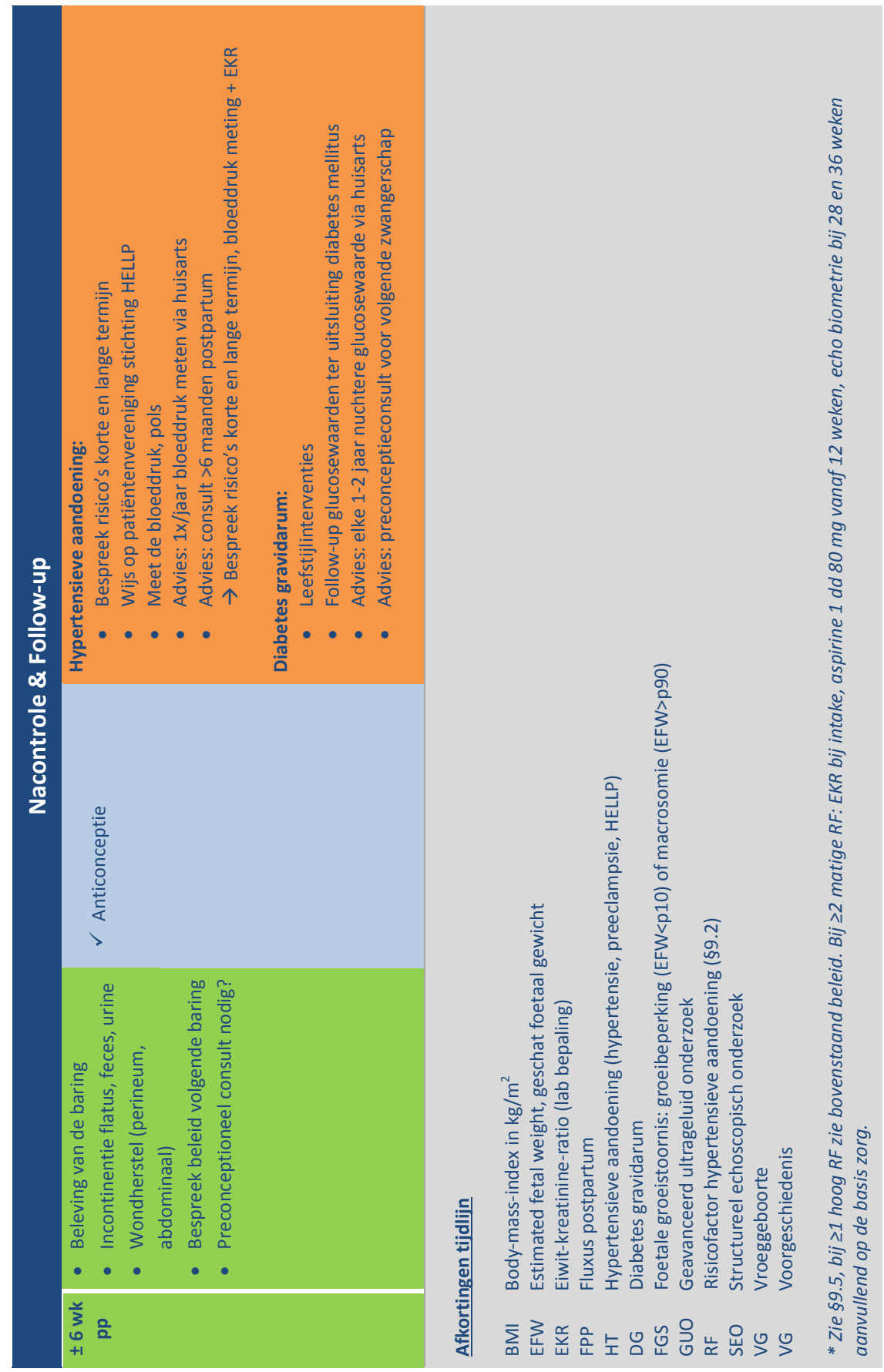




\section{BASIS PRENATALE ZORG}

\subsection{Prenatale controle (algemeen)}

Bij elke prenatale controle worden de volgende handelingen standaard uitgevoerd en gedocumenteerd:

O Maternale gewicht $(\mathrm{kg})$

○ Bloeddruk $(\mathrm{mmHg})$

- Abdominale palpatie van de uterus, hoogte fundus uteri

○ Fundus-symfyse meting (vanaf 20 weken) met meetlint $(\mathrm{cm})$

- Foetale harttonen m.b.v. doptone/echo (normale frequentie en ritme)

\subsection{Eerste trimester $\left(\mathrm{t} / \mathrm{m} 13^{+6}\right.$ weken)}

\subsubsection{Anamnese eerste trimester}

- Intake:

$>$ Algemene voorgeschiedenis

- Leeftijd

O Etniciteit

- Intoxicaties (roken, alcohol, drugs) op dit moment en in het verleden

- Allergieën (waarvoor en wat voor reactie)

○ Vaccinaties (oa. waterpokken)

- Medicatie (op recept en zelfzorg)

○ Voedingspatroon, soort voeding

○ Beweging, sport (welke sport, uren per week)

○ Zorgverzekering

$>$ Medische voorgeschiedenis

○ Maternale aangeboren afwijkingen

○ Ziekten

- Operaties

$>$ Obstetrische voorgeschiedenis

- Verloop zwangerschap(pen), baring en kraambed (zelfde partner?)

$>$ Psychosociale voorgeschiedenis

- Behandeling (geweest) bij een psycholoog, psychiater of huisarts in verband met een psychisch probleem 
$>$ Seksueel overdraagbare aandoeningen (SOA's) en negatieve seksuele ervaringen

$>$ Partner anamnese

○ Etniciteit

- Intoxicaties (roken, alcohol, drugs) op dit moment en in het verleden

○ Eerdere kind(eren)

○ Ziekten

- Aangeboren afwijkingen

$>$ Familie anamnese

○ Ziekten

- Aangeboren afwijkingen

- Aanvullende anamnese tijdens het $1^{\mathrm{e}}$ trimester (mag ook tijdens intake):

○ Leef- en woonomstandigheden

- Sociaal netwerk

○ Werk en opleidingsniveau

○ Huiselijk geweld

- Betrokkenheid van externe instanties* uitvragen en controleren of instanties betrokken dienen te worden.

* Bijvoorbeeld prezorg (extramurale begeleiding door een verpleegkundige), maatschappelijk werk, jeugdzorg, schuldsanering et cetera.

\subsubsection{Voorlichting \& advies eerste trimester}

Alle mondelinge voorlichting zal, waar mogelijk, ondersteund worden met schriftelijk materiaal in de vorm van een folder of verwijzing naar een website.

Geef voorlichting/informeer de zwangere en haar partner over:

$\checkmark$ Het aantal te verwachten zwangerschapscontroles en de inhoud ervan (o.b.v. anamnese, risico uit predictiemodel en zorgpad) Zie tijdlijn pagina 10-14.

$\checkmark$ Hoofdbehandelaarschap:

$\checkmark \quad$ Uitleggen dat we streven naar gezamenlijke zorg door de verloskundige en gynaecoloog. Hoofdbehandelaarschap is afhankelijk van het risicoprofiel van de individuele zwangere en is (o.a.) gebaseerd op de uitkomst van het 
predictiemodel voortkomend uit de Expect-studie. Bij voorkeur vindt er een gezamenlijk overleg plaats, waarin de zwangere besproken wordt naar aanleiding van de intake en waar bepaald wordt welk zorgpad zij krijgt.

$\checkmark$ Counseling prenatale screening (PNS) en diagnostiek (PND) vóór 11 weken zwangerschap (uitvoering serumscreening 9-14 weken, nekplooi meting 11-14 weken, SEO/GUO 18-20 weken)

$\checkmark$ Voeding en supplementen (vitamines)

$\checkmark$ Leefstijl (o.a. sport, dagelijkse activiteiten)

$\checkmark$ Kraamzorg (informeren huisbezoek, zie H17).

$\checkmark$ Voorlichting door kraamcentrum. Alle patiënten krijgen het advies om kraamzorg aan te vragen en, indien niet in behandeling in de eerste lijn, een verloskundige te benaderen voor de kraambedcontroles.

$\checkmark$ Contact opnemen met de hoofdbehandelaar bij verontrustende signalen (o.a. vaginaal bloed- en/of vochtverlies, (buik)pijnklachten).

$\checkmark$ De hoofdbehandelaar informeert de huisarts over de zwangerschap.

$\checkmark$ De mogelijkheid van voorlichting in groepsverband (infoavond baring, borstvoeding etc.).

Adviseer aan alle zwangeren:

○ Foliumzuur 0.4-0.5 mg/dag vanaf 4 weken vóór de conceptie t/m 10 weken zwangerschap, bij spina bifida in de anamnese $5 \mathrm{mg} /$ dag vanaf ten minste 3 maanden vóór de conceptie $\mathrm{t} / \mathrm{m} 14$ weken zwangerschap

- Calcium 1 gram/dag ter preventie van preeclampsie (tabletvorm of ten minste 5 glazen melk)

Let op! Bij calcium in combinatie met ferrofumaraat en/of thyrax gebruik: calcium dient ten minste 4 uur voor of na ferrofumaraat/thyrax ingenomen te worden i.v.m. de opnamecapaciteit.

- Vitamine D 10 microgram/dag

- Visolie 1 capsule/dag (geen combinatiepreparaat)

\subsubsection{Onderzoek eerste trimester}

\section{- Intake:}

○ Lengte, gewicht (bereken BMI) (zie H2) 
○ Bloeddruk (mmHg) (zie H9)

- Abdominale palpatie van de uterus

- Foetale harttonen beoordelen d.m.v. doptone/echo (slagen/min)

- Lab:

○ Bloedgroeptypering (bloedgroep, Rhesus D + c, irregulaire antistoffen)

○ Hemoglobinewaarde $(\mathrm{Hb})$

- MCV waarde uitsluitend in combinatie met een veneuze $\mathrm{Hb}$ bepaling

- Glucose bepaling (random bepaling, maar bij voorkeur nuchter in veneus plasma)

○ HIV

○ Hepatitis B (HbsAg)

- Lues (syphilis)

○ Rubella (optioneel)*

* Rubellascreening vindt alleen plaats bij zwangere vrouwen waarvan het onwaarschijnlijk/ onzeker is dat zij in het verleden gevaccineerd zijn.

\subsubsection{Echo eerste trimester}

- Termijnbepaling

○ Bij voorkeur bij 10-12 weken amenorroe door meting van de kopromplengte (crownrump length, CRL).

\subsection{Tweede trimester $\left(14^{+0}-26^{+6}\right.$ weken)}

\subsubsection{Anamnese tweede trimester}

- Algemeen welbevinden

- Kindsbewegingen

- Symptomen/klinische verschijnselen passend bij preeclampsie/HELLP syndroom

- Symptomen/klinische verschijnselen passend bij een dreigende vroeggeboorte

\subsubsection{Voorlichting \& advies tweede trimester}

Alle mondelinge voorlichting zal, waar mogelijk, ondersteund worden met schriftelijk materiaal in de vorm van een folder of verwijzing naar een website.

Geef voorlichting/informeer de zwangere en haar partner over: 
$\checkmark$ Kindsbewegingen

$\checkmark$ Symptomen/klinische verschijnselen passend bij preeclampsie/HELLP syndroom

$\checkmark$ Symptomen/klinische verschijnselen passend bij een dreigende vroeggeboorte

$\checkmark$ Voorbereiding op de baring (oa. zwangerschapsgym)

\subsubsection{Onderzoek tweede trimester}

○ Gewicht $(\mathrm{kg})$

○ Bloeddruk $(\mathrm{mmHg})$

- Abdominale palpatie van de uterus

- Fundus-symfyse meting $(\mathrm{cm})$ vanaf 20 weken

- Foetale harttonen beoordelen d.m.v. doptone/echo (slagen/min)

- Lab: nuchtere glucose bepaling (veneus plasma)

\subsubsection{Echo tweede trimester}

- Termijnbepaling (indien $1^{\mathrm{e}}$ controle na 13 weken zwangerschap)

○ $1^{\mathrm{e}}$ controle tussen 13-24 weken

- Termijnbepaling bij een eerste controle na 13 weken amenorroe vindt plaats door meting van de kopromplengte (crownrump length, $C R L$ ) in combinatie met de distantia biparietalis (DBP) en de hoofdomtrek (head circumference, $\mathrm{HC})$.

- $1^{\mathrm{e}}$ controle na 24 weken

- Bij een ongecontroleerde zwangerschap ontdekt na 24 weken amenorroe, wordt de termijn bepaald op basis van echo biometrie in combinatie met een cerebellum meting.

- Structureel echoscopisch onderzoek (SEO, 20 weken echo)

- SEO verricht bij een termijn van 18 - 20 weken. De gemeten percentielen tijdens het SEO, worden aangehouden als referentiewaarde voor het individuele groeipotentieel.

\subsection{Derde trimester $\left(\geq 27^{+0}\right.$ weken)}

\subsubsection{Anamnese derde trimester}

- Algemeen welbevinden 
- Kindsbewegingen

- $\quad$ Symptomen/klinische verschijnselen passend bij preeclampsie/HELLP syndroom

- Symptomen/klinische verschijnselen passend bij een dreigende vroeggeboorte

\subsubsection{Voorlichting \& advies derde trimester}

Alle mondelinge voorlichting zal, waar mogelijk, ondersteund worden met schriftelijk materiaal in de vorm van een folder of verwijzing naar een website.

Geef voorlichting/informeer de zwangere en haar partner over:

$\checkmark$ Borst-en flesvoeding

$\checkmark$ De baring en mogelijke baringscomplicaties

$\checkmark$ Pijnstilling tijdens de baring

$\checkmark$ Continue begeleiding tijdens de baring (door kraamverzorgende)

$\checkmark$ Bevalplan; aanbevolen wordt dat alle zwangeren een bevalplan invullen en bespreken met hun hoofdbehandelaar.

\subsubsection{Onderzoek derde trimester}

○ Gewicht $(\mathrm{kg})$

○ Bloeddruk $(\mathrm{mmHg})$

- Abdominale palpatie van de uterus (incl. aard en indaling voorliggend deel)

- Fundus-symfyse meting $(\mathrm{cm})$ vanaf 20 weken

- Foetale harttonen beoordelen d.m.v. doptone/echo (slagen/min)

- Lab: Hemoglobinewaarde $(\mathrm{Hb})$ bepalen (veneus/capillair), MCV uitsluitend in combinatie met een veneuze $\mathrm{Hb}$ bepaling.

\subsubsection{Echo derde trimester}

\section{- Biometrie}

Standaard verricht bij een termijn van 32 weken.

\section{- Liggingsecho}

In het $3^{\mathrm{e}}$ trimester (rond 36 weken) dient een liggingsecho plaats te vinden.

Melden aan de zwangere dat uitsluitend gekeken wordt naar de ligging en géén biometrie gemeten zal worden, tenzij daar een indicatie voor bestaat. 


\subsection{Uitvoering van onderzoeken}

\subsubsection{Bloeddrukmeting}

- Bij elke prenatale controle wordt de bloeddruk gemeten.

- Meten van de bloeddruk geschied als volgt:

- na enkele minuten rustig zitten

- handmatig/automatisch

- zwangere in zittende houding

- niet praten tijdens de meting

- meet aan de rechter arm ter hoogte van het hart - tenzij het verschil tussen beide armen

$0 \quad \geq 10 \mathrm{mmHg}$ is, houdt in dat geval de hoogste waarde aan

- De hartfrequentie (pols) dient in combinatie met de bloeddruk gemeten te worden bij alle vrouwen met hypertensie en/of klachten (o.a. gejaagdheid).

\subsubsection{Abdominale palpatie}

- Abdominale palpatie voor uitwendige beoordeling van de groei, dient standaard verricht te worden bij elke prenatale controle.

\subsubsection{Fundus-symfyse meting}

- De fundus-symfyse meting voor uitwendige beoordeling van de groei, wordt:

- standaard verricht bij elke prenatale controle vanaf 20 weken

- met een minimaal interval van 2 weken

○ verricht bij een zwangere in liggende houding met een lege blaas

- gemeten van symfyse naar fundus of van fundus naar symfyse

- uitgedrukt in centimeters

Als de fundus-symfyse meting $+3 \mathrm{~cm}$ dan wel $-3 \mathrm{~cm}$ afwijkt t.o.v. de normaalwaarde in centimeters (zie Figuur 3), wordt vervolgonderzoek ingezet. Hierbij kan gedacht worden aan een herhaling van de meting op korte termijn of een echo biometrie. 


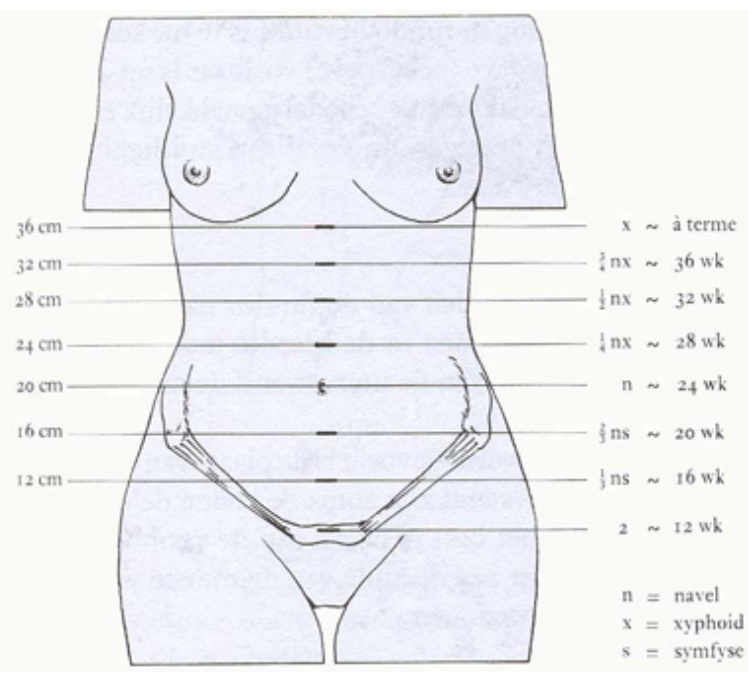

Figuur 3 Heineman e.a., Obstetrie en gynaecologie, 2004.

\subsubsection{Echo biometrie}

- Echo biometrie wordt standaard verricht bij 20 + 32 weken zwangerschap door een daartoe bevoegd en bekwaam persoon.

- Een foetale groeistoornis kan het beste gediagnosticeerd worden aan de hand van het geschat foetale gewicht (estimated fetal weight, EFW), bepaald door middel van een echo.

- Echo biometrie wordt verricht met een minimaal interval van 2 weken.

- De foetale groei wordt uitgezet op populatiecurves, groeicurves gebaseerd op gegevens van de algemene populatie.

NB 1. Gezien het hoge percentage vrouwen dat kiest voor een SEO bij 20 weken, is deze echo opgenomen als zijnde standaard zorg. Het besluit 'biometrie bij 32 weken' zal geëvalueerd worden als de resultaten van de IRIS-studie bekend zijn.

NB 2. Op het moment dat de GROW curves gevalideerd zijn voor de NL populatie, zal deze curve ter besluitvorming aan de werkgroep worden voorgelegd.

\subsubsection{Eiwit-kreatinine-ratio}

- Als diagnostische test voor proteïnurie tijdens de zwangerschap, wordt primair de eiwit-kreatinine-ratio (EKR) bepaald in de urine door een lab bepaling (niet d.m.v. stick). 


\section{OBESITAS}

\subsection{Definitie obesitas}

- Obesitas wordt gedefinieerd als een body-mass-index (BMI) $\geq 30 \mathrm{~kg} / \mathrm{m}^{2}$.

\subsection{Detectie obesitas}

- Alle zwangeren dienen bij elke prenatale controle gewogen te worden (zie H1).

\subsection{Beleid zwangerschap obesitas}

\section{- Ideale gewichtstoename}

- Er wordt in eerste instantie uitgegaan van de BMI bij aanvang van de zwangerschap.

- Indien de ideale gewichtstoename (Tabel 1) tijdens de zwangerschap overschreden wordt, wordt het BMI opnieuw berekend en bekeken of het beleid voor de zwangerschap en/of baring aangepast dient te worden.

Tabel 1 Gewichtstoename tijdens de zwangerschap, Institute of medicine, Weight Gain During Pregnancy Reexamining the Guidelines, 2009.

\begin{tabular}{|cccc|}
\hline \multicolumn{4}{|c|}{ Ideale gewichtstoename tijdens de zwangerschap } \\
\hline Categorie & $\begin{array}{c}\text { BMI bij aanvang van } \\
\text { de zwangerschap }\end{array}$ & $\begin{array}{c}\text { Ideale gewichts-toename } \\
\text { tijdens } \\
\text { de zwangerschap } \\
12.5-18 \mathrm{~kg}\end{array}$ & $\begin{array}{c}\text { Gemiddelde gewichts- } \\
\text { toename per week } \mathbf{2}^{\mathrm{e}} \boldsymbol{\beta}^{\mathbf{e}} \\
\text { trimester (spreiding in } \mathbf{~ k g}) \\
0.5 \mathrm{~kg}(0.5-0.6)\end{array}$ \\
Ondergewicht & $\mathrm{BMI}<18.5 \mathrm{~kg} / \mathrm{m}^{2}$ & $11.5-16 \mathrm{~kg}$ & $0.5 \mathrm{~kg}(0.4-0.5)$ \\
Normaal gewicht & $\mathrm{BMI} 18.5-24.9 \mathrm{~kg} / \mathrm{m}^{2}$ & $7-11.5 \mathrm{~kg}$ & $0.3 \mathrm{~kg}(0.2-0.3)$ \\
Overgewicht & $\mathrm{BMI} 25.0-29.9 \mathrm{~kg} / \mathrm{m}^{2}$ & $\begin{array}{c}5-9 \mathrm{~kg} \\
\text { niet afvallen }\end{array}$ & $0.2 \mathrm{~kg}(0.2-0.3)$ \\
\hline Obesitas & $\mathrm{BMI} \geq 30 \mathrm{~kg} / \mathrm{m}^{2}$ & &
\end{tabular}

- Hoofdbehandelaarschap

- Indien tijdens de zwangerschap de BMI $40 \mathrm{~kg} / \mathrm{m}^{2}$ overschrijdt, vindt overdracht van zorg plaats naar de gynaecoloog.

\section{- Geavanceerd ultrageluid onderzoek}

- Bij vrouwen met een $\mathrm{BMI} \geq 40 \mathrm{~kg} / \mathrm{m}^{2}$ waarbij sprake is van slechte beeldvorming bij het SEO, wordt een GUO-II geadviseerd. 
- $\quad$ Orale glucose tolerantie test (OGTT)

- Een $\mathrm{BMI} \geq 30 \mathrm{~kg} / \mathrm{m}^{2}$ is reden voor een OGTT bij 24-28 weken zwangerschap.

- Consult anesthesie

- Tijdens de zwangerschap wordt een consult bij de anesthesist geadviseerd in het $3^{\mathrm{e}}$ trimester van de zwangerschap, aan vrouwen met een BMI $\geq 40 \mathrm{~kg} / \mathrm{m}^{2}$ bij aanvang van de zwangerschap of overschrijding van deze BMI waarde tijdens de zwangerschap.

- Tijdens dit consult wordt onder andere de toegankelijkheid van de luchtweg beoordeeld en de risico's en mogelijkheden ten aanzien van spinale/epidurale anesthesie toegelicht.

N.B. Voor uitgebreidere informatie en overige indicaties m.b.t. het consult anesthesie verwijzen wij u naar de besluitenlijst anesthesie, te vinden in hoofdstuk 13 van het document 'Besluitenlijsten werkgroepen'.

\section{- Consult diëtiste}

- Tijdens de zwangerschap kan begeleiding van een diëtiste overwogen worden, voor vrouwen met een $\mathrm{BMI} \geq 40 \mathrm{~kg} / \mathrm{m}^{2}$ en een $\mathrm{BMI}<18 \mathrm{~kg} / \mathrm{m}^{2}$.

- Indien de zwangere afwijkt van de ideale gewichtstoename (te grote toename, geen of te geringe toename) (Tabel 1) vóór het bereiken van de a terme periode $\left(<37^{+0} \mathrm{wk}\right)$, bij ten minste 2 controles met een interval van 2 weken, kan begeleiding door een diëtiste overwogen worden.

- Extra echo biometrie

- Een $\mathrm{BMI} \geq 30 \mathrm{~kg} / \mathrm{m}^{2}$ is een reden om de groei intensiever te volgen door middel van een extra echo biometrie bij 28 en 36 weken (naast de standaard echo's biometrie bij 20 en 32 weken).

\subsection{Beleid baring obesitas}

- Een plaatsbepaling voor de baring wordt afgesproken bij vrouwen met een BMI $\geq 35 \mathrm{~kg} / \mathrm{m}^{2}$ bij aanvang van de zwangerschap.

Indien tijdens de zwangerschap de BMI de grens van $35 \mathrm{~kg} / \mathrm{m}^{2}$ overschrijdt, kan een plaatsbepaling voor de baring overwogen worden. Hierover is geen consensus bereikt binnen de groep. 


\section{HYPEREMESIS GRAVIDARUM}

\subsection{Definitie hyperemesis gravidarum}

- Hyperemesis gravidarum wordt gedefinieerd als overmatig braken tijdens de zwangerschap. Hierbij kan ketonurie aanwezig zijn, gewichtsverlies en het dagelijks functioneren van de zwangere kan belemmerd zijn. Gezien de heterogeniteit van dit ziektebeeld, hebben wij de definitie niet aan de regio voorgelegd. De inschatting of er sprake is van hyperemesis gravidarum, zal door de hoofdbehandelaar op basis van de kliniek en ervaring bepaald worden.

\subsection{Detectie hyperemesis gravidarum}

- De detectie van hyperemesis gravidarum geschiedt op basis van de anamnese, eventueel aangevuld door bepaling van ketonen in de urine, gewichtsverlies, de aanwezigheid van klinische symptomen van dehydratie (bijv. oligurie, afgenomen turgor) en/of een elektrolytstoornis aangetoond door lab bepaling.

\subsection{Beleid hyperemesis gravidarum}

- Voedingsadviezen door de hoofdbehandelaar.

- Gember (bijvoorbeeld 4dd $250 \mathrm{mg}$ ) is de niet-medicamenteuze behandeloptie van voorkeur bij hyperemesis gravidarum.

- Emesafene (12.5 mg meclozine $+25 \mathrm{mg}$ pyridoxine, 3dd 1 zetpil) of primperan (3dd 10-20 mg zetpil) zijn de anti-emetica van voorkeur bij hyperemesis gravidarum.

- De inschatting of een opname noodzakelijk is, wordt door de hoofdbehandelaar gemaakt.

\section{- Bij opname i.v.m. hyperemesis gravidarum:}

○ 2x per week wegen.

- Dagelijks lab controle indien sprake is van een elektrolytstoornis. Lab controle kan bestaan uit bepaling van het hemoglobine, lever- en nierfunctie, elektrolyten, schildklierfunctie.

- Intraveneuze vochttoediening volgens lokaal protocol.

- Sondevoeding overwegen, indien tijdens opname géén verbetering optreedt binnen 48 uur.

NB. Zodra de resultaten van de MOTHER trial bekend zijn, wordt dit besluit opnieuw geëvalueerd. 


\section{MEERLINGZWANGERSCHAP}

\subsection{Definitie meerlingzwangerschap}

- Een meerlingzwangerschap wordt gedefinieerd als een zwangerschap van meer dan één foetus, waarbij de dichoriale-diamniotische tweelingzwangerschap het meest frequent voorkomt, gevolgd door de monochoriale-diamniotische en mono-amniotische zwangerschap.

\subsection{Detectie meerlingzwangerschap}

- De diagnose meerlingzwangerschap wordt echoscopisch gesteld, evenals de bepaling van de chorioniciteit.

\subsection{Beleid zwangerschap meerling}

- Een tweeling zwangerschap is een reden voor:

- Vroege verwijzing (bij voorkeur <10 weken zwangerschap) naar de gynaecoloog (= hoofdbehandelaar).

○ Bepaling van de chorioniciteit in het ziekenhuis.

- SEO bij een dichoriale tweelingzwangerschap.

- GUO bij een monochoriale tweelingzwangerschap.

○ Cervixlengtemeting gelijktijdig met de 20 weken echo (SEO/GUO)

- Het gebruik van een (Arabin) pessarium dient met de zwangere besproken te worden, indien sprake is van een tweelingzwangerschap en een cervixlengte $<38 \mathrm{~mm}$ tussen 16-22 weken zwangerschap.

Hierbij dient uitgelegd te worden dat de precieze afkapwaarde voor het gebruik van een pessarium nog onbekend is, maar dat een pessarium mogelijk wel effectief is in het voorkomen van vroeggeboorte.

- Echo

- Bij dichoriale tweelingen dient ten minste elke 4 weken een echo biometrie gemaakt te worden vanaf een termijn van 14-16 weken.

- Bij monochoriale tweelingen dient ten minste elke 2 weken een echo gemaakt te worden vanaf een termijn van 14-16 weken, bestaande uit:

- Biometrie

- Vruchtwater

- Lokalisatie en beweeglijkheid van het tussenschot 
- Maag- en blaasvulling

- Dopplermetingen (a.umbilicalis, a.cerebri media)

- Afwijkende dopplermetingen en/of geen mogelijkheid tot het adequaat meten van de dopplers bij een monochoriale meerlingzwangerschap, vereisen verwijzing naar een perinatologisch centrum.

\section{- Tweeling Transfusie Syndroom}

- Een patiënte die zwanger is van een monochoriale tweeling, dient geïnstrueerd te worden om bij plotselinge toename van de buikomvang zo spoedig mogelijk (<24u) contact op te nemen met haar hoofdbehandelaar.

- Bij een verdenking op het Tweeling Transfusie Syndroom (TTS) vanaf Quintero stadium 1 (Tabel 2), vindt overleg met een perinatologisch centrum plaats.

- Laserablatie is de behandeloptie van eerste keus bij een ernstige TTS vóór 26 weken zwangerschap (in Leiden of Leuven).

Tabel 2 Quintero Stadia, RCOG Management monochorionic twin pregnancy, 2008

\begin{tabular}{|ll|}
\hline Stage & Classification \\
\hline I & $\begin{array}{l}\text { There is a discrepancy in amniotic fluid volume with oligohydramnios of a maximum vertical pocket (MVP) } \leq 2 \mathrm{~cm} \text { in } \\
\text { one sac and polyhydramnios in other } \operatorname{sac}(M V P \geq 8 \mathrm{~cm}) \text {. The bladder of the donor twin is visible and Doppler studies } \\
\text { are normal }\end{array}$ \\
The bladder of the donor twin is not visible (during length of examination, usually around 1 hour) but Doppler studies \\
are not critically abnormal
\end{tabular}

\subsection{Beleid baring meerling}

- Inleiden van de baring (indien $1^{\mathrm{e}}$ kind in hoofdligging):

○ dichoriale tweeling $40^{+0}$ weken, tenzij discordante groei (>20\% verschil) dan $38^{+0}$ weken

$\circ$ monochoriale tweeling $36^{+0}$ weken

- Electieve sectio caesarea na voorbereiding met corticosteroïden:

- monoamniotische tweeling $32^{+0}-34^{+0}$ weken 


\section{FOETALE GROEIBEPERKING}

\subsection{Definities}

\section{- Small for gestational age}

Het afkappunt voor 'small for gestational age' (SGA), voor wat betreft het inzetten van vervolgbeleid, is een geschat foetaal gewicht onder het $10^{\mathrm{e}}$ percentiel $(\mathrm{EFW}<\mathrm{p} 10)$ en/of een foetale abdominale omtrek onder het $5^{\mathrm{e}}$ percentiel $(\mathrm{AC}<\mathrm{p} 5)^{1}{ }^{1}$

- Afbuigende groei

Er is mogelijk sprake van een afbuigende groei waarbij vervolgbeleid ingezet moet worden, indien de groei in de curve meer dan:

○ 20 percentiel verandert in $\mathbf{2}$ weken of

$\circ \mathbf{4 0}$ percentiel verandert in $\mathbf{1 0}$ weken

- Vruchtwater meting

De hoeveelheid vruchtwater wordt uitgedrukt in diepste vruchtwaterpoel (single deepest pocket, SDP) of vruchtwaterindex (amniotic fluid index, AFI).

O Oligohydramnion: $\quad \mathrm{SDP}<2 \mathrm{~cm}$ of $\mathrm{AFI}<8 \mathrm{~cm}$

- Polyhydramnion: $\mathrm{SDP}>8 \mathrm{~cm}$ of $\mathrm{AFI}>24 \mathrm{~cm}$

- Doppler meting

De doppler is afwijkend indien een pulsatility index (PI):

o. umbilicalis (a.umb) boven het $95^{\mathrm{e}}$ percentiel $(\mathrm{PI}>\mathrm{p} 95$ ) wordt gemeten onafhankelijk van de einddiastolische flow (EDF).

- $\quad$ arteria cerebri media $(\mathrm{ACM})$ onder het $5^{\mathrm{e}}$ percentiel $(\mathrm{PI}<\mathrm{p} 5)$ wordt gemeten

\subsection{Risicofactoren foetale groeibeperking}

- Zwangere vrouwen met één of meer van onderstaande risicofactoren, worden als hoog risicogroep beschouwd voor een foetale groeibeperking:

- Vrouwen met in de voorgeschiedenis een kind of zelf een geboortegewicht onder het $10^{\mathrm{e}}$ percentiel

- Intra-uteriene vruchtdood (IUVD) in de voorgeschiedenis

- Pre-existente hypertensie

\footnotetext{
Het beleid bij kinderen met een EFW>p10 en een AC tussen p5-10 ligt ter discussie voor aan de achterban. Een definitief besluit hierover gaat genomen worden in het najaar van 2016.
} 
- Chronische nierziekte

- Auto-immuunziekte (o.a. Systemische Lupus Erythematosus, antifosfolipidensyndroom)

- Diabetes mellitus

- Leeftijd $>40$ jaar

- Roken $>11$ sigaretten/dag

NB. Bij bovenstaande risicofactoren is gekozen voor een odds ratio >2.0 (zie literatuurdocument 'foetale groeistoornissen'.)

Zodra het predictiemodel van de Expect studie operationeel is, wordt de hoog risico groep op basis van het model vastgesteld.

\subsection{Detectie foetale groeibeperking}

Voor uitleg over onderstaande onderzoeken, zie \$1.5.

- Abdominale palpatie

- $\quad$ Fundus-symfyse meting

- Termijnbepaling

- Echo biometrie bij elke prenatale controle vanaf 20 weken zwangerschap bij voorkeur tussen 10 en 12 weken zwangerschap 20 en 32 weken zwangerschap

\subsection{Beleid hoog risico foetale groeibeperking}

\section{- Extra echo biometrie}

Een verhoogd risico op een groeibeperking, vastgesteld vroeg in de zwangerschap, is een reden om de groei intensief te volgen door middel van een extra echo biometrie bij $\mathbf{2 8}$ en $\mathbf{3 6}$ weken (naast de standaard echo's biometrie bij 20 en 32 weken).

\subsection{Verdenking foetale groeibeperking}

Zodra een negatieve dyscongruentie wordt vastgesteld, bestaat er een verdenking op een foetale groeibeperking (IUGR) en worden in de daaropvolgende twee weken $\mathbf{3}$ echo's gemaakt om de diagnose foetale groeibeperking te stellen (Tabel 3).

Als tijdens het SEO een foetale groei (EFW) onder het $3^{e}$ percentiel gemeten wordt, dan wordt direct een GUO-II afgesproken en vindt overdracht van zorg naar de gynaecoloog plaats. 
Tabel 3 Beleid verdenking IUGR.

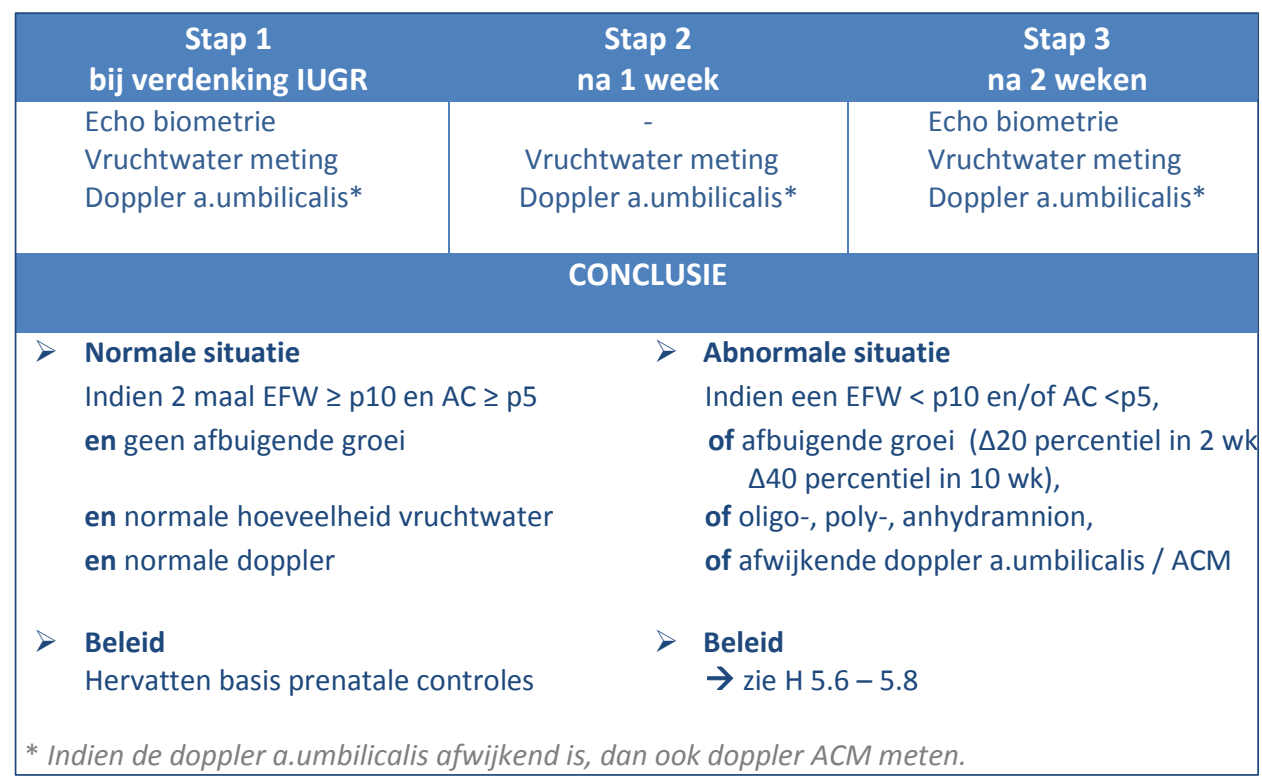

\subsection{Beleid foetale groeibeperking tijdens de zwangerschap}

\subsubsection{Hoofdbehandelaarschap}

- Bij een foetale groeibeperking met een EFW p5-10 o.b.v. 2 echo's en normale hoeveelheid vruchtwater en normale doppler blijft het hoofdbehandelaarschap ongewijzigd.

- Een foetale groeibeperking met een EFW en/of AC $<p 5$ of een afwijkende hoeveelheid vruchtwater of een afwijkende doppler, is reden voor overdracht van zorg naar de gynaecoloog.

\subsubsection{Geavanceerd ultrageluid onderzoek}

\section{- GUO-II indicaties}

Een echoscopisch vastgestelde:

- EFW $<$ p5 bij een zwangerschapsduur tussen de $24^{+0}-36^{+6}$ weken,

- EFW $<$ p10 bij een zwangerschapsduur $<24^{+0}$ weken,

o oligo- of anhydramnion $<37^{+0}$ weken (zonder gebroken vliezen),

○ polyhydramnion $<37^{+0}$ weken 
- Voorwaarden

- Een GUO-II wordt verricht tot een termijn van $37^{+0}$ weken en daarna alleen indien het vermoeden bestaat op een foetale afwijking.

- Een GUO-II vindt plaats binnen 3-5 werkdagen na het stellen van de indicatie.

NB. De werkgroep heeft besloten gezien de lage incidentie afwijkingen die gevonden wordt bij LGA kinderen (EFW >p90), bij deze groep géén GUO-II te verrichten, indien er geen andere bij screening zichtbare bijzonderheden zijn aan foetus, vruchtwater of doppler onderzoek.

\subsubsection{Invasieve diagnostiek}

- Invasieve diagnostiek wordt geadviseerd bij een foetale groeibeperking (EFW of $A C)<p 10$ en een termijn $<24^{+0}$ weken.

- Bij een foetale groeibeperking (EFW of $A C)<p 5$ en een termijn tussen de $24^{+0}$. $36^{+6}$ weken, wordt eerst een GUO-II verricht en vervolgens bekeken of verdere (evt. invasieve) diagnostiek geïndiceerd is.

\subsubsection{Infectieserologie}

- Indicatie voor infectieserologie:

- Structurele foetale afwijkingen.

NB. Infectieserologie wordt niet ingezet bij foetale groeistoornissen en/of afwijkende hoeveelheden vruchtwater zonder aanvullende echoscopische foetale afwijkingen.

- Inhoud infectieserologie:

○ Parvovirus B19

- Toxoplasma

- Cytomegalievirus (CMV)

- Herpes simplex virus

- Rubella alléén op indicatie: zwangeren met een onbekende vaccinatiePATCH status en bevolkingsgroepen waar de incidentie niet-gevaccineerden hoog is. 


\subsection{Schematische weergave beleid foetale groeibeperking}

Tabel 4 Beleid foetale groeibeperking.

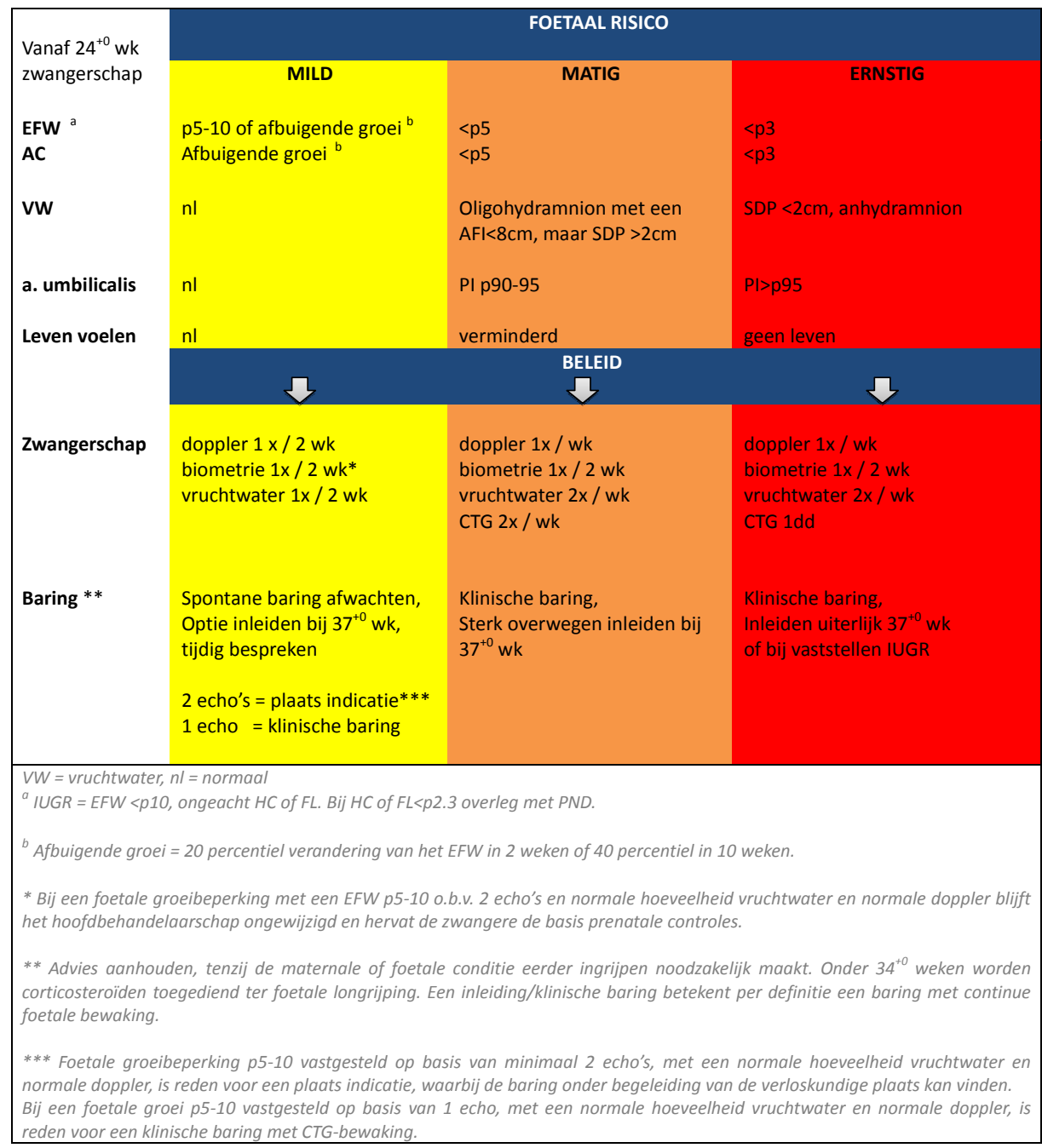




\subsection{Samenvatting}

\begin{tabular}{|c|c|c|c|}
\hline \multicolumn{4}{|c|}{ FOETALE GROEIBEPERKING (IUGR) } \\
\hline DEFINITIE & $\begin{array}{l}\text { SGA } \\
\text { Afbuigende groei } \\
\text { Doppler a.umbilicalis } \\
\text { Doppler ACM } \\
\text { Oligohydramnion } \\
\text { Polyhydramnion } \\
\text { Fundus-symfyse meting }\end{array}$ & \multicolumn{2}{|c|}{$\begin{array}{l}=\mathrm{EFW}<\mathrm{p} 10 \text { en/of } \mathrm{AC}<\mathrm{p} 5 \\
=20 \text { percentiel verandering in } 2 \text { weken } \\
=40 \text { percentiel verandering in } 10 \text { weken } \\
=\text { afwijkend }>\mathrm{p} 95 \\
=\text { afwijkend }<\mathrm{p} 5 \\
=\mathrm{SDP}<2 \mathrm{~cm} \text { of } \mathrm{AFI}<8 \mathrm{~cm} \\
=\mathrm{SDP}>8 \mathrm{~cm} \text { of } \mathrm{AFI}>24 \mathrm{~cm} \\
=\text { afwijkend }+3 \mathrm{~cm} \text { of }-3 \mathrm{~cm} \text { t.o.v. normaalwaarde in cm }\end{array}$} \\
\hline $\begin{array}{l}\text { DETECTIE } \\
\text { Laag risico }\end{array}$ & $\begin{array}{l}\text { WIE? } \\
\text { Alle zwangeren } \\
\text { Alle zwangeren }\end{array}$ & $\begin{array}{l}\text { WANNEER? } \\
\text { Elke controle } \\
\text { Elke controle >20 } \\
\text { wk (interval } 2 \text { wk) }\end{array}$ & $\begin{array}{l}\text { WAT? } \\
\text { Abdominale palpatie } \\
\text { Fundus-symfyse meting }(\mathrm{cm}) \\
\text { Echo }\end{array}$ \\
\hline & $\begin{array}{l}\text { Alle zwangeren } \\
\text { Alle zwangeren } \\
\text { Alle zwangeren }\end{array}$ & $\begin{array}{l}10-12 w k \\
18-20 w k \\
32 w k\end{array}$ & $\begin{array}{l}\text { Termijnbepaling o.b.v. CRL } \\
\text { SEO } \\
\text { Biometrie }\end{array}$ \\
\hline Hoog risico & Hoog risico IUGR & $28+36 w k$ & Extra echo biometrie \\
\hline DIAGNOSTIEK & $\begin{array}{l}\text { Negatieve } \\
\text { dyscongruentie }\end{array}$ & $\begin{array}{l}\text { Verdenking } \\
\text { groeistoornis } \\
1 \text { wk na } 1^{\mathrm{e}} \\
\text { biometrie } \\
2 \text { wk na } 1^{\mathrm{e}} \\
\text { biometrie }\end{array}$ & $\begin{array}{l}1^{\mathrm{e}} \text { biometrie + vruchtwater } \\
+ \text { doppler a.umbilicalis } \\
\text { Vruchtwater + doppler } \\
\text { a.umbilicalis } \\
2^{\mathrm{e}} \text { biometrie + vruchtwater } \\
+ \text { doppler a.umbilicalis } \\
\text { Indien doppler a.umbilicalis } \\
\text { afwijkend is } \rightarrow \text { ACM meten }\end{array}$ \\
\hline $\begin{array}{l}\text { BELEID } \\
\text { Zwangerschap }\end{array}$ & $\begin{array}{l}\text { Verloskundige } \\
\text { Gynaecoloog } \\
\text { GUO-II indicaties: } \\
\text { EFW of AC }<\text { p5 }\left(24^{+0}-\right. \\
36^{+6} \text { wk) } \\
\text { EFW of AC }<\text { p10 }\left(<24^{+0}\right. \\
\text { wk) } \\
\text { poly-, oligo-, an- } \\
\text { hydramnion }<37^{+0} \text { wk }\end{array}$ & $\begin{array}{l}\text { EFW p 5-10 } 2 \\
\text { echo's, } \\
\mathrm{nl} \text { vruchtwater, } \\
\mathrm{nl} \text { doppler } \\
\text { EFW p 5-10 } 1 \text { echo, } \\
\text { EFW of AC }<\mathrm{p} 5 \text {, } \\
\text { afw. vruchtwater, } \\
\text { afw. doppler } \\
\text { Invasieve } \\
\text { diagnostiek: } \\
\text { EFW of AC }<\mathrm{p} 10 \\
\left(<24^{+0} \mathrm{wk}\right)\end{array}$ & $\begin{array}{l}\text { Infectieserologie (PATCH): } \\
\text { Structurele foetale afwijkingen }\end{array}$ \\
\hline Baring & Zie schema H5.7. & & \\
\hline
\end{tabular}




\section{FOETALE MACROSOMIE}

\subsection{Definities}

\section{- Large for gestational age}

Het afkappunt voor 'large for gestational age' (LGA), voor wat betreft het inzetten van vervolgbeleid, is een echoscopisch vastgesteld geschat foetaal gewicht boven het $90^{\mathrm{e}}$ percentiel (EFW >p90) en/of een foetale abdominale omtrek boven het $95^{\mathrm{e}}$ percentiel $(\mathrm{AC}>\mathrm{p} 95)$.

- Te snelle groei

- Er is mogelijk sprake van een foetale groeistoornis (te snel stijgende groei) waarbij vervolgbeleid ingezet moet worden, indien de groei in de curve meer dan:

20 percentiel verandert in $\mathbf{2}$ weken of $\mathbf{4 0}$ percentiel verandert in $\mathbf{1 0}$ weken

\section{- Vruchtwater meting}

De hoeveelheid vruchtwater wordt uitgedrukt in diepste vruchtwaterpoel (single deepest pocket, SDP) of vruchtwaterindex (amniotic fluid index, AFI).

$\circ$ Oligohydramnion $\mathrm{SDP}<2 \mathrm{~cm}$ of $\mathrm{AFI}<8 \mathrm{~cm}$

- Polyhydramnion SDP $>8 \mathrm{~cm}$ of $\mathrm{AFI}>24 \mathrm{~cm}$

\subsection{Risicofactoren foetale macrosomie}

- Als hoog risico groep worden beschouwd:

- Vrouwen met een kind met een geboortegewicht boven het $90^{\mathrm{e}}$ percentiel in de voorgeschiedenis

- $\mathrm{BMI}>30 \mathrm{~kg} / \mathrm{m}^{2}$ bij aanvang van de zwangerschap

- Diabetes gravidarum of pre-existente diabetes mellitus

NB. Zodra het predictiemodel van de Expect studie operationeel is, wordt de hoog risico groep op basis van het model vastgesteld.

\subsection{Detectie foetale macrosomie}

Voor uitleg over onderstaande onderzoeken, zie $§ 1.5$.

- Abdominale palpatie bij elke prenatale controle

- Fundus-symfyse meting vanaf 20 weken zwangerschap 
- Termijnbepaling

- Echo biometrie bij voorkeur tussen 10 en 12 weken zwangerschap 20 en 32 weken zwangerschap

\subsection{Beleid hoog risico foetale macrosomie}

- Extra echo biometrie

Een verhoogd risico op foetale macrosomie, vastgesteld vroeg in de zwangerschap, is een reden om de groei intensief te volgen door middel van een extra echo biometrie bij 28 en $\mathbf{3 6}$ weken (naast de standaard echo's biometrie bij 20 en 32 weken).

\subsection{Verdenking foetale groeibeperking}

- De diagnose foetale macrosomie wordt gesteld op basis van 2 opeenvolgende echo's biometrie waarbij een EFW >p90 of AC >p95 gemeten wordt.

- De verdenking op foetale macrosomie vervalt en de basis prenatale controles worden hervat, indien 2 opeenvolgende echo's biometrie een normale groei (EFW $\leq$ p90 en AC $\leq$ p95) en vruchtwater laten zien.

\subsection{Beleid zwangerschap macrosomie}

\subsubsection{Hoofdbehandelaarschap}

- Bij een foetale groei >p95 en/of AC >p95 is de gynaecoloog hoofdbehandelaar. $\mathrm{Bij}$ een EFW en/of AC p90-95, zonder overige pathologie, is de verloskundige hoofdbehandelaar.

De hoofdbehandelaar is eindverantwoordelijke, maar is niet per definitie degene die alle zwangerschapscontroles uitvoert.

\subsubsection{Aanvullend onderzoek}

- $\quad$ EFW of $A C>p 90 \rightarrow$ Echo biometrie

- $\quad \mathrm{EFW}$ of $\mathrm{AC}>\mathrm{p95} \rightarrow$ Orale glucose tolerantietest (OGTT)

- Polyhydramnion $\rightarrow$ OGTT + GUO-II 


\subsubsection{Biometrie}

- Indien een foetale groei (EFW of AC) >p90 wordt vastgesteld, wordt rond 36-37 weken zwangerschap een adequate gewichtsschatting met echo en uitwendige palpatie gemaakt, bij voorkeur op dezelfde locatie waar de voorgaande echo's zijn gemaakt.

\subsection{Beleid baring foetale macrosomie}

- $\quad$ EFW en/of AC p 90 - 95:

- Plaatsindicatie voor de baring overwegen en bespreken met de zwangere.

- Aan het begin van de baring dient door de parteur een gewichtsschatting en liggingsbepaling uitgevoerd en gedocumenteerd te worden, zodat het beleid t.a.v. de baring zo nodig aangepast kan worden.

\section{- $\quad$ EFW en/of AC >p 95:}

Klinische baring.

- Aan het begin van de baring dient door de parteur een gewichtsschatting en liggingsbepaling uitgevoerd en gedocumenteerd te worden, zodat het beleid t.a.v. de baring zo nodig aangepast kan worden.

- Mogelijkheid van inleiding van de baring rond $39^{+0}$ weken, tijdig met de zwangere bespreken.

- Bij een EFW $>4500$ gram in combinatie met een diabetes gravidarum of een EFW $\geq 5000$ gram dient de zwangere tijdig geïnformeerd (inclusief bespreken voor- en nadelen) te worden over de mogelijkheid van een primaire sectio caesarea rond $39^{+0}$ weken zwangerschap.

\section{- Polyhydramnion:}

o Klinische baring. 


\subsection{Samenvatting}

\begin{tabular}{|c|c|c|c|}
\hline \multicolumn{4}{|c|}{ FOETALE MACROSOMIE } \\
\hline DEFINITIE & $\begin{array}{l}\text { LGA } \\
\text { Groeiversnelling } \\
\text { Polyhydramnion }\end{array}$ & \multicolumn{2}{|c|}{$\begin{array}{l}=\text { foetale groei EFW }>\text { p90 en/of } A C>p 95 \\
=20 \text { percentiel verandering in } 2 \text { weken } \\
=40 \text { percentiel verandering in } 10 \text { weken } \\
=S D P>8 \mathrm{~cm} \text { of } A F I>24 \mathrm{~cm}\end{array}$} \\
\hline $\begin{array}{l}\text { DETECTIE } \\
\text { Laag risico }\end{array}$ & Hoog risico macrosomie & $\begin{array}{l}\text { WANNEER? } \\
\text { Elke controle } \\
\text { Vanaf }>20 \text { wk } \\
10-12 w k \\
18-20 w k \\
32 w k \\
28+36 w k\end{array}$ & $\begin{array}{l}\text { WAT? } \\
\text { Abdominale palpatie } \\
\text { Fundus-symfyse meting (interval } \\
\text { min. } 2 \text { wk) } \\
\text { Echo } \\
\text { - Termijnecho } \\
\text { - SEO } \\
\text { - Echo biometrie } \\
\text { Extra echo biometrie }\end{array}$ \\
\hline DIAGNOSTIEK & Verdenking macrosomie & $\begin{array}{l}\text { Bij verdenking } \\
2 \text { wk later }\end{array}$ & $\begin{array}{l}\text { Biometrie + vruchtwater } \\
\text { Biometrie + vruchtwater }\end{array}$ \\
\hline $\begin{array}{l}\text { BELEID } \\
\text { Zwangerschap }\end{array}$ & $\begin{array}{l}\text { Verloskundige } \\
\text { Gynaecoloog } \\
\text { EFW of } A C>p 90 \\
\text { EFW of AC >p95 } \\
\text { Polyhydramnion }\end{array}$ & $\begin{array}{l}\text { EFW of } A C \leq p 95 \\
\text { EFW of } A C>p 95 \\
36-37 \text { wk } \\
\text { Na vaststellen } \\
\mathrm{Na} \text { vaststellen }\end{array}$ & $\begin{array}{l}\text { Hoofdbehandelaar } \\
\text { Hoofdbehandelaar } \\
\text { Echo biometrie } \\
\text { OGTT } \\
\text { OGTT + GUO-II }\end{array}$ \\
\hline Baring & $\begin{array}{l}\text { EFW en/of AC p90-95 } \\
\text { EFW en/of } A C>p 95 \\
E F W \geq 4500 \mathrm{gr}+D G \\
E F W \geq 5000 \mathrm{gr}\end{array}$ & $39 w k$ & $\begin{array}{l}\text { Spontaan begin van de baring } \\
\text { afwachten } \\
\text { Inleiding (optioneel) } \\
\text { Primaire SC (optioneel) }\end{array}$ \\
\hline
\end{tabular}




\section{DIABETES GRAVIDARUM}

\subsection{Definitie DG}

- Diabetes gravidarum (DG) is elke vorm van hyperglycaemie die tijdens de zwangerschap wordt ontdekt, bij een normoglycaemische situatie vóór de zwangerschap, onafhankelijk van het feit of deze afwijking na de zwangerschap weer verdwijnt.

\subsection{Detectie DG}

- Wegen

- Alle zwangere vrouwen worden bij elke prenatale controle gewogen.

- Glucose referentiewaarde

$\circ \mathbf{1}^{\mathrm{e}}$ trimester

$\mathrm{Bij}$ alle zwangeren wordt in het $1^{\mathrm{e}}$ trimester (10-12 wk) van de zwangerschap een random glucosewaarde bepaald (veneus plasma). Indien mogelijk heeft een nuchtere glucosebepaling de voorkeur.

Beleid random glucosewaarde:

$<6.1 \mathrm{mmol} / \mathrm{l} \quad$ normaal, geen verdere actie

6.1-11.0 mmol/l afwijkend, bepaling nuchtere glucosewaarde (veneus plasma)

$\geq 11.0 \mathrm{mmol} / \mathrm{l} \quad$ pre-existente diabetes mellitus, verwijzing internist en gynaecoloog

Beleid nuchtere glucosewaarde:

$<6.1 \mathrm{mmol} / \mathrm{l} \quad$ normaal, geen verdere actie

$>6.1 \mathrm{mmol} / \mathrm{I} \quad$ afwijkend, verricht een OGTT en GUO-II

○ $\mathbf{2}^{\mathrm{e}}$ trimester

In het $2^{\mathrm{e}}$ trimester (24-26 wk) van de zwangerschap wordt bij alle zwangeren een nuchtere glucosewaarde bepaald. Deze losse glucose bepaling vervalt uiteraard indien zwangeren o.b.v. risicofactoren in aanmerking komen voor een OGTT. 


\subsection{Risicofactoren DG}

- Zwangere vrouwen met één of meer van onderstaande risicofactoren, worden als hoog risicogroep beschouwd voor diabetes gravidarum:

- $\mathrm{BMI}>30\left(\mathrm{~kg} / \mathrm{m}^{2}\right)^{*}$ bij de $1^{\mathrm{e}}$ prenatale controle

○ Eerder kind met een geboortegewicht $\geq$ p95 en/of $\geq 4500$ gram

- Diabetes gravidarum in de voorgeschiedenis

- $1^{\mathrm{e}}$ graads familielid (ouders) met diabetes

○ Etniciteit waar diabetes veel voorkomt (Zuid-Aziaten, Hindoestanen, AfroCaribiërs, Marokkanen, Egyptenaren, vrouwen uit het Midden-Oosten)

- Polycysteus ovarium syndroom (PCOS) ${ }^{* *}$

○ Onverklaarde intra-uteriene vruchtdood (IUVD) in voorgeschiedenis**

- Chronisch corticosteroïden gebruik**

$\circ$

* Verschillende BMI afkapwaarden worden gehanteerd: BMI >25 kg/m², BMI $>27 \mathrm{~kg} / \mathrm{m}^{2}, B M I>30 \mathrm{~kg} / \mathrm{m}^{2}$ is de waarde zoals nu beschreven in de NVOG richtlijn.

** Niet vermeld in alle richtlijnen.

\subsection{Beleid hoog risico DG}

\section{- Orale glucose tolerantietest}

- Alleen bij vrouwen met diabetes gravidarum in de voorgeschiedenis vindt screening op diabetes gravidarum plaats d.m.v. een OGTT bij 16-18 weken. ndien de OGTT bij 16-18 weken normaal is, wordt de OGTT herhaald bij 2428 weken.

- Bij vrouwen met één of meer risicofactor(en) (§7.3) vindt screening op diabetes gravidarum plaats d.m.v. een OGTT bij 24-28 weken. 
Tabel 5 Referentiewaarden OGTT.

\begin{tabular}{|c|c|}
\hline 75 g-OGTT referentiewaarden & IADPSG $^{*}$ \\
\hline Normaalwaarden & veneus plasma (mmol/l) \\
\hline $\begin{array}{l}\text { - Nuchter } \\
\text { - } 1 \text { uur na inname van } 75 \text { gram glucose } \\
\text { - } 2 \text { uur na inname van } 75 \text { gram glucose }\end{array}$ & $\begin{array}{l}<5.1 \\
<10.0 \\
<8.5\end{array}$ \\
\hline \multicolumn{2}{|l|}{ Afwijkende OGTT } \\
\hline \multicolumn{2}{|l|}{ BELEID } \\
\hline $\begin{array}{l}\text { - Nuchtere glucosewaarde }>7.0 \mathrm{mmol} / \\
\text { - } \quad \geq 1 \text { glucosewaarde( } \mathrm{n} \text { ) afwijkend } \\
\text { *IADPSG = International Association of Diabet }\end{array}$ & $\begin{array}{l}\rightarrow \text { direct verwijzing internist } \\
\rightarrow \text { dieetadvies + na } 1 \text { week glucose dag } \\
\text { curve } \\
\text { egnancy Study Groups }\end{array}$ \\
\hline
\end{tabular}

Tabel 6 Referentiewaarden glucose dagcurve.

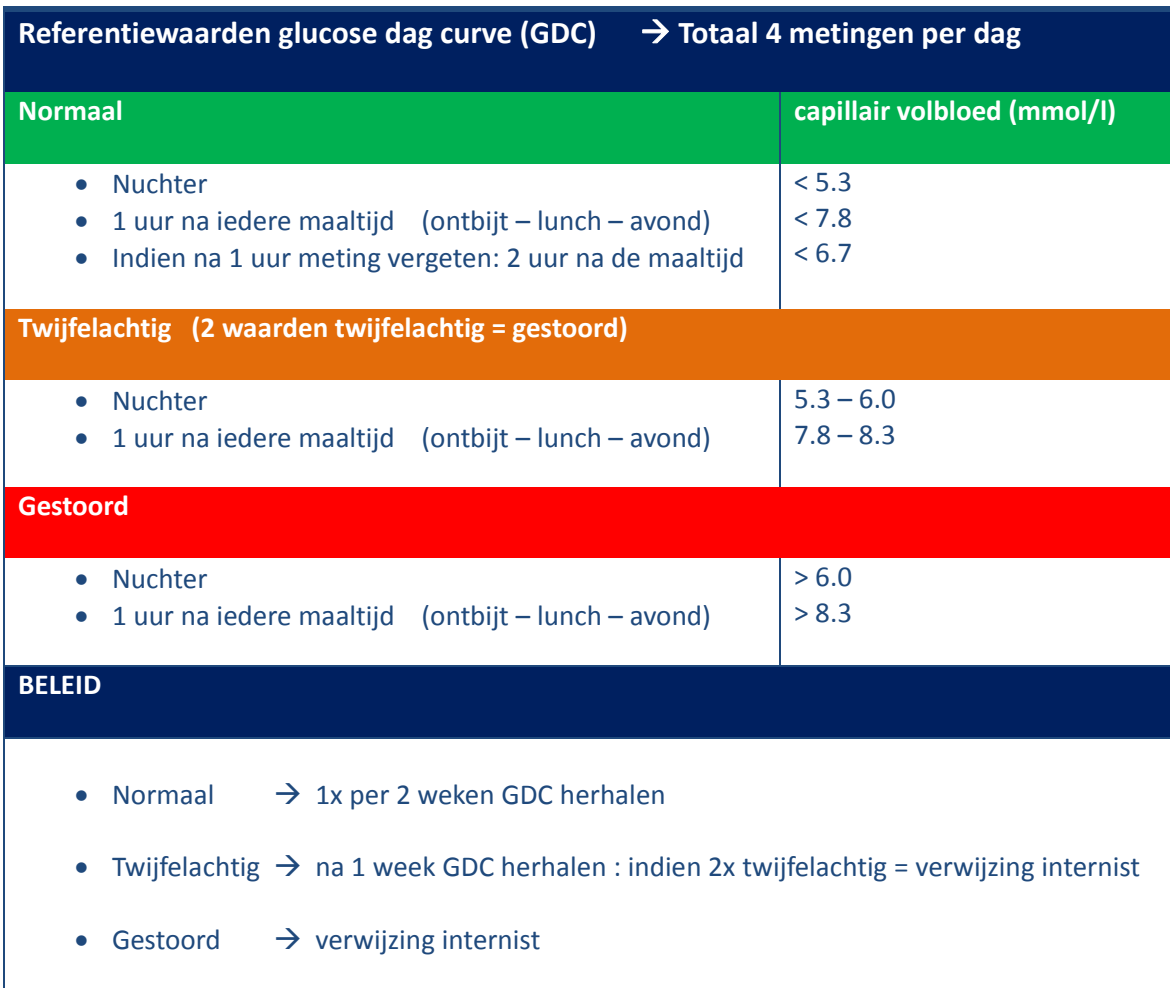




\subsection{Beleid zwangerschap DG}

\subsubsection{Hoofdbehandelaarschap}

- De verloskundige is hoofdbehandelaar:

- bij een zwangere met diabetes gravidarum waarbij behandeling met een dieet plaatsvindt en sprake is van een EFW $\leq$ p90 en $A C \leq p 95$.

- De gynaecoloog is hoofdbehandelaar:

○ bij een zwangere met diabetes gravidarum waarbij behandeling met bloedglucose verlagende medicatie plaatsvindt, ongeacht de foetale groei.

○ bij een zwangere met diabetes gravidarum waarbij behandeling met een dieet plaatsvindt en sprake is van macrosomie (EFW > p90 en/of AC >p95)

\subsubsection{Behandeling d.m.v. dieet}

- De $1^{\mathrm{e}}$ evaluatie van het dieet effect vindt 1 week na het dieetadvies plaats d.m.v. een glucose dagcurve.

- Indien de uitslag normaal is worden de volgende evaluaties d.m.v. een glucose dag curve elke 2 weken verricht.

- Gestoorde glucose dagcurves zijn reden voor verwijzing naar de internist.

\subsubsection{Medicamenteuze behandeling}

- Toediening van orale bloedglucose verlagende middelen (bijv. metformine) behoort tot de medicamenteuze behandelopties van diabetes gravidarum.

- Medicamenteuze behandeling van diabetes gravidarum vindt plaats bij de internist (diabetesteam).

- Controle van de glucosewaarden d.m.v. een glucose dag curve, vindt bij een diabetes gravidarum met medicatie na goede instelling, ten minste $\underline{2 x}$ per week plaats.

- Elke regio dient af te spreken wie in de zwangerschap de glucosewaarden controleert, indien sprake is van een diabetes gravidarum. 


\subsubsection{Foetaal}

\section{- Echo biometrie}

Diabetes gravidarum is gezien de verhoogde kans op macrosomie, een reden voor het vervolgen van de foetale groei d.m.v. echo biometrie:
○ DG + dieet biometrie elke 4 weken
○ $\quad$ DG + medicatie biometrie elke 2 weken

- GUO

○ Bij een afwijkende (hoge) nuchtere glucosewaarde (>6.1 mmol/l) in het $1^{\mathrm{e}}$ trimester, passend bij een niet eerder ontdekte diabetes mellitus, is een geavanceerd ultrageluid onderzoek (GUO-II) geïndiceerd.

\subsection{Beleid baring DG}

De mogelijkheid tot inleiding van de baring wordt tijdig met de zwangere en haar partner besproken.

- Diabetes gravidarum zonder risicofactoren*:

- mogen thuis of poliklinisch bevallen

$\circ \quad$ indien gewenst een inleiding van de baring bij 40-41 weken.

- Diabetes gravidarum met $\geq 1$ risicofactor(en)*:

- dienen klinisch te bevallen

○ indien gewenst een inleiding van de baring bij 38-39 weken.

- Tijdig informeren m.b.t. de mogelijkheid van een primaire sectio caesarea rond $39^{+0}$ weken:

○ $\quad$ EFW $\geq 4500$ gram + DG ongeacht behandeling

○ $\quad E F W \geq 5000$ gram, ongeacht wel/geen DG

\section{* Risicofactoren:}

○ Polyhydramnion

- Macrosomie (EFW >p90 en/of $A C>p 95)$

$\circ$ Intra-uteriene groeibeperking (EFW $<$ p10 en/of $A C<p 5)$

- Bloedglucose verlagende medicatie

- Matig ingestelde glucosewaarden 


\subsection{Beleid postpartum DG}

\subsubsection{Maternaal}

\section{- Kraambed DG met medicatie}

- Glucose verlagende medicatie kan postpartum gestaakt worden.

- Nacontrole DG

- Leefstijlinterventies bespreken.

- Follow-up van de glucosewaarden ter uitsluiting van diabetes mellitus.

- Follow-up DG

- Advies elke 1-2 jaar via de huisarts een nuchtere glucosewaarde laten controleren.

- Advies preconceptioneel consult voor een volgende zwangerschap.

\subsubsection{Neonataal}

- Bij diabetes gravidarum en behandeling d.m.v. een dieet en een normoglycaemische moeder, dient er extra aandacht te zijn voor symptomen van een neonatale hypoglycaemie aangezien bij deze neonaten niet routinematig glucosecontroles plaatsvinden.

\section{- Neonatale glucose controles postpartum}

o Indicaties:

- Diabetes gravidarum en behandeling met bloedglucose verlagende middelen

- Diabetes gravidarum en behandeling d.m.v. een dieet waarbij de glucosehuishouding niet goed gereguleerd is (afwijkende dagcurves)

- Geboortegewicht $\geq$ p95

- Neonatale symptomen die glucosecontroles indiceren (bijv. 'fladderen').

- Voorwaarden:

- Neonatale glucosecontroles postpartum dienen in het ziekenhuis plaats te vinden, gezien de betrouwbaarheid van de meetapparatuur.

- De neonatale observatieperiode in het kader van neonatale hypoglycaemie detectie is 24 uur. 


\subsection{Samenvatting}

\begin{tabular}{|c|c|c|c|}
\hline \multicolumn{4}{|c|}{ DIABETES GRAVIDARUM (DG) } \\
\hline DEFINITIE & \multicolumn{3}{|c|}{$\begin{array}{l}\text { Elke vorm van hyperglycaemie die tijdens de zwangerschap wordt ontdekt, bij een } \\
\text { normoglycemische situatie vóór de zwangerschap, onafhankelijk van het feit of deze } \\
\text { afwijking na de zwangerschap weer verdwijnt. }\end{array}$} \\
\hline $\begin{array}{l}\text { DETECTIE } \\
\text { Laag risico }\end{array}$ & $\begin{array}{l}\text { WIE? } \\
\text { Alle zwangeren } \\
\text { Alle zwangeren incl.hoog risico } \\
\text { Laag risico zwangeren }\end{array}$ & $\begin{array}{l}\text { WANNEER? } \\
\text { Elke controle } \\
1^{\mathrm{e}} \text { trimester (intake) } \\
2^{\mathrm{e}} \text { trimester ( } 24-28 \mathrm{wk} \text { ) }\end{array}$ & $\begin{array}{l}\text { WAT? } \\
\text { Wegen } \\
\text { Nuchtere glucose } \\
\text { Glucose (voorkeur nuchter) }\end{array}$ \\
\hline Hoog risico & $\begin{array}{l}\text { DG i.a. } \\
\geq 1 \text { risicofactor(en)* }\end{array}$ & $\begin{array}{l}16-18 w k \\
24-28 w k \\
28+36 w k\end{array}$ & $\begin{array}{l}\text { OGTT } \\
\text { OGTT } \\
\text { Extra echo biometrie }\end{array}$ \\
\hline DIAGNOSTIEK & $\begin{array}{l}\mathrm{EFW}>\mathrm{p} 90 \text { of } \mathrm{AC}>\mathrm{p} 95 \text { of } \\
\text { polyhydramnion }\end{array}$ & $\mathrm{Na}$ vaststellen & OGTT \\
\hline $\begin{array}{l}\text { BELEID } \\
\text { Zwangerschap }\end{array}$ & $\begin{array}{l}1^{\mathrm{e}} \text { trim. glucose }>6.1 \mathrm{mmol} / \mathrm{l} \\
\text { Nuchtere waarde } \\
\text { Random waarde } \\
\text { DG + dieet } \\
\text { DG + medicatie }\end{array}$ & $\begin{array}{l}\text { 18-20 wk (zie §7.2) } \\
\text { Direct } \\
\text { Elke } 4 \mathrm{wk} \\
\text { Elke } 2 \mathrm{wk}\end{array}$ & $\begin{array}{l}\text { GUO-II, OGTT } \\
\text { Nuchtere glucose bepalen } \\
\text { Echo biometrie } \\
\text { Echo biometrie }\end{array}$ \\
\hline Baring & $\begin{array}{l}\mathrm{DG}+\text { dieet }+\mathrm{EFW}<\mathrm{p} 90 \\
+\mathrm{EFW} \geq \mathrm{p90} \\
\mathrm{DG}+\text { medicatie }\end{array}$ & $\begin{array}{l}40-41 w^{* * *} \\
40-41 w^{* * *} \\
38-39 w k\end{array}$ & $\begin{array}{l}\text { Thuis / poliklinisch (open vk) } \\
\text { Klinisch } \\
\text { Klinisch }\end{array}$ \\
\hline Kraambed & $\begin{array}{l}\text { DG + medicatie } \\
\text { *zie §7.3: BMI > } 30 \mathrm{~kg} / \mathrm{m}^{2} \text { bij aanvo } \\
\geq 4500 \text { gram in VG, ouders met dia } \\
\text { gebruik. } \\
\text { ** Tenzij polyhydramnion, EFW } \leq p 1 \\
\text { klinisch. }\end{array}$ & $\begin{array}{l}\text { Direct postpartum } \\
\text { van de zwangerschap, kind } \\
\text { es, etniciteit, PCOS, IUVD in } \\
\text { n/of AC }<\mathrm{p} 5 \text {, matig ingeste }\end{array}$ & $\begin{array}{l}\text { Glucose verlagende } \\
\text { medicatie staken } \\
\text { et geboortegewicht } \geq p 95 \text { en/of } \\
\text {, chronisch corticosteroïden } \\
\text { glucosewaarden, dan 38-39wk }\end{array}$ \\
\hline
\end{tabular}




\section{PRE-EXISTENTE DIABETES MELLITUS}

\subsection{Definitie DM}

- Stofwisselingsziekte ten gevolge van een absoluut of relatief insulinetekort, reeds vóór de zwangerschap aanwezig of vastgesteld voor 20 weken zwangerschap, leidend tot verhoogde glucosewaarden.

\subsection{Preconceptioneel}

- Indien sprake is van diabetes mellitus bij een vrouw met kinderwens, wordt een preconceptioneel consult geadviseerd.

\subsection{Beleid DM zwangerschap}

\section{- Glucosecontroles}

Indien sprake is van pre-existente diabetes mellitus, worden glucosecontroles bij voorkeur uitgevoerd door een internist (diabetesteam) in hetzelfde ziekenhuis als de verloskundig hoofdbehandelaar.

- Prenatale controle:

Indien sprake is van pre-existente diabetes mellitus, vindt elke 2 weken een prenatale controle plaats.

- GUO:

Pre-existente diabetes mellitus is reden voor een geavanceerd ultrageluid onderzoek (GUO).

- Invasieve diagnostiek:

Ondanks het feit dat er geen verhoogd risico bestaat op chromosomale afwijkingen bij diabetes mellitus, dient wel conform de richtlijn, invasieve diagnostiek in de vorm van een amnionpunctie aangeboden te worden.

\section{- Echo biometrie:}

Indien sprake is van pre-existente diabetes mellitus, wordt vanaf 28 weken zwangerschap elke 2-4 weken een echo biometrie geadviseerd.

\subsection{Beleid DM baring}

- Indien sprake is van pre-existente diabetes mellitus, wordt aanbevolen de baring bij $38^{+0}$ weken zwangerschap in te leiden.

$\bigcirc$ De internist is in consult durante partu gezien de glucoseregulatie. 


\subsection{Beleid DM kraambed}

- Consult internist in verband met glucoseregulatie en glucose regulerende medicatie.

- Consult kinderarts in verband met neonatale glucosecontroles.

\subsection{Samenvatting}

\begin{tabular}{|c|c|c|c|}
\hline \multicolumn{4}{|c|}{ Pre-existente DIABETES MELLITUS (DM) } \\
\hline DEFINITIE & $\begin{array}{l}\text { Pre-existente } \\
\text { diabetes mellitus }\end{array}$ & \multicolumn{2}{|c|}{$\begin{array}{l}\text { = stofwisselingsziekte ten gevolge van een } \\
\text { insulinetekort, reeds aanwezig vóór de } \\
\text { zwangerschap (type } 1 \text { of 2). }\end{array}$} \\
\hline BELEID & WIE? & WANNEER? & WAT? \\
\hline $\begin{array}{l}\text { Preconceptioneel } \\
\text { Zwangerschap }\end{array}$ & $\begin{array}{l}\text { Consult gynaecoloog } \\
\text { geadviseerd. } \\
\text { Begeleiding samen met } \\
\text { internist. }\end{array}$ & & \\
\hline & Vrouwen met DM & $\begin{array}{l}\text { Elke } 2 \text { wk } \\
18-20 \text { wk } \\
>28^{+0} \text { wk elke } 2-4 \text { wk }\end{array}$ & $\begin{array}{l}\text { Prenatale controle } \\
\text { GUO-I } \\
\text { Echo biometrie }\end{array}$ \\
\hline Baring & Vrouwen met DM & $\begin{array}{l}38^{+0} \mathrm{wk} \\
\text { Durante partu }\end{array}$ & $\begin{array}{l}\text { Inleiding van de baring } \\
\text { Consult internist i.v.m. } \\
\text { medicatie }\end{array}$ \\
\hline Kraambed & Vrouwen met DM & Postpartum & $\begin{array}{l}\text { Consult internist i.v.m. } \\
\text { medicatie }\end{array}$ \\
\hline
\end{tabular}




\section{HYPERTENSIEVE AANDOENINGEN}

\subsection{Definities}

- Milde/matige

- $\quad$ zwangerschapshypertensie: SBD 140 - 159 mmHg en/of DBD 90 - 109 mmHg.

- Ernstige

- zwangerschapshypertensie: $\mathrm{SBD} \geq 160 \mathrm{mmHg}$ en/of $\mathrm{DBD} \geq 110 \mathrm{mmHg}$.

- Proteïnurie: $\quad \geq 0.3 \mathrm{~g} / 24$ uur of $\geq 30 \mathrm{~g} / \mathrm{mol}$ kreatinine

- Ernstige proteïnurie: $\quad>5.0 \mathrm{~g} / 24$ uur of $>50 \mathrm{~g} / \mathrm{mol}$ kreatinine

- Preeclampsie: zwangerschapshypertensie + proteïnurie

- Ernstige preeclampsie: $\quad 1$ ) ernstige hypertensie in de zwangerschap + proteïnurie 2 ) hypertensie in de zwangerschap + ernstige proteïnurie $\quad 3$ ) preeclampsie + HELLP syndroom NB. De differentiatie in mild/ matige/ ernstige preeclampsie, wordt niet gemaakt uitsluitend op basis van zwangerschapsduur.

\subsection{Risicofactoren HT aandoening}

Zie ook \$9.5, beleid hoog risico hypertensieve aandoening.

- Onderstaande risicofactoren zoals beschreven in de NICE richtlijn (Tabel 7), met een onderscheid in hoog en matige risicofactoren, worden aangehouden. NB. Zodra het predictiemodel van de Expect studie operationeel is, zal het predictiemodel het risico op preeclampsie schatten en onderstaande risicofactoren vervangen. Voor zwangerschapshypertensie blijven onderstaande risicofactoren wel van toepassing. 
Tabel 7 NICE guideline Hypertension in pregnancy, 2011.

\section{NICE risicofactoren hypertensieve aandoening}

Hoog risicofactoren:

- hypertensieve aandoening i.a.

- chronische nierziekte

- auto-immuun ziekte (SLE of

antifosfolipidensyndroom)

- diabetes mellitus type 1 of 2

- chronisch hypertensie

\section{Matige risicofactoren:}

- nullipariteit

- leeftijd >40 jaar

- zwangerschapsinterval >10 jaar

- $\mathrm{BMI}>35 \mathrm{~kg} / \mathrm{m}^{2}$ bij $1^{\mathrm{e}}$ bezoek

- familiegeschiedenis met

preeclampsie

- meerlingzwangerschap

- Er is sprake van een hoog risico op een hypertensieve aandoening, indien de zwangere:

$0 \geq 1$ hoog risicofactor of

$\circ \quad \geq 2$ matige risicofactoren heeft.

\subsection{Detectie HT aandoening}

\section{- Bloeddruk meting}

○ Bij elke prenatale controle wordt de bloeddruk gemeten.

\subsection{Preventie HT aandoening}

\section{- Calcium}

Alle zwangeren worden geadviseerd 1 gram calcium per dag tot zich te nemen ter preventie van preeclampsie. Dat kan door intake via de voeding (ten minste $>5$ glazen melk per dag) of door suppletie in tabletvorm.

\section{- Aspirine}

Zwangeren met een hoog risico op een hypertensieve aandoening wordt geadviseerd vanaf

12 weken zwangerschap aspirine $80 \mathrm{mg}$ per dag te nemen ter preventie van preeclampsie (door gynaecoloog laten voorschrijven tijdens intakebespreking of via huisarts). 


\subsection{Beleid hoog risico HT aandoening}

Onderstaande zorg voor vrouwen met een hoog risico op een hypertensieve aandoening wordt gegeven aanvullend op de basiszorg die voor alle zwangere vrouwen geldt (\$9.3).

- Vrouwen met $\geq 1$ hoog risicofactor krijgen aanvullend op de basis zorg:

- Prenatale controles elke 2 weken gedurende de gehele zwangerschap

- EKR bepaling tegelijk met het intake lab

○ Uitgangs toxlab tegelijk met het intake lab:

$\mathrm{Hb}$, trombocyten, ureum, urinezuur, creatinine, ASAT, ALAT, LDH

- Aspirine (1dd $80 \mathrm{mg}$ vanaf $12 \mathrm{wk}$ zwangerschap) ter preventie van preeclampsie

- Extra echo biometrie $28+36$ weken

- Vrouwen met $\geq \mathbf{2}$ matige risicofactoren krijgen aanvullend op de basis zorg:

- EKR bepaling tegelijk met het intake lab

- Aspirine (1dd $80 \mathrm{mg}$ vanaf $12 \mathrm{wk}$ zwangerschap) ter preventie van preeclampsie

- Extra echo biometrie $28+36$ weken

NB: Totdat het predictiemodel van de EXPECT-studie operationeel is, zullen de NICE risicofactoren aangehouden worden voor het definiëren van de vrouwen met een hoog risico op preeclampsie, voor zwangerschapshypertensie blijven de NICE risicofactoren van toepassing (\$9.3).

\subsubsection{Hoofdbehandelaarschap}

- Bij vrouwen met een hoog risico op een hypertensieve aandoening tijdens de zwangerschap, wordt bij de intakebespreking (per VSV) bekeken wie hoofdbehandelaar wordt. Gezien de variatie in ernst van hypertensieve aandoeningen en de vele andere factoren die bij het inschatten van het (herhalings)risico een rol spelen, is gekozen het hoofdbehandelaarschap per individu te bepalen. 


\subsection{Verdenking HT aandoening}

- De hartfrequentie (pols) dient in combinatie met de bloeddruk gemeten te worden bij alle vrouwen met een verdenking op een hypertensieve aandoening, vastgestelde hypertensie en/of klachten passend bij een hypertensieve aandoening.

- Als diagnostische test voor proteïnurie tijdens de zwangerschap, wordt primair de eiwit-kreatinine-ratio (EKR) bepaald in het lab (niet d.m.v. stick).

\section{- $\quad$ Stijging van de bloeddruk, maar $<140 / 90 \mathrm{mmHg}$}

Wanneer sprake is van een stijging van de systolische bloeddruk van $>30$ $\mathrm{mmHg}$ en/of diastolisch bloeddruk $>20 \mathrm{mmHg}$ t.o.v. de bloeddruk bij de daaraan voorafgaande meting of de bloeddruk bij de eerste prenatale controle, zijn de volgende aanbevelingen van toepassing:

- Eiwit-kreatinine-ratio bepalen (aansluitend)

- Herhalen bloeddrukmeting + pols ( $<1$ week)

- Stijging van de bloeddruk $>\mathbf{1 4 0 / 9 0} \mathrm{mmHg}$ en/of klachten passend bij een hypertensieve aandoening

Wanneer sprake is van een de novo bloeddruk $>140 / 90 \mathrm{mmHg}$ en/of klachten passend bij een hypertensieve aandoening, vindt klinische evaluatie (in het ziekenhuis) plaats bestaande uit:

- Een automatische bloeddrukmeting elke 3-5 minuten gedurende 30 minuten

○ Eiwit-kreatinine-ratio bepalen

- Inzetten van bloedonderzoek 'toxlab', ten minste inzetten:

- Hemoglobine, trombocyten

- Ureum, Urinezuur, Creatinine

- ASAT, ALAT, LDH

- Echo biometrie inclusief vruchtwatermeting, tenzij de laatste echo biometrie $<2$ weken geleden heeft plaatsgevonden.

- Laagdrempelig dopplermeting van de a.umbilicalis

- CTG (optioneel): heeft weinig meerwaarde indien sprake is van een normale groei, vruchtwater en leven voelen, maar wordt in de praktijk 
vaak routinematig uitgevoerd tegelijkertijd met de automatische bloeddrukmeting (30 minuten).

\subsection{Beleid zwangerschap HT aandoening}

\subsubsection{Hoofdbehandelaarschap}

- Indien zwangerschapshypertensie is vastgesteld, is het afhankelijk van de bevindingen tijdens de klinische evaluatie (bloeddrukmeting, EKR, toxlab, biometrie en evt. doppler) waar de verdere prenatale controles plaatsvinden en of overdracht van zorg nodig is.

- Bij preeclampsie en/of HELLP is de gynaecoloog hoofdbehandelaar.

\subsubsection{Milde/matige zwangerschapshypertensie}

\section{- Maternaal}

- Starten met antihypertensiva kan overwogen worden.

\section{Hierover bestaat internationaal geen consensus en/of sluitend bewijs.}

- Een daling van de bloeddruk $<140 / 90 \mathrm{mmHg}$, dient $<1$ week na het starten van antihypertensiva meetbaar te zijn. Indien de bloeddruk onvoldoende gedaald is, dient de dosering en/of frequentie en/of soort antihypertensivum aangepast/aangevuld te worden.

- Foetaal

○ Elke 2-4 weken een echo biometrie en vruchtwater meting. Een dopplermeting van de a.umbilicalis wordt alleen op indicatie verricht.

\subsubsection{Ernstige zwangerschapshypertensie of preeclampsie}

- Maternaal

○ Klinische opname.

- Starten met antihypertensiva.

- Bij voorkeur methyldopa (Aldomet), labetalol (Labetalol, Trandate) en nifedipine (Adalat) of een combinatie van deze middelen.

- De hoogte van de hartfrequentie (pols) speelt een rol bij de keuze voor het antihypertensivum.

- Een daling van de bloeddruk dient < 24 uur na het starten van antihypertensiva zichtbaar te zijn. Hierbij wordt gestreefd naar een 
bloeddruk van onder de $\pm 135 / 85 \mathrm{mmHg}$. Bij onvoldoende daling van de bloeddruk dient de dosering en/of frequentie en/of soort antihypertensivum aangepast/aangevuld te worden.

- Bloeddruk meten (ten minste 3 maal daags)

○ Bloedonderzoek 'toxlab' (ten minste 2x per week)

- EKR bepaling (2x per week)

- Dagelijks vragen naar symptomen/klinische verschijnselen passend bij een hypertensieve aandoening.

○ Magnesiumsulfaat is geïndiceerd bij ernstige preeclampsie en/of een eclamptisch insult of bij de verwachting dat de baring voor $32^{+0}$ weken plaats zal vinden, ter maternale en foetale neuroprotectie.

- Bij preeclampsie voor $32^{+0}$ weken en de verwachting dat de baring binnen enkele dagen plaats zal vinden, dient tevens overplaatsing naar een perinatologisch centrum plaats te vinden.

- Foetaal

○ Elke 2-4 weken een echo biometrie en vruchtwater meting. Een dopplermeting van de a. umbilicalis wordt alleen op indicatie verricht.

\subsection{Beleid baring HT aandoening}

\subsubsection{Zwangerschapshypertensie}

- $\quad$ Bij zwangerschapshypertensie wordt gestreefd naar baring bij $37^{+0}-38^{+0}$ weken zwangerschap, tenzij de maternale of foetale conditie eerder ingrijpen noodzakelijk maakt.

- Bij zwangerschapshypertensie met een stabiel normale bloeddruk $(<140 / 90$ $\mathrm{mmHg}$ ) met (onveranderde) medicatie, bestaat de mogelijkheid een expectatief beleid te voeren t.a.v. de baring ook na $37^{+0}-38^{+0}$ weken zwangerschap.

- Bij vrouwen met een milde / matige hypertensie in de zwangerschap wordt de bloeddruk durante partu elk 2 uur gemeten.

- Bij vrouwen met ernstige zwangerschapshypertensie wordt de bloeddruk durante partu continue (elke 5 minuten) gemeten totdat een stabiele bloeddruk 135/85 mmHg bereikt is met medicatie. Daarna wordt de bloeddruk elke 15 minuten gemeten. 


\subsubsection{Preeclampsie en/of HELLP}

- Bij preeclampsie/ HELLP wordt gestreefd naar baring bij $37^{+0}$ weken zwangerschap, tenzij de maternale of foetale conditie eerder ingrijpen noodzakelijk maakt.

- Bij vrouwen met preeclampsie en/of HELLP wordt de bloeddruk durante partu continue (elke 5 minuten) gemeten totdat een stabiele bloeddruk 135/85 $\mathrm{mmHg}$ bereikt is met medicatie. Daarna wordt de bloeddruk elke 15 minuten gemeten.

\subsection{Beleid postpartum HT aandoening}

\subsubsection{Kraambed}

\section{- Observatie}

- Milde/matige hypertensie, klinische postpartum observatie ten minste 24 uur.

- Ernstige hypertensie, preeclampsie en/of HELLP, klinische postpartum observatie ten minste 48 uur.

\section{- Bloeddruk meting}

Bij vrouwen met een hypertensieve aandoening tijdens de zwangerschap, wordt de bloeddruk postpartum:

- Ten minste $3 \mathrm{dd}$ gemeten tot aan het ontslag in een klinische setting

- Daarna ten minste $1 \mathrm{dd}$ gemeten gedurende het kraambed

\section{- Bloedonderzoek}

- Bij vrouwen met preeclampsie en/of HELLP tijdens de zwangerschap, wordt postpartum voor ontslag bloedonderzoek ingezet: hemoglobine, trombocyten, ureum, urinezuur, creatinine, ASAT, ALAT, LDH.

- Afbouwen antihypertensiva

- Gedurende het kraambed worden antihypertensiva na overleg tussen verloskundige en gynaecoloog afgebouwd.

- Na het kraambed worden antihypertensiva door de gynaecoloog, huisarts of internist verder afgebouwd. Hierbij wordt gestreefd naar de uitgangsbloeddruk. 


\subsubsection{Nacontrole (6 weken pp)}

Bij vrouwen met een hypertensieve aandoening tijdens de zwangerschap wordt tijdens de nacontrole:

- Bloeddruk en pols gemeten

Daarnaast worden zij:

- Geïnformeerd over de korte en lange termijn risico's waar zij rekening mee dienen te houden.

- Gewezen op de patiëntenvereniging van stichting HELLP-syndroom.

- Geadviseerd hun bloeddruk jaarlijks bij de huisarts te laten controleren.

\subsubsection{Consult (>6 maanden $p p)$}

- Vrouwen met een hypertensieve aandoening (zwangerschapshypertensie, PE, HELLP) in de voorgeschiedenis, dienen na ten minste 6 maanden postpartum een consult aangeboden te krijgen bij de gynaecoloog voor uitleg over risico's op korte en lange termijn en mogelijke complicaties waar men op dient te letten.

- Een preconceptioneel consult voor vrouwen met een hypertensieve aandoening in de voorgeschiedenis, bevat ten minste een bloeddruk meting en een screening op proteïnurie (EKR). 


\subsection{Samenvatting}

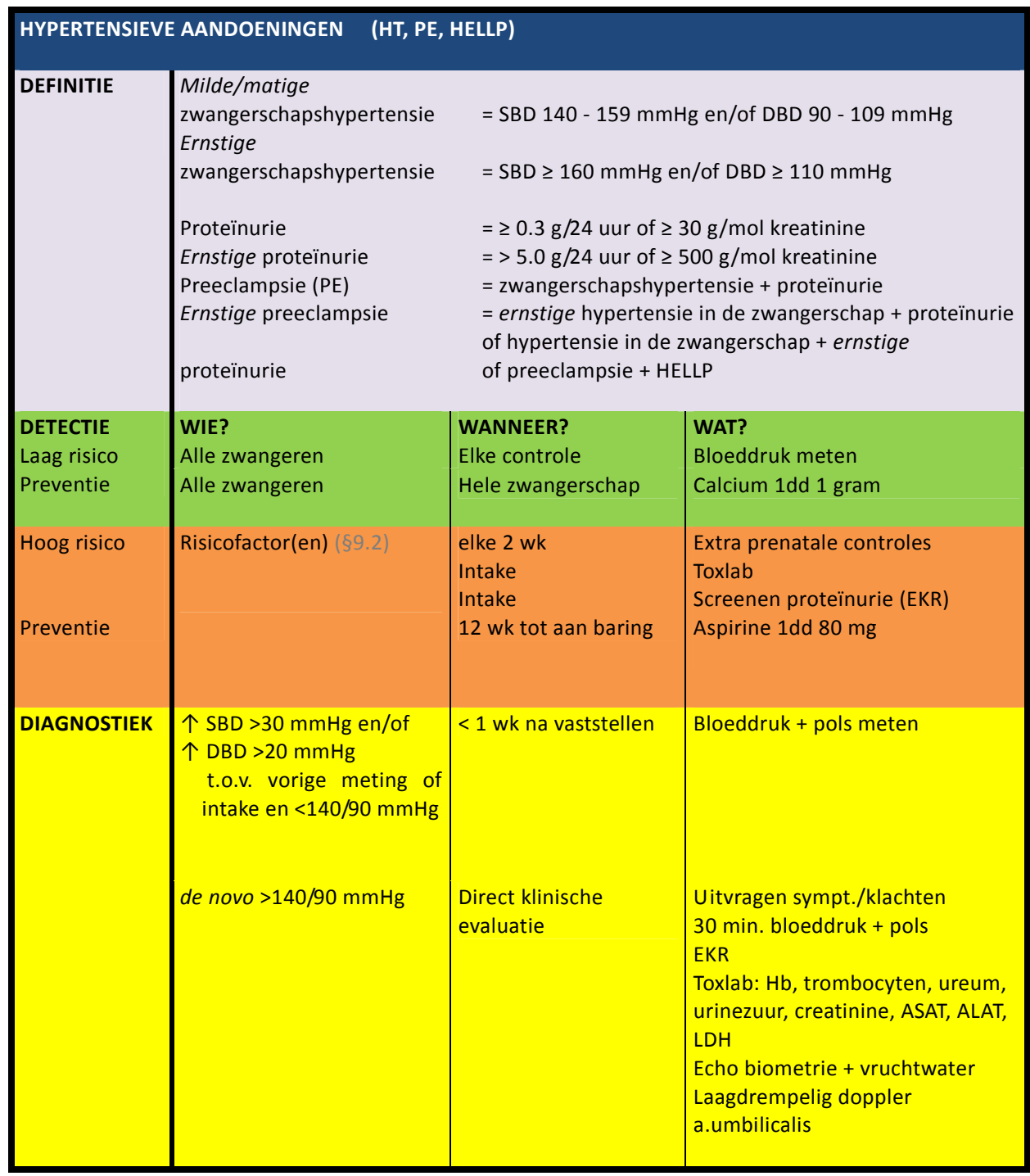




\begin{tabular}{|c|c|c|c|}
\hline \multirow[t]{5}{*}{$\begin{array}{l}\text { BELEID } \\
\text { Zwangerschap }\end{array}$} & $\begin{array}{l}\text { Hypertensie en/of klachten } \\
\text { (o.a. gejaagdheid) }\end{array}$ & & Bloeddruk + pols meten \\
\hline & $\begin{array}{l}\text { Alle zwangeren met } \\
\text { een HT aandoening }\end{array}$ & $\begin{array}{l}\text { Elke } 2-4 \mathrm{wk} \\
\text { Baring }<32^{+0} \mathrm{wk} \\
\text { Baring }<34^{+0} \mathrm{wk}\end{array}$ & $\begin{array}{l}\text { Echo biometrie (optie a.umb) } \\
\text { Overplaatsing perinat.centrum } \\
\mathrm{MgSO}_{4} \\
\text { Corticosteroïden im }\end{array}$ \\
\hline & Milde/matige $\mathrm{HT}$ & <1 wk na starten AHT & $\begin{array}{l}\text { Antihypertensiva overwegen } \\
\text { Streefwaarde } \pm 135 / 85 \mathrm{mmHg}\end{array}$ \\
\hline & Ernstige $\mathrm{HT}$ & $\begin{array}{l}\text { Direct } \\
\text { Direct } \\
\text { 24u na starten AHT }\end{array}$ & $\begin{array}{l}\text { Klinische opname voor stabilisatie } \\
\text { Start methyldopa, labetalol, } \\
\text { nifedipine of combinatie } \\
\rightarrow \text { pols meewegen in besluit AHT } \\
\text { Streefwaarde } \pm 135 / 85 \mathrm{mmHg}\end{array}$ \\
\hline & $\begin{array}{l}\text { Preeclampsie } \\
\qquad \begin{array}{l}\text { Ernstige PE } \\
\text { Eclamptisch insult }\end{array}\end{array}$ & $\begin{array}{l}\text { Direct } \\
3 x / d a g \\
2 x / w k \\
2 x / w k \\
1 x / d a g \\
\text { Direct } \\
\text { Direct }\end{array}$ & $\begin{array}{l}\text { Klinische opname } \\
\text { Bloeddruk meten } \\
\text { Toxlab } \\
\text { Proteïnurie vervolgen } \\
\text { Vragen naar sympt./klachten } \\
\text { Magnesiumsulfaat iv } \\
\text { Magnesiumsulfaat iv }\end{array}$ \\
\hline \multirow[t]{3}{*}{ Baring } & $\begin{array}{l}\text { Onders } \\
\text { tenzij de maternale }\end{array}$ & $\begin{array}{l}\text { aande termijnen worder } \\
\text { f foetale conditie eerder }\end{array}$ & $\begin{array}{l}\text { aangehouden, } \\
\text { ingrijpen noodzakelijk maakt }\end{array}$ \\
\hline & $\begin{array}{l}\text { Hypertensie } \\
\text { PE/HELLP }\end{array}$ & $\begin{array}{l}37^{+0}-38^{+0} w k \\
37^{+0} w k\end{array}$ & $\begin{array}{l}\text { Baring nastreven of expectatief bij } \\
\text { stabiele } \mathrm{RR}<140 / 90 \mathrm{mmHg} \text { met } \\
\text { onveranderde medicatie } \\
\text { Baring nastreven }\end{array}$ \\
\hline & $\begin{array}{l}\text { Milde/matige HT } \\
\text { Ernstige HT / PE } \\
\qquad \mathrm{RR}>135 / 85 \mathrm{mmHg} \\
\mathrm{RR}<135 / 85 \mathrm{mmHg}\end{array}$ & $\begin{array}{l}\text { Durante partu a } 2 \text { uur } \\
\text { Durante partu } \\
\text { elke } 5 \mathrm{~min} \\
\text { elke } 15 \mathrm{~min}\end{array}$ & $\begin{array}{l}\text { Bloeddruk meten } \\
\text { Bloeddruk meten }\end{array}$ \\
\hline \multirow[t]{2}{*}{ Kraambed } & $\begin{array}{l}\text { Milde/matige HT } \\
\text { Ernstige HT of PE/HELLP }\end{array}$ & $\begin{array}{l}\text { Direct postpartum } \\
\text { Klinisch min. } 3 \mathrm{dd} \\
\text { Na ontslag 1dd } \\
\text { Direct postpartum } \\
\text { Klinisch min. } 3 \mathrm{dd} \\
\text { Voor ontslag } \\
\text { Na ontslag 1dd }\end{array}$ & $\begin{array}{l}\text { 24u maternale observatie } \\
\text { Bloeddruk meten } \\
\text { Bloeddruk meten } \\
\text { 48u maternale observatie } \\
\text { Bloeddruk meten } \\
\text { Toxlab } \\
\text { Bloeddruk meten }\end{array}$ \\
\hline & $\begin{array}{l}\text { Verloskundige i.o.m. gyn } \\
\text { Gyn / huisarts / internist }\end{array}$ & $\begin{array}{l}\text { Gedurende kraambed } \\
\text { Na kraambed }\end{array}$ & $\begin{array}{l}\text { AHT afbouwen } \\
\text { AHT afbouwen } \\
\text { Streefwaarde = } \\
\text { uitgangsbloeddruk }\end{array}$ \\
\hline
\end{tabular}




\section{VERSCHILLENDE KLACHTEN TIJDENS DE ZWANGERSCHAP}

\subsection{Vaginaal bloedverlies}

\subsubsection{Definitie}

- Bloedverlies per vaginam tijdens de zwangerschap.

\subsubsection{Detectie}

- Informatie verkregen via anamnese, geobjectiveerd d.m.v. observatie en speculumonderzoek.

\subsubsection{Beleid}

- (Klinische) evaluatie:

o Spontaan vaginaal bloedverlies tijdens de zwangerschap is altijd reden voor evaluatie.

o Spontaan vaginaal bloedverlies na 24 weken zwangerschap bij een zwangere die niet in partu is, is altijd een reden voor klinische evaluatie in het ziekenhuis (o.a. beoordeling cervix, placenta, foetale conditie).

- Klinische opname:

o Indicatie: vaginaal bloedverlies, door de betreffende zorgverlener als zorgwekkend geschat, ongeacht de termijn.

o Bedrust (met was/toilet permissie) geadviseerd totdat het bloedverlies gestopt is, daarna wordt gestart met mobiliseren. Indien met mobiliseren ten minste 24 uur geen bloedverlies is opgetreden, volgt ontslag.

- Baring nastreven:

- Bloedverlies van uteriene oorsprong en met een zorgwekkende omvang na 37 weken zwangerschap, is een reden om baring na te streven (klinisch).

\subsection{Koorts}

\subsubsection{Definitie}

- Een temperatuur van $>38.0^{\circ} \mathrm{C}$ graden Celsius tijdens de zwangerschap wordt aangehouden als ondergrens voor het inzetten van verdere (infectie)diagnostiek. 


\subsubsection{Detectie}

- Door middel van een rectale of auriculaire meting met behulp van een thermometer.

\subsubsection{Beleid}

- Maternale koorts onder verdenking van een intra-uteriene infectie a terme is een reden om te streven naar baring.

\subsection{Gebroken vliezen}

\subsubsection{Definitie}

- Bij het breken van de vliezen komt kleurloos, meconium houdend of purulent vruchtwater vrij. De naamgeving is afhankelijk van de termijn waarbij de vliezen breken en of het breken van de vliezen gevolgd wordt door weeën activiteit.

De vliezen kunnen:

- Spontaan breken vóór $37^{+0}$ weken zwangerschap zonder aansluitende weeën activiteit (Preterm Premature Rupture of Membranes, PPROM),

○ Spontaan breken na $37^{+0}$ weken zwangerschap zonder aansluitende weeën activiteit (Premature Rupture of Membranes, PROM),

- Spontaan breken na $37^{+0}$ weken zwangerschap (Spontaneous Rupture of Membranes, SROM),

- Artificieel worden gebroken door een verloskundige zorgverlener (Artificial Rupture of Membranes, AROM).

\subsubsection{Detectie}

- Anamnese van plotseling vaginaal vochtverlies of de aanwezigheid van voortdurend vaginaal vochtverlies, gecombineerd met observatie van vochtverlies, zo nodig aangevuld met speculumonderzoek, echo onderzoek en/of een test om aan te tonen dat het opgevangen vocht vruchtwater is. 


\subsubsection{Beleid}

- Meconium houdend vruchtwater (MHVW):

- Streven naar baring (klinisch)

- Continue foetale bewaking durante partu

- Purulent vruchtwater:

- Direct streven naar baring (klinisch)

- Continue foetale bewaking durante partu

- Infectiediagnostiek inzetten

- Start antibiotica i.v.

- Temperatuur meten

- Prematuur gebroken vliezen (PPROM):

- Bij PPROM $<32^{+0}$ weken zwangerschap, overplaatsing naar perinatologisch centrum.

- $\quad \mathrm{Bij}$ PPROM $<37^{+0}$ weken groep-B-streptokokken (GBS) diagnostiek (introïtus vaginae - anus kweek) inzetten.

GBS kweek positief:

GBS profylaxe:

GBS kweek onbekend en $<37^{+0}$ weken:

GBS kweek onbekend en $>37^{+0}$ weken:

GBS kweek negatief: overweeg inleiden van de baring tussen $34^{+0}-37^{+0}$ weken.

durante partu antibiotica geven.

GBS profylaxe: durante partu antibiotica geven.

Keuze aan zorgverlener wel/geen GBS profylaxe.

Inleiden van de baring bij $37^{+0}$ weken.

Geen GBS profylaxe.

$\circ \quad \mathrm{Bij}$ PPROM $<34^{+0}$ wk of een niet goed ingedaald voorliggend deel wordt bedrust (met was/toilet permissie) geadviseerd.

Bij PPROM $>34^{+0} \mathrm{wk}+$ voldoende vruchtwater + ingedaald caput + geen tekenen van infectie, mag de zwangere na een observatieperiode van minimaal 48 uur naar huis met poliklinische controles (inclusief dagelijks CTG), indien de zorgverlener dit verantwoord acht. 
- A terme gebroken vliezen (PROM):

- Indien a terme $\left(>37^{+0} \mathrm{wk}\right)$ sprake is van gebroken vliezen met helder vruchtwater zonder contracties, wordt maximaal 24-72 uur een expectatief beleid gevoerd, alvorens de baring wordt nagestreefd.

- Eventuele overdracht van zorg naar de gynaecoloog vindt plaats 24 uur nadat de vliezen zijn gebroken.

- Bij langdurig gebroken vliezen (>24 uur) a terme wordt GBS diagnostiek ingezet. 


\section{VROEGGEBOORTE}

\subsection{Definitie}

- Vroeggeboorte wordt gedefinieerd als een geboorte vóór $37^{+0}$ weken zwangerschap.

\subsection{Risicofactoren vroeggeboorte}

- Zwangere vrouwen met een vroeggeboorte $<34^{+0}$ weken zwangerschap in de voorgeschiedenis, worden als hoog risicogroep beschouwd voor vroeggeboorte in de huidige zwangerschap.

NB. Zodra het predictiemodel van de Expect studie operationeel is wordt de hoog risico groep vastgesteld op basis van het model.

\subsection{Detectie vroeggeboorte}

- Bij asymptomatische laag risico zwangeren vindt geen standaard onderzoek plaats ter detectie van een dreigende vroeggeboorte. Onderzoek wordt wel ingezet bij asymptomatische zwangeren met een hoog risico op vroeggeboorte en/of zodra symptomen van een dreigende vroeggeboorte optreden.

\subsection{Beleid hoog risico vroeggeboorte}

\subsubsection{Hoofdbehandelaar}

- Indien sprake is van een hoog risico op vroeggeboorte is de gynaecoloog hoofdbehandelaar tot $37^{+0}$ weken zwangerschap, daarna kan de zorg indien gewenst worden overgedragen aan de verloskundige.

\subsubsection{Cervixlengte screening}

Voor het stroomschema vroeggeboorte zie §11.6.

- Bij zwangere vrouwen met een hoog risico op vroeggeboorte, dient de cervixlengte elke 4 weken gemeten te worden van 12-32 weken zwangerschap. 
- Voor het inzetten van vervolgbeleid worden de volgende criteria aangehouden:

$\circ \quad$ Een cervixlengte $<5^{\mathrm{e}}$ percentiel (Figuur 4)

- Een afname van de cervixlengte van 40 percentiel (overeenkomend met \pm 1 $\mathrm{cm}$ ) in 2 weken

○ Funneling, ongeacht de cervixlengte

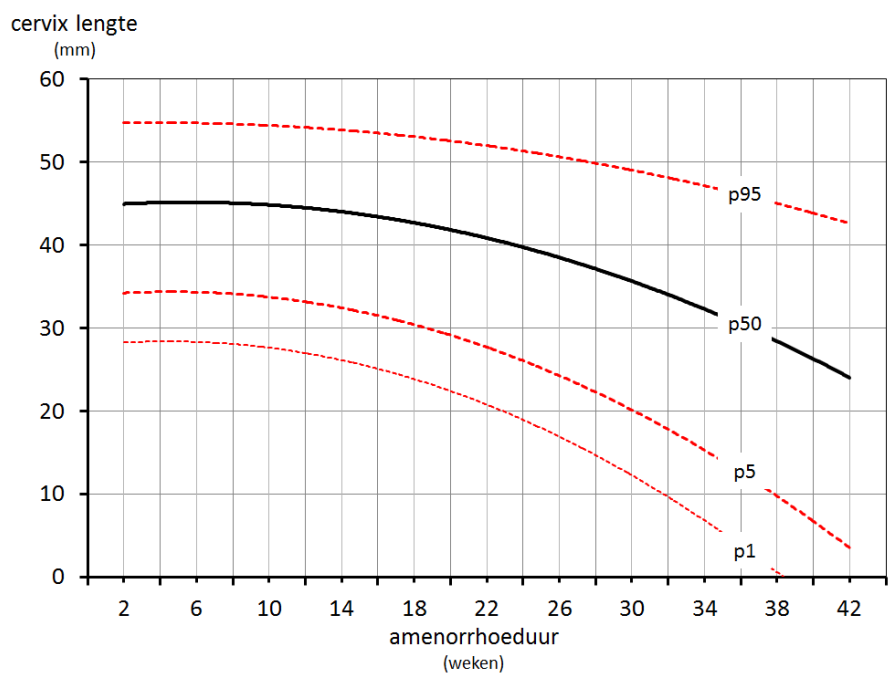

Figuur 4 Normwaarden cervixlengte tijdens de zwangerschap. Salomon, Ultrasound Obstet Gynecol 2009, Conde AJOG 2010.

\subsubsection{Progesteron}

- Indien sprake is van een hoog risico op vroeggeboorte i.v.m. een vroeggeboorte $<34^{+0} \mathrm{wk}$ in de voorgeschiedenis, wordt progesteron besproken en geadviseerd van $16^{+0}-36^{+6}$ wk zwangerschap.

- Progesteron dient bij voorkeur in vaginale vorm (dagelijkse toediening) te worden aangeboden.

Bij bezwaren voor vaginale toediening kunnen zwangeren na counseling voor intramusculaire toediening kiezen. 


\subsection{Dreigende vroeggeboorte tijdens huidige zwangerschap}

\subsubsection{Hoofdbehandelaar}

- Na een opname i.v.m. een dreigende vroeggeboorte, blijft de gynaecoloog hoofdbehandelaar tot $37^{+0}$ weken zwangerschap, daarna kan de verloskundige de zorg overnemen.

\subsubsection{Corticosteroïden}

- Bij een dreigende vroeggeboorte tussen $23^{+5}$ en $25^{+6}$ weken, wordt de zwangere verwezen naar een perinatologisch centrum en worden corticosteroïden toegediend indien na counseling voor een actief beleid gekozen wordt.

- Bij een dreigende vroeggeboorte tussen $26^{+0}$ weken en $33^{+6}$ weken worden corticosteroïden standaard gegeven.

- Een corticosteroïden kuur kan herhaald worden indien een $2^{\mathrm{e}}$ episode van een dreigende vroeggeboorte $<34^{+0}$ wk optreedt en de $1^{e}$ kuur vóór $32^{+0}$ wk gegeven is met een tijdsinterval van minimaal 2 weken tussen 2 kuren.

\subsubsection{Fibronectinetest}

- Bij zwangeren met symptomen van een dreigende vroeggeboorte en een transvaginaal gemeten cervixlengte tussen de $16-30 \mathrm{~mm}$ bij een termijn $<34^{+0}$ weken, wordt de fibronectinetest als aanvullend diagnosticum ingezet om de kans op vroeggeboorte te voorspellen.

○ Positieve fibronectinetest: bij een actief beleid overplaatsing naar perinatologisch centrum, tocolyse, corticosteroïden, magnesiumsulfaat ter neuroprotectie.

○ Negatieve fibronectinetest: observatie, cervixlengte vervolgen.

\subsubsection{Overplaatsing}

- Er vindt overplaatsing naar een perinatologisch centrum plaats bij een dreigende vroeggeboorte $<32^{+0}$ weken in combinatie met:

$\circ$ een cervixlengte $<15 \mathrm{~mm}$ en/of

$\circ>3 \mathrm{~cm}$ ontsluiting en/of 
- PPROM ongeacht of er sprake is van contracties

OF

○ een cervixlengte $16-30 \mathrm{~mm}+$ een positieve fibronectinetest

\subsubsection{Groep-B-streptokokken}

- $\quad B i j$ een dreigende vroeggeboorte $<37^{+0}$ weken wordt GBS diagnostiek (introïtus vaginae - anus kweek) ingezet.

GBS kweek positief: $\quad$ GBS profylaxe: durante partu antibiotica geven.

GBS kweek onbekend: GBS profylaxe: durante partu antibiotica geven. GBS kweek negatief: $\quad$ Geen GBS profylaxe.

\subsubsection{Magnesiumsulfaat}

- $\quad$ Bij een dreigende vroeggeboorte wordt tot $32^{+0}$ weken magnesiumsulfaat $\left(\mathrm{MgSO}_{4}\right)$ gegeven i.v.m. het neuroprotectieve effect 


\subsection{Stroomdiagram vroeggeboorte}

\section{Stroomdiagram (ver) korte (nde) cervix}

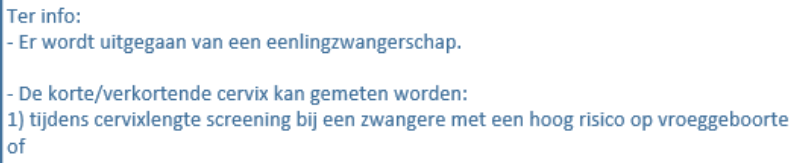

- Reeds tijdens een eerdere werkgroep is besloten als definitie van een korte cervix het 5e percentiel aan te houden en voor een verkortende cervix een afname van de cervixlengte van 40 percentiel $( \pm 1 \mathrm{~cm})$ in 2 weken (zie figuur 1 ).

- Bij zwangeren met een vroeggeboorte meest waarschijnlijk ten gevolge van een cervixinsufficiëntie in de voorgeschiedenis, kan een primaire cerclage sterk worden overwogen.

In onderstaand stroomdiagram is een tijdlijn weergegeven, met de momenten (12-16-20-24-28-32 wk) waarop cervixlengte screening plaats zal vinden in de groep vrouwen met een hoog risico op vroeggeboorte. Wie een hoog risico heeft, zal bepaald worden door het predictiemodel van de Expect studie. Bij elk screeningsmoment zijn de bevindingen van de cervixlengte meting en het te volgen beleid weergegeven. Gezien het feit dat we het schema zo eenvoudig en uniform mogelijk willen maken, staan er situaties in die in de praktijk vrijwel niet of nooit voor zullen komen. 


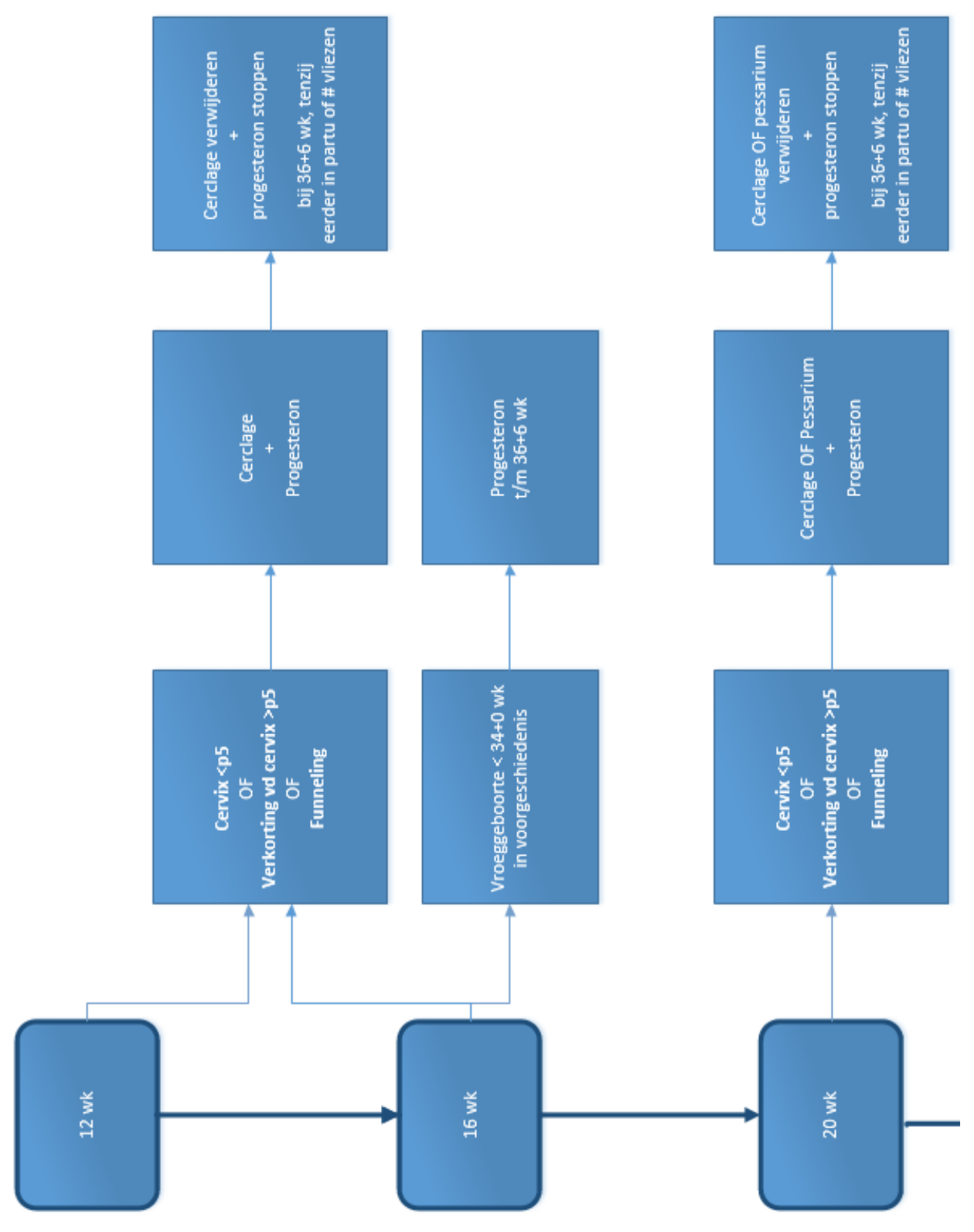




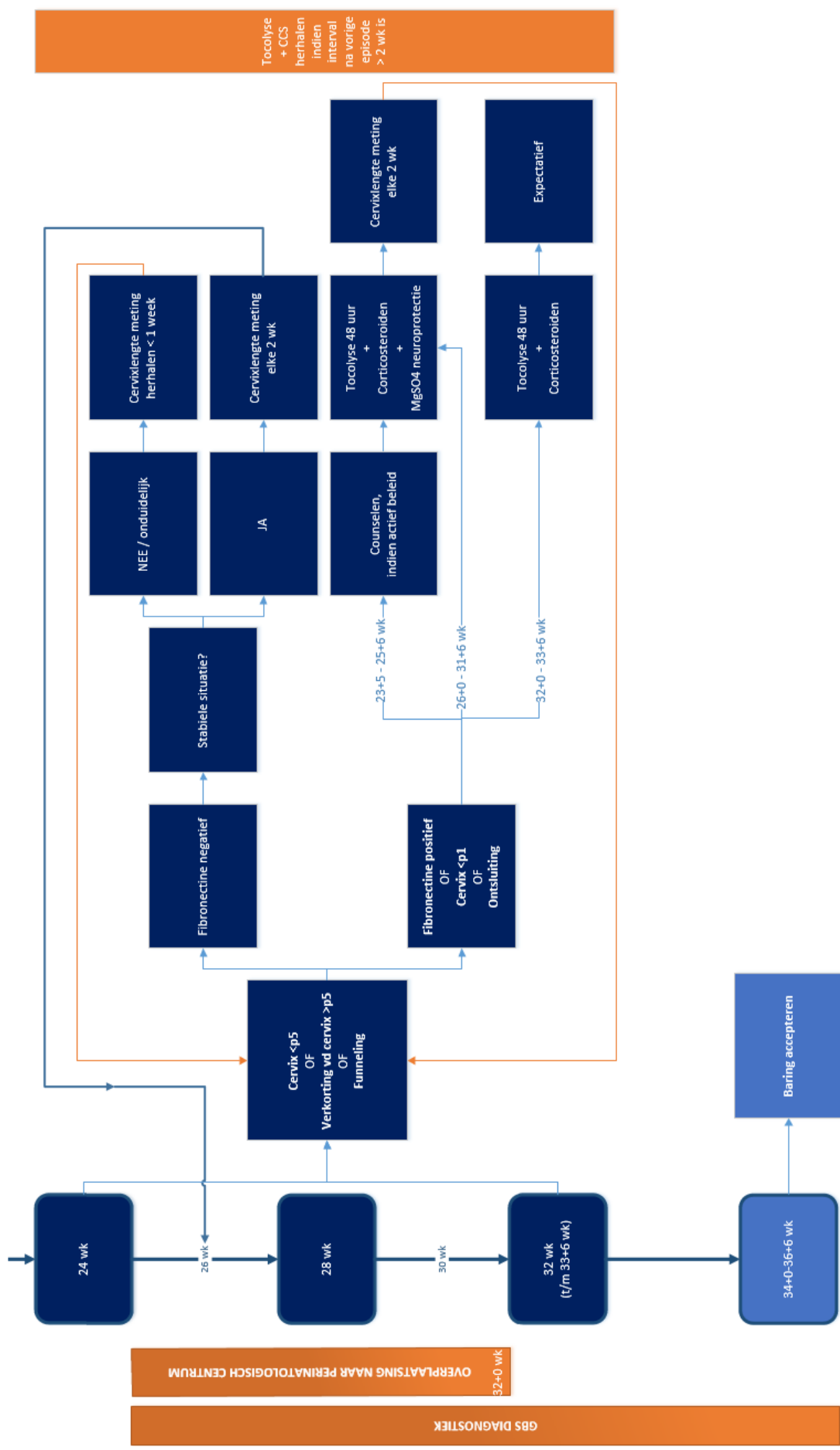




\section{SEROTINITEIT}

\subsection{Definitie serotiniteit}

- Serotiniteit wordt in dit document gedefinieerd als een zwangerschapsduur na $42^{+0}$ weken op basis van de echoscopische termijnbepaling (CRL). In de praktijk wordt de term 'dreigende serotiniteit' vaak gehanteerd na een termijn van $41^{+0}$ weken.

\subsection{Beleid serotiniteit}

\section{- Hoofdbehandelaar}

Indien de verloskundige de hoofdbehandelaar is, blijft zij dat tot aan de datum van inleiding of $42^{+0}$ weken, tenzij complicaties optreden die verandering van hoofdbehandelaar noodzakelijk maken.

\section{- Counseling}

Bij een normaal ontwikkelende zwangerschap vindt counseling i.v.m. serotiniteit en het inleiden van de baring bij alle zwangeren plaats rond $40^{+0}$ weken (bij voorkeur door hoofdbehandelaar).

\section{- Consult gynaecoloog}

Bij een zwangerschapsduur van $40^{+5}-41^{+1}$ weken dient een consult bij de gynaecoloog plaats te vinden ter beoordeling van de foetale conditie.

- Expectatief beleid

- Indien na $41^{+0}$ weken voor een expectatief beleid gekozen wordt, vindt ten minste $2 x$ per week een prenatale controle plaats, inclusief een CTG + echo vruchtwater.

- Inleiden van de baring wordt nagestreefd bij uiterlijk $42^{+0}$ weken. Dit wordt met alle zwangeren besproken.

NB. Zodra de resultaten van de Index-trial bekend zijn, zullen deze worden meegewogen in bovenstaand besluit.

\section{- Strippen}

- Strippen om de kans op het spontaan op gang komen van de baring te vergroten en serotiniteit te voorkomen, behoort tot de mogelijkheden na voorlichting over het beoogde effect en de kans op pijn/contracties en vaginaal bloedverlies. 
- Strippen kan vanaf een termijn van $38^{+0}$ weken worden besproken/ aangeboden en dient vanaf $40^{+0}$ weken actief aangeboden/aangeraden te worden.

\section{- Inleiden}

Op verzoek van de zwangere kan zij vanaf $41^{+0}$ weken worden ingeleid na counseling over de voor- en nadelen. 


\section{NORMALE BARING}

\section{Begrippen plaatsbepaling of klinische baring}

Waar in de LOQS documenten gesproken wordt over een plaatsbepaling voor de baring, wordt bedoeld een baring in het ziekenhuis (open verloskamer) onder verantwoordelijkheid van de eerstelijns verloskundige. Een klinische baring impliceert een baring in het ziekenhuis onder verantwoordelijkheid van de gynaecoloog.

\subsection{Wel/niet in partu}

- Om semantische discussies te voorkomen heeft de werkgroep besloten geen fases van de baring te hanteren maar uit te gaan van de begrippen 'wel/niet in partu'.

\subsubsection{Beoordeling wel/niet in partu}

- Beoordeling van de zwangere dient plaats te vinden, indien sprake is van:

- Contracties in combinatie met portioveranderingen.

- Gebroken vliezen in combinatie met pijnlijke contracties.

○ Contracties in combinatie met zorgwekkend bloedverlies (\$10.1).

- Een zwangere met contracties ( $\geq 3$ per 10 min.) in combinatie met een (niet volledig) verstreken portio wordt binnen 2 - 4 uur herbeoordeeld om te kunnen beoordelen of zij wel/niet 'in partu' is.

- In een klinische setting zal een periode van 2 uur gehanteerd worden.

- In de thuissituatie wordt een periode van 2-4 uur gehanteerd.

De zwangere wordt de keuze gegeven wanneer zij wenst dat de verloskundige terugkomt voor deze herbeoordeling.

\subsubsection{In partu}

- Primipara: 'in partu' vanaf $3 \mathrm{~cm}$ ontsluiting in combinatie met contracties.

- Multipara: 'in partu' vanaf $6 \mathrm{~cm}$ ontsluiting in combinatie met contracties.

\subsubsection{Niet in partu}

- Met een zwangere met pijnlijke contracties, die op basis van de vastgestelde criteria niet 'in partu' wordt verklaard, dienen de verschillende opties van 
pijnstilling/sedatie (conform het lokale ziekenhuisprotocol) en begeleiding besproken te worden.

\subsection{Durante partu}

\subsubsection{Begeleiding}

- Zodra de zwangere in partu is verklaard, dient er continue begeleiding te zijn door een zorgverlener, tenzij de zwangere dit niet wenst (begeleiding kan gedaan worden door o.a. verloskundige, verpleegkundige, kraamverzorgende).

\subsubsection{Vaginaal toucher}

- Een vaginaal toucher (VT) dient gedurende de hele baring verricht te worden met een interval van 2 uur.

- Na een interventie (vliezen breken en/of bijstimulatie met oxytocine) wordt het VT 2 uur na de interventie herhaald.

\subsubsection{Partogram}

- Zodra de zwangere 'in partu' verklaard is, wordt het aantal centimeters per uur ingevuld in een partogram (Figuur 5).

- Het ontsluitingsbeloop dient van begin tot eind lineair te verlopen, dat wil zeggen met een vaste snelheid per uur.

- Primipara normale ontsluitingssnelheid 1 centimeter per 2 uur.

- Multipara normale ontsluitingssnelheid 1 centimeter per uur.

- In het partogram wordt het normale ontsluitingsbeloop (waarschuwingslijn) in combinatie met twee actielijnen (oranje en rood) weergegeven.

Voor verschillende interventies (minimale/zwaardere interventies) wordt een andere actielijn aangehouden op basis van de impact die de interventie heeft op de barende.

De actielijn voor een minimale interventie (oranje) ligt op 2 uur van het normale ontsluitingsbeloop. Onder een minimale interventie wordt verstaan:

- Artificieel breken van de vliezen (AROM).

- Bespreken van de mogelijkheid van oxytocine toediening na 2 uur. 
○ Bespreken van de mogelijkheid van adequate medicamenteuze pijnstilling na 2 uur.

De actielijn voor een zwaardere interventie (rood) ligt op 4 uur van het normale ontsluitingsbeloop. Onder een zwaardere interventie wordt verstaan:

- Abdominale kunstverlossing (sectio caesarea).

- Adviseren oxytocine toediening na 4 uur.

○ Adviseren medicamenteuze pijnstilling na 4 uur.

Bij het bepalen van het moment van de interventie dient de plaats waar de barende zich bevindt (thuis/ziekenhuis) meegewogen te worden in de besluitvorming.

De wens van de barende om langer af te wachten alvorens over te gaan tot een interventie moet gehonoreerd worden, mits er sprake is van een goede foetale conditie.

$>\quad \mathrm{Bij}$ het bepalen van het beleid wordt de draaglast/draagkracht van de zwangere door de zorgverlener meegewogen in de besluitvorming.

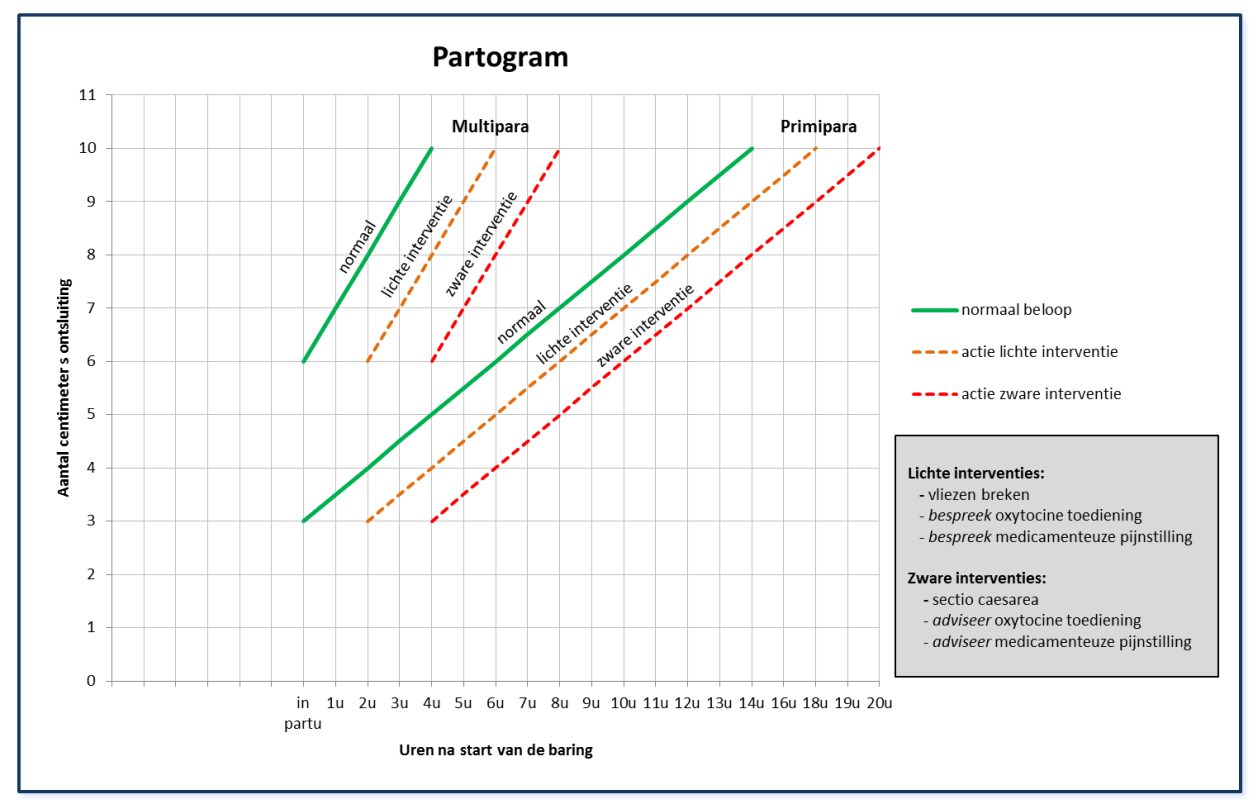

Figuur 5 Partogram. 


\subsection{Uitdrijving}

\subsubsection{Start persen}

- Bij volledige ontsluiting zonder persdrang mag maximaal 2 uur afgewacht worden alvorens gestart wordt met actief persen.

\subsubsection{Actief persen}

- De periode waarin actief geperst wordt met nulliparae is $\mathbf{2}$ uur onder voorwaarden van:

- goede weeën activiteit (minimaal 2 contracties per 10 minuten, caput succedaneum)

○ voldoende vordering van de uitdrijving (inschatting parteur)

$\circ$ de inschatting dat het kind binnen 2 uur geboren wordt

- De periode waarin actief geperst wordt met multiparae is $\mathbf{1}$ uur onder voorwaarden van

- goede weeën activiteit (minimaal 2 contracties per 10 minuten, caput succedaneum)

○ voldoende vordering van de uitdrijving (inschatting parteur)

$\circ$ de inschatting dat het kind binnen 1 uur geboren wordt

Indien niet aan bovenstaande criteria wordt voldaan is sprake van een niet vorderende uitdrijving, zie $\$ 14.4$.

\subsection{Maternale controles durante partu}

- Durante partu dient de bloeddruk en pols minimaal eenmaal gemeten te worden.

- De temperatuur wordt alleen op indicatie gemeten.

- $\quad$ Er wordt actie ondernomen indien een:

○ systolische bloeddruk (SBD) $<90 \mathrm{mmHg}$ of $>140 \mathrm{mmHg}$ gemeten wordt durante partu

- diastolische bloeddruk (DBD) $<50 \mathrm{mmHg}$ of $>90 \mathrm{mmHg}$ gemeten wordt durante partu

- stijging van $\mathrm{SBD} \geq 25 \mathrm{mmHg}$ ten opzichte van de voorgaande meting gemeten wordt 
○ stijging van $\mathrm{DBD} \geq 15 \mathrm{mmHg}$ ten opzichte van de voorgaande meting gemeten wordt

- maternale pols $<50$ of $>105$ slagen/minuut gemeten wordt durante partu

- subjectieve klachten bestaan die zouden kunnen wijzen op een preeclampsie/HELLP

○ temperatuur $\geq 38.0^{\circ} \mathrm{C}$ gemeten wordt

De actie kan bestaan uit het herhalen van de metingen, verdere diagnostiek en zo nodig behandeling ter uitsluiting van vasculaire of infectieuze problematiek.

(Zie H9 hypertensieve aandoeningen.)

\subsection{Foetale controles durante partu}

- Een foetale basis hartfrequentie $<110$ of $>150$ slagen/minuut, vereist klinische evaluatie.

- Bij intermitterende auscultatie d.m.v. doptone durante partu, wordt:

- aan het begin van de baring de foetale basis hartfrequentie vastgesteld door enkele minuten aaneengesloten te luisteren

○ ten minste elke 2 uur naar de foetale hartfrequentie geluisterd + conclusie en beleid in het dossier genoteerd

- bij iedere interventie (VT, AROM) naar de foetale hartfrequentie geluisterd

○ tijdens de uitdrijving na elke contractie geluisterd naar de foetale hartfrequentie (documentatie achteraf)

- Bij continue foetale bewaking d.m.v. een cardiotocogram (CTG) durante partu, wordt:

○ tijdens de ontsluiting ten minste elk uur het CTG geclassificeerd + conclusie en beleid in het dossier te genoteerd

- tijdens de uitdrijving elke 15 minuten het CTG te geclassificeerd (documentatie achteraf)

- bij aanhoudende variabele deceleraties in combinatie met gebroken vliezen amnioninfusie aanbevolen.

NB. Gezien de complexiteit van continue foetale bewaking d.m.v. CTG en de beoordeling ervan, wordt verwezen naar de NVOG richtlijn 'Intrapartum foetale bewaking a terme', mei 2014. 


\section{NIET VORDERENDE BARING}

\subsection{Definitie}

Niet vorderende ontsluiting (NVO):

- Primipara: indien de ontsluiting minder dan $\mathbf{1}$ centimeter per $\mathbf{2}$ uur vordert

- Multipara: indien de ontsluiting minder dan $\mathbf{1}$ centimeter per $\mathbf{1}$ uur vordert Niet vorderende uitdrijving (NVU):

- Primi- en multipara: gedurende $\mathbf{3 0}$ minuten absoluut géén vordering/indaling van het caput tijdens de uitdrijving (na toepassing van conventionele middelen zoals houdingsveranderingen en/of aanmoediging)

\subsection{Detectie niet vorderende baring}

- Door middel van vaginaal touchers durante partu en notitie van het aantal centimeters ontsluiting in een partogram kan een niet vorderende ontsluiting worden vastgesteld.

- Door middel van vaginaal touchers tijdens de uitdrijving, waarmee onder andere de indaling van het caput wordt beoordeeld, kan een niet vorderende uitdrijving worden vastgesteld.

\subsection{Beleid niet vorderende ontsluiting}

\section{Zie ook het partogram \$13.2.3, figuur 5.}

- Eerste actie (stap 1$)$

De eerste actie bij een NVO is het artificieel breken van de vliezen.

NB. Voorafgaande aan deze eerste stap kunnen niet-invasieve interventies plaatsvinden zoals blaaslediging, houdingsverandering, douche/bad, et cetera.

- Tweede actie (stap 2)

De tweede actie bij een NVO is intraveneuze bijstimulatie met oxytocine in combinatie met adequate pijnbestrijding.

- Derde actie (stap 3)

De derde actie bij een NVO, ondanks maximale oxytocine bijstimulatie en adequate pijnbestrijding, is een sectio caesarea.

NB. Indien adequate pijnbestrijding uit epidurale anesthesie bestaat, dient het trombocytenaantal ten minste $>80 \times 10^{9}$ te zijn. Voor overige voorwaarden, zie de NVA richtlijn 'Neuraxisblokkade en antistolling', 2014. 


\subsection{Beleid niet vorderende uitdrijving}

- Onvoldoende weeën

- Start oxytocine stimulatie, indien als oorzaak van de NVU een gebrek aan weeën (géén caput succedaneum, moulage) het meest waarschijnlijk wordt geacht.

- Voldoende weeën

\section{○ Vaginale kunstverlossing}

Een NVU ondanks voldoende weeën, waarbij de grootste diameter van het caput de bekkeningang gepasseerd is, wordt in beginsel beëindigd door middel van een vaginale kunstverlossing.

\section{- Sectio caesarea}

Een NVU ondanks voldoende weeën, waarbij de grootste diameter van het caput de bekkeningang nog niet gepasseerd is, wordt beëindigd door middel van een sectio caesarea. Een vaginale kunstverlossing is dan gecontra-indiceerd. 


\section{SCHOUDERDYSTOCIE}

\subsection{Definitie}

- Er wordt gesproken van een schouderdystocie bij toepassing van andere handelingen dan de standaard ontwikkeling van de schouders (bimanueel omvatten en sacraalwaarts bewegen van het caput).

- Er wordt gesproken van een ernstige schouderdystocie bij toepassing van 2 of meer extra (naast bovengenoemde) handgrepen en/of letsel van het kind.

\subsection{Beleid schouderdystocie in voorgeschiedenis}

- Gewichtsschatting

Bij een schouderdystocie in de voorgeschiedenis dient tijdens de huidige zwangerschap rond $36^{+0}$ weken door de hoofdbehandelaar een adequate gewichtsschatting gemaakt te worden, d.m.v. een echo biometrie in combinatie met uitwendige palpatie. Deze gewichtsschatting in combinatie met de echo biometrie en uitwendige palpatie rond 36 weken, bepalen mede de plaats van de baring (zie onderstaand).

- Plaatsindicatie

Voor de baring bestaat ten minste een plaats indicatie bij een schouderdystocie in de voorgeschiedenis en in de huidige zwangerschap een vergelijkbaar groot kind (maximaal 500 gram zwaarder t.o.v. geboortegewicht van het kind waarbij de schouderdystocie optrad).

- Klinische baring

- Een klinische baring is geïndiceerd bij een schouderdystocie in de voorgeschiedenis en in de huidige zwangerschap een kind met een geschat gewicht dat $>\mathbf{5 0 0}$ gram zwaarder is t.o.v. het geboortegewicht van het kind waarbij de schouderdystocie optrad.

- Bij een ernstige schouderdystocie in de voorgeschiedenis wordt een primaire sectio caesarea besproken.

$\mathrm{Na}$ het optreden van een schouderdystocie documenteert de parteur een advies ten aanzien van de volgende baring (vaginale (proef)baring of primaire sectio caesarea) en bespreekt dit met relevante zorgverleners, de zwangere en haar partner. 


\section{FLUXUS POSTPARTUM}

\subsection{Definitie}

- In Nederland wordt een primaire fluxus postpartum (FPP) gedefinieerd als bloedverlies peripartum van $1000 \mathrm{ml}$ of meer.

\subsection{Risicofactoren FPP}

- In het ziekenhuis zal de FLUXIM-checklist (§16.3) gebruikt worden ter inventarisatie van de groep vrouwen met een hoog risico op een fluxus postpartum.

- Verloskundigen zullen onderstaande risicofactoren aanhouden, waarop zij het risico op een fluxus voor de zwangere beoordelen en zodoende de plaats voor de baring bepalen.

$\mathrm{Er}$ is geen consensus bereikt voor het gebruik van de FLUXIM-checklist door verloskundigen.

- Risicofactoren voor een fluxus postpartum die een klinische baring rechtvaardigen:

- Pre-existente hypertensie

- Trombocytopathie / -penie

- Stollingsstoornis

- Uterus myomatosus

- Sectio caesarea in anamnese

- Grote uitzetting (meerling, EFW >p95 en/of AC >p95, polyhydramnion)

- Zwangerschapshypertensie, preeclampsie, HELLP

- Placenta praevia, accreta, increta, percreta

- Risicofactoren voor een fluxus postpartum die ten minste een plaatsindicatie rechtvaardigen:

- $\mathrm{BMI}>35 \mathrm{~kg} / \mathrm{m}^{2}$

- Fluxus postpartum in anamnese

- Manuele placentaverwijdering in anamnese 
- Indien 1 of meer van onderstaande risicofactoren aanwezig zijn, dient gezien het licht verhoogde risico op een fluxus postpartum, een plaatsindicatie voor de baring overwogen te worden.

- Aziatische etniciteit

- Grande multipara ( $>5 x$ bevallen)

○ Anemie $\mathrm{Hb}<5.6$ in $3^{\mathrm{e}}$ trimester

- Recidiverend vaginaal bloedverlies tijdens het $2^{\mathrm{e}} / 3^{\mathrm{e}}$ trimester van de zwangerschap

(Komt uit oude richtlijnen, hier is geen bewijs voor indien de oorzaak van het bloedverlies onbekend is) 


\subsection{FLUXIM checklist}

\section{"Fluxus implementatie strategie" Hemorrhagie postpartum (HPP)}

\section{Stopmoment 2 Intake verloskamers}

Doel stopmoment 2: risicomanagement en beleidsbepaling.

\section{Risicomanagement}

- Intake te verrichten bij binnenkomst patiente op de verloskamers

- Controleren medisch dossier patiente

1. Is stopmoment 1 verricht op de polikliniek?

$\square$ Nee, ga naar vraag 2

$\square$ Ja, en er is wel sprake van een verhoogd risico $\Rightarrow$ ga naar beleidsbepaling

$\square \mathrm{Ja}$, en er is geen sprake van een verhoogd risico $\Rightarrow$ controleer voor de volgende aanvullende risicofactoren:

$\square$ AD $<31$ weken
$\square$ Inleiding
$\square$ IUVD
Indien $1 \geq$ risicofactor(en) aanwezig $\Rightarrow$ ga door naar beleidsbepaling

2. Controleer voor de volgende risicofactoren.

Algemene voorgeschiedenis
$\square$ BMI > 35 kg/m²
$\square$ Aziatische etniciteit
$\square$ Pre-existente hypertensie
$\square$ Trombocytopathie/-penie
$\square$ Stollingsstoornis
$\square$ Uterus myomatosus

Obstetrische voorgeschiedenis Hemorrhagie postpartum MPV

Sectio caesarea

Grande multipara (para $>3$ )

Huidige graviditeit

$\square$ Grote uitzetting

(meerling, groei $>$ p95, polyhydramnion)

Bloedverlies $2^{\mathrm{e}} / 3^{\mathrm{e}}$ trimester

Antistolling gebruik durante partu

Zwangerschapshypertensie

Preeclampsie of HELLP-syndroom

$\mathrm{Hb}<6.5 \mathrm{mmol} / \mathrm{I}$ ( $3^{\mathrm{e}}$ trimester)

Indien $1 \geq$ risicofactor(en) aanwezig $\Rightarrow$ ga door naar beleidsbepaling

Indien geen risicofactor aanwezig $\Rightarrow$ geen verhoogd risico, einde checklist intake verloskamers

\section{Beleid bepalen en noteren}

Waakinfuus aanwezig durante partu

Geldig kruisbloed aanwezig durante partu

$\mathrm{Hb}$ controleren / bepalen indien geen recent $\mathrm{Hb}$

Actief nageboortetijdperk

- $5 \mathrm{EH}$ oxytocine iv

- Gevolgd door $10 \mathrm{EH}$ oxytocine in 4 uur

- Frequente controle tonus van de uterus

Bloedverlies meten

Team informeren over hoog risico en beleid

Patiënte en partner informeren over verhoogd risico en beleid

COLOFON

(C) 2014. Fluxim projectgroep. Deze checklist is opgesteld door de Fluxim projectgroep in samenwerking met de Nederlandse vereniging voor Obstetrie en

Gynaecologie. De inhoud correspondeert met de NVOG richtlijn hemorrhagia postpartum dd 18-11-2013 


\section{"Fluxus implementatie strategie" Hemorrhagie postpartum (HPP)}

\section{Stopmoment 3 \\ Time-out}

Doel stopmoment 3: risicomanagement en beleidsbepaling.

\section{Risicomanagement}

- Time-out te verrichten kort voor start uitdrijving (7-9 cm ontsluiting) - In aanwezigheid van: parteur, verpleegkundige, patiente \& partner

\section{Is er sprake van een hoog risico? \\ $\square$ Ja, ga naar beleidsbepaling \\ $\square$ Nee, ga naar vraag 2}

2. Controleer de volgende aanvullende risicofactoren:

$\square$ Langdurige baring ( $>10$ uur) of bijstimulatie

$\square$ Maternale koorts of verdenking IU infectie

$\square$ Gebruik tocolyse (in verband met dreigende vroeggeboorte) durante partu

Indien $1 \geq$ risicofactor(en) aanwezig $\Rightarrow$ ga door naar beleidsbepaling

Indien geen risicofactor aanwezig $\Rightarrow$ ga naar vraag 3

3. Zijn de volgende mogelijke risicofactoren bij het team bekend:
$\square$ Langdurige uitdrijving
$\square$ Kunstverlossing
$\square$ Fundusexpressie
$\square$ Episiotomie
$\square$ Schouderdystocie
$\square$ Nageboortetijdperk > 30 minuten

\section{Beleidsbepaling}

Controleren

$\square$ Waakinfuus aanwezig?

$\square$ Geldig kruisbloed?

$\square$ Recent $\mathrm{Hb}$ bekend? (3e trimester)

Indien hoog risico op basis van stollingsprobleem?

$\square$ Stollingsstatus bekend?

$\square$ Te nemen aanvullende maatregelen bekend?

\section{Afspraken}

$\square$ ledereen op de hoogte van het volgende beleid?

- Actief nageboortetijdperk

- 5 EH Oxytocine iv

- Gevolgd door 10 EH Oxytocine in 4 uur

- Controle tonus van de uterus (Frequentie optioneel: a 5 of $10 \mathrm{~min}$ )

- Verwijder direct 1e mat na geboorte kind

- Bloedverlies meten

$\square$ Medicatie opgetrokken?

$\square$ Bekend indien > $500 \mathrm{cc}$ bloedverlies start checklist HPP?

$\square$ Uitvoerder checklist HPP benoemd? 
"Fluxus implementatie strategie" Hemorrhagie postpartum (HPP)

Checklist behandeling HPP

Patientsticker

Doel checklist: handleiding behandeling HPP

- Start checklist bij persisterend bloedverlies >500cc (achterzijde)

Telefoonnummers

Dienstdoende

- AIOS:

- Gynaecoloog:

OK:

Anesthesie:

Transfusielab:

Reanimatiesein:
Shock klassificatie

\begin{tabular}{|r|r|r|r|r|}
\hline Shock klasse & Klasse 1 & Klasse 2 & Klasse 3 & Klasse 4 \\
\hline Bloedverlies & $<750 \mathrm{cc}$ & $750-1500 \mathrm{cc}$ & $1500-2000 \mathrm{cc}$ & $>2000 \mathrm{cc}$ \\
\hline Volume & $<15 \%$ & $15-30 \%$ & $30-40 \%$ & $>40 \%$ \\
\hline Pols & $<100 \mathrm{sl} / \mathrm{min}$ & $>100 \mathrm{sl} / \mathrm{min}$ & $>120 \mathrm{sl} / \mathrm{min}$ & $>140 \mathrm{sl} / \mathrm{min}$ \\
\hline Bloeddruk & normaal & normaal & verlaagd & verlaagd \\
\hline Urine productie & $>30 \mathrm{cc} / \mathrm{u}$ & $20-30 \mathrm{cc} / \mathrm{u}$ & $5-15 \mathrm{cc} / \mathrm{u}$ & nihil \\
\hline Mentaal & alert & angst & verward & lethargie \\
\hline
\end{tabular}

\section{Registratie vocht en medicatie}

\begin{tabular}{|c|c|c|c|}
\hline vocht & Tijd & Medicatie & Tijd \\
\hline$\square$ Kristalloiden ........ cc & & $\square$ Bolus Oxytocine $5 \mathrm{E}$ iv & \\
\hline$\square$ Kristalloiden ........ cc & & $\square$ Oxytocine $10 \mathrm{EH}$ iv pomp & \\
\hline$\square$ Kristalloiden ........ cc & & $\square \ldots . .$. & \\
\hline$\square$ Kristalloiden ........ cc & & $\square$ Methergin $0,2 \mathrm{mg} \mathrm{IM}$ of IV & \\
\hline$\square \ldots \ldots$. & & $\square 2^{\mathrm{e}}$ bolus Methergin $0,2 \mathrm{mg}$ IM of IV & \\
\hline$\square$ Packet cell 1 & & $\square$ Sulproston $500 \mathrm{mcg} / 30 \mathrm{~min}$ & \\
\hline$\square$ Packet cell 1 & & $\square$ Sulproston $500 \mathrm{mcg}$ & \\
\hline$\square$ Packet cell 1 & & (dosering $60-120 \mathrm{mcg} / \mathrm{u}$ ) & \\
\hline$\square$ Packet cell 1 & & $\square$ Tranexamine zuur ...... gr & \\
\hline$\square$ FFP 1 & & $\square$ Fibrinogeen 2 gr & \\
\hline$\square$ FFP 1 & & $\square \ldots \ldots$ & \\
\hline
\end{tabular}

Notities 


\section{$500 \mathrm{cc}$ en persisterend}

\begin{tabular}{|c|c|c|}
\hline Hulp & $\ldots \ldots \ldots \ldots$ & $\square$ Waarschuw gynaecoloog (in opleiding) \\
\hline Controle & (n......... & $\begin{array}{l}\square \text { Bloedverlies wegen } \\
\square \text { Vitale parameters controles: } \square \text { pols \& saturatie continue } \quad \square \text { bloeddruk a 5-10 min } \\
\square \text { Kruisbloed Hb \& Ht afnemen indien onbekend }\end{array}$ \\
\hline Actie & 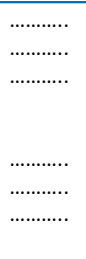 & $\begin{array}{ll}\text { Vullen ruim NaCL of Ringers of REFILL studie } & \\
\square \text { Continu uterusmassage } & \\
\square \text { Eenmalige katheterisatie of CAD } & \text { Placenta niet geboren } \\
\text { Placenta geboren } & \square \text { Eenmalig poging geboorte placenta } \\
\begin{array}{ll}\square \text { Inspecteer geboortekanaal } & \text { MPV } \\
\square \text { Controleer compleetheid placenta, } & \square \text { OK/anesthesie bellen } \\
\text { Indien twijfel: natasten } & \\
& \end{array} \text { Patiënte en partner informeren over hoeveelheid bloedverlies en beleid }\end{array}$ \\
\hline Medicatie & 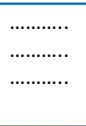 & $\begin{array}{l}\square \text { Herhaal bolus Oxytocine } 5 \mathrm{EH} \mathrm{IV} \mathrm{in} 1-2 \mathrm{~min} \\
\square \text { placenta geboren: overweeg Methergine 0,2 mg IM, Niet geboren: indien geen vertraging: } \\
\text { sulproston (nalador) } 500 \mathrm{mcg} \text { (stand 16.7) } \\
\square \text { Overweeg Tranexaminezuur } 2 \text { gram }\end{array}$ \\
\hline 10 & 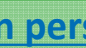 & te \\
\hline
\end{tabular}

\begin{tabular}{|c|c|c|}
\hline Hulp & …...... & $\begin{array}{l}\square \text { Noodbel } \\
\square \text { Gynaecoloog met spoed laten komen }\end{array}$ \\
\hline Controle & …....... & $\begin{array}{l}\square \text { Vitale parameters controleren: } \square \text { pols \& saturatie continue } \\
\square \text { Urine productie controleren dmv CAD en urimeter } \\
\square \text { CITO Hb, Ht, Trombo's, APTT, PT, fibrinogeen bepalen of ROTEM }\end{array}$ \\
\hline Actie & 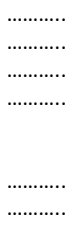 & $\begin{array}{l}\square \text { Continue uterus massage } \\
\square 15 \mathrm{~L} \mathrm{O}_{2} \text { geven, non-rebreathing masker } \\
\square \text { 2de infuus inbrengen } \\
\square \text { Vulling continueren, NaCL of Ringers eventueel REFILL studie (verwarmd, onder druk) } \\
\square \text { Houd patiënte warm } \\
\square \text { Bel anesthesie en OK team } \\
\square \text { Transporteer patiënte naar OK tenzij in directe afwachting behandeling atonie } \\
\square \text { Patiënte en partner informeren over hoeveelheid bloedverlies en beleid }\end{array}$ \\
\hline Medicatie & 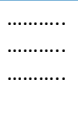 & $\begin{array}{l}\square \text { Methergin 0,2 mg IM of IV (indien placenta al geboren, bij herhaling pas na } 2 \mathrm{uur} \text { geven) } \\
\square \text { Sulproston (nalador) } 500 \mathrm{mcg} \text { in } 30 \mathrm{~min} \text { (stand 16.7), gevolgd door 60-120mcg/u, max } 1500 \\
\mathrm{mcg} / 24 \mathrm{u} \\
\square \text { Tranexaminezuur } 2 \mathrm{gr} \text { indien nog niet gegeven }\end{array}$ \\
\hline
\end{tabular}

\section{$>2000 \mathrm{cc}$}

\begin{tabular}{|c|c|c|}
\hline Hulp & 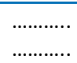 & $\begin{array}{l}\square \text { Overweeg extra gynaecoloog erbij halen } \\
\square \text { Overweeg overleg interventie radioloog }\end{array}$ \\
\hline Controle & ................ & $\square$ Herhalen: CITO Hb, Ht, Trombo's, APTT, PT, fibrinogeen of ROTEM \\
\hline Actie & 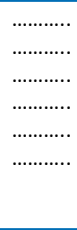 & $\begin{array}{l}\square \text { Continue uterus massage } \\
\square \text { Bimanuele compressie/aorta compressie als tijdswinst } \\
\square \text { Overweeg Bakri ballon } \\
\square \text { Start protocol massale transfusie } \\
\square \text { Transporteer patiënte naar OK of angiokamer } \\
\square \text { Overweeg B lynch bij open buik, primair embolisatie na vag partus } \\
\square \text { indien embolisatie niet effectief lapartomie: onderbinden vaten/uterusextirpatie } \\
\square \text { Patiënte en partner informeren over hoeveelheid bloedverlies en beleid }\end{array}$ \\
\hline Medicatie & ............... & $\begin{array}{l}\square \text { Corrigeer stolling (Streefwaardes: Fibrinogeen }>2,5 \text {, Trombo's }>50 \text { (indien chirurgische } \\
\text { ingreep }>80 \text { ). ROTEM: FIBTEM na } 10 \mathrm{~min}>15 \mathrm{~mm} \\
\square \text { PC als } \mathrm{Hb}<5.0\end{array}$ \\
\hline
\end{tabular}




\subsection{Detectie FPP}

- Bij 'ruim' bloedverlies (inschatting zorgverlener) postpartum dient het bloedverlies gewogen te worden.

\subsection{Preventie FPP}

- $\quad$ Actief leiden nageboortetijdperk

Bij alle vrouwen wordt het nageboortetijdperk actief geleid d.m.v. het toedienen van $10 \mathrm{IE}$ oxytocine intramusculair of $5 \mathrm{IE}$ oxytocine intraveneus direct postpartum.

\subsection{Beleid hoog risico FPP}

Een hoog risico op een fluxus postpartum vereist:

- Ten minste een plaats-indicatie voor de baring

- Een waaknaald durante partu inclusief afname van kruisbloed

- Tonus en hoogte van de fundus uteri postpartum elke 5-10 minuten controleren gedurende ten minste 60 minuten

- Bloedverlies postpartum wegen

- Thuissituatie/poliklinisch: postpartum 4 uur observatie/meting van de pols, vaginaal bloedverlies en de tonus + hoogte van de fundus uteri door de parteur ten minste elke 30 minuten.

○ Klinisch: preventief wordt postpartum (naast de standaard gift oxytocine) 2.5 IE per uur extra oxytocine intraveneus gegeven gedurende 4 uur.

\subsection{Beleid (dreigende) FPP}

- Baring thuis + persisterend bloedverlies (ruimer dan normaal) $>\mathbf{5 0 0 ~} \mathrm{ml}$ :

- Spoedverwijzing naar het ziekenhuis

○ Bloeddruk + pols ten minste elke 5-10 minuten meten

- Verblijfskatheter (CAD) inbrengen

- Tijdens de telefonische overdracht aan het ziekenhuis door de verloskundige, wordt de noodzaak tot parallelle acties besproken: 
Hierbij wordt meegewogen:

- Aan- of afwezigheid van tekenen van shock (o.a. pols $>110$ slagen/min, lage bloeddruk)

- Wel/niet geboren zijn van de placenta

En wordt afgesproken:

- Waar de patiënt naartoe gaat; direct naar de operatiekamers of eerst naar de verloskamers

- Baring met plaatsindicatie + bloedverlies $>\mathbf{5 0 0} \mathrm{ml}$ :

- Overdracht van zorg aan de gynaecoloog

○ Bloeddruk en pols ten minste elke 5-10 minuten meten

○ Verblijfskatheter (CAD) inbrengen

- Retentio placentae:

○ 30 Minuten na de geboorte van het kind vindt overdracht van zorg naar de gynaecoloog plaats, ongeacht de hoeveelheid bloedverlies.

\subsection{Medicamenteuze behandeling FPP}

Tabel 8 Medicamenteuze behandeling bij een fluxus postpartum.

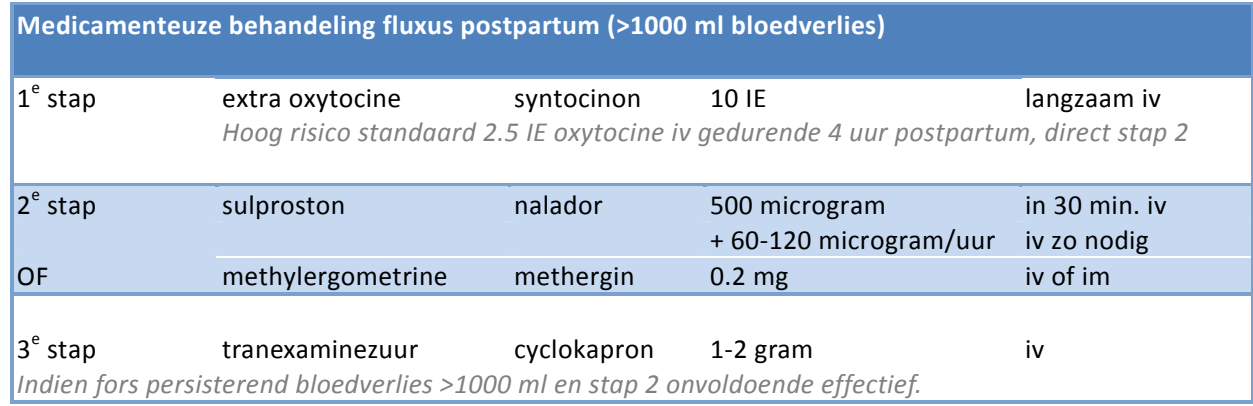

NB1. Medicatie ter behandeling van een fluxus postpartum wordt gegeven volgens de aanbevelingen van de NVOG richtlijn 'Hemorrhagia postpartum', november 2013. Voor andere niet-medicamenteuze behandelopties wordt eveneens verwezen naar deze richtlijn.

NB2. Bij beschikbaarheid van oxytocine heeft misoprostol geen meerwaarde in de behandeling van een fluxus postpartum. 


\subsection{Beleid kraambed}

- Indien sprake is van een fluxus postpartum (>1000 ml bloedverlies), wordt 2448 uur postpartum het maternale hemoglobinegehalte $(\mathrm{Hb})$ bepaald. 


\section{KRAAMZORG}

\subsection{Zwangerschap}

- Huisbezoek

De kraamzorg legt een huisbezoek af bij iedere zwangere vóór een zwangerschapsduur van 34 weken.

Doel van het huisbezoek is:

- Observeren van de gezinssituatie en signaleren of er sprake is van (psycho)sociale problematiek binnen het gezin;

- Waar nodig aanvullende prenatale voorlichting geven;

- Beoordelen of in de thuissituatie van de vrouw een veilige bevalling en kraamperiode mogelijk is. Daarbij gaat het zowel om de veiligheid van de zwangere en het (ongeboren) kind als om de veiligheid van de werksituatie voor de professionals (verloskundige en kraamverzorgende);

- Beoordelen onder welke aan te passen condities de thuissituatie eventueel wel voldoende veilig is;

○ Inschatten hoeveel uren kraamzorg geïndiceerd zijn volgens het Landelijk Indicatie Protocol Kraamzorg (2008).

○ Voorlichting geven o.a. over veilig slapen, veilige thuisbevalling, vroegtijdige partusassistentie.

\section{- Vroegsignalering}

Aanwezigheid van 2 of meer van onderstaande risicofactoren (Tabel 9) is reden om contact op te nemen met de hoofdbehandelaar, tenzij de hulpverlener de aanwezigheid van 1 risicofactor als zeer ernstig inschat. Op onderstaande signalen dient gelet te worden tijdens het huisbezoek, maar uiteraard ook gedurende de kraamperiode. 
Tabel 9 TNO signaleringslijst.

- Een of beide ouders zijn jonger dan negentien jaar

- Laag opleidingsniveau (opleidingsniveau maximaal lbo/vbo, praktijkonderwijs of vmbo Kaderberoepsgerichte leerweg. Of maximaal twee jaar onderwijs in een ande-re schoolopleiding in het voortgezet onderwijs aansluitend op het basisonderwijs

- Sociaal isolement of gebrek aan sociale steun

- Verslavingsproblematiek ouder(s)

- Actueel gezinsgeweld of partnergeweld

- Eerder sprake van gezinsgeweld of partnergeweld

- Zelf als kind mishandeld (gezinsgeweld of mishandeling in jeugd van een van beide ouders)

- Psychische problematiek, zoals angsten en depressie

- Psychiatrie bij moeder en/ of vader

- Zwakbegaafde moeder en / of vader

- Ernstige gedragsproblematiek moeder/vader

- Irreële opvattingen over aanstaand moederschap, sterke voorkeur voor geslacht, beeld over de tijdsinvestering verzorging (minder dan vier uren is onrealistisch), beeld over reden van huilen van de baby? (als moeder aangeeft dat dit stoutigheid is of verwend gedrag, is dit onrealistisch)

- Niet afgemaakte vooropleiding, schoolverlater, werkloos

- Financiële en/of huisvestingsproblemen

- Alleenstaande moeder

- Negatieve beleving zwangerschap, ongewenst kind

- Wegblijven van moeder uit de zorg of laat aanmelden voor zorg

- "Niet pluis"-gevoel van hulpverlener

- Slecht de Nederlandse taal sprekend

- Geïsoleerd gezin

- Agressief gedrag van moeder en/of vader

- Illegaliteit van moeder en vader (ivm verzekering en mogelijkheid op aanspraak van hulp)

- Geen huisvesting

\section{- Continue begeleiding durante partu}

De mogelijkheid van continue begeleiding door de kraamverzorgende tijdens de baring, wordt actief aangeboden/aangeraden en tijdens de zwangerschap besproken.

\subsection{Baring}

- In de thuissituatie

- Na het in partu verklaren wordt het kraamcentrum door de verloskundige geïnformeerd over de baring en wordt afgesproken wanneer de kraamverzorgende komt.

- Partusassistentie door een kraamverzorgende is noodzakelijk en de kraamverzorgende dient tijdens de uitdrijving aanwezig te zijn. 


\subsection{Maternale postpartum controles}

\subsubsection{Eerste periode postpartum ( $<24$ uur)}

- De eerste periode postpartum betreft de eerste 24 uur postpartum.

- Controle van onderstaande maternale kenmerken vindt ten minste $\mathbf{1} \mathbf{- 2}$ keer routinematig plaats in de eerste 24 uur postpartum.

- Na een spontane vaginale baring gaat de kraamvrouw huiswaarts of verlaat de verloskundige de kraamvrouw afhankelijk van de plaats van de baring, indien onderstaande controles normaal zijn.

- In de eerste periode wordt gemeten/beoordeeld:

- Bloeddruk

- Pols (hartfrequentie)

- Temperatuur

- Hoeveelheid vaginaal bloedverlies

- Hoogte van de fundus uteri

- Optreden van spontane mictie (<4-6 uur)

- Perineum

17.3.2 Tweede periode postpartum $(24 u-8 e / 10 e$ dag pp)

- De tweede periode postpartum betreft de periode vanaf 24 uur postpartum $\mathrm{t} / \mathrm{m}$ de $8^{\mathrm{e}}$ dag postpartum bij een normaal kraambed, en $\mathrm{t} / \mathrm{m}$ de $10^{\mathrm{e}}$ dag postpartum bij een verlengd kraambed.

- De opnameduur na een sectio caesarea is bij een ongecompliceerd beloop, indien onderstaande controles normaal zijn, en een gezonde neonaat ten minste 72 uur.

- In de tweede periode wordt 1 maal per dag routinematig gemeten/ beoordeeld:

- Pols (hartfrequentie)

○ Temperatuur (\$17.4.2)

- Hoeveelheid vaginaal bloedverlies

- Hoogte van de fundus uteri

- Perineum

○ Borsten (\$17.4.5)

○ Benen (tekenen DVT?) (\$17.4.6)

- Controle op voldoende mictie 
- Gevraagd naar:

- Algemeen welbevinden

- Mictie en/of defecatie klachten (\$17.4.4)

Klachten passend bij:

- Hypertensieve aandoening

- Infectie (uterus, urinewegen, wond)

- Trombose

○ Bloedverlies

- Emotionele instabiliteit (waaronder ernstige slaapproblematiek)

- Besproken:

○ Anticonceptie

- (Borst)voeding

- De eerste 48 uur postpartum dient er voldoende begeleiding te zijn om zorg te dragen voor een goede start van de borstvoeding.

- De lactatiekundige wordt bij problemen met de borstvoeding tijdig ingeschakeld.

- Gebruik van vitamine K en D voor de neonaat

○ Neonatale hielprik en gehoorscreening

○ Beleving

- Tijdens het kraambed dient besproken te worden hoe de vrouw en haar partner de baring hebben ervaren (gezien deze beleving kan afwijken van de beleving van de zorgverlener) en dient er voldoende aandacht te zijn voor de psychische gesteldheid van beiden.

- Indien ouders vragen hebben die zij zouden willen bespreken met de hulpverlener die hen verwezen heeft of met de parteur, kan een consult bij deze hulpverlener worden aangeboden.

- Bij tekenen van psychose dient direct aanvullende hulp te worden ingeroepen.

- Het psychisch welbevinden van vrouwen met een verhoogd risico op een postpartum depressie (o.a. depressie in de voorgeschiedenis, andere psychiatrische problematiek), dient $3-4$ weken postpartum geëvalueerd te worden (door verloskundige, huisarts).

Bij aanwezigheid van klachten vindt een gerichte intensivering van de maternale controles plaats. 
Bij complicaties in het kraambed wordt primair naar de huisarts verwezen, tenzij de aard en ernst van de complicatie een ziekenhuisopname aannemelijk maakt.

Bij voorkeur worden complicaties tijdens het kraambed door de verloskundige aan de gynaecoloog gerapporteerd, bij vrouwen die tijdens hun zwangerschap en baring onder verantwoordelijkheid van de gynaecoloog vielen.

\subsection{Maternale postpartum complicaties}

\subsubsection{Bloeddruk}

- Postpartum de novo hypertensie (>140/90 mmHg) en/of preeclamptische klachten is reden voor aanvullende diagnostiek en zo nodig behandeling.

\subsubsection{Temperatuur}

- Koorts, definitie: een herhaaldelijk (2 metingen, interval 2-4 uur) gemeten temperatuur $\geq 38.5^{\circ} \mathrm{C}$.

- $\quad$ Na een eerste meting $38.5^{\circ} \mathrm{C}$, worden conventionele middelen* ingezet.

*o.a. aandacht voor omgevingstemperatuur, warme kleding, voldoende drinken, paracetamol, rust.

- Indien koorts is vastgesteld wordt:

○ bloeddruk en pols gemeten

$\circ$ indien de pols $>110$ slagen/minuut is $\rightarrow$ lokale sepsisprotocol in werking

- lichamelijk onderzoek van borsten, buik, benen en op indicatie longen verricht

- beoordeeld of opname noodzakelijk is

- bloed afgenomen (bloedbeeld, infectieparameters)

- een kweek ingezet van de meest waarschijnlijke focus voor de koorts (o.a. bloed-, urine-, vagina-, wondkweek)

\subsubsection{Uterus}

- Riekende lochia in combinatie met koorts en/of buikpijn, is reden voor het inzetten van aanvullende diagnostiek (o.a. vaginakweek, infectielab) en zo nodig behandeling. 
- Medicamenteuze behandeling van endometritis bestaat uit amoxicilline $3 \mathrm{dd}$ $500 \mathrm{mg}$ in combinatie met metronidazol $3 \mathrm{dd} 500 \mathrm{mg}$ gedurende 7 dagen of amoxicilline/clavulaanzuur $3 \mathrm{dd} \quad 500 / 125 \mathrm{mg}$ gedurende 7 dagen. Kraamvrouwen die klinisch opgenomen zijn, worden behandeld conform het lokale ziekenhuisprotocol.

\subsubsection{Mictie en defecatie}

- De kraamvrouw dient binnen 4-6 uur na de bevalling spontane mictie te hebben gehad.

- Medicamenteuze behandeling van een urineweginfectie postpartum bestaat uit nitrofurantoïne 2 dd $100 \mathrm{mg}$ gedurende 5 dagen of amoxicilline/clavulaanzuur 3 dd $500 / 125$ mg gedurende 5 dagen. Kraamvrouwen die klinisch opgenomen zijn, worden behandeld conform het lokale ziekenhuisprotocol.

- Defecatie dient binnen 4-6 dagen postpartum plaats te vinden, daarna wordt (naast conventionele middelen) laxerende medicatie aangeboden.

\subsubsection{Borsten}

- Bij symptomen passend bij een beginnende mastitis (o.a. roodheid, pijn, koorts) worden als eerste stap conventionele middelen/methoden (oa. warme/koude kompressen, borst goed leeg kolven, voldoende drinken) ingezet.

- Indien conventionele middelen ter preventie van mastitis onvoldoende effectief zijn binnen 24 uur, wordt aanvullende diagnostiek en zo nodig behandeling ingezet.

- Medicamenteuze behandeling van mastitis bestaat uit flucloxacilline 3dd 500 mg gedurende 7 dagen en bij overgevoeligheid voor penicillinen erytromycine 3-4dd 500mg gedurende 7 dagen. Kraamvrouwen die klinisch opgenomen zijn, worden behandeld conform het lokale ziekenhuisprotocol.

\subsubsection{Benen / longen}

- Tromboseprofylaxe in het kraambed bestaat uit laag moleculaire heparines (LMWH). 
- Bij tekenen van een veneuze trombotische embolie (VTE)* dient een arts geraadpleegd te worden.

* diep veneuze trombose/longembolie: o.a. roodheid, pijnlijke kuit, zwelling, kortademigheid, pijn op de borst.

NB. De huidige NVOG richtlijn 'Veneuze trombo-embolie' uit 2009 blijft leidend.

\subsubsection{Post-punctionele hoofdpijn}

- Houdingsafhankelijke hoofdpijn aansluitend op epidurale/spinale anesthesie niet reagerend op cafeïne en paracetamol binnen 3 dagen, is reden voor klinische evaluatie en behandeling.

\subsection{Neonatale controles}

\subsubsection{Wegen}

- De neonaat wordt ten minste 3 keer gewogen:

- bij geboorte,

○ halverwege het kraambed,

- einde van het kraambed.

- Wegen van de (blote) neonaat in de $1^{\mathrm{e}}$ week postpartum wordt bij voorkeur telkens op dezelfde weegschaal, door dezelfde persoon en op hetzelfde tijdstip (bijvoorbeeld altijd direct voor een voeding) gedaan.

\subsubsection{Voeding}

- Bij borstvoeding is een gewichtsafname van:

○ $7 \%$ ten opzichte van het geboortegewicht reden om extra aandacht te besteden aan de voeding*.

○ $10 \%$ ten opzichte van het geboortegewicht reden om te starten met bijvoeding en contact op te nemen met de kinderarts.

- Bij flesvoeding is een gewichtsafname van:

- $10 \%$ ten opzichte van het geboortegewicht reden om extra aandacht te besteden aan de voeding* en contact op te nemen met de kinderarts. 


\section{* Met extra aandacht voor de voeding wordt bedoeld:}

o Letten op de moeder-kind interactie

- Drinktechniek (manier van drinken, boeren, spugen, loopt voeding uit mondje enz).

o Duur van het voeden

- Technische aspecten (soort speen, gebruik hulpmiddelen zoals tepelhoedje, soort fles, omgeving waarin gevoed wordt enz.)

- Neonatale mictie en defecatie

- Vochtintake moeder

- Frequentie van het aanleggen

- Voor en na de voeding wegen

- Koemelkallergie in de familie

- Laagdrempelig laten afkolven

- Overweeg consult lactatiekundige

\subsubsection{Temperatuur}

- Neonatale temperatuur meten:

○ $1^{\mathrm{e}}$ dag postpartum bij elke voeding

- $2^{\mathrm{e}}$ dag tot het einde van het kraambed ten minste 2 maal daags gemeten

- Een eenmalig gemeten neonatale temperatuur $>38.0^{\circ} \mathrm{C}$ is reden voor contact met de kinderarts.

- Een neonatale subfebriele temperatuur van $37.5-38.0{ }^{\circ} \mathrm{C}$ is reden om verkoelende maatregelen te nemen.

- Een neonatale ondertemperatuur $<36.5^{\circ} \mathrm{C}$ is reden om warmte bevorderende maatregelen te nemen.

- Indien extra maatregelen voor een subfebriele- of ondertemperatuur onvoldoende effect hebben binnen 1-2 uur, dient een kinderarts geraadpleegd te worden.

\subsubsection{Mictie en defecatie}

- Bij het uitblijven van spontane mictie door de neonaat binnen 24 uur postpartum en/of het uitblijven van defecatie door de neonaat binnen 24-48 uur postpartum, dient de kinderarts geraadpleegd te worden. 


\subsubsection{Overige}

- De navelstomp dient dagelijks gecontroleerd en verzorgd te worden, bij tekenen van infectie (o.a. roodheid, warmte) wordt de hoofdbehandelaar geraadpleegd.

- Een neonaat met $\geq 1$ van de volgende alarmsymptomen is een reden voor de kraamverzorgende om contact op te nemen met de hoofdbehandelaar (gynaecoloog of verloskundige):

$\circ \quad$ Niet alert, suf

- Hypotoon, hypertoon

- Geprikkeld, overstrekken

- Afwijkende kleur (blauw, grauw, bleek, geel)

- Trillerig, 'fladderen'

- Koorts / ondertemperatuur

- Braken

- Onvoldoende natte luiers ( $<4 \mathrm{dd}$ vanaf de 3 e dag postpartum)

$\circ \quad$ Onvoldoende defecatie ( $\leq 1 \mathrm{dd}$ )

- Versnelde ademhaling (>60 ademhalingen/min)

- Versnelde hartslag (>160 slagen/min)

- Onvoldoende drinken

- Overmatig huilen

○ 'Niet pluis' gevoel van de kraamverzorgende

Bij een verdenking op een neonatale hyperbilirubinemie wordt verwezen naar de landelijke richtlijn hyperbilirubinemie. https://www.nvkc.nl/kwaliteitsborging/ documents/richtlijnhyperbilirubinemiedefinitief.pdf

\subsection{Voorlichting kraambed}

Gedurende het kraambed zal door de kraamverzorgende onder andere informatie aan de kraamvrouw en haar partner worden gegeven over:

- Voeding (borst- en flesvoeding)

- Verzorging baby (incl. veilig slapen, huilen)

- Verzorging kraamvrouw (incl. gezonde voeding)

- Roken

- Interactie in gezin

- Screeningen/consultatiebureau/JGZ

- Emotionele veranderingen 


\subsection{Postpartum controle (na \pm 6 weken)}

Tijdens de nacontrole met de ouders dienen ten minste de volgende punten aan bod te komen:

- Beleving van de baring

- Sociale steun

- Wondherstel van het perineum en/of abdominaal

- Incontinentie voor flatus, faeces en/of urine

- Anticonceptie

- Voeding neonaat

- Leefstijladviezen (op indicatie)

- Beleid voor een eventuele volgende zwangerschap en baring (o.a. preconceptioneel advies)

Indien tijdens de zwangerschap en/of baring complicaties zijn opgetreden, dienen deze complicaties tijdens de nacontrole besproken te worden en afspraken gemaakt te worden voor follow-up indien nodig. Zie daarvoor de betreffende hoofdstukken.

\subsection{Communicatie}

- Indien een kraamverzorgende gedurende het kraambed één of meer van onderstaande signalen (Tabel 10) opmerkt, is dit een reden om contact op te nemen met de hoofdbehandelaar. 
Tabel 10 Signalen die overleg met de hoofdbehandelaar noodzakelijk maken.

\section{Signalen opgemerkt door de kraamverzorgende tijdens het kraambed}

\section{Baby}

- Baby huilt veel of de ouders vinden dat de baby veel huilt.

Geef hierbij aan hoeveel uur per dag de baby huilt.

\section{Moeder}

- Moeder lijkt zich ongelukkig te voelen/ zich niet goed in haar vel te voelen

- Moeder laat merken dat ze het niet goed aan kan

- Problemen in het contact met de baby, bijvoorbeeld:

* Moeder maakt geen oogcontact met de baby

* Moeder zegt geen bemoedigende woorden tegen de baby

* Moeder houdt de baby niet graag vast

- Moeder heeft een afkeer van de verzorging van de baby

- Moeder raakt erg van streek van het huilen van de baby

- Moeder lijkt niet van de baby te genieten

\section{Andere (eigen) kinderen}

- Ander kind is onverzorgd (niet aangekleed, krijgt onvoldoende eten, enz.)

- Gewoonte om ander kind alleen te laten zonder begeleiding

- Strenge straffen (zoals slaan, opsluiting)

- Ouders schreeuwen veel tegen kinderen

- Blauwe plekken of andere verwondingen bij een kind

- Ander kind trekt meer naar kraamverzorgende toe dan naar de ouders

- Ouders stellen weinig grenzen en geven weinig structuur aan kinderen

\section{Gezinssituatie}

- Ouders blijven zeggen dat ze teleurgesteld zijn over het geslacht van de baby of dat de baby ongewenst is

- Alcohol- of drugsmisbruik in het gezin

- Één van de ouders heeft de neiging van slag te raken en boos te worden

- Geweld of ruzie tussen ouders

- Er is niet veel steun van de partner

- Als kraamverzorgende voel ik me niet prettig in dit gezin

- Ouders hebben een vijandige houding naar de kraamverzorgende toe

- Financiële zorgen/armoede in het gezin

\section{Woon-/leefsituatie}

- De communicatie met de moeder verloopt moeizaam

- Gezin heeft weinig steun van familie en vrienden

\section{Overige}

- Signalen die niet onder de andere kopjes passen maar die ik als kraamverzorgende wel belangrijk vindt om door te geven aan de hoofdbehandelaar.

\section{- Ontslag uit ziekenhuis}

- Het ontslaggesprek met de kraamvrouw in het ziekenhuis, vindt bij voorkeur de dag voor ontslag plaats. 
- De ontslagbrief bevat naast de gebruikelijke PRN gegevens, een korte toelichting over het beloop van de baring, eventuele complicaties tijdens de zwangerschap en/of baring en een advies t.a.v. preconceptioneel advies, de volgende zwangerschap en baring.

- Na elke baring vindt bij ontslag een schriftelijke en telefonische overdracht plaats van het ziekenhuis naar de kraamzorg en verloskundige.

\section{- Huisarts informeren}

De huisarts dient <48 uur na de baring door de hoofdbehandelaar geïnformeerd te worden over (het beloop van) de baring.

- Communicatie

- De communicatie tussen verloskundige en kraamverzorgende in het kraambed verloopt d.m.v. het zorgplan van de kraamzorg en/of mondeling.

- De overdracht van kraamzorg naar de jeugdgezondheidszorg verloopt d.m.v. het overdrachtsformulier van de kraamzorg, ingevuld door alle disciplines. 




\section{ADDENDUM}

Afkortingen

Samenstelling werkgroepen

Geraadpleegde achterban

Publicatielijst

Curriculum Vitae

Dankwoord 



\section{AFKORTINGEN}

ACM arteria cerebri media

AHT antihypertensieve therapie

AROM artificial rupture of membranes

A.umb arteria umbilicalis

BMI body-mass-index

$\mathrm{Cm}$ centimeter

CRL crown rump length, kruin romp lengte

CTG cardiotocogram

CxI cervixlengte

DBD diastolische bloeddruk

DBP distantia biparietalis

EFW estimated fetal weight, geschat foetaal gewicht

FPP fluxus postpartum

GBS groep-b-streptokokken

GUO geavanceerd ultrageluids onderzoek

$\mathrm{Hb}$ hemoglobine

HBsAg hepatitis-B surface antigeen

HC head circumference, hoofdomtrek

HELLP Hemolysis Elevated Liver enzymes Low Platelets

HIV humaan immunodeficiëntie virus

Kg kilogram

LGA large for gestational age

MCV mean cell volume

$\mathrm{Mm} \quad$ millimeter

$\mathrm{mmHg} \quad$ millimeter kwik

$\mathrm{nl}$ normaal

NVO niet vorderende ontsluiting

NVU niet vorderende uitdrijving

PE preeclampsie

PND prenatale diagnostiek

PNS prenatale screening

PPROM preterm prelabour rupture of membranes, prematuur gebroken vliezen

PRN Perinatale Registratie Nederland

PROM premature rupture of membranes, PROM 
SBP systolic blood pressure, systolische bloeddruk

SGA small for gestational age

SEO structureel echoscopisch onderzoek

SOA seksueel overdraagbare aandoening

SROM spontaneous rupture of membranes

TTS tweeling transfusie syndroom

VG voorgeschiedenis

VT vaginaal toucher

VW vruchtwater 


\section{SAMENSTELLING WERKGROEPEN}

\section{Samenstelling werkgroep 'Zwangerschap' (tot maart 2016)}

○ Drs. B. (Babette) Peeters, directeur kraamzorg, gemachtigde kraamzorgorganisaties Limburg

○ K. (Karin) Maas-Oirbans, verloskundige, gemachtigde verloskundige kring Noord Limburg

○ Drs. E.J. (Ella) Wijnen-Duvekot, gynaecoloog, gemachtigde gynaecologenmaatschap VieCuri MC

○ K. (Kristel) Gijsen, verloskundige, gemachtigde verloskundige kring Midden Limburg

- Drs. I.M.A. (Ivo) van Dooren, gynaecoloog, gemachtigde gynaecologenmaatschap St. Jans Gasthuis

- Drs. I.M. (Iris) Zwaan, gynaecoloog, gemachtigde gynaecologenmaatschap Laurentius Ziekenhuis

○ J.I. (José) ten Thije, verloskundige, gemachtigde verloskundige kring Westelijke Mijnstreek

- Dr. R. (Robert) Aardenburg, gynaecoloog, gemachtigde gynaecologenmaatschap Atrium-Orbis MC, locatie Sittard

- N. (Nicky) Maassen, verloskundige, gemachtigde verloskundige kring Oostelijk Zuid Limburg

- Dr. J.P.M. (Jos) Offermans, gynaecoloog, gemachtigde gynaecologenmaatschap Atrium-Orbis MC, locatie Heerlen (tot 1 januari 2016, overgenomen door dr. J. Langenveld)

○ Drs. J.K.J. (Judit) Keulen, verloskundige, gemachtigde verloskundige kring Maastricht Heuvelland e.o.

○ Dr. H.C.J. (Liesbeth) Scheepers, gynaecoloog-perinatoloog, gemachtigde gynaecologenstaf Maastricht UMC

○ Dr. H.A.A. (Hennie) Wijnen, verloskundige, docent-onderzoeker, gemachtigde Academie Verloskunde Maastricht

\section{Samenstelling werkgroep 'Baring en kraambed' (tot maart 2016)}

○ J. (Joke) Verbugt, directeur bestuurder geboortezorg Limburg kraamzorg, gemachtigde kraamzorgorganisaties Limburg 
- M.P.P. (Margo) Vermazeren BSc, verloskundige, gemachtigde verloskundige kring Noord Limburg

○ Drs. A.M. (Annemieke) van Wijck, gynaecoloog, gemachtigde gynaecologenmaatschap VieCuri MC

- H.M.M. (Lenie) Caris, verloskundige, gemachtigde verloskundige kring Midden Limburg (tot 1 september 2015, overgenomen door Kristel Gijsen)

○ C. (Cindy) Bastings, verloskundige, vertegenwoordiger klinisch werkende verloskundigen

D Drs. W.E. (Ernst) Nolting, gynaecoloog, gemachtigde gynaecologenmaatschap St. Jans Gasthuis

- Drs. M.W.G. (Desiree) Moonen - Delarue, gynaecoloog, gemachtigde gynaecologenmaatschap

Laurentius Ziekenhuis (tot juni 2014, vervangen door drs. I.M. Zwaan)

○ Drs. I.M. (Iris) Zwaan, gynaecoloog, gemachtigde gynaecologenmaatschap Laurentius Ziekenhuis (vanaf juni 2014)

○ C. (Claudia) Brouwers, verloskundige, gemachtigde verloskundige kring Westelijke Mijnstreek

- Dr. M. (Martine) Wassen, gynaecoloog, gemachtigde gynaecologenmaatschap Atrium-Orbis MC, locatie Sittard

- D. (Desiree) Greven, verloskundige, gemachtigde verloskundige kring Oostelijk Zuid Limburg

○ Dr. J. (Josje) Langenveld, gynaecoloog, gemachtigde gynaecologenmaatschap Atrium-Orbis MC, locatie Heerlen

○ Drs. J.K.J. (Judit) Keulen, verloskundige, gemachtigde verloskundige kring Maastricht Heuvelland e.o.

- Dr. H.C.J. (Liesbeth) Scheepers, gynaecoloog-perinatoloog, gemachtigde gynaecologenstaf Maastricht UMC

○ Dr. H.A.A. (Hennie) Wijnen, verloskundige, docent-onderzoeker, gemachtigde Academie Verloskunde Maastricht

\section{Samenstelling werkgroep Zorgpaden LOQS (vanaf maart/juni 2016)}

○ Drs. B. (Babette) Peeters, directeur kraamzorg, gemachtigde kraamzorgorganisaties Limburg

○ J. (Joke) Verbugt, directeur bestuurder geboortezorg Limburg kraamzorg, gemachtigde kraamzorgorganisaties Limburg 
○ Drs. E.J. (Ella) Wijnen-Duvekot, gynaecoloog, gemachtigde gynaecologenmaatschap VieCuri MC

○ Drs. A.M. (Annemieke) van Wijck, gynaecoloog, gemachtigde gynaecologenmaatschap VieCuri MC

- W. (Wendy) Gijsen, verloskundige, gemachtigde verloskundige kring Midden Limburg (VSV Roermond)

- B. (Badia) El Haddad, gemachtigde verloskundige kring Midden Limburg (VSV Weert)

- L. (Lilian) Custers, gemachtigde verloskundige kring Midden Limburg (VSV Weert)

- Drs. I.M. (Iris) Zwaan, gynaecoloog, gemachtigde gynaecologenmaatschap Laurentius Ziekenhuis

$\circ \quad$ C. (Cindy) Bastings, verloskundige, vertegenwoordiger klinisch werkende verloskundigen

- Drs. I.M.A. (Ivo) van Dooren, gynaecoloog, gemachtigde gynaecologenmaatschap St. Jans Gasthuis

○ Drs. W.E. (Ernst) Nolting, gynaecoloog, gemachtigde gynaecologenmaatschap St. Jans Gasthuis

○ J.I. (José) ten Thije, verloskundige, gemachtigde verloskundige kring Westelijke Mijnstreek

○ C. (Claudia) Brouwers, verloskundige, gemachtigde verloskundige kring Westelijke Mijnstreek

○ Dr. R. (Robert) Aardenburg, gynaecoloog, gemachtigde gynaecologenmaatschap Atrium-Orbis MC, locatie Sittard

- Dr. M. (Martine) Wassen, gynaecoloog, gemachtigde gynaecologenmaatschap Atrium-Orbis MC, locatie Sittard

○ Dr. J. (Josje) Langenveld, gynaecoloog, gemachtigde gynaecologenmaatschap Atrium-Orbis MC, locatie Heerlen

○ N. (Nicky) Maassen, verloskundige, gemachtigde verloskundige kring Oostelijk Zuid Limburg

- D. (Desiree) Greven, verloskundige, gemachtigde verloskundige kring Oostelijk Zuid Limburg

- I.(Ina) Bastiaans, verloskundige, docent-onderzoeker, gemachtigde Academie Verloskunde Maastricht

○ Dr. H.C.J. (Liesbeth) Scheepers, gynaecoloog-perinatoloog, gemachtigde gynaecologenstaf Maastricht UMC 


\section{Overige deelnemers/betrokkenen werkgroep bijeenkomsten}

(Geen vragenlijsten ingevuld, met uitzondering van Hilde Coolen en Salwan Al-Nasiry)

- Prof. dr. M.E.A. (Marc) Spaanderman, gynaecoloog-perinatoloog, hoogleraar transmurale verloskunde Maastricht UMC, projectleider LOQS

- Drs. S.M.P. (Stéphanie) Lemmens, arts-onderzoeker zorgpadenontwikkeling

- H. (Hilde) Coolen, verloskundige, ondersteuning zorgpadenontwikkeling

- Dr. L.J.M. (Luc) Smits, klinisch epidemioloog UM, Expect-studie

- Drs. L.J.E. (Linda) Meertens, arts-onderzoeker Expect-studie

- Dr. S. (Salwan) Al-Nasiry, gynaecoloog-perinatoloog, Maastricht UMC

- Y.C.M. (Yvonne) Röselaers, senior adviseur Robuust, gespreksleider, projectmanagement LOQS 


\section{GERAADPLEEGDE ACHTERBAN}

In onderstaande lijst zijn, in alfabetische volgorde, alle mensen opgenomen die eenof meerdere malen zijn uitgenodigd voor het invullen van de online LOQS vragenlijsten.

$\begin{array}{ll}\circ & \text { Gerrie van de Aalst } \\ \circ & \text { Karien Aarts } \\ \circ & \text { Salwan Al-Nasiry } \\ \circ & \text { Mayke van Ansenwoude } \\ \circ & \text { Carola Backx } \\ \circ & \text { Hans van Beek } \\ \circ & \text { Martin Bergmans } \\ \circ & \text { Ingrid Beurskens } \\ \circ & \text { Dieuwke Boskamp } \\ \circ & \text { Petra Bourdrez } \\ \circ & \text { Stephanie Braun } \\ \circ & \text { Gerard Bremer } \\ \circ & \text { Marjon Brinkhuis } \\ \circ & \text { Manon de Bruyn } \\ \circ & \text { Linda Bus } \\ \circ & \text { Vivianne Castermans } \\ \circ & \text { Hilde Coolen } \\ \circ & \text { Astrid Coopmans } \\ \circ & \text { Audrey Coumans } \\ \circ & \text { Cindy van Crugten } \\ \circ & \text { Lilian Custers } \\ \circ & \text { Anika Dam } \\ \circ & \text { Wim Dankers } \\ \circ & \text { Marcelle Debets } \\ \circ & \text { Emmely Delhoofen } \\ \circ & \text { Dionne Denessen } \\ \circ & \text { Daisy Derkx } \\ \circ & \text { Jenny Derkx } \\ \circ & \text { Ingrid Devies } \\ \circ & \text { Geeske Donner } \\ \circ & \text { Badia El Haddad } \\ \circ & \text { Mirjam Engelen } \\ \circ & \text { Janneke van Hal } \\ \circ & \text { Lilian van Es } \\ \circ & \text { Julie Fincken } \\ \circ & \text { Iris van Gestel } \\ \circ & \text { Nicole van Gestel } \\ & \end{array}$

\begin{tabular}{|c|c|}
\hline ○ & Hanneke van Ginkel \\
\hline 0 & Ed Gondrie \\
\hline & Eveline Grosfeld \\
\hline & Kim Haest \\
\hline o & Monique Heldens \\
\hline & Karin Hordijk \\
\hline ○ & Esther Jacobs \\
\hline ○ & Waltje Jager \\
\hline ○ & Emmy Janssen \\
\hline O & Paul Kampschoer \\
\hline O & Martine Knotters \\
\hline ○ & Sanne Kohl \\
\hline ○ & Kirsten van Kollenburg \\
\hline - & Ingrid Lamers \\
\hline ○ & Erika Lemmens \\
\hline ○ & Ellen Lemmens \\
\hline ○ & Miriam van Leuken \\
\hline O & Chantal Leveau \\
\hline ○ & Sarah Mathijs \\
\hline ○ & Leonie van Melick \\
\hline 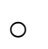 & Patricia Mercelina \\
\hline . & Helen Mertens \\
\hline 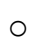 & Sonja van Meyl \\
\hline$\circ$ & Steffie Mooren \\
\hline 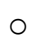 & Myrtho Motten \\
\hline ○ & Robertjan Mulder \\
\hline$\circ$ & Katja Mulder \\
\hline ○ & Chantal Mulkens \\
\hline$\circ$ & Jeanette Nickien \\
\hline 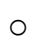 & Angelique Nijenhof \\
\hline 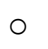 & Jan Nijhuis \\
\hline 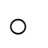 & Tanja Oeyen \\
\hline . & Desiree Paffen \\
\hline ० & Charlotte Peerboom \\
\hline ○ & Ingrid Peeters \\
\hline 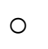 & Christie Peeters \\
\hline 0 & Mijntje Pieters \\
\hline
\end{tabular}


- Yvonne Geurts

- Wendy Gijsen

- Saskia van Ginkel

- Esther Schoffelen

- Julienne Schoffelen

- Judith Schrouff

- Gwen Slabbers

- Cecile Smeets

- Nicol Smeets

- Erik Sollie

- Cindy Stock

- Angelique Sup

- Stijn Van Teeffelen

- Marlon Theunissen

- Chantal Triebels

- Jorik Vellekoop

- Lincy Verbeek

- Aty Viguurs

- Katrin Vincenz

o Jan Vinders

- Judith van Vleuten

- Monique Vloet

- Sharon Vroemen

- Marja Vroomen

- Stefanie Vroomen

- Francis Vrouenraets

- Chantalle Wagemans

- Mireille Waterval

- Diana Wentink

- Gertie Westenberg

- Marianne van Westreenen

- Loes Wijnhoven

- Christine Willekes

- Rian Willems

- Chantal Wingen

- Daphne Wollaert

\section{Anesthesie}

- Jon Anderson

- Max Ausems

- A. Beckers

- A. Boeke

- Fabiënne Borgers
- Marloes Raijer

- Frans Roumen

- Naomi Satijn

- B. Depoorter

- Vincent van Dongen

- N. van Dijk

- Marten van Eerd

- Nicole Engel

o D. Enk

- Raymond Frederiks

- R. Frietman

- H. Gramke

- N. Grupa

- A. Hamaekers

- E. Hanssen

- J. Heijmans

- E. Hofland

- K. Houben

- J. Jansen

- Jaqueline Jansen

- Markus Janssen

- W. Jessen

- P. Kansen

- Maarten van Kleef

- J. Klein Ovink

- Marcel de Korte

- P. van Kruchten

- Peter Kuijpers

- F. Kwinten

- Marcus Lance

- Ralph Maassen

- E. Machiels

- Johan Nel

- R. van Osch

- D. Peek

- Yolande Peeters

- Jan Pinckaers

- K. Piotrowski

- Jan Willem de Poel

- E. Pragt

- C. Punt

- Khaled Rafiqpoor

o H. Renkens 
- H. Bos

- Esther Bouman

○ P. Brog

- Wolfgang Buhre

- M. Bussink

- A. Commies

- B. Cox

- R. Dakheel

- Ruud Timmer

- B. Timmerman

- Hans Ubben

- M. van der Woude

\section{Kinderartsen}

- Leonie van den Broek

- Karin van Dael

- Pieter Degraeuwe

- Danilo Gavilanes

- Johan Hanekom

- Han Hendriks

- Mark van der Hoeven

- Jeroen van Hoorn

- Tali Hubregtse

- Mieke Jansen

- Roelie Jonkers

○ Elly Kerkvliet

- Wieneke Kneepkens

- Simone van Kordelaar

- Boris Kramer

- Bettina Loza

- Rob Moonen

- Twan Mulder

- Hendrik Niemarkt

- Steph Potgieter

- Janneke Raaijmakers

- Attie Slabber

- Rod Thompson

- Colleen Vaessens

- Eduardo Villamor

- Johan Zietsman

- Luc Zimmermann
- R. Schnabel

- Ingrid Schneider

- Luuk Schouten

- J. Schreiber

- V. Smit

- Micha Sommer

- Carla Stefelmanns

- Fabian Tijssen 



\section{PUBLICATIELIJST}

Al-Nasiry S, Ghossein-Doha C, Polman SE, Lemmens SMP, Scholten RR, Heidema WM, Spaan JJ, Spaanderman MEA. Metabolic syndrome after pregnancies complicated by pre-eclampsia or small-for-gestational-age: a retrospective cohort. BJOG. 2015 Dec;122(13):1818-23. doi: 10.1111/1471-0528.13117. Epub 2014 Oct 16. PMID: 25318833

Smits LJM, Van Montfort P, Meertens LJE, Lemmens SMP, Willemse JPMM, Röselaers YCM, Spaanderman MEA, Scheepers HCJ. Populatie-brede preventie van preeclampsie: de Limburgse aanpak, Nederlands Tijdschrift voor Obstetrie \& Gynaecologie (NTOG) vol. 132, mei 2019, 130-132.

Lemmens SMP, Scheepers HCJ, Lopes van Balen VA, Röselaers YCM, De Vries RG, Spaanderman MEA, (2019) Agreement Conform Current Operational Rules and Directives (ACCORD): A Novel Tool to Reach Multidisciplinary Consensus. J Womens Health Gyn 2019, 5: 1-11.

Lemmens SMP, Lopes van Balen VA, De Vries RG, Scheepers HCG, Spaanderman MEA, Do representatives represent you? Integrative Journal of Nursing and Health, Vol. 2 No. 1 (2019) DOI: https://doi.org/10.18314/ijnh.v2i1.1805

Lemmens SMP, van Montfort P, Meertens LJE, Spaanderman MEA, Smits LJM, de Vries RG, Scheepers HCJ. Perinatal factors related to pregnancy and childbirth satisfaction: a prospective cohort study. J Psychosom Obstet Gynaecol. 2020 Jan 8:19. doi: 10.1080/0167482X.2019.1708894

Van Montfort P, Smits LJM, Van Dooren IMA, Lemmens SMP, Zelis M, Zwaan IM, Spaanderman MEA, Scheepers HCJ. Implementing a pre-eclampsia prediction model in obstetrics: cut-off determination and health care professionals' adherence, Medical Decision Making, 2020 Jan;40(1):81-89. doi: 10.1177/0272989X19889890.

Lemmens SMP, Lopes van Balen VA, Röselaers YCM, Scheepers HCJ, Spaanderman MEA. The Risk Matrix Approach: a helpful tool weighing probability and impact when deciding on preventive and diagnostic interventions. [submitted] 



\section{CURRICULUM VITAE}

Stéphanie Maria Paula Lemmens werd op 4 december 1986 geboren in Maastricht en is opgegroeid in Margraten. Ze behaalde haar gymnasium diploma aan het Porta Mosana college te Maastricht in 2005 en startte vervolgens haar geneeskunde studie aan de Vrije Universiteit te Amsterdam.

$\mathrm{Na}$ het behalen van haar artsexamen is zij in 2012

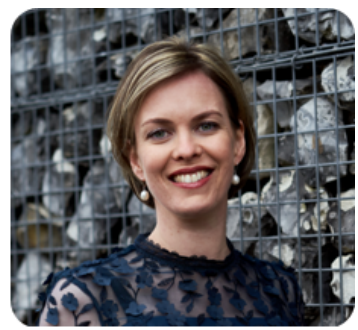
begonnen als ANIOS gynaecologie en obstetrie in het Sint Elisabeth Ziekenhuis te Tilburg (opleider dr. P.F. Boekkooi). In 2013 startte zij haar promotietraject in Maastricht onder leiding van prof. dr. M.E.A. Spaanderman, prof. dr. L.J.M. Smits en dr. H.C.J. Scheepers en heeft zij gewerkt aan de LOQS zorgpaden beschreven in dit proefschrift. In 2017 vervolgde zij haar loopbaan als AIOS gynaecologie en obstetrie in het Maxima Medisch Centrum te Veldhoven (opleiders dr. J.W.M. Maas, dr. P.M.A.J. Geomini) en het Maastricht Universitair Medisch Centrum (opleider prof. dr. R.F.P.M. Kruitwagen).

Vanaf 1 maart 2019 is zij een ander carrière pad ingeslagen als huisarts in opleiding en het eerste jaar werkzaam geweest bij huisartspraktijk Ulestraten (opleider drs. J. Ridderbeks).

Stéphanie is getrouwd met Justin Poort en zij zijn de trotse ouders van hun zoon Twan. 


\section{DANKWOORD}

Het proefschrift is af! Wat een fijn gevoel. Als beginnend promovendus bij het LOQS project, wist ik dat we zorgpaden voor de verloskundige zorg gingen ontwikkelen, maar gelukkig niet welke hobbels we tegen gingen komen. Het waren roerige tijden in de wereld van de verloskunde in Nederland, des te meer reden om trots te zijn op het mooie eindresultaat wat we met alle zorgverleners hebben neergezet! Tijdens dit hele proces heb ik veel geleerd, niet alleen op wetenschappelijk vlak, maar ook over de dynamiek in groepsprocessen, het belang van communicatie en bovenal over mezelf en waar ik voor sta in het leven. Velen hebben mij de afgelopen jaren gesteund, waarvan ik een aantal in het bijzonder wil bedanken.

Allereerst een woord van dank aan mijn promotoren prof. dr. Spaanderman, prof. dr. Smits en mijn co-promotor dr. Scheepers.

Marc, ondanks jouw overvolle agenda wist je toch altijd even langs te komen op de uni om te sparren over een artikel. Ook voor jou was het LOQS gedeeltelijk nieuw terrein, net zoals de artikelen die hieruit zijn ontstaan. Dank voor je altijd kritische blik, na onze gesprekken ging ik altijd vol goede moed weer aan de slag. Je leerde me elke hobbel als een nieuwe uitdaging en leermoment te zien. Net zoals je me gesteund hebt in mijn keuze om een ander carrière pad in te slaan.

Luc, dank voor de fijne samenwerking. Het LOQS project zou niet compleet zijn zonder de Expect studie.

Liesbeth, zei Marc links, dan zei jij vaak rechts en andersom. Dit maakte het boeiend, maar niet altijd eenvoudig om met zijn drieën samen te werken, maar het is gelukt en dit proefschrift is zeker ook jouw verdienste! Je had een belangrijke bijdrage in de werkgroepen en wist daarnaast als co-promotor mijn artikelen altijd met een frisse blik te bekijken. Juist door jullie verschillen heb ik mijn stukken telkens vanuit een ander perspectief kunnen bekijken en ik denk dat dat het proces alleen maar ten goede is gekomen. Dank daarvoor!

Leden van de beoordelingscommissie, prof. dr. B.W.W. Kramer, prof. dr. L.J.I. Zimmermann, prof. dr. M.J. Nieuwenhuijze, prof. dr. W.J.J. Assendelft en prof. dr. J.A.M. Van der Post, ik wil u allen hartelijk danken voor het lezen en beoordelen van mijn proefschrift. 
Yvonne, aangezien we elkaar al een lange tijd kenden, vond ik het extra bijzonder om binnen het LOQS als collega's samen te mogen werken. Ik kijk met een fijn gevoel terug op onze ritjes in de aygo onderweg van en naar de LOQS bijeenkomsten en heb geleerd van onze gesprekken en jouw ervaring, zowel werkgerelateerd als privé. Tijdens de bijeenkomsten toonde je je een uitstekende voorzitter, want het was soms een hele uitdaging om alle deelnemers in het gareel te houden. Ik vond het heel prettig om met je samen te werken, maar ben ook heel blij dat de 'IE' nu eindelijk toegevoegd kan worden aan de 'promotie trein'.

Dank ook aan alle deelnemers van het LOQS: alle verloskundigen, gynaecologen, kraamcentra en in het bijzonder alle werkgroepleden voor jullie inzet afgelopen jaren. Speciale dank aan Hilde voor het meedenken over de vragenlijsten. Het was een monsterklus, maar die hebben we samen toch mooi geklaard!

Linda en Pim, dank voor de fijne samenwerking! Linda, onze koffie (lees: spui) momentjes waren altijd fijn, ook even kletsen over niet promotiezaken. Knap hoe je de Expect studie hebt opgezet en je promotie hebt afgerond. Ik ben blij dat we collega's blijven en hoop dat we daarnaast nog vele wandelingen met Jolijn en Twan zullen maken! Pim, ik heb groot respect voor de snelheid en de gedrevenheid waarmee jij de Expect studie hebt voortgezet. Succes met je verdere carrière, binnenkort zijn we voor even weer directe collega's.

Prof. dr. Raymond de Vries, dank voor het meedenken over mijn artikelen en het mooier maken van mijn zinnen.

Manon, Eveline en Monique van het secretariaat, bedankt dat jullie altijd een plekje wisten te creëren in Marc's agenda, een bijna onmogelijke opgave ;-)

Dank aan alle collega's van de PERIM onderzoeksgroep, voor het meedenken tijdens de periscoop bijeenkomsten en de gezelligheid tussendoor.

Philippe, de placenta man, onze 'romance' begon in kamer 1.320 en ik ben blij dat we elkaar nog steeds zien. Ik heb bewondering voor het gemak waarmee je les geeft en de snelheid waarmee je je promotie hebt afgerond. Jij weet met je presentaties (uiteraard met bewegende plaatjes) altijd iedereen te boeien. Daarnaast ben je altijd 
vriendelijk, in staat om echt te luisteren naar wat de ander bezighoudt en in voor een grapje: de placenta op sterk water zal ik nooit vergeten!

Veronica, V1, eigenlijk beschouw ik jou als mijn tweede copromotor. We waren collega's als ANIOS en het klikte meteen. In Maastricht waren we uiteindelijk kamergenootjes en hebben we vele mooie en minder mooie momenten gedeeld. Ik waardeer je eerlijkheid, ook al zeg je 't niet altijd, jouw gezicht spreekt boekdelen ;) je kritische feedback op mijn artikelen, jouw collegialiteit, gedrevenheid, bescheidenheid en bovenal je gezelligheid. Men mag blij zijn met jou als toekomstig gynaecoloog!

Eva, Eef, mijn lange, blonde, altijd vrolijke, energieke en 'klein beetje grappige' collega. Voor mij, als jouw honkvaste collega, was jouw aanstekelijke lach altijd al van verre te horen :) Ik bewonder je positieve 'go with the flow' instelling, hier kunnen veel mensen, waaronder ikzelf, nog wat van leren. Ook al wonen jij en Jalmar nu in Zwolle, we blijven elkaar vast nog zien en ik wens je alle geluk voor de toekomst!

Veronique, V2, roomie, altijd in voor een goede kop koffie en gezelligheid, maar ook serieus werken ging ons goed af samen. Jij hebt de Pulse studie knap voortgezet en ik weet zeker dat dit snel resulteert in een mooie promotie waar je trots op mag zijn! Ik wens je veel succes met je verdere carrière!

Jonas, sugardaddy, de enige man in ons midden, maar ook de enige met een publicatie zonder revisions! Met jou erbij is het altijd lachen geblazen, kletsen over de meest uiteenlopende onderwerpen, medisch maar vooral ook niet-medisch. Ik ben trots op jou en hoe je naast je drukke baan en gezinsleven met Anne, Benthe en Pepijn ook je promotie nog voortzet (geloof mij, dat eind komt echt een keer in zicht!).

Nicki, als kamergenootjes gestart op de Uns 50, maar inmiddels vriendinnen geworden. Jij hebt altijd een luisterend oor, bent heel attent en mag heel trots zijn op jezelf! Ik ben blij dat we allebei onze weg gevonden hebben en hoop dat we elkaar nog lang blijven zien! 
Ghislaine, Ghis, wat een stoere stap heb jij gezet door naar Duitsland te gaan. Knap hoe je een nieuw land en een nieuwe opleiding zo goed weet te combineren met je gezin. Gelukkig bestaat er voor elk life event een excel bestand!

MWC vrienden, aka 'de donderdagavond groep': dank voor jullie interesse in mijn promotie de afgelopen jaren, maar bovenal voor jullie gezelligheid. Vanaf het moment dat ik jullie leerde kennen wist ik het zeker, 'age is just a number'! Ik hoop dat we snel weer samen op wintersport kunnen en onze dirndls en lederhosen weer uit de kast kunnen halen!

Aileen en Ingrid, mijn paranimfen, waar zou ik zijn zonder jullie. Ik ben trots op onze vriendschap. Hoe ver we ook bij elkaar vandaan wonen, ik weet dat ik altijd bij jullie terecht kan. Dat jullie zullen luisteren, niet oordelen en me zullen helpen waar dat kan. Lieve $\mathrm{Ai}$, wat begon met naast elkaar zitten op de allereerste dag van de introductie, is uitgegroeid tot een vriendschap waar we hopelijk nog vele jaren aan vastplakken. Jij bent de enige die altijd precies op hetzelfde moment, hetzelfde opmerkt en dan ook nog hetzelfde denkt, één blik en we weten genoeg. Ik hoop dat we nog vaak gezellige weekendjes samen beleven en etentjes met onze mannen en kids. Lieve Ing, onze vakanties samen waren de beste! Met dank aan jou durfde deze bangerd toch net wat meer ;-) Ook al zien we elkaar niet zo vaak, het voelt altijd vertrouwd en ik ben heel blij dat je vandaag achter me staat. Zullen we snel weer een reisje plannen, zodra het mag?

Elke, lieve El, wat een geluk dat ik toch besloten heb een kamer in Broekhoven te gaan bekijken. Ik had geen beter huisgenootje kunnen wensen en zal onze gezellige avondjes, nachtelijke avonturen en festivals niet snel vergeten. Nu zijn we beiden in een wat rustiger vaarwater terecht gekomen. Ik ben heel blij dat we elkaar nog steeds regelmatig zien en bijna wekelijks spreken. Het is een fijn gevoel dat ik altijd bij jou terecht kan. Onze sauna dagjes voelen als een mini-vakantie en ik kan niet wachten om samen met onze mini's, Yente en Twan, erop uit te gaan!

Heleen en Marjolein, in dezelfde leergroep begon onze vriendschap. Zo fijn dat we elkaar zijn blijven zien! Jullie steunen mij in goede en slechte tijden en gingen mij voor in het huisartsenvak. Lieve Heleen, mijn voorbeeld als het gaat om goede voorbereiding. Het is altijd fijn als we elkaar zien, je biedt een luisterend oor en hebt 
vaak goed advies. Ik vind het knap hoe je de overstap naar het bedrijfsleven hebt durven maken en ben blij dat je daar helemaal op je plek zit.

Lieve Marjolein, ik waardeer jouw heerlijk nuchtere kijk op het leven; doe maar normaal, dan doe je al gek genoeg. Dankzij filmpjes van jouw jongens, die ik soms met zweet in $\mathrm{mn}$ handen bekijk, weet ik wat me te wachten staat! Ik zal vast nog bij je aankloppen voor advies ;-) Ik wens je heel veel geluk samen met je mannen en hoop dat je je weg vindt in jouw verdere carrière. De afstand Zeist, Amersfoort en Maastricht is voor ons geen probleem, dus ik ga er vanuit dat we nog vaak met z'n drieën gaan lunchen!

Catherine en Linda, de drie eenheid, vriendinnen sinds de middelbare school. Lieve Cathy, onze vriendschap begon tijdens het turnen, maar ook op het Jeanne d'Arc hebben we heel wat uurtjes samen doorgebracht. Veel kletsen, soms tot ongenoegen van de leraren en samen met $P$ en $A$ naar het gala. Ik hoop dat we nog vele jaren vriendschap eraan vastplakken!

Lieve Linnie, carnavalszondag is onze vaste date, samen met het Utrechtse clubje is het elk jaar weer een feestje. Jouw ritmegevoel is in de loop der jaren niet veranderd, al is een verbetering te zien en Linnie blijft gelukkig gewoon Linnie en dat moet vooral zo blijven! Over een paar jaar kunnen ook onze jongens met elkaar spelen en dansen mit vastelaovend.

Familie Poort, dank voor jullie interesse in mijn onderzoek, jullie gastvrijheid en gezelligheid! Ik ben blij dat ik onderdeel van jullie familie mag uitmaken en hoop nog vele mooie momenten samen te delen. Folkert en Margriet, speciale dank voor de mooie gedichten, de heerlijke appeltaarten en 'mijn' plekje voor de haard.

Hans en Monique, lieve pap en mam, dank dat jullie mij altijd steunen en er voor mij zijn als dat nodig is. Ik weet dat de deur altijd open staat en dat jullie het beste met mij voor hebben. Jullie kennen mij als geen ander en weten soms eerder dan ikzelf hoe ik me voel. Een wandeling, zitten voor de open haard, mutti's eten of een spelletje kaarten zijn fijne momenten. Daarnaast zijn jullie een lieve en trotse opa en oma voor Twan. Ik hoop dat ons reisje naar II Gabbiano dit jaar wel door kan gaan!

Michelle, lieve zus, ondanks dat we heel verschillend zijn, weet je me te vinden als ik het nodig heb. Gelukkig zien we elkaar steeds vaker, sinds je lieve tante bent van 
Twan en daar zijn we heel blij mee. Ik wens jou veel geluk voor de toekomst en hoop dat je de weg vindt die bij je past. Vertrouw op jezelf, want je hebt veel meer in je mars dan je denkt!

Lieve Twan, onze mooie, lieve en altijd vrolijke zoon. Jij hebt 2020 voor ons tot een prachtig jaar gemaakt, ondanks alle maatregelen. Jouw glimlach maakt elke dag tot een feestje. Ik ben heel blij jouw mama te zijn en vanaf nu is maandag ook echt mama-dag en tijd voor quality time.

Lieve Justin, door jou leer ik out of the box te denken, mogelijkheden zien in plaats van beren op de weg, maar ook om sneller te fietsen en harder te skiën. Je hebt me laten canyoningen (de eerste en de laatste keer), wie had dat ooit durven dromen! Opgeven is geen optie en 'kan niet, bestaat niet' is jouw motto. Dat heb je zelf bewezen door de start van EE. Ik ben trots op jou en hoe je je dromen waarmaakt. Ik kijk uit naar nog vele mooie jaren samen met ons mannetje en houd ontzettend veel van jullie! 